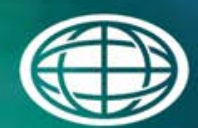

Savannah River

National Laboratory "m

OPERATED BY SAVANNAH RIVER NUCLEAR SOLUTIONS

\title{
DWPF Simulant CPC Studies for SB8
}

D. C. Koopman, J. R. Zamecnik

June 2013

SRNL-STI-2013-00106 
SRNL-STI-2013-00106

Revision 0

\section{DISCLAIMER}

This work was prepared under an agreement with and funded by the U.S. Government. Neither the U.S. Government or its employees, nor any of its contractors, subcontractors or their employees, makes any express or implied:

1. warranty or assumes any legal liability for the accuracy, completeness, or for the use or results of such use of any information, product, or process disclosed; or

2. representation that such use or results of such use would not infringe privately owned rights; or

3. endorsement or recommendation of any specifically identified commercial product, process, or service.

Any views and opinions of authors expressed in this work do not necessarily state or reflect those of the United States Government, or its contractors, or subcontractors.

\section{Printed in the United States of America \\ Prepared for U.S. Department of Energy}


Keywords: DWPF, SB8

Retention: Permanent

\section{DWPF Simulant Flowsheet Studies for SB8}

D. C. Koopman

J. R. Zamecnik

June 2013

Prepared for the U.S. Department of Energy under contract number DE-AC09-08SR22470.

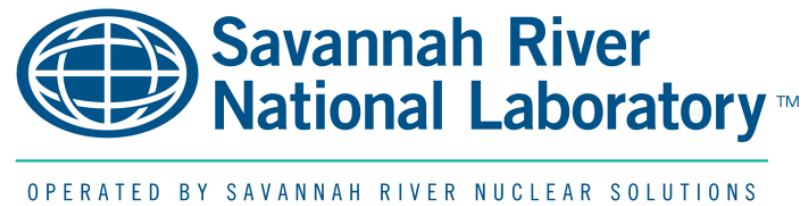




\section{REVIEWS AND APPROVALS}

AUTHORS:

D. C. Koopman, Process Technology Programs

Date

TECHNICAL REVIEW:

J. D. Newell, Process Technology Programs-Document Review per E7, 2.60 Date

APPROVAL:

D. R. Click, Manager

Date

Process Technology Programs

S. L. Marra, Manager

Date

Environmental \& Chemical Process Technology Research Programs

E. J. Freed, Manager

Date

Waste Solidification Engineering 


\section{ACKNOWLEDGEMENTS}

The authors wish to acknowledge the assistance of M. E. Stone, D. G. Sumpter, M. R. Williams, J. W. Duvall, V. J. Williams, R. J. Workman, D. P. Healy, W. B. Matthews, and V. L. Bush in performing the necessary lab-scale process simulations to complete this task. The authors also wish to thank D. R. Best, W. T. Riley, and B. G. Wall for their efforts and dedication in analyzing the majority of the process samples in the face of very tight deadlines. Sample analysis assistance was also provided by SRNL Analytical Development personnel including A. A. Ekechukwu. The efforts of H. B. Shah, J. M. Gillam, and D. W. McIlmoyle were also appreciated for providing the most up-to-date projections for SB8 compositions in Tank 40 and Tank 51. Finally, we would like to mention the important role of our DWPF customers, and T. L. Fellinger, J. W. Ray, and A. Samadi-Dezfouli in particular, in helping to define the scope of this program. 
SRNL-STI-2013-00106

Revision 0

\section{EXECUTIVE SUMMARY}

The Savannah River National Laboratory (SRNL) accepted a technical task request (TTR) from Waste Solidification Engineering to perform simulant tests to support the qualification of Sludge Batch 8 (SB8) and to develop the flowsheet for SB8 in the Defense Waste Processing Facility (DWPF). These efforts pertained to the DWPF Chemical Process Cell (CPC). Separate studies were conducted for frit development and glass properties (including REDOX). The SRNL CPC effort had two primary phases divided by the decision to drop Tank 12 from the SB8 constituents. This report focuses on the second phase with SB8 compositions that do not contain the Tank 12 piece. A separate report will document the initial phase of SB8 testing that included Tank 12.

The second phase of SB8 studies consisted of two sets of CPC studies. The first study involved CPC testing of an SB8 simulant for Tank 51 to support the CPC demonstration of the washed Tank 51 qualification sample in the SRNL Shielded Cells facility. SB8-Tank 51 was a high ironlow aluminum waste with fairly high mercury and moderate noble metal concentrations. Tank 51 was ultimately washed to about $1.5 \mathrm{M}$ sodium which is the highest wash endpoint since SB3Tank 51. This study included three simulations of the DWPF Sludge Receipt and Adjustment Tank (SRAT) cycle and Slurry Mix Evaporator (SME) cycle with the sludge-only flowsheet at nominal DWPF processing conditions and three different acid stoichiometries. These runs produced a set of recommendations that were used to guide the successful SRNL qualification SRAT/SME demonstration with actual Tank 51 washed waste.

The second study involved five SRAT/SME runs with SB8-Tank 40 simulant. Four of the runs were designed to define the acid requirements for sludge-only processing in DWPF with respect to nitrite destruction and hydrogen generation. The fifth run was an intermediate acid stoichiometry demonstration of the coupled flowsheet for SB8. These runs produced a set of processing recommendations for DWPF along with some data related to Safety Class documentation at DWPF. Some significant observations regarding SB8 follow:

- Reduced washing in Tank 51 led to an increase in the wt.\% soluble solids of the DWPF feed. If wt.\% total solids for the SRAT and SME product weren't adjusted upward to maintain insoluble solids levels similar to past sludge batches, then the rheological properties of the slurry went below the low end of the DWPF design bases for the SRAT and SME.

- Much higher levels of dissolved manganese were found in the SRAT and SME products than in recent sludge batches. Closed crucible melts were more reduced than expected. The working hypothesis is that the soluble $\mathrm{Mn}$ is less oxidizing than assumed in the REDOX calculations. A change in the coefficient for Mn in the REDOX equation was recommended in a separate report.

- The DWPF (Hsu) stoichiometric acid equation was examined in detail to better evaluate how to control acid in DWPF. The existing DWPF equation can likely be improved without changing the required sample analyses through a paper study using existing data.

- The recommended acid stoichiometry for initial SB8 SRAT batches is $115-120 \%$ stoichiometry until some processing experience is gained. The conservative range (based on feed properties) of stoichiometric factors derived in this study was from 110-147\%, but SRNL recommends using only the lower half of this range, $110-126 \%$ even after initial batches provide processing experience. 
- The stoichiometric range for sludge-only processing appears to be suitable for coupled operation based on results from the run in the middle of the range.

- Catalytic hydrogen was detectable $(>0.005$ vol $\%)$ in all SRAT and SME cycles. Hydrogen reached $30-35 \%$ of the SRAT and SME limits at the mid-point of the stoichiometry window (bounding noble metals and acid demand). 


\section{TABLE OF CONTENTS}

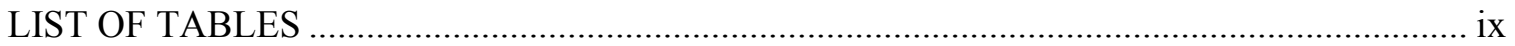

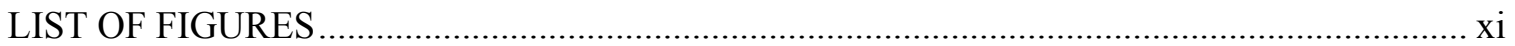

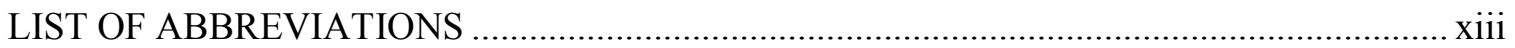

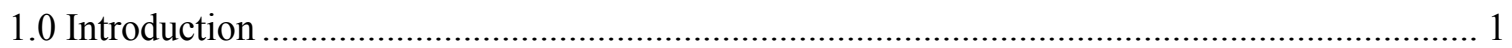

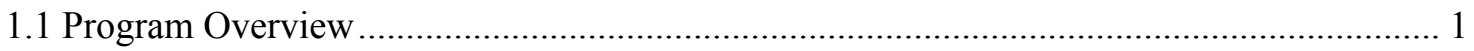

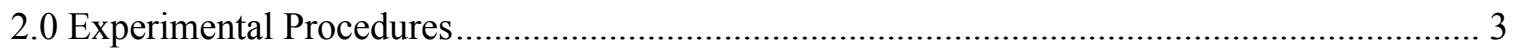

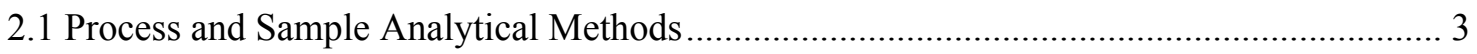

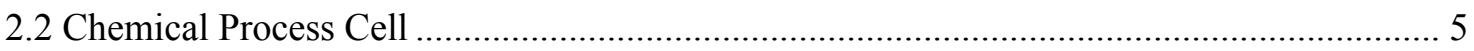

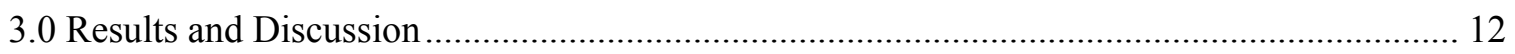

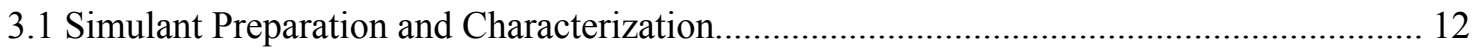

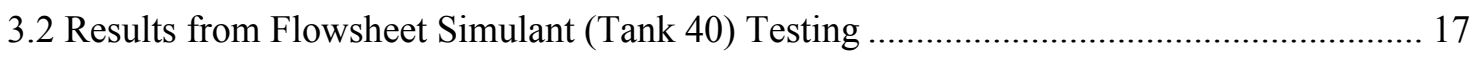

3.2.1 Approach to Defining a Stoichiometric Acid Window ............................................... 17

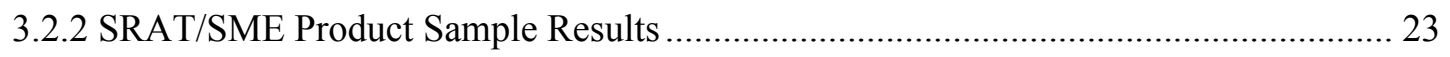

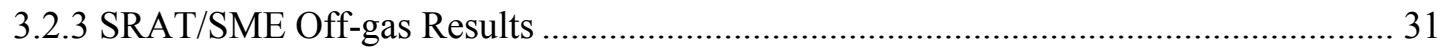

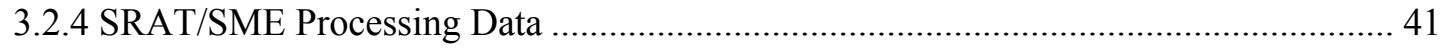

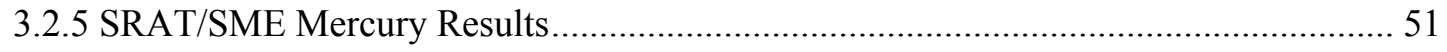

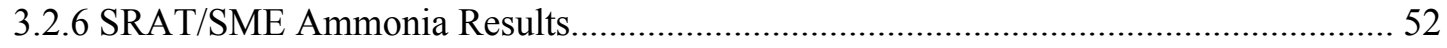

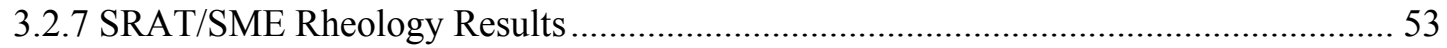

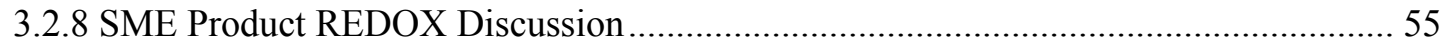

3.3 Results from Qualification Simulant (Tank 51) Testing..................................................... 59

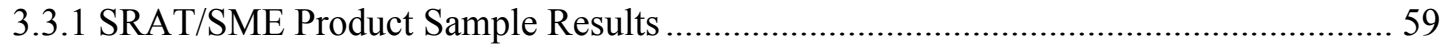

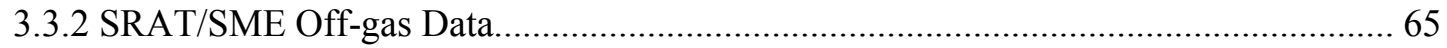

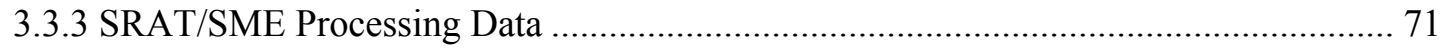

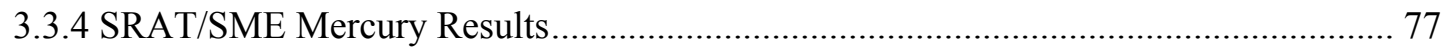

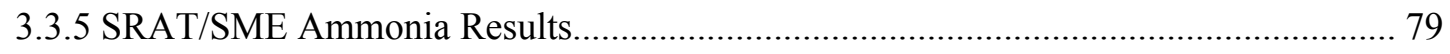

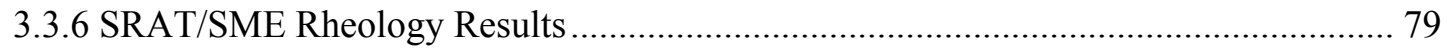

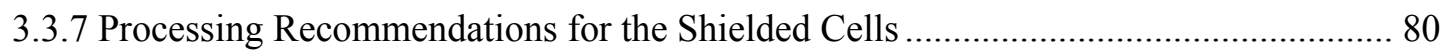

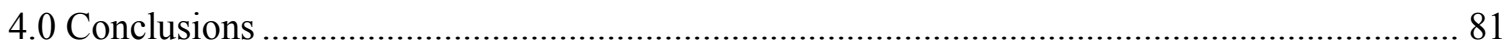

5.0 Recommendations for SB8 Processing and Future Work ….............................................. 82

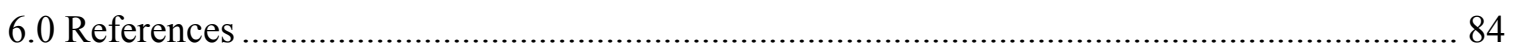

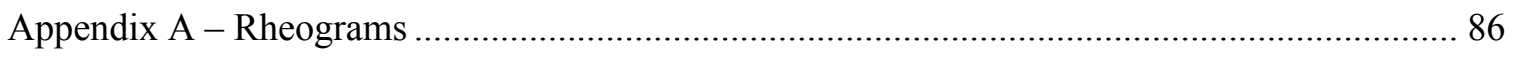




\section{LIST OF TABLES}

Table 2-1. Stoichiometric Acid Calculation Results, mol acid/L trimmed slurry ........................ 7

Table 2-2. Mercury and Noble Metal Estimates....................................................................... 9

Table 2-3. Mercury and Noble Metal Targets of Individual Flowsheet Runs............................. 10

Table 2-4. Mercury and Noble Metal Targets of SB8-Tank 51 Runs ....................................... 10

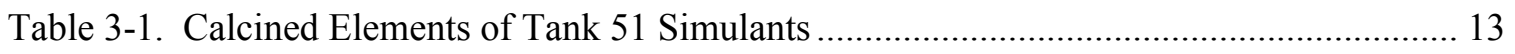

Table 3-2. Soluble Concentration of Tank 51 Simulant (Supernate-Basis) ................................. 14

Table 3-3. Other Tank 51 Simulant Properties............................................................................ 14

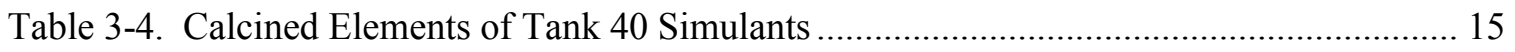

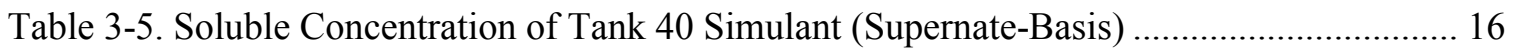

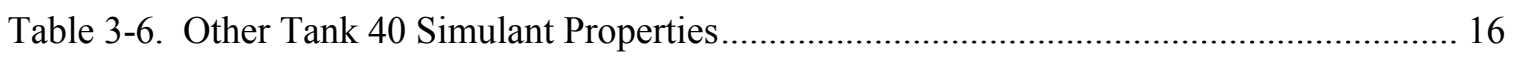

Table 3-7. Acid Demand-related Comparison for SB8-Tank 40 Supernates ............................... 19

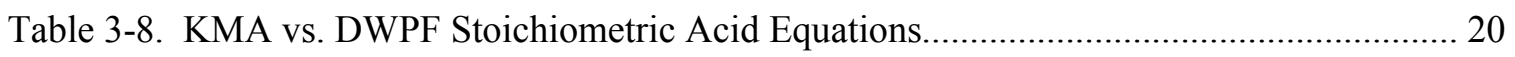

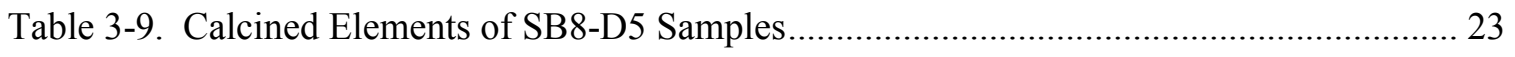

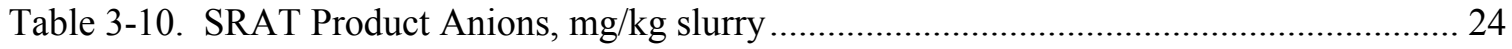

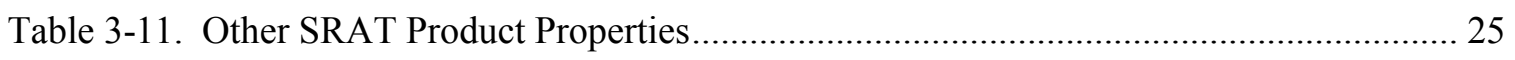

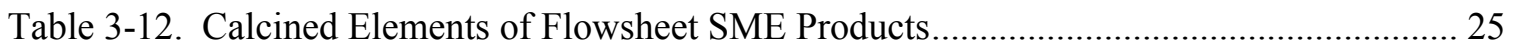

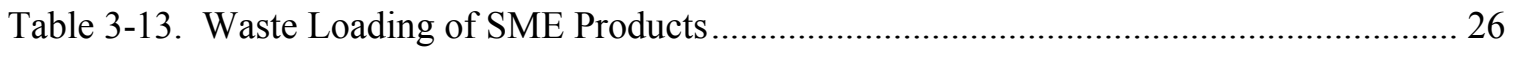

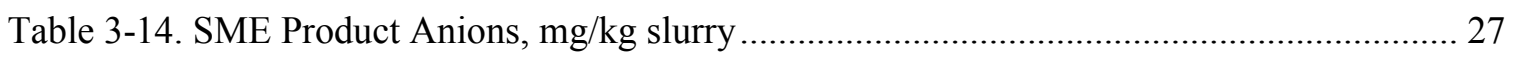

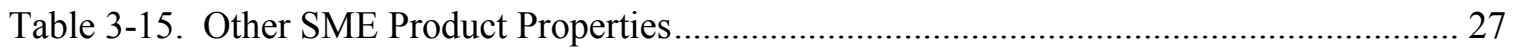

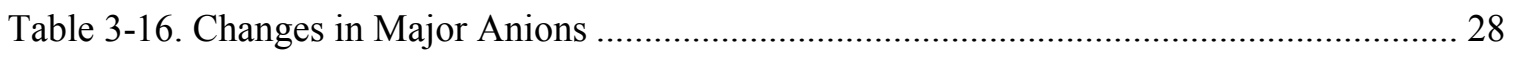

Table 3-17. Major SRAT Product Supernate Elements, mg/L ................................................. 29

Table 3-18. Selected SRAT Product Supernate Elements, \% of total ......................................... 29

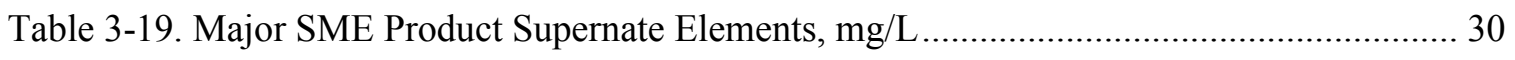

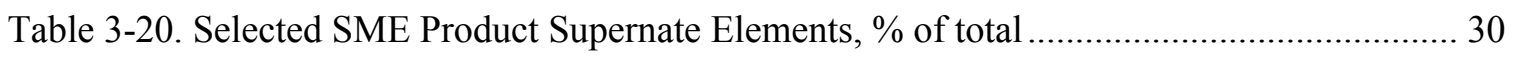

Table 3-21. SRAT and SME Maximum Hydrogen Generation Rate ......................................... 32

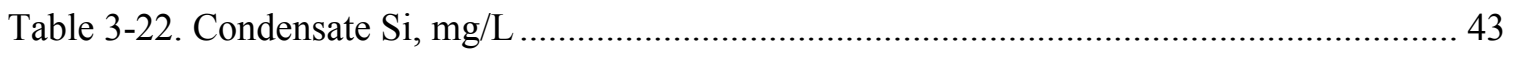

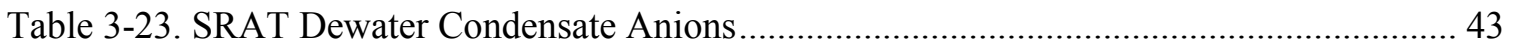




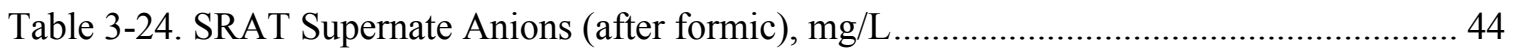

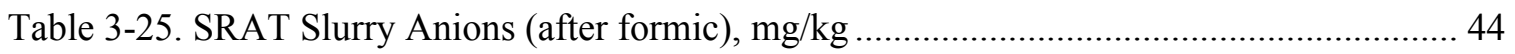

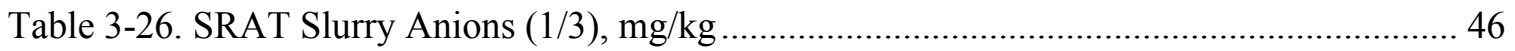

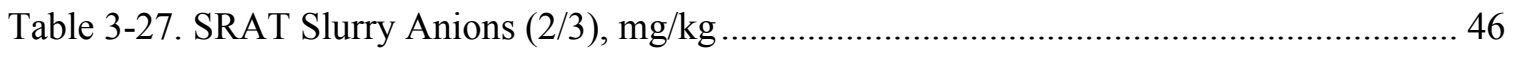

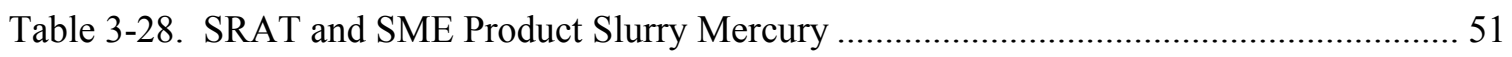

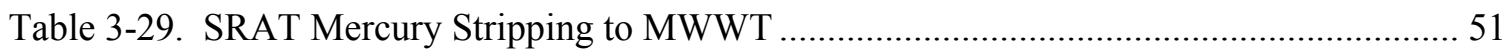

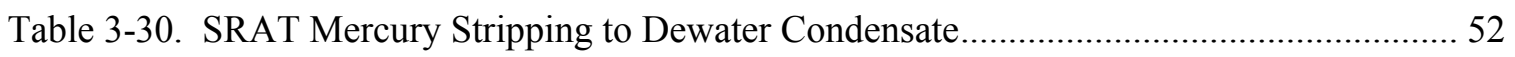

Table 3-31. Ammonia Detection in Scrubber Liquid ................................................................... 53

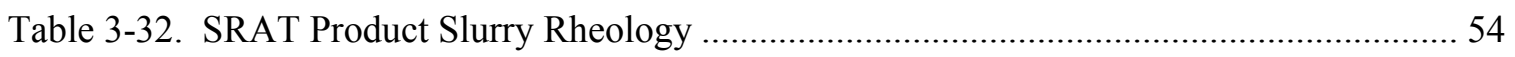

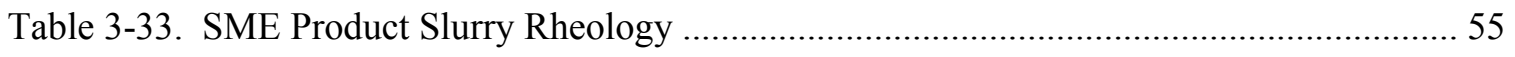

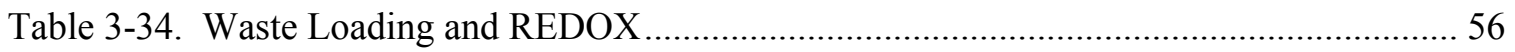

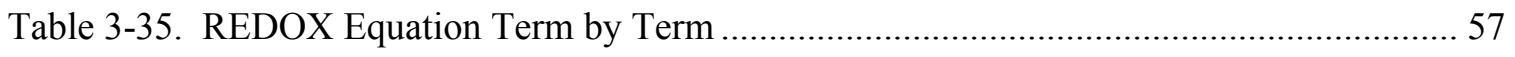

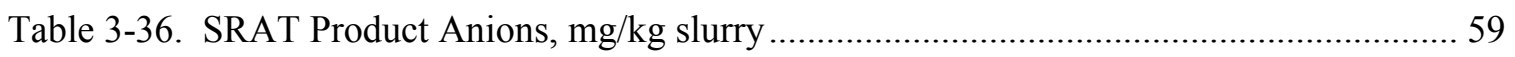

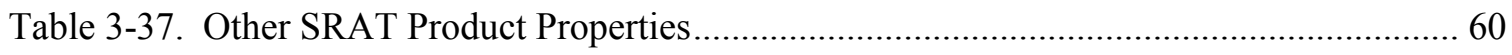

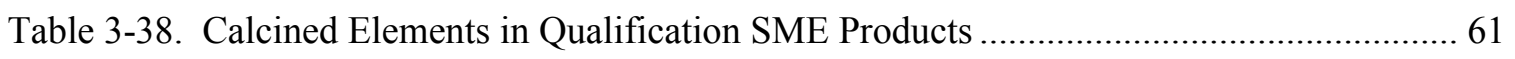

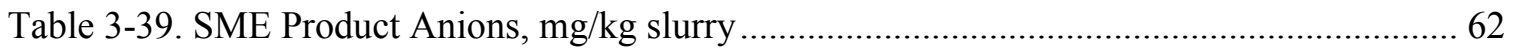

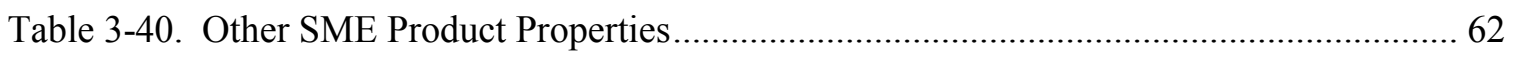

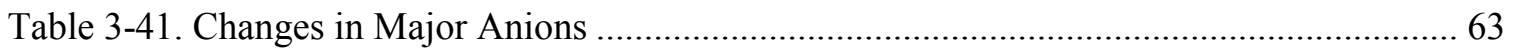

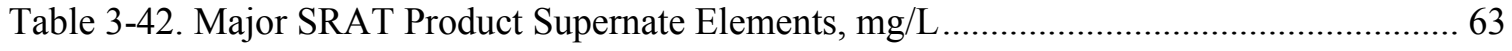

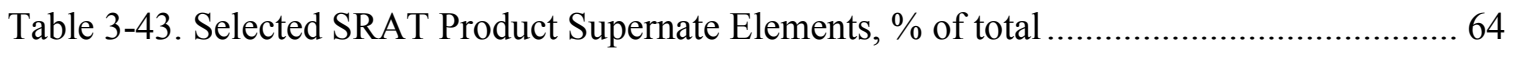

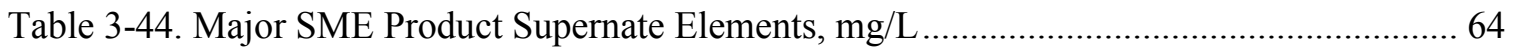

Table 3-45. Selected SME Product Supernate Elements, \% of total ............................................ 65

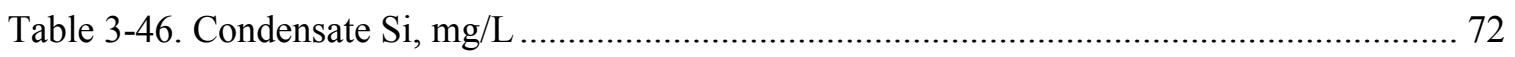

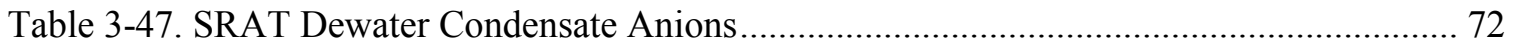

Table 3-48. SRAT Supernate Anions (after formic), mg/L..................................................... 72

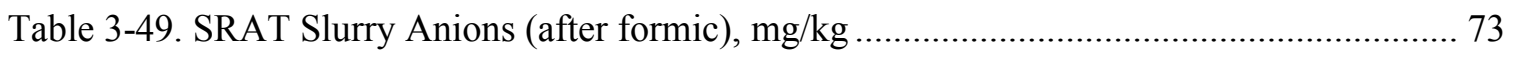

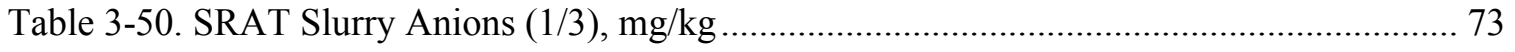

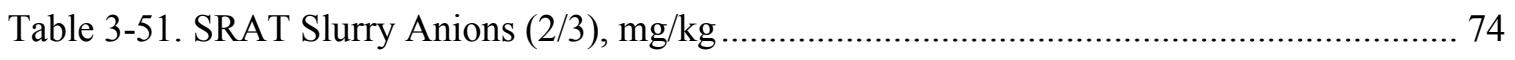

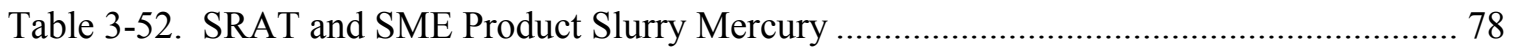




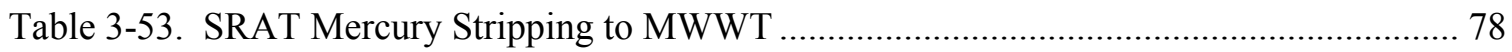

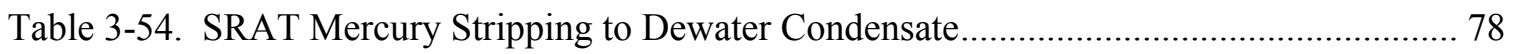

Table 3-55. Ammonia Detection in Scrubber Liquid ................................................................ 79

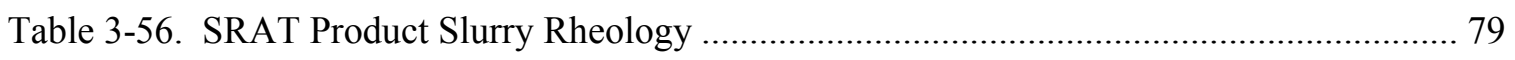

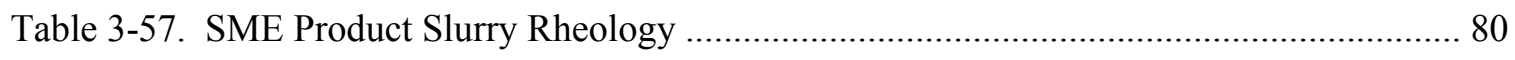

Table 3-58. Processing Targets for Qualification SRAT Cycle ............................................... 80

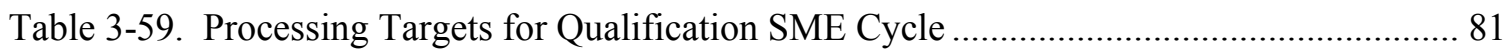

\section{LIST OF FIGURES}

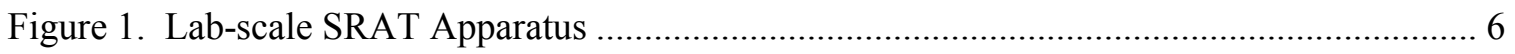

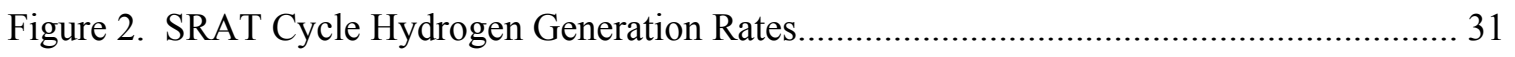

Figure 3. SME Cycle Hydrogen Generation Rates.............................................................. 32

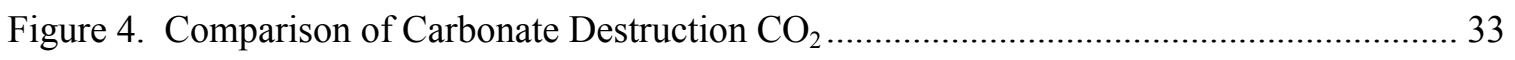

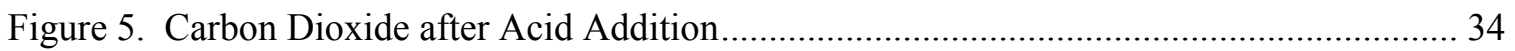

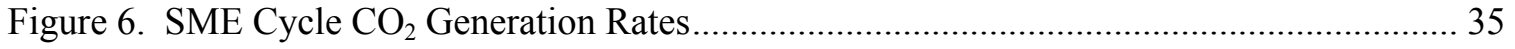

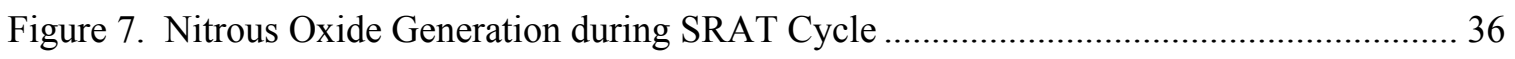

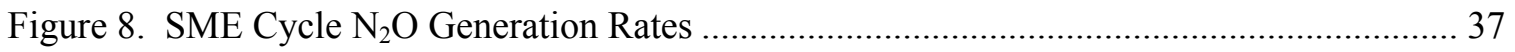

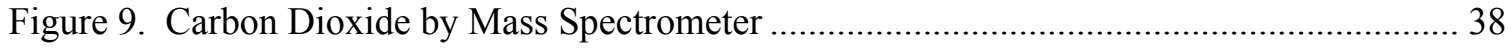

Figure 10. Nitrogen Dioxide by Mass Spectrometer............................................................... 38

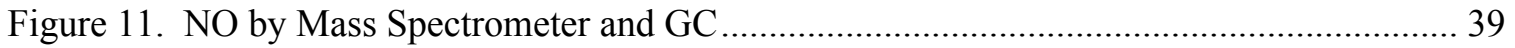

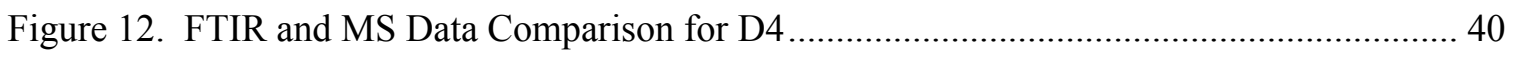

Figure 13. Antifoam Decomposition During D4 SRAT Cycle ............................................... 41

Figure 14. Rate of Nitrate Loss at High Acid Stoichiometry ................................................... 47

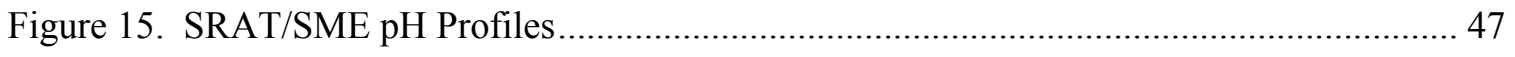

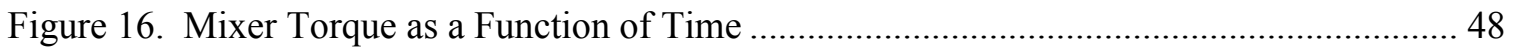

Figure 17. SRAT Heat Input during Acid Addition .................................................................. 49

Figure 18. $\mathrm{CO}_{2}($ vol\%) Release as a Function of $\mathrm{pH}$ Probe Reading ...................................... 49

Figure 19. Slurry Film Heat Transfer Coefficient as a Function of Processing Time................. 50 
Figure 20. Effective Viscosity of SRAT Product Slurries.......................................................... 54

Figure 21. REDOX Operating Window vs. Melter Flammability Constraint .............................. 58

Figure 22. SB8-Tank 51 SRAT Hydrogen Generation Rates .................................................. 65

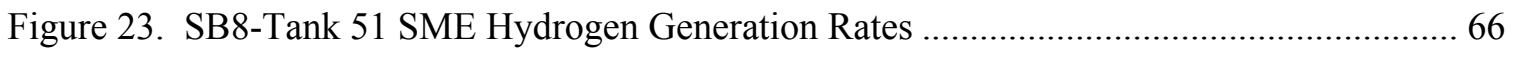

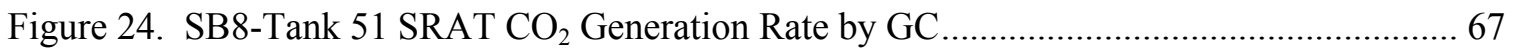

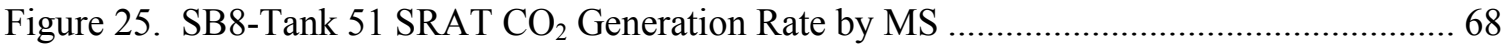

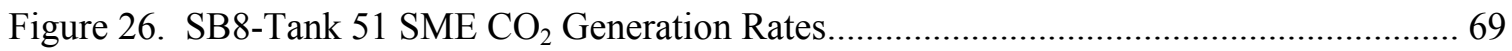

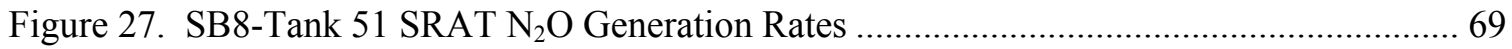

Figure 28. SB8-Tank 51 SRAT $\mathrm{NO}_{2}$ Generation Rate by MS …............................................ 70

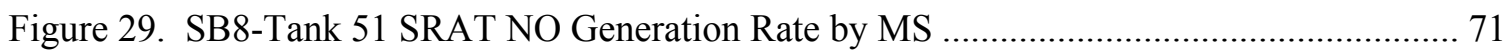

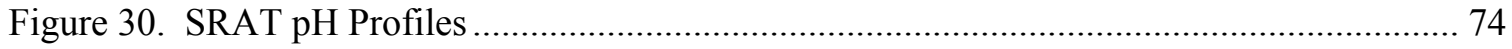

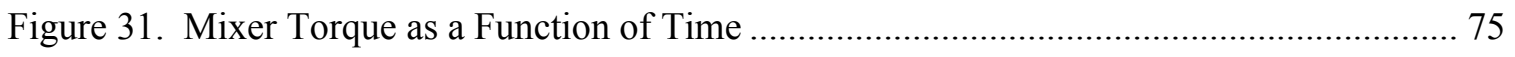

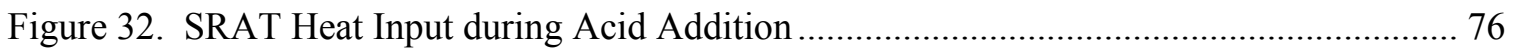

Figure 33. Slurry Film Heat Transfer Coefficient as a Function of Processing Time .................. 76

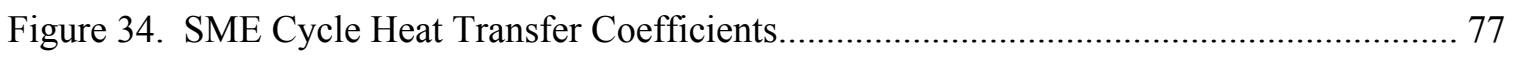

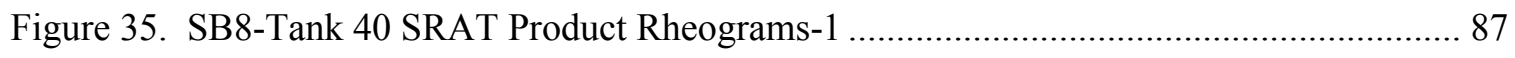

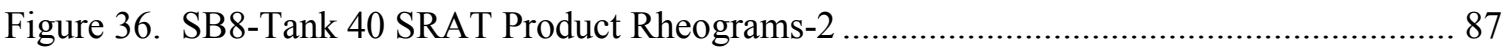

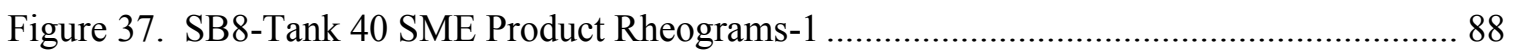

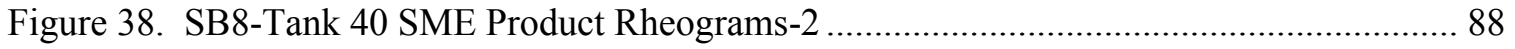

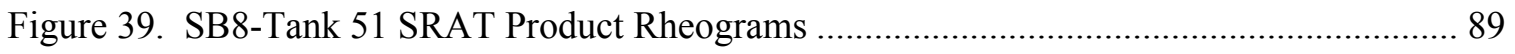

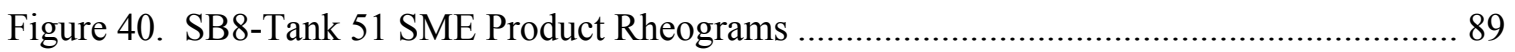




\section{LIST OF ABBREVIATIONS}

$\begin{array}{ll}\text { ACTL } & \text { Aiken County Technology Laboratory } \\ \text { AD } & \text { Analytical Development } \\ \text { ARP } & \text { Actinide Removal Process } \\ \text { CPC } & \text { Chemical Process Cell } \\ \text { DWPF } & \text { Defense Waste Processing Facility } \\ \text { FAVC } & \text { Formic Acid Vent Condenser } \\ \text { FTIR } & \text { Fourier Transform Infrared (Spectrometry) } \\ \text { GC } & \text { Gas Chromatograph } \\ \text { HMDSO } & \text { Hexamethyl disiloxane } \\ \text { IC } & \text { Ion Chromatography } \\ \text { ICP-AES } & \text { Inductively Coupled Plasma-Atomic Emission Spectroscopy } \\ \text { KMA } & \text { Koopman Minimum Acid equation } \\ \text { MCU } & \text { Modular Caustic-side solvent extraction Unit } \\ \text { MS } & \text { Mass Spectroscopy } \\ \text { MWWT } & \text { Mercury Water Wash Tank } \\ \text { PSAL } & \text { Process Science Analytical Laboratory } \\ \text { R\&D } & \text { Research \& Development } \\ \text { REDOX } & \text { Reduction-Oxidation potential } \\ \text { SB } & \text { Sludge Batch, e.g. SB7b, SB8 } \\ \text { SME } & \text { Slurry Mix Evaporator } \\ \text { SMECT } & \text { Slurry Mix Evaporator Condensate Tank } \\ \text { SRAT } & \text { Sludge Receipt and Adjustment Tank } \\ \text { SRNL } & \text { Savannah River National Laboratory } \\ \text { TIC } & \text { Total Inorganic Carbon } \\ \text { TOC } & \text { Total Organic Carbon } \\ \text { TTR } & \text { Task Technical Request } \\ \text { TTQAP } & \text { Task Technical \& Quality Assurance Plan } \\ & \end{array}$


SRNL-STI-2013-00106

Revision 0

\subsection{Introduction}

\subsection{Program Overview}

Sludge Batch 8 (SB8) in Tank 40 will be processed by the Defense Waste Processing Facility (DWPF) starting about May 2013. SB8 was less washed than previous batches in Tank 51, but was designed to combine with a relatively large heel of SB7b in Tank 40 (about 57\% new material on a total solids mass basis). A sodium-driven new frit design (frit 803) was developed for SB8 to deal with varying amounts of Actinide Removal Process (ARP) slurry with the less washed sludge. The sodium to insoluble solids ratio of Tank 51 at the time of transfer to Tank 40 was constrained to a somewhat narrow range by the new frit as was the maximum quantity of nominal ARP composition slurry.

SRNL was requested by a DWPF Task Technical Request (TTR) to perform simulant studies to support SB8. ${ }^{1}$ This task was technical baseline research and development, but the requirements of DOE/RW-0333P were not applicable. SRNL developed a task technical and quality assurance plan (TTQAP) for the proposed scope of work. ${ }^{2}$ E7 procedures relevant to this task are outlined in the quality assurance (QA) matrix of the approved TTQAP. Details of simulant preparation and lab-scale process simulations were recorded in controlled laboratory notebooks SRNL-NB2012-00108 and -00110. These notebooks contain sufficient data to reproduce the simulant preparation and simulant testing as well as containing processing data recorded manually every twenty minutes during DWPF process simulations. (A higher data logging rate is normally achieved with the automated process control systems, e.g. data every minute on most temperatures, agitator speeds, gas chromatograph and mass spectrometry scans, etc., but space considerations (the electronic data would run to many hundreds of pages) preclude placing hard copies of these data in the laboratory notebooks. Instead these data are placed on the cpcdatabase server where they are backed-up daily by Information Technology.) Details of simulation liquid and slurry sample analyses (final results only presented in this report) were recorded in controlled laboratory notebooks held by either the Process Science Analytical Laboratory (PSAL) or SRNL Analytical Development (AD). Special data not recorded by the above methods, such as rheological flow curves, are included in the main body or the appendix (rheology) of this report. Software used in performing the DWPF simulations conforms to the requirements of E7, 5.0, Software Engineering and Control. Additional details related to QA and the implementing procedures within SRNL can be found in the QA matrix pages at the end of the TTQAP.

A flexible approach was required during initial simulant design while the frit suitability was confirmed, since this issue could impact the selected blend point (and composition of critical species to DWPF processing such as mercury, noble metals, and oxalate). Initial projections for SB8 included oxalate-rich material from Tank 12. Early SRNL simulants and simulant SRAT/SME runs were based on these compositions. This preliminary SB8 work is documented in another report. ${ }^{3}$ Subsequently, a decision was made to accelerate preparation of SB8 by delaying the Tank 12 contribution to a future sludge batch, and this report deals with the Tank 51 and Tank 40 compositions resulting from this decision.

Separate simulants of SB8-Tank 51 and SB7b-Tank 40 were prepared for the new case without Tank 12 (see Section 3.1). These were only blended to the projected SB8-Tank 40 composition when CPC testing was imminent in order to obtain the most up-to-date composition available. SB8-Tank 51 simulant was also used in simulant tests to support the Shielded Cells qualification run of SB8 with the washed Tank 51 sample. This report summarizes potential impacts of SB8 
and provides recommended operating strategies for the DWPF Sludge Receipt and Adjustment Tank (SRAT) and Slurry Mix Evaporator (SME) cycles.

Four process demonstrations of the SRAT and SME cycles were performed for the sludge-only flowsheet using SB8-Tank 40 simulant. One coupled flowsheet SRAT/SME run was performed using SB8-Tank 40 simulant. The results of the above five SRAT/SME tests are documented in the body of this report below (Section 3.2). In addition, this report also documents three simulant SRAT/SME runs performed with the SB8-Tank 51 simulant to support the SB8 qualification test in the SRNL Shielded Cells (Section 3.3). These three runs were all performed using the sludgeonly flowsheet. The stoichiometric acid factor was varied from run to run in order to define the acid window for nitrite destruction and excessive hydrogen generation. This was a prerequisite for making a recommendation for a stoichiometric factor for the Shielded Cells qualification SRAT run (SC-14) with the washed Tank 51 sample. The SRNL Shielded Cells qualification SRAT/SME run with glass preparation and testing is documented in a separate report. 
SRNL-STI-2013-00106

Revision 0

\subsection{Experimental Procedures}

\subsection{Process and Sample Analytical Methods}

Eight lab-scale SRAT/SME runs were performed with updated Tank 51 or Tank 40 simulants for the "no contribution from Tank 12 case" for SB8. Testing was completed at the Aiken County Technology Laboratory (ACTL). Six of the eight SB8 SRAT/SME runs occurred in pairs; however the other two runs occurred in parallel with alternate reductant flowsheet testing. All runs were performed using round-the-clock operations.

The automated data acquisition system developed for the 4-L lab-scale SRAT/SME was used to collect electronic data on a computer. Collected data included SRAT slurry temperature, bath temperatures for the cooling water to the SRAT condenser and Formic Acid Vent Condenser (FAVC), slurry pH, SRAT mixer speed and torque, air and helium purge flows (helium is used as an internal standard and is set to $0.5 \%$ of the nominal SRAT air purge flow). Expanded recording capacity for these runs (compared to SB7b) included temperatures in the SRAT condenser, FAVC, and ammonia scrubber. Air and helium flow data were collected electronically on only six of eight runs due to a failure in the data hub on one side of the lab during the SB8 program. Air and helium data were also obtained and recorded manually, however, so no gas flow data of consequence were lost. Additional new data recording capacity (compared to SB7b) was used to monitor the individual temperatures of the two heating rods, the total rod current draw, and the total rod power consumption. These new quantities combined with the vessel slurry temperature permit calculation of a time-dependent heat transfer coefficient between the rods and slurry.

Raw chromatographic data were acquired by gas chromatograph (GC) on samples of the FAVC off-gas stream using a separate computer interfaced to the data acquisition computer. The chilled off-gas leaving the FAVC was passed through a Nafion dryer in counter-current flow with a dried air stream to reduce the moisture content at the GC inlet. The dried, chilled off-gas stream was sampled by GC from the beginning of heat-up to temperature to start the SRAT cycle through most of the cool down following the SME cycle. Sampling frequency was approximately one chromatogram every 4.5 minutes.

Each experiment had a dedicated Agilent (or Inficon) 3000A dual column micro GC. Column-A can collect data related to $\mathrm{He}, \mathrm{H}_{2}, \mathrm{O}_{2}, \mathrm{~N}_{2}, \mathrm{NO}$, and $\mathrm{CO}$, while column-B can collect data related to $\mathrm{CO}_{2}, \mathrm{~N}_{2} \mathrm{O}$, and water. GC's were calibrated with a standard calibration gas containing 0.510 vol $\% \mathrm{He}, 1.000$ vol $\% \mathrm{H}_{2}, 20.10$ vol $\% \mathrm{O}_{2}, 50.77$ vol $\% \mathrm{~N}_{2}, 25.1 \mathrm{vol} \% \mathrm{CO}_{2}$ and $2.52 \mathrm{vol} \% \mathrm{~N}_{2} \mathrm{O}$. The calibration was verified prior to starting the SRAT cycle and after completing the SME cycle. Room air was used to give a two point calibration for $\mathrm{N}_{2}$. No evidence for $\mathrm{CO}$ generation was obtained while examining the region of the chromatogram where it would elute. NO was observed in all runs during nitrite destruction, but $\mathrm{NO}$ is not in the GC calibration gas, so only the timing of $\mathrm{NO}$ generation was quantitatively determined from $\mathrm{GC}$ data.

The GC's were baked out before and between runs. GC performance showed signs of equipment aging. The two GCs used on the three Tank 51 runs and first two Tank 40 runs were replaced before the final three Tank 40 runs, but three of the four GCs had performance issues. Sample pump performance seemed degraded in more than one instance. New calibration gas cylinder regulators and pressure gauges were purchased to permit calibrating the GC's at pressures less than 1 psig (versus 3-6 psig historically). The lower calibration gas pressure mitigated some of the sample pump-related calibration issues. GC data were reprocessed after the simulations to 
bring the observed readings in-line with the known compositions for the calibration gas and room air, and to off-set small drifts in calibration $(\sim 10 \%)$ that were observed in some of the tests.

GC data were supplemented in most cases by parallel Extrel Core mass spectrometer (MS) readings on FAVC off-gas samples. Samples originated from the same part of the off-gas system as the GC samples. A single MS is able to monitor off-gas data from both hoods simultaneously due to its automated sampling system. MS data require more reprocessing because the helium and hydrogen sensitivities drift noticeably on a time scale of 60-120 minutes, i.e. much less than the run time of a SRAT/SME experiment. The drift is normal for MS, and it does not indicate an equipment malfunction. Higher molecular weight gases show far less drift during a SRAT/SME test. To correct for the drift, calibration gas containing $\mathrm{He}$ and $\mathrm{H}_{2}$ was checked regularly during an experiment. After the test, the $\mathrm{He}$ and $\mathrm{H}_{2}$ compositions were adjusted by linear interpolation to the most recent calibration gas result and the nearest future calibration gas result such that the two compositions match the calibration gas exactly at either end of the interpolation range.

The MS obtains data by molecular weight of ionized fragments of the original molecules. The data can be reconstructed to give quantitative concentrations for $\mathrm{H}_{2}, \mathrm{He}, \mathrm{N}_{2}, \mathrm{O}_{2}, \mathrm{NO}, \mathrm{NO}_{2}, \mathrm{CO}_{2}$, and Ar. The compound list is specified by the MS run method plus the species in a set of six different calibration gases. $\mathrm{GC} \mathrm{N}_{2} \mathrm{O}$ data is also used to improve the oxides of nitrogen results for $\mathrm{NO}$ and $\mathrm{NO}_{2}$ from the MS as well as the $\mathrm{N}_{2}$ and $\mathrm{CO}_{2}$ results. The MS sampler cycles back and forth between the off-gas streams from the two hoods (from the two parallel SRAT/SME tests). It takes a reading every 6-7 seconds, so the time resolution of events is much sharper than that provided by the GC. A periodic MS scan out to molecular weights of 240 is made, but these scans must be reviewed manually to determine if any species heavier than $\mathrm{CO}_{2}$ were detected. The potential to detect small quantities of mercury or antifoam decomposition products exists, but review of these data remains to be done at some future date.

The MS obtains data on one hood for about 2.2 minutes, then switches to the other hood for the same time, then switches back, and so on, so there are about 20 MS data sets per GC chromatogram on both hoods. Roughly 19,000 data sets, including calibration gas checks, were obtained during the third and fourth flowsheet tests (SB8-D3 and D4). After reprocessing for drift and to convert to an Excel workbook, the MS data for this run pair filled 1.3 million cells. These workbooks are archived on the cpc-database server, since it is not feasible to incorporate them within a technical report in table form.

GC and MS data were further supplemented by a MKS Fourier Transform Infrared (FTIR) spectrometer for two of the runs. The FTIR is connected to the two SRAT/SME off-gas systems like the MS, but it is manually valved into one or the other for the duration of the run. Two of the eight SB8 SRAT/SME runs occurred in parallel with runs supporting the alternate reductant test program. The FTIR was used on the alternate reductant runs rather than for SB8, since the alternate reductant flowsheet is not as well understood as the current flowsheet. One of the three pairs of SB8 runs occurred while the FTIR was off-line, so only two sets of FTIR data were ultimately obtained from the eight SB8 tests. The FTIR gives $\mathrm{CO}_{2}, \mathrm{NO}, \mathrm{NO}_{2}, \mathrm{~N}_{2} \mathrm{O}, \mathrm{H}_{2} \mathrm{O}$, and hexamethyl disiloxane (HMDSO) concentrations as currently configured. HMDSO is a volatile marker for decomposed antifoam. Although the GC detects water, the FTIR gives a quantitative concentration for moisture in the chilled off-gas leaving the Nafion drier. The FTIR obtained data roughly every 19 seconds (about 7400 data sets for SB8-D4 vs. 600 GC data sets). The D4 Excel worksheet contained roughly 110,000 filled cells related to the run.

Process samples (liquid, solid, or slurry) were analyzed by various methods. Slurry and supernate elemental compositions were determined by inductively coupled plasma-atomic emission 
spectroscopy (ICP-AES). Slurry samples were calcined at $1100{ }^{\circ} \mathrm{C}$ and then digested prior to analysis by either lithium metaborate and/or sodium peroxide fusions at the PSAL. Slurry samples were calcined at $1100^{\circ} \mathrm{C}$. The main advantage of this approach is to permit easier comparisons between SRAT product elements and sludge elements. Noble metals and mercury are trimmed uniquely to each SRAT, and their concentrations are known more accurately from material balance considerations than they could be from ICP-AES analyses.

Water soluble slurry anions were determined by ion chromatography (IC) on 100-fold weighted dilutions of slurry with water followed by filtration to remove the remaining insoluble solids. IC results were obtained on three slurry samples during the SRAT, as well as on the SRAT and SME products. Anions were also checked in some of the SRAT cycle condensates. SRAT cycle, SRAT product, and SME product slurry samples were submitted to PSAL for mercury analysis by ICP-AES. Simulants, SRAT products, and SME products were analyzed by PSAL for slurry and supernate density using the Anton-Parr DMA-4500 density instrument. Starting sludge simulants, plus a composite SRAT receipt sample from the flowsheet tests, were titrated to $\mathrm{pH} 7$ using the PSAL auto-titrator to determine the base equivalents for input into the stoichiometric acid equation.

Three SB8-Tank 51 and five SB8-Tank 40 SRAT and SME product samples were submitted to AD for total inorganic carbon (TIC) and total organic carbon (TOC) analysis (16 total samples). The three new simulants, the SB8-Tank 40 blend simulant, and a composite SRAT receipt sample were submitted to AD for TIC-TOC analysis of both the bulk slurry and the supernate. Single slurry samples were submitted straight and at two arbitrary dilutions, while supernate samples were submitted in duplicate. Samples from the ammonia scrubber reservoir vessel were analyzed by $\mathrm{AD}$ using cation chromatography for ammonium ion.

As a part of the SB8 testing, samples of the SRAT dewater condensate were analyzed for silicon. Antifoam molecules terminate in end groups composed of multi-methyl siloxanes, so silicon is a potential marker for volatilized or steam stripped antifoam lost from the SRAT slurry. The test cannot discriminate between silicon derived from antifoam and silicon from the $\mathrm{SiO}_{2}$ in the slurry, but it can bound potential antifoam losses to the condensate related to $\mathrm{Si}$.

\subsection{Chemical Process Cell}

The 4-L lab-scale SRAT equipment was used for these tests. A photo of a typical 4-L rig is shown in Figure 1. The SRAT vessel was insulated when at processing temperatures. The trimmed SRAT receipt volume was about 3.0 L for the SB8-Tank 40 flowsheet testing following caustic pre-concentration. 


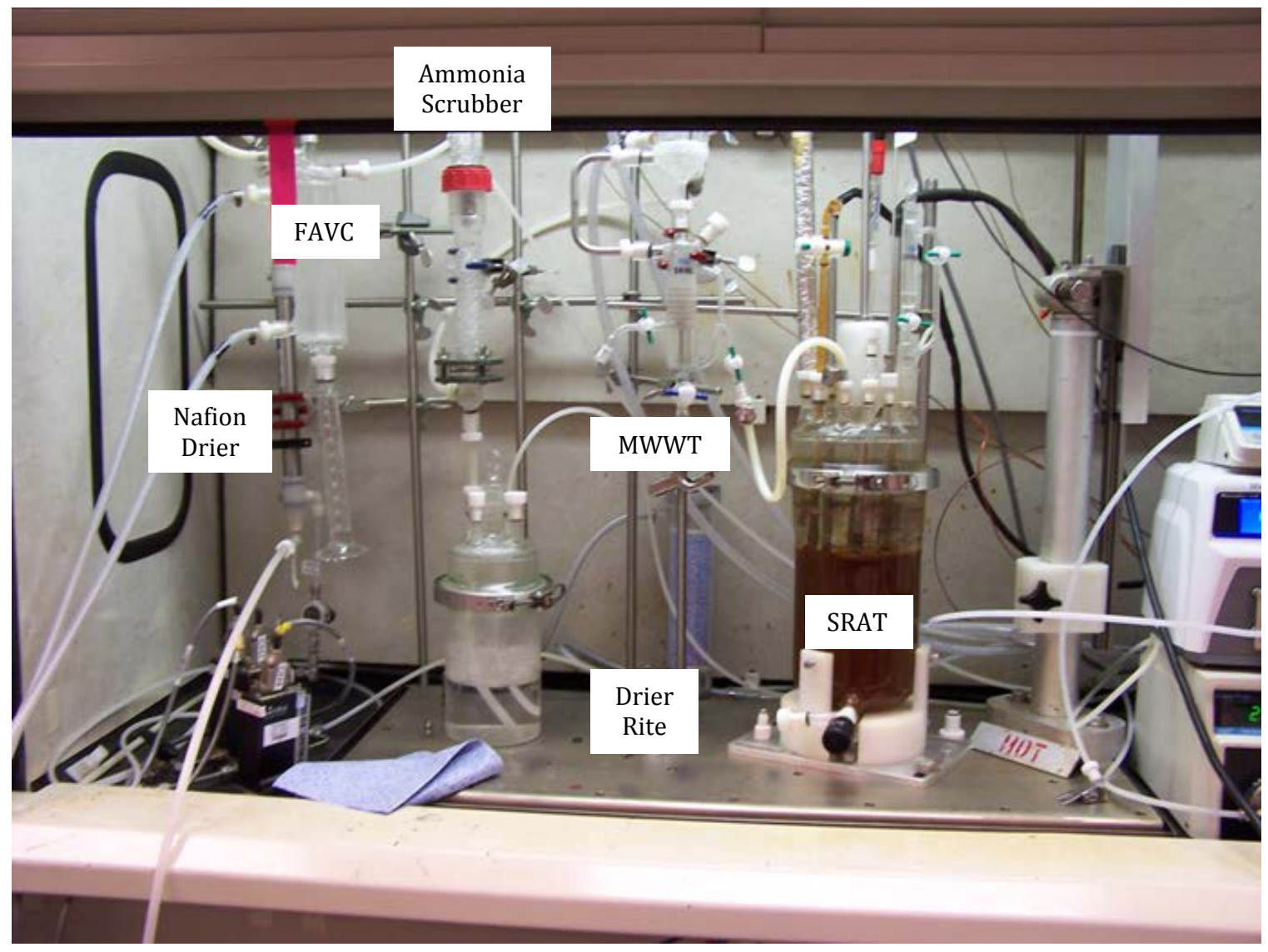

Figure 1. Lab-scale SRAT Apparatus

The modified lab-scale SRAT rig design was used (off-center agitation, heating rods). More details about the new design are in the CPC equipment set-up reference. ${ }^{5}$ DrierRite columns in the air supply line to the rig equipment remove any moisture from the compressed air used for process purges.

The reservoir below the ammonia scrubber was charged with a solution of $749 \mathrm{~g}$ of de-ionized water and $1 \mathrm{~g}$ of $50 \mathrm{wt} . \%$ nitric acid. Condensates from the SRAT and SME were not drained into this reservoir. The dilute acid reservoir solution was recirculated by a MasterFlex driven Micropump gear pump at about $300 \mathrm{~mL}$ per minute to a spray nozzle at the top of the packed section. The main purpose of the lab-scale ammonia scrubber is to collect ammonia vapor in the SRAT/SME condenser off-gas for quantification of ammonia generation, whereas the main purpose of the DWPF SRAT and SME ammonia scrubbers is to prevent build-up of ammonium nitrate crystals in the off-gas system.

The modified SRAT condenser/mercury water wash tank (MWWT) combination was used for the SB8 runs. The new configuration drops SRAT/SME condensate vertically into the MWWT at a point below the gas-liquid interface inside the MWWT. This design significantly reduced the hold-up of mercury and antifoam degradation products in the condenser drain leg that had been seen in various prior test programs.

Initial simulant acid calculations were based on the Koopman minimum acid (KMA) requirement equation (all terms have units of moles/L slurry). ${ }^{6}$ 


$$
\frac{\text { moles acid }}{L \text { slurry }}=\text { base equivalents }+H g+\text { soluble } T I C+\text { nitrite }+1.5 *(C a+M g+M n)
$$

Stoichiometric factors ranging from $105 \%$ to $140 \%$ were used in both the SB8-Tank 51 and SB8Tank 40 tests. The coupled flowsheet test included Actinide Removal Process (ARP) slurry and dilute acid from the Modular Caustic-side Solvent Extraction Unit (MCU). The ARP/MCU run was matched to the nominal, or $120 \%$, SB8-Tank 40 flowsheet case. Parallel acid calculations were also performed using the current DWPF algorithm (Hsu equation) for comparison: ${ }^{7}$

$$
\frac{\text { moles acid }}{\text { L slurry }}=\text { base equivalents }+2 * \text { total TIC }+0.75 * \text { nitrite }+1.2 * \mathrm{Mn}+\mathrm{Hg}
$$

The accuracy of the Hsu equation could be improved by changing the nitrite coefficient from 0.75 to $\sim 1.0$ and finding a somewhat lower coefficient for slurry (total) TIC as an alternative to converting to the KMA (without adding the need to track $\mathrm{Mg}$ and $\mathrm{Ca}$ ). Section 3.2.1 discusses the considerations needed to be made in taking the lab-scale simulant results over to the full-scale SRAT.

The results of these two different stoichiometric acid calculations for the trimmed SB8-Tank 51, SB8-Tank 40, and SB8-Tank 40-ARP combination simulants are summarized in Table 2-1. The SB8-Tank 40 results are per liter of "pre-concentrated" slurry, that is the volume after the preconcentration dewatering has occurred (or, equivalently, per liter slurry ready for nitric acid addition). The SB8-ARP result is per liter of pre-concentrated sludge plus ARP slurry less dewatered ARP condensate. The table also includes the actual acid additions made based on $115 \%$ (Tank 51)-120\% (Tank 40) of the Koopman minimum acid equation and the equivalent DWPF stoichiometric factors (percent) to go from the DWPF acid equation (Hsu equation) values to the actual acid additions.

Table 2-1. Stoichiometric Acid Calculation Results, mol acid/L trimmed slurry

\begin{tabular}{|l|c|c|c|c|}
\hline & $\begin{array}{c}\text { DWPF Eqn. } \\
\text { moles/L }\end{array}$ & $\begin{array}{c}\text { Koopman Min. } \\
\text { moles/L }\end{array}$ & $\begin{array}{c}\text { Actual addition at } \\
\mathbf{1 1 5 - 1 2 0 \%} \text { moles/L }\end{array}$ & $\begin{array}{c}\text { Equivalent } \\
\text { DWPF factor }\end{array}$ \\
\hline SB8-Tank 51 & 2.16 & 2.37 & $2.72(115 \%)$ & $126 \%$ \\
\hline SB8-Tank 40 & 1.84 & 1.94 & $2.32(120 \%)$ & $126 \%$ \\
\hline SB8-ARP & 1.80 & 1.88 & $2.25(120 \%)$ & $125 \%$ \\
\hline
\end{tabular}

The calculated stoichiometry by both the Hsu and KMA equations were based on the sum of the sludge simulant acid demand plus the ARP simulant acid demand in the case of the coupled flowsheet. Analysis of the SRAT receipt sample following combining and dewatering the two slurries gave an acid demand that was 5.7\% lower than the sum of the individual demands which is well within analytical uncertainties for the input terms. The changes were due to $\sim 12 \%$ decreases in $\mathrm{Mn}$ and base equivalents moles versus the predictions from the sum of the sludge plus ARP values. Since there was no Mn in the ARP, this entire change came from the sludge. A review of all available SB8-Tank $40 \mathrm{Mn}$ data (see Table 3-4) indicated that the sludge simulant analysis was roughly $11 \%$ higher than the overall average, i.e. the coupled run sludge-ARP receipt $\mathrm{Mn}$ result was more consistent with the body of Mn data than the SB8-Tank 40 simulant result. In that case, the SB8-Tank 40 runs nominally at $105 \%, 120 \%$, and $140 \%$ were more 
nearly at $108 \%, 123 \%$ and $144 \%$ (if the best available Mn value after the runs were over had been used as an input to the acid equations instead of the SB8-Tank 40 simulant analysis result).

Total acid demand was partitioned between formic and nitric acids using the current reduction oxidation (REDOX) equation. ${ }^{8}$ The REDOX target was set to $0.10 \mathrm{Fe}^{2+} / \sum \mathrm{Fe}$ for SB8. This is a 0.10 drop from previous sludge batch testing and was due to the assumed impact of the argon bubblers on melter REDOX in DWPF. Assumptions of $20-34 \%$ formate loss and of $5-32 \%$ nitrite-to-nitrate conversions were also made to allow the REDOX prediction to be performed. Oxalate was assumed to be $10 \%$ destroyed in the SB8-Tank 40 runs, while a zero destruction rate was assumed for the SB8-Tank 51 (where feed oxalate was projected to be so low in concentration without the Tank 12 waste that the assumed loss was essentially irrelevant). The collective anion change assumptions were based on earlier experience with the SB8 $8^{3}$ simulants that included a Tank 12 component.

No negative nitrite-to-nitrate conversion assumptions were needed for SB8, which was a sign that nitrate destruction rates were lower than either SB7 or SB7b and also that ammonium ion formation rates might be lower. Smaller formate loss and higher nitrite-to-nitrate conversion assumptions were assigned to lower acid stoichiometry. These assumptions gave a formic acid fraction of the total acid moles in the range of $0.86-0.92$ (or, equivalently nitric acid fraction in the 0.14-0.08 range). The ARP run had an intermediate fraction of 0.87 formic acid/total acid relative to the range in the seven non-ARP runs.

Scaled design basis DWPF SRAT/SME processing conditions were generally used. The SRAT and SME cycles, however, did not have a heel from a prior batch. R\&D directions were prepared for each run and used to supplement the standard SRNL procedure for non-radioactive CPC simulations. $^{9}$

- Sludge and noble metal trim chemicals were added to the vessel.

- The SRAT air purge scaled to $230 \mathrm{scfm}$ in DWPF.

$\circ$ In the SB8-Tank 40 flowsheet runs only:

- A 100 ppm antifoam addition was made prior to boiling.

- The SRAT was brought to boiling and dewatered 12\% (by mass).

- A SRAT receipt sample was pulled.

- The SRAT was cooled to $93{ }^{\circ} \mathrm{C}$.

- Mercuric oxide trim chemical was added to the vessel.

- A 200 ppm antifoam addition was made prior to nitric acid addition.

- A 100 ppm antifoam addition was made prior to formic acid addition.

- Nitric and formic acid addition were made at $93{ }^{\circ} \mathrm{C}$.

- Acids were added at two gallons per minute scaled per the discussion below.

- A $500 \mathrm{ppm}$ antifoam addition was made prior to going to boiling following acid addition.

- Boiling assumed a condensate production rate of 5,000 lb/hr at DWPF scale.

- SRAT dewatering took about 3-4 hours to produce a 28-30 wt. \% total solids slurry.

- Reflux followed dewatering. The end of the reflux period defined the end of the SRAT cycle. Total reflux time was calculated based on mercury content of the slurry and assumed stripping efficiencies. MCU addition/dewatering replaced the majority of the reflux time in the coupled flowsheet test. The SME air purge scaled to $74 \mathrm{scfm}$ in DWPF.

- A 100 ppm antifoam addition was made at the start of the SME cycle.

- Canister decontamination water additions and dewaterings were not simulated.

- Two frit 418-water-formic acid additions were made targeting 36\% waste loading.

- The SME was dewatered following each frit slurry addition. 
- The final SME solids target was 50-51 wt.\%.

Twelve to fifteen samples were taken during each SRAT cycle to monitor mercury and the progress of major reactions. Major anions were checked immediately after acid addition. Selected cations were checked in the SRAT supernate and in SRAT condensates. Samples were pulled during boiling to monitor suspended and dissolved mercury in the SRAT slurry. These samples were pulled directly into digestion vials to eliminate potential segregation of mercury during sub-sampling/aliquoting steps. The SRAT and SME product slurries were sampled by the same method once the vessel contents had cooled to $90^{\circ} \mathrm{C}$ while still mixing.

Additional SRAT and SME product samples were taken from each run after the product had cooled further for compositional and solids analyses as well as for rheological characterization of each slurry. The MWWT and FAVC were drained and the condensates weighed after both the SRAT and SME cycles. Elemental mercury was separated from the aqueous phase in the postSRAT MWWT sample when possible, and the mass of the mercury-rich material determined.

Gas chromatograph off-gas data were scaled to DWPF flow rates. The calculation methodology has been previously documented. ${ }^{10}$ An internal standard flow is usually established with helium. Other gas flow rates are determined relative to helium by taking the ratio of the two gas volume percentages times the helium standard flow. The result is normally scaled by the ratio of 6,000 gallons of fresh sludge divided by the volume of fresh sludge in the simulant SRAT charge. In the SB8 flowsheet simulations, the scaling was performed assuming the volume following preconcentration was equivalent to 6,000 gallons at DWPF scale. The SB8 qualification SRAT runs did not have pre-concentration, so the initial simulant volume was set equivalent to 6,000 gallons at DWPF scale. Identical logic was used to convert MS off-gas data to DWPF-scale flow rates.

SRNL prepared conservative estimates of the noble metal and mercury concentrations for SB8Tank 51 and SB8-Tank 40 simulants prior to performing the SRAT/SME runs. Estimates were based on the measured concentrations in the SB7b WAPS sample and the SRNL washed SB8Tank 51 qualification sample. The SB8-Tank 40 blend was forecast to be $42.7 \% \mathrm{SB} 7 \mathrm{~b}$ heel on a total solids mass basis, and this factor was used to weight the results from the two radioactive sample analyses. Noble metals were trimmed at $125 \%$ of the estimated values while mercury was trimmed at $110 \%$ of the estimated values. The ARP slurry was assumed to have no noble metals and mercury based on sample results that show negligible entrained sludge solids content in the slurry (slurry is essentially MST and salt solution).

Table 2-2. Mercury and Noble Metal Estimates

\begin{tabular}{|l|l|l|c|c|c|}
\hline & $\begin{array}{c}\text { SB7b } \\
\text { WAPS } \\
\text { Analysis }\end{array}$ & $\begin{array}{c}\text { SRNL- } \\
\text { washed } \\
\text { Tank 51 }\end{array}$ & $\begin{array}{c}\text { SB8-Tank 40 } \\
(42.7 \% \text { SB7b) } \\
\text { estimate }\end{array}$ & $\begin{array}{c}\text { SB8-Tank 51 } \\
\text { simulant trim }\end{array}$ & $\begin{array}{c}\text { SB8-Tank 40 } \\
\text { simulant trim }\end{array}$ \\
\hline $\mathrm{Hg}$ & 0.71 & $1.65-2.20$ & $1.42-1.94$ & 2.384 & $1.25-2.14$ \\
\hline $\mathrm{Rh}$ & 0.0207 & 0.00901 & 0.0140 & 0.0123 & 0.0175 \\
\hline $\mathrm{Ru}$ & 0.102 & 0.0398 & 0.0664 & 0.0515 & 0.0830 \\
\hline $\mathrm{Ag}$ & 0.0118 & 0.014 & 0.0131 & 0.0129 & 0.0164 \\
\hline $\mathrm{Pd}$ & 0.00254 & 0.00288 & 0.0027 & 0.0027 & 0.0034 \\
\hline
\end{tabular}

Mercury measurements on the SRNL-washed Tank 51 sample were evolving as the preparations for the SB8-Tank 40 flowsheet runs were being made (SB8-Tank 51 qualification simulant runs were over). The values used for SB8-Tank 51 came from a paper calculation of the impact of 
washing on the unwashed Tank 51 qualification sample. Initial results on the washed Tank 51 qualification sample were much lower than expected and were received after the first pair of SB8Tank 40 flowsheet SRAT/SME simulations had been completed (D1, D2). Subsequent analysis resulted in a higher value that was closer to the expected value based on the unwashed sample, but these results came after the second pair of flowsheet runs (D3, D4) had been completed. Results for the Tank 51 reconfirmation sample in April 2013 were low like the first washed Tank 51 qualification sample. One unusual result is that there were no $\mathrm{Hg}$ values in the middle of the $20-25 \%$ range of Table 2-2, only higher values (two samples) and lower values (two samples).

Consequently, the five SB8-Tank 40 simulant flowsheet runs were completed at several different mercury levels as well as two different noble metal levels. A detailed breakdown of the mercury, noble metals, and acid stoichiometries of the five SB8-Tank 40 tests is given in Table 2-3.

Table 2-3. Mercury and Noble Metal Targets of Individual Flowsheet Runs

\begin{tabular}{|l|c|c|c|c|c|c|}
\hline Run ID & Acid & $\mathrm{Hg}$ & $\mathrm{Rh}$ & $\mathrm{Ru}$ & $\mathrm{Ag}$ & $\mathrm{Pd}$ \\
\hline SB8-D1 & $105 \%$ & 2.145 & 0.0175 & 0.083 & 0.0164 & 0.0034 \\
\hline SB8-D2 & $140 \%$ & 2.142 & 0.0175 & 0.083 & 0.0164 & 0.0034 \\
\hline SB8-D3 & $120 \%$ & 1.638 & 0.0175 & 0.083 & 0.0164 & 0.0034 \\
\hline SB8-D4 & $140 \%$ & 1.250 & 0.0175 & 0.083 & 0.0164 & 0.0034 \\
\hline SB8-D5 & $120 \%$ & 1.559 & 0.0167 & 0.079 & 0.0156 & 0.0032 \\
\hline
\end{tabular}

Values given in Table 2-3 for the coupled flowsheet run, SB8-D5, are based on the combined total solids (sludge solids plus ARP solids). Generally, two runs are not made at the same acid stoichiometry for the same flowsheet. However, since mercury has been shown to impact hydrogen generation, and since hydrogen generation is a critical aspect of the acid stoichiometry window, there were two runs at $140 \%$ acid stoichiometry. These were at the high and low end of the projected mercury window to ensure that the worst case for hydrogen generation was captured in the simulations.

Table 2-4 gives the mercury and noble metal targets for the three SB8-Tank 51 sludge-only qualification simulant runs without Tank 12: B3, B4, and B5, compared to the targets for the initial two tests with the high oxalate supernate: B1 and B2. Mercury was set at $105 \%$ of the best estimate for Tank 51 , while the noble metals were set at $125 \%$ of the best estimates for Tank 51 as of October 2012.

Table 2-4. Mercury and Noble Metal Targets of SB8-Tank 51 Runs

\begin{tabular}{|l|c|c|c|c|c|}
\hline & $\mathrm{Hg}$ & $\mathrm{Rh}$ & $\mathrm{Ru}$ & $\mathrm{Ag}$ & $\mathrm{Pd}$ \\
\hline SB8-B1, B2 & 2.540 & 0.0111 & 0.0427 & 0.014 & 0.0002 \\
\hline SB8-B3 to B5 & 2.384 & 0.0123 & 0.0515 & 0.013 & 0.0027 \\
\hline
\end{tabular}

All five of the B series runs started from the same untrimmed simulant and had essentially identical insoluble species with the exception of insoluble sodium oxalate (which was partially removed during the washing to produce the simulant for case studies without a Tank 12 contribution). B3 to B5 mercury and noble metal targets were calculated based on results from the unwashed qualification sample (mathematical wash calculation). The B1-B2 targets were based on results from a Tank 13 sample prior to transfer to Tank 51, plus contributions for the Tank 51 heel and Tank 12, along with some blending and washing calculations. Reducing $\mathrm{Hg}$, 
while increasing $\mathrm{Rh}$ and $\mathrm{Ru}$, meant that the first two runs were no longer bounding for hydrogen generation.

The potential for hydrogen generation was further impacted due to the reduced oxalate concentration after Tank 12 was removed from SB8. Reduced oxalate increased the fraction of total acid that needed to be formic acid for REDOX control (formic acid is the primary reactant for catalytic hydrogen generation; oxalate lacks the potential for significant catalytic hydrogen production). The ultimate goal was to keep the simulant studies bounding with respect to hydrogen generation relative to the real waste. 
SRNL-STI-2013-00106

Revision 0

\subsection{Results and Discussion}

This section is divided into three major sub-sections. These cover the preparation of a number of SB8 related simulants to perform the lab-scale testing (3.1), the SB8-Tank 40 flowsheet testing results (3.2), and the SB8-Tank 51 qualification simulant testing results (3.3).

\subsection{Simulant Preparation and Characterization}

SRNL had completed initial tests with simulants for SB8-Tank 40 and SB8-Tank $51^{3}$ when a decision was made in October 2012 to take Tank 12 (and all of its oxalate content) out of SB8. Simultaneously, a decision was made to wash the Tank 51 slurry to a higher sodium molarity endpoint, and to move up the transfer date for the Tank 51 to Tank 40 transfer. The timing change meant that there would be significantly more SB7b in the SB8-Tank 40 DWPF feed than originally planned. Newly projected noble metal concentrations for SB8-Tank 40 were higher, since SB7b-Tank 40 concentrations of noble metals were higher than SB8-Tank 51 concentrations. The combination of higher nitrate from reduced washing plus the need to substitute additional formate to off-set lost oxalate as well as to acidify the less washed sludge meant that the initial SB8 simulant tests were no longer bounding for either the anticipated CPC flowsheet processing behavior or to serve as a basis for the Tank 51 sample qualification SRAT/SME.

The remaining SB8-Tank 51 simulant (with Tank 12 included) was rewashed and trimmed back to the new projected Tank 51 wash endpoint without Tank 12. This simulant was then used for three SRAT/SME tests to support CPC qualification of the washed Tank 51 actual waste sample in the SRNL Shielded Cells, SC-14. This sequence was a critical path activity in the SB8 preparation schedule. The quantity of existing simulant was limited, however, and much of it was consumed in the new qualification testing.

New DWPF CPC flowsheet testing was also necessary with a SB8-Tank 40 simulant to provide inputs for DWPF sludge batch acceptance documents. The SB7b-SB8 blend point (blend date) was not firm initially, so flexibility was needed in the simulant design. Therefore a new SB7b simulant was prepared, and additional SB8-Tank 51 simulant was prepared. The SB7b simulant was based on the WAPS sample results. ${ }^{11}$ SB8-Tank 40 simulant was prepared by blending together SB7b-Tank 40 simulant with the two SB8-Tank 51 simulants rather than by precipitating SB8-Tank 40 simulant directly. The blending followed qualification simulant testing, and was based on the most up-to-date projection for the 51-40 blend ratio as of November 2012. The resulting SB8-Tank 40 simulant was used in five SRAT/SME tests to support the DWPF flowsheet.

Characterization data are presented below for the four simulants discussed above. These are the SB8-Tank 51r (for retrimmed - no Tank 12), SB8-Tank 51n (for new), SB7b-Tank 40, and the SB8-Tank 40 blended simulants. SB8-Tank 51n simulant never had the Tank 12 components. Table 3-1 gives the October 2012 projection for SB8-Tank 51 elemental composition on a glass basis compared to results for the two Tank 51 simulants calcined at $1100{ }^{\circ} \mathrm{C}$. Results for the SRNL-washed Tank 51 SB8 qualification sample are given for another comparison. ${ }^{12}$ 
Table 3-1. Calcined Elements of Tank 51 Simulants

\begin{tabular}{|l|c|c|c|c|}
\hline Wt.\% of & $\begin{array}{c}10 / 16 / 2012 \\
\text { projection }\end{array}$ & $\begin{array}{c}\text { Tank 51r } \\
\text { simulant }\end{array}$ & $\begin{array}{c}\text { Tank 51n } \\
\text { simulant }\end{array}$ & $\begin{array}{c}\text { SRNL washed } \\
\text { Qual sample }\end{array}$ \\
\hline $\mathrm{Al}$ & 6.72 & 5.31 & 5.49 & 7.05 \\
\hline $\mathrm{Ba}$ & 0.094 & 0.098 & 0.087 & 0.09 \\
\hline $\mathrm{Ca}$ & 1.54 & 1.95 & 1.54 & 1.44 \\
\hline $\mathrm{Cd}$ & 0.000 & $<0.1$ & $<0.1$ & 0.006 \\
\hline $\mathrm{Ce}$ & 0.330 & 0.353 & 0.319 & 0.345 \\
\hline $\mathrm{Cr}$ & 0.220 & 0.178 & 0.156 & 0.131 \\
\hline $\mathrm{Cu}$ & 0.039 & 0.040 & 0.034 & 0.064 \\
\hline $\mathrm{Fe}$ & 22.7 & 26.6 & 24.6 & 22.1 \\
\hline $\mathrm{K}$ & 0.12 & 0.15 & 0.15 & 0.11 \\
\hline $\mathrm{La}$ & 0.039 & 0.056 & 0.044 & n.r. \\
\hline $\mathrm{Mg}$ & 0.212 & 0.241 & 0.202 & 0.209 \\
\hline $\mathrm{Mn}$ & 8.44 & 9.59 & 9.38 & 8.09 \\
\hline $\mathrm{Na}$ & 22.3 & 18.8 & 20.6 & 21.7 \\
\hline $\mathrm{Ni}$ & 1.06 & 1.21 & 1.12 & 1.04 \\
\hline $\mathrm{P}$ & 0.0 & 0.078 & 0.098 & 0.306 \\
\hline $\mathrm{Pb}$ & 0.047 & 0.015 & $<0.01$ & 0.046 \\
\hline $\mathrm{S}$ & 0.404 & 0.284 & 0.364 & 0.458 \\
\hline $\mathrm{Si}$ & 1.23 & 1.36 & 1.34 & 1.16 \\
\hline $\mathrm{Sn}$ & 0.000 & 0.097 & 0.1 & n.r. \\
\hline $\mathrm{Sr}$ & 0.0 & 0.0 & 0.0 & n.r. \\
\hline $\mathrm{Th}$ & 0.802 & 0.0 & 0.0 & 0.787 \\
\hline $\mathrm{Ti}$ & 0.016 & 0.015 & 0.013 & 0.017 \\
\hline $\mathrm{U}$ & 3.48 & 0.0 & 0.0 & 3.37 \\
\hline $\mathrm{Zn}$ & 0.039 & 0.032 & 0.042 & 0.030 \\
\hline $\mathrm{Zr}$ & 0.149 & 0.162 & 0.119 & 0.183 \\
\hline & & & & \\
& $\mathrm{n}$ & no element projection - but $0.006 \mathrm{M}$ phosphate in supernate per wash sheet & \\
\hline & noported & & & \\
\hline
\end{tabular}

The new Tank 51 simulant was prepared by targeting the 10-16-2012 composition, while the retrimmed simulant did not make major element adjustments associated with removing Tank 12 from the projected composition (only the supernate sodium and anions were retargeted). The lower than targeted Al content of both simulants was unexpected, but an investigation into what might have caused this found no issues with either the aluminum nitrate or the $\mathrm{NaAlO}_{2}$ that were used to produce the insoluble and soluble aluminum species respectively. Based on recipes, there was more aluminum in these simulants than indicated by sample analysis. SRAT and SME product analyses also suggest more Al was present than indicated. In contrast to the bulk elemental sodium values in Table 3-1, the supernate sodium came back $1.81 \mathrm{M}$ for Tank $51 \mathrm{r}$ and $1.63 \mathrm{M}$ for Tank $51 \mathrm{n}$ (opposite in relative magnitude compared to the total sodium). The results are within expected analytical uncertainties which are typically of order $\pm 10 \%$ for major species and more for minor species.

Table 3-2 compares the Tank 51 simulant concentrations of soluble species either as directly measured or as measured on a slurry basis and converted to an equivalent supernate molarity to the October 18, 2012 projected wash endpoint of $1.75 \mathrm{M}$ sodium. Results for the SRNL-washed SB8 Tank 51 qualification sample are included for comparison. ${ }^{12}$ Most of the projected supernate compositions for Tank 40 and Tank 51 were not charge balanced (90-97\% balanced), so either the 
anions or cations were renormalized to match the other in total charge before determining the soluble trim species in the simulant recipes.

Table 3-2. Soluble Concentration of Tank 51 Simulant (Supernate-Basis)

\begin{tabular}{|l|c|c|c|c|}
\hline & $\begin{array}{c}10 / 18 / 2012 \\
\text { Projection, } \mathrm{M}\end{array}$ & $\begin{array}{c}\text { Tank 51r } \\
\text { simulant, } \mathrm{M}\end{array}$ & $\begin{array}{c}\text { Tank 51n } \\
\text { simulant, } \mathrm{M}\end{array}$ & $\begin{array}{c}\text { SRNL Washed } \\
\text { Qual, M }\end{array}$ \\
\hline Sodium & 1.75 & 1.81 & 1.63 & 1.79 \\
\hline Nitrite & 0.56 & 0.54 & 0.57 & 0.49 \\
\hline Nitrate & 0.32 & 0.27 & 0.32 & 0.32 \\
\hline Chloride & 0.0037 & $<0.017$ & $<0.004$ & $(2)$ \\
\hline Sulfate & 0.025 & 0.023 & 0.024 & 0.026 \\
\hline Fluoride & 0.0053 & $<0.032$ & $<0.032$ & $(2)$ \\
\hline Carbonate & 0.069 & 0.14 & 0.14 & 0.079 \\
\hline Aluminate & 0.13 & 0.12 & 0.16 & 0.14 \\
\hline Oxalate & 0.0068 & 0.034 & $<0.007$ & 0.025 \\
\hline Phosphate & 0.0055 & $<0.007$ & $<0.007$ & $(2)$ \\
\hline Potassium & 0.0061 & 0.010 & 0.011 & 0.0062 \\
\hline
\end{tabular}

1 - Oxalate projected based on SRNL analytical results (about 500 ppm versus the 10/18 Tank Farm wash projection of $0.0015 \mathrm{M}$ which gave only about $110 \mathrm{ppm}$ )

2 - Below detection limits

The two Tank 51 simulants were very close to projected wash values except for carbonate, where the simulants were at roughly twice the projected value. This departure was based on the argument that $1 \mathrm{M}$ sodium supernates had tended to be $0.06-0.09 \mathrm{M}$ in carbonate (see previous sludge batch analyses), so a $1.5-1.75 \mathrm{M}$ sodium supernate should be closer to $0.10-0.15 \mathrm{M}$ in carbonate. The ultimate goal was to ensure that the simulant was conservative with respect to stoichiometric acid demand. Tank $51 \mathrm{r}$ was originally at about $0.09 \mathrm{M}$ oxalate and was given a 7:1 wash, so the expected oxalate concentration of Tank $51 \mathrm{r}$ simulant was about $0.013 \mathrm{M}$ rather than the $0.034 \mathrm{M}$ reported from sample analysis. The rewashed Tank 51 simulant was actually much closer to the SRNL-washed Tank 51 sample than to the projected composition in terms of oxalate.

Other significant properties of the two Tank 51 simulants are documented in Table 3-3.

Table 3-3. Other Tank 51 Simulant Properties

\begin{tabular}{|l|c|c|}
\hline & Tank 51r & Tank 51n \\
\hline Wt.\% total solids & 21.6 & 20.6 \\
\hline Wt. \% insoluble solids & 12.3 & 10.8 \\
\hline Wt. \% soluble solids & 9.3 & 9.8 \\
\hline Wt. \% calcined solids & 16.6 & 15.2 \\
\hline Slurry density, g/mL & 1.193 & 1.164 \\
\hline Supernate density, g/mL & 1.083 & 1.084 \\
\hline Slurry base equivalents, M & 0.980 & 0.878 \\
\hline Slurry TIC, mg C/kg slurry & 1,635 & 1,570 \\
\hline
\end{tabular}

The two SB8-Tank 51 simulants described above were blended together and combined with a new SB7b-Tank 40 simulant (and some rinse water) to produce the SB8-Tank 40 simulant that was used to perform the SB8 DWPF flowsheet process simulations. The SB7b-Tank 40 simulant 
was based on the WAPS sample analyses. ${ }^{11}$ The SB8-Tank 40 simulant was based on Tank Farm projections in the October 30-November 6, 2012 period.

Table 3-4 gives the SB7b WAPS and November 2012 projection for SB8-Tank 40 elemental composition (120 inch heel in Tank 40 with 100 inches added from Tank 51) on a glass basis compared to results for the two Tank 40 simulants calcined at $1100{ }^{\circ} \mathrm{C}$. The SB8-Tank 40 simulant values are averages of up to twelve analyses that included the simulant, SRAT receipt sample composite, and sludge-only flowsheet SRAT product results in order to obtain the most representative composition from the available information. There was no direct recipe basis for SB8-Tank 40, so this average represents the best estimate of the elemental distribution (a mathematical composite recipe basis using the two Tank 51 and SB7b WAPS recipes could be constructed, but it would have to assume that the blending slurry transfers were exactly as planned).

Table 3-4. Calcined Elements of Tank 40 Simulants

\begin{tabular}{|l|c|c|c|c|}
\hline & $\begin{array}{c}\text { SB7b WAPS } \\
\text { sample }\end{array}$ & $\begin{array}{c}\text { SB7b-Tank 40 } \\
\text { simulant }\end{array}$ & $\begin{array}{c}\text { SB8-Tank 40 } \\
120 "+100 ” \\
\text { projection }\end{array}$ & $\begin{array}{c}\text { SB8-Tank 40 } \\
\text { simulant }\end{array}$ \\
\hline $\mathrm{Al}$ & 11.5 & 12.1 & 9.17 & 8.10 \\
\hline $\mathrm{Ba}$ & 0.12 & 0.13 & 0.11 & 0.10 \\
\hline $\mathrm{Ca}$ & 0.87 & 0.95 & 1.33 & 1.33 \\
\hline $\mathrm{Cd}$ & 0.036 & $<0.10$ & n.p. & n.a. \\
\hline $\mathrm{Ce}$ & 0.17 & 0.18 & 0.28 & 0.28 \\
\hline $\mathrm{Cr}$ & 0.051 & 0.053 & 0.16 & 0.12 \\
\hline $\mathrm{Cu}$ & 0.055 & 0.52 & 0.05 & 0.17 \\
\hline $\mathrm{Fe}$ & 17.4 & 20.8 & 21.6 & 22.4 \\
\hline $\mathrm{Gd}$ & 0.092 & 0.098 & n.p. & $<0.01$ \\
\hline $\mathrm{K}$ & 0.067 & 0.13 & 0.12 & 0.14 \\
\hline $\mathrm{La}$ & 0.091 & 0.107 & 0.065 & 0.073 \\
\hline $\mathrm{Mg}$ & 0.37 & 0.39 & 0.30 & 0.29 \\
\hline $\mathrm{Mn}$ & 3.87 & 4.53 & 6.85 & 7.20 \\
\hline $\mathrm{Na}$ & 18.0 & 19.3 & 18.8 & 20.0 \\
\hline $\mathrm{Ni}$ & 3.37 & 4.01 & 2.18 & 2.31 \\
\hline $\mathrm{P}$ & 0.14 & 0.16 & n.p. & 0.091 \\
\hline $\mathrm{Pb}$ & 0.033 & $<0.10$ & 0.043 & 0.013 \\
\hline $\mathrm{S}$ & 0.61 & 0.32 & 0.49 & 0.36 \\
\hline $\mathrm{Si}$ & 1.39 & 2.07 & 1.37 & 1.46 \\
\hline $\mathrm{Sn}$ & $<0.055$ & 0.021 & n.p. & n.m. \\
\hline $\mathrm{Sr}$ & 0.055 & 0.0 & n.p. & n.a. \\
\hline $\mathrm{Th}$ & 1.35 & 0.0 & 0.84 & n.a. \\
\hline $\mathrm{Ti}$ & 0.023 & 0.025 & 0.02 & 0.021 \\
\hline $\mathrm{U}$ & 5.98 & 0.0 & 3.64 & n.a. \\
\hline $\mathrm{Zn}$ & 0.050 & 0.070 & 0.046 & 0.053 \\
\hline $\mathrm{Zr}$ & 0.22 & 0.22 & 0.19 & 0.13 \\
\hline & & 0.05 & \\
\hline
\end{tabular}

n.p. - not projected, n.m. - not measured, n.a. - not analyzed

The lower than targeted Al content of the SB8-Tank 40 simulant was somewhat anticipated based on the low reported Al contents of the two SB8-Tank 51 simulants that made up nearly half of the 
blend. Iron and other insoluble elements were generally slightly lower in the radioactive wastes than in the simulants due to the presence of radioactive species that tended to dilute their concentrations on a percent basis. (Potential analytical uncertainties cover most cases where the opposite is observed.)

Table 3-5 compares the Tank 40 simulant concentrations of soluble species either as directly measured, or as measured on a slurry basis and converted to an equivalent supernate molarity, to the WAPS results or the October 30, 2012 projected SB8 wash endpoint of 1.21 M sodium.

Table 3-5. Soluble Concentration of Tank 40 Simulant (Supernate-Basis)

\begin{tabular}{|l|c|c|c|c|}
\hline & $\begin{array}{c}\text { SB7b WAPS } \\
\text { sample, M }\end{array}$ & $\begin{array}{c}\text { SB7b-Tank } \\
\text { 40 Sim., M }\end{array}$ & $\begin{array}{c}\text { 10/30/2012 } \\
\text { Proj.-SB8 }\end{array}$ & $\begin{array}{c}\text { SB8-Tank 40 } \\
\text { Sim., M }\end{array}$ \\
\hline Sodium & 0.98 & 1.02 & 1.21 & 1.27 \\
\hline Nitrite & 0.23 & 0.23 & 0.35 & 0.34 \\
\hline Nitrate & 0.098 & 0.070 & 0.18 & 0.16 \\
\hline Chloride & $<0.0089$ & $<0.016$ & 0.002 & $<0.003$ \\
\hline Sulfate & 0.023 & 0.015 & 0.022 & 0.019 \\
\hline Fluoride & $<0.017$ & $<0.03$ & 0.003 & $<0.03$ \\
\hline Carbonate & 0.093 & 0.16 & 0.084 & 0.14 \\
\hline Aluminate & 0.036 & 0.083 & 0.071 & 0.12 \\
\hline Oxalate & 0.039 & 0.037 & 0.020 & 0.035 \\
\hline Phosphate & $<0.0033$ & $<0.006$ & 0.003 & $<0.006$ \\
\hline Potassium & 0.0019 & 0.0054 & 0.003 & 0.007 \\
\hline
\end{tabular}

The two Tank 40 simulants were very close to targets. Carbonate was the main exception as discussed above for the Tank 51 simulants. Oxalate analyzed a little higher than desired in SB8Tank 40 perhaps due to the presence of some extra oxalate in the rewashed and trimmed SB8Tank 51r simulant.

Other significant properties of the two Tank 40 simulants are documented in Table 3-6.

Table 3-6. Other Tank 40 Simulant Properties

\begin{tabular}{|l|c|c|}
\hline & SB7b-Tank 40 & SB8-Tank 40 \\
\hline Wt.\% total solids & 14.0 & 16.5 \\
\hline Wt. \% insoluble solids & 8.1 & 9.0 \\
\hline Wt. \% soluble solids & 5.9 & 7.5 \\
\hline Wt. \% calcined solids & 10.6 & 12.6 \\
\hline Slurry density, g/mL & 1.114 & 1.138 \\
\hline Supernate density, g/mL & 1.052 & 1.066 \\
\hline Slurry base equivalents, M & 0.702 & 0.739 \\
\hline Slurry TIC, mg C/kg slurry & 1,980 & 1,700 \\
\hline
\end{tabular}

There was one error in preparing the SB7b simulant. The slurry TIC target was set at 1,500 $\mathrm{mg} / \mathrm{kg}$, when the intended target was $1,000 \mathrm{mg} / \mathrm{kg}(1,980$ is the measured value, not the recipe value, 1,980 is highly unlikely but not impossible). DWPF SB7b acid calculation worksheets show values of 900-1100 ppm for SRAT receipt samples which, for an assumed heel of $20 \%$ that is free of TIC, corresponds to $1125-1375 \mathrm{mg} / \mathrm{kg}$ in the fresh slurry from Tank 40, so the 1500 
ppm target was likely not a major error. In either case, the simulant bounds the likely acid demand of the real waste and is expected to be conservative for CPC processing (more acid demand, greater off-gas generation and potential foaming, etc.).

The wt.\% total solids of SB8-Tank 40 was higher in the simulant and higher in the projections than SB7b. This higher solids concentration state was encouraged during SB8 planning in order to reduce SRAT batch pre-concentration time in DWPF which adds to CPC cycle time and can lead to reduced throughput and canister production.

\subsection{Results from Flowsheet Simulant (Tank 40) Testing}

Five SB8-Tank 40 SRAT/SME simulations were performed for the projected compositions without Tank 12 waste. Earlier SB8 simulations that included a Tank 12 component are documented in a separate report. ${ }^{3}$ The unique features of the five runs were summarized in Table 2-3. Four were sludge-only runs, while the fifth was a coupled flowsheet run with ARP addition prior to nitric acid and MCU acid (nitric acid, no organics) addition after SRAT cycle dewatering. There were no major issues with the five runs. Results from process samples, off-gas analysis, and material balance calculations are organized into the eight sections below. The results for the three SB8-Tank 51 simulations without Tank 12 are discussed in Section 3.3.

\subsubsection{Approach to Defining a Stoichiometric Acid Window}

One important aspect of DWPF process flowsheet simulations for new sludge batches is to determine a processing window in terms of acid stoichiometry. This section lays out various processing scenarios, examines the relevant acid window data, compares the simulant and actual waste lab-scale processing results, and presents guidance for applying the SRNL data to the actual DWPF SRAT. Obtaining an exact match between the acid requirement of the simulant and the real waste in terms of moles acid/L slurry or moles acid/kg non-water species (total solids species) is unlikely for the Tank 40 feed. The incorporation of variable quantities of salt processing streams with variable compositions further complicates the problem of constraining the SRAT acid demand.

In addition to simulant-waste mismatch and flowsheet options, canister production goal considerations combined with low potential waste oxide mass per unit gallon in the nominal 6000 gallons of Tank 40 slurry per SRAT batch can cause DWPF to bring in additional Tank 40 slurry (perhaps as high as 10,000 gallons total of Tank 40 slurry) by performing a caustic preconcentration on the two initial slurry transfers to make room for a third slurry transfer. Such concentrated slurries can potentially contain more acid demand, higher noble metal concentrations, etc. than were covered in the simulant flowsheet testing. In that case, it is possible to put more moles of excess acid into the SRAT using the recommended acid stoichiometric factor range than were shown to be acceptable from a catalytic hydrogen generation standpoint during flowsheet simulations.

To proceed with the above analysis, it was necessary to estimate the practical minimum number of SRAT cycles that DWPF could perform in a year and still meet the canister production goal. Some nominal processing assumptions were made for DWPF to better calculate the ratio between lab-scale and full-scale SRAT and SME batches. These included:

- 275 canisters per year 
SRNL-STI-2013-00106

Revision 0

- 3,850 pounds glass per canister

- $36 \%$ waste oxides in the glass (waste loading)

- 5.5 days per SRAT cycle

- $80 \%$ service factor for the DWPF Chemical Process Cell (CPC)

Based on these assumptions, DWPF would need to perform 53 SRAT cycles per year containing an average waste oxide content of roughly $3,260 \mathrm{~kg}$. Assuming 6,000 gallons (22,712 liters) of new sludge per batch (excluding heel), there need to be $0.143 \mathrm{~kg}$ of waste oxides per liter of feed. SB8-Tank 40 simulant contained $0.144 \mathrm{~kg}$ waste oxides/L of feed, i.e. it was suitable as prepared for a normal processing scenario of 53 SRAT cycles per year. To keep canister production rate up with a lower service factor, however, would force DWPF to bring in more $\mathrm{kg}$ of waste oxides per SRAT batch.

To make the same number of canisters (275) in 47 SRAT cycles per year (rather than 53) would require DWPF to pre-concentrate the SB8-Tank 40 slurry by $12 \%$ to maintain 6,000 gallon volume batches (fresh material excluding the heel). In order to better simulate likely DWPF processing extremes, 3,750 gram batches of nominal sludge simulant were pre-concentrated to 3,300 grams by caustic boiling. Scaling for sludge-only processing was performed by assuming 3,300 grams of pre-concentrated simulant was equivalent to 6,000 gallons of SB8-Tank 40 fresh sludge in the DWPF SRAT (again, neglecting the heel volume). Lab-scale SRAT cycles were at about $1 / 7,840$ scale by volume. Lab-scale SME cycles were at about $1 / 9,100$ scale by volume (the difference in scale was caused by the mass of SRAT product removed for samples). This constitutes the bounding assumption for fresh waste oxide through-put per SRAT batch for sludge-only processing (roughly 3,700 kg of waste oxides from Tank 40 per SRAT batch, not counting heel oxides which are assumed to remain in the SRAT and not move forward to the melter and help fill canisters). This set of assumptions was used to define the stretch processing scenario. Simulant flowsheet process simulations were designed to bound the stretch processing scenario (and, of course, the normal processing scenario described in the preceding paragraph is bound by the stretch processing scenario).

Before it can be claimed that the simulant testing bounds the stretch scenario entirely, and not just in terms of canister production, the SB8 flowsheet simulant needs to be compared to the projected composition of real waste in the context of the stoichiometric acid requirement and noble metals. As described in Section 2.2, in the discussion for Table 2-3, simulant noble metal concentrations were chosen to bound those determined from sample results for the real waste. The projected anion and sodium concentrations of SB8-Tank 40 supernate as of April 22, 2013 are compared in Table 3-7. 
Table 3-7. Acid Demand-related Comparison for SB8-Tank 40 Supernates

\begin{tabular}{|l|c|c|c|}
\hline & $\begin{array}{c}\text { SB8-Tank 40 } \\
\text { April 22 projection } \\
\mathrm{M}\end{array}$ & $\begin{array}{c}\text { SB8-Tank 40 } \\
\text { simulant, before pre- } \\
\text { concentration, M }\end{array}$ & $\begin{array}{c}\text { SB8-Tank 40 } \\
\text { simulant, after pre- } \\
\text { concentration, M }\end{array}$ \\
\hline Sodium & 1.073 & 1.27 & 1.48 \\
\hline Nitrite & 0.293 & 0.361 & 0.420 \\
\hline Free Hydroxide & 0.231 & $\sim 0.4^{1}$ & - \\
\hline Carbonate & 0.074 & 0.143 & 0.167 \\
\hline Aluminate & 0.060 & 0.124 & 0.145 \\
\hline Nitrate & 0.153 & 0.168 & 0.196 \\
\hline
\end{tabular}

1 - see discussion in the paragraph following the table

Free hydroxide is not measured routinely on simulants. A base equivalents titration to $\mathrm{pH} 7$ is performed. The SB8-Tank 40 simulant titrated to $0.739 \mathrm{M}$ before pre-concentration (slurry volume basis) or $0.76 \mathrm{M}$ on a supernate volume basis. Historically about $5-20 \%$ of this appears to come from insoluble species. The remainder is approximately due to free hydroxide, aluminate, and the carbonate to bicarbonate conversion. Therefore, $(90 \%$ of $0.76 \mathrm{M})-0.124 \mathrm{M}-0.143 \mathrm{M}$ equals $\sim 0.417 \mathrm{M}$ free hydroxide. This value serves as an estimate for the free hydroxide of the SB8-Tank 40 simulant (before pre-concentration).

It can be seen in Table 3-7 that the original SB8-Tank 40 simulant species bound all of the likely supernate inputs to the DWPF acid equation for the projected composition two weeks prior to the SB8 Tank 51 to Tank 40 transfer. The SB8-Tank 40 simulant after pre-concentration should bound the supernate inputs of real waste should DWPF need to pre-concentrate as described earlier in this section to meet canister production goals in the stretch scenario. A conservative concentration for mercury has already been selected for simulant tests in Section 2.2. The only remaining input to the DWPF acid equation is Mn. As seen above in Section 3.1, Table 3-4, the simulant Mn appears to bound the projected Mn. Therefore, it can be concluded that the simulant bounds the inputs to the DWPF acid equation expected for SB8-Tank 40 both individually and in total. Therefore, the flowsheet testing performed as part of this task using pre-concentrated SB8Tank 40 simulant should lead to an acid stoichiometric factor window that is conservative with respect to real waste.

Several issues remain, however, and these will be discussed next. These include coupled flowsheet cycles, SRAT heels, and bias in the DWPF stoichiometric acid equation. The KMA has been demonstrated to respond to changing SRAT receipt compositions in a manner more consistent with the observed changes in the minimum acid required to destroy nitrite than the current DWPF equation. Consequently, there is a non-zero difference in the minimum stoichiometric factor required for nitrite destruction between the two equations. The KMA factor for nitrite destruction stays near $100 \%$, while the DWPF acid equation factor varies from 100$125 \%$ or more to get to the same moles of acid required. SRNL probably has sufficient data in hand to modify the DWPF equation as shown below without additional laboratory testing (paper study):

$$
\frac{\text { moles acid }}{L \text { slurry }}=\text { base equivalents }+A^{*} \text { total TIC }+B^{*} \text { nitrite }+1.2 * \mathrm{Mn}+\mathrm{Hg}
$$

Coefficient A replaces 2.0 as the coefficient for slurry (total) TIC, and B replaces 0.75 as the coefficient for nitrite. Coefficient A would probably be $1<\mathrm{A}<1.5$ and B would probably be 
about 1.0 based on experience obtained developing the KMA equation. Once modified, the DWPF acid equation ought to more closely track with the KMA equation (less bias or offset). This is a recommendation for future work primarily if the alternate reductant flowsheet is not adopted. This modification should be easier to implement in DWPF than the KMA equation, since this modification has no new input terms. If the alternate reductant flowsheet is adopted, then it is recommended that the DWPF acid equation (and the KMA equation) be reevaluated against data from tests of that flowsheet which had residual nitrite in the SRAT product.

The extent of the bias between the two stoichiometric acid equations is summarized in Table 3-8 for the most relevant examples to SB8-Tank 40. SB7b simulant results are from SRNL-STI2011-00547, ${ }^{13}$ while SB7b Cells results are from SRNL-STI-2011-00548 (the revised acid equation inputs case). ${ }^{14}$ SB8 Cells results are from SRNL-STI-2013-00116. ${ }^{4}$ The remaining simulant results are contained within this document. The last two rows of the table show results from the two coupled flowsheet runs with simulants for SB7b and SB8 (both Tank 40 basis compositions).

Table 3-8. KMA vs. DWPF Stoichiometric Acid Equations

\begin{tabular}{|l|c|c|c|}
\hline & KMA factor & $\begin{array}{c}\text { Equivalent } \\
\text { DWPF factor }\end{array}$ & $\begin{array}{c}\text { Bias } \\
\text { DWPF/KMA }\end{array}$ \\
\hline SB7b Tank 40 simulant & $110 \%$ & $112 \%$ & $1.6 \%$ \\
\hline SB7b Tank 40 Cells & $108 \%$ & $116 \%$ & $7.4 \%$ \\
\hline SB8 Tank 51 simulant & $115 \%$ & $126 \%$ & $9.6 \%$ \\
\hline SB8 Tank 51 Cells & $115 \%$ & $133 \%$ & $15.7 \%$ \\
\hline SB8 Tank 40 simulant & $120 \%$ & $126 \%$ & $5.0 \%$ \\
\hline SB7b coupled simulant & $112 \%$ & $114 \%$ & $2 \%$ \\
\hline SB8 coupled simulant & $120 \%$ & $123 \%$ & $2 \%$ \\
\hline
\end{tabular}

The bias has always been positive since the KMA was developed (a larger factor is required for the DWPF equation than for the KMA equation). Note that the SB8-Tank 40 simulant bias of 5\% is intermediate between the SB7b and SB8-Tank 51 values of $1.6 \%$ and $9.6 \%$ as is the composition of SB8-Tank 40. This is what should happen if the acid equation input terms are being accurately measured. The Cells bias has tended to be somewhat larger than the corresponding simulant bias ( $6 \%$ here) .

In recommending a stoichiometry window for DWPF, an assumption has been made that the simulant testing is already sufficiently conservative in other ways that the rad-simulant bias difference can be been neglected. So, for example, if the SB8-Tank 40 window for nitrite destruction up to nominal stoichiometry is $105-120 \%$ per the KMA, this range is adjusted to the DWPF equation basis to give $110-126 \%$, but a further range shift up to $116-132 \%$ to account for Cells-simulant bias is not made. In support of this assumption, it is noted that the Cells titration for base equivalents is not made by auto-titrator unlike DWPF and PSAL. There have been other issues in the past with analyses for Cells acid calculations in addition to the issues with SB7b qualification, e.g. SB4 where the hydrogen limit was exceeded.

The next issue to address is the SRAT heel. A nominal heel is about 1500 gallons that is typically at a higher wt.\% total solids than the fresh receipt sludge coming from Tank 40 via the Low Point Pump Pit Tank. The heel is primarily a diluent with respect to the inputs to the KMA and DWPF acid equations. It is not equivalent to water however. There can be some TIC in the heel from absorption of $\mathrm{CO}_{2}$ produced from the destruction of formic acid/formate ion. In addition, 
manganese is present in both the heel and the fresh sludge. The KMA uses a coefficient of 1.5 for manganese acid demand for fresh sludge while DWPF uses a coefficient of 1.2 for manganese in the SRAT receipt sample. $20-25 \%$ of the DWPF SRAT receipt sample Mn has already been through a reductive acidification in the previous SRAT cycle, so using a factor for $\mathrm{Mn}$ that is $80 \%$ of the KMA approximately corrects for the presumed lack of acid demand for heel Mn in DWPF.

The acid requirements for the other terms in the DWPF acid equation relate to species that are essentially not in the heel. It is for these reasons that the claim is made that the lab-scale tests without heels are equivalent to the fresh sludge in the DWPF SRAT (the heel is assumed to have no acid demand). The recommended processing window in terms of the stoichiometric factor range is thus insensitive to the heel (within reason - a DWPF SRAT batch with no heel is not foreseen, nor is a batch with a 4000 gallon heel and 3500 gallons of fresh sludge; such off-normal situations are not being considered in detail here). Therefore, if a stoichiometric factor range of $110-126 \%$ is recommended for a bounding fresh sludge volume, the same range is recommended for various typical fresh sludge-heel sludge combinations included caustic pre-concentrated fresh sludges to the extent these were bound in the testing. Alternative ways of setting acid demand, such as fixing a moles acid per L of SRAT receipt volume or moles acid per $\mathrm{kg}$ of SRAT receipt dried solids are potentially strongly influenced by the relative amounts of fresh sludge and heel sludge. Consequently, SRNL does not recommend such approaches for DWPF, since they are expected to be insufficiently robust to handle a reasonable variety of processing scenarios.

The final issue to address is coupled flowsheet operation. The ARP stream contains monosodium titanate solids combined with minor amounts of entrained sludge solids in a caustic supernate phase that includes other dissolved sodium salts such as sodium nitrate and sodium oxalate. The compositions of species in this stream are not controlled to narrow ranges. The acid demand for this stream, both as-received and following concentration of it to increase its wt.\% total solids to be more like sludge, is likely to be different from that of fresh sludge when presented as moles acid/L of ARP slurry or moles acid/kg of ARP slurry total solids.

The original studies of the impact of ARP on DWPF used an assumed composition that pre-dated start-up of the ARP facility. ${ }^{15,16}$ These studies, as well as those performed in support of the DWPF flowsheet for SB5, SB6, SB7a, and SB7b, were based on the original assumed ARP composition. Prior to SB8, available sample data for the actual ARP stream were pooled, and an average composition was generated. The new average composition was much lower in entrained sludge solids and higher in sodium than the assumed composition prior to start-up. The current titanium in glass limit was constraining the amount of ARP MST that could be added into a single SRAT batch. It had been assumed that DWPF could take up to 7,000 gallons of ARP into a single SRAT, but $\mathrm{Ti}$ was limiting this to less than about 3,000 gallons (depending on composition).

From an acid stoichiometry standpoint, the main issue with ARP is that its acid demand is largely due to sodium hydroxide. Applying a DWPF acid equation stoichiometric factor of $125-135 \%$ to the ARP acid demand in addition to the Tank 40 sludge acid demand guarantees the introduction of excess acid on the ARP side. This issue is significantly mitigated by the KMA equation, and it could be mitigated better in DWPF with a modified DWPF-style acid equation as discussed earlier in this section. Early tests brought significant entrained sludge into the SRAT along with the supernate and MST. Bounding noble metal concentrations were initially assigned to the entrained sludge. The combination of additional noble metals and additional excess acid in these coupled flowsheet tests led to a significant increase in the peak hydrogen generation rates compared to sludge-only processing of the same Tank 40 feed for the same stoichiometric factor using the DWPF acid equation. 
The current understanding of ARP suggests that some of the initial conclusions regarding acid stoichiometry from the early studies were overly conservative, but the studies have not been repeated using the latest ARP composition information. DWPF has noted in discussions with SRNL that the main conclusion of the initial ARP incorporation research is at least qualitatively valid. Specifically, the DWPF acid equation stoichiometric factor needs to be lowered proportionately to the volume (at fixed composition) of ARP blended into the Tank 40 sludge. It is the portion of the stoichiometric factor greater than $\sim 100 \%$ (or the factor that just gives nitrite destruction, since the two aren't the same) that needs to be scaled back.

A new frit was developed for SB8, frit 803 . The frit was suitable up to $40 \%$ waste oxides in glass for nominal ARP (the new average composition mentioned above) on the interval of 0 to 1050 gallons for the projected SB8-Tank 40 composition in late 2012. Subsequent changes in the projected SB8-Tank 40 composition have opened up the allowable ARP interval for SB8 somewhat. This limited range was driven by sodium and glass waste form property constraints, not by titanium. The coupled flowsheet SRAT/SME demonstration for SB8 was targeted to be more realistic than those in prior sludge batch flow sheet studies (which were recognized as overly conservative).

One coupled flowsheet SRAT/SME run was performed using SB8-Tank 40 feed. Scaling for this batch was handled differently than for the sludge-only flow sheet tests. It was assumed that the combined SB8-Tank 40 simulant plus ARP, once caustic concentrated to the nominal SB8-Tank $40 \mathrm{wt} . \%$ total solids value, would be the equivalent volume to 6000 gallons of fresh general waste (sludge plus ARP) inside the DWPF SRAT. The 6000 gallons was partitioned between Tank 40 and ARP to meet this goal. The ARP mass to sludge mass ratio was chosen to match the preliminary SB8 limit of 1,050 gallons of nominal ARP slurry (before concentration) per SRAT batch.

A sludge simulant mass of 3,750 grams was chosen as a basis. This was pre-concentrated to 3,300 grams and represented 5,645 gallons at full scale. To this was added 557 grams of nominal ARP slurry simulant representing the presumed bounding volume of 1,050 gallons. ${ }^{17}$ After caustic boiling concentration, the ARP simulant volume was reduced to the equivalent to 455 gallons. The caustic concentrated sludge plus ARP volumes scaled to 6,000 gallons combined. The actual maximum allowable ARP slurry volume within DWPF will depend on the actual ARP slurry composition. It will also depend on glass property prediction considerations and the actual Tank 40 composition after transfer. CPC considerations do not necessarily limit the ARP volume for SB8 to less than 1,050 gallons.

The SB8 coupled demonstration SRAT cycle was 1/7,396 scale and the SME cycle was 1/8,770. The test scale was slightly larger than the sludge-only runs due to the ARP contribution in addition to an identical amount of sludge simulant. All scale-dependent parameters (feed rates, boil-up rates, antifoam addition masses, etc.) were rescaled accordingly for the lab-scale coupled flowsheet demonstration. With these factors, the coupled-flowsheet demonstration was directly comparable to the sludge-only flowsheet demonstrations.

From an acid stoichiometry perspective, the question to be answered is whether or not the above combination feed in the coupled flowsheet is comparable, or more or less conservative, than sludge-only with respect to hydrogen generation. Although the inputs to the two acid stoichiometry equations for coupled SB8 simulant were slightly less biased than for sludge-only (which might suggest a slightly less conservative acid window), the maximum hydrogen generation rates in the SRAT and SME (Section 3.2.3) were lower than in the matching sludge- 
only run. Therefore in the context of a batch as described above (caustic pre-concentration as described for SB8-Tank 40, and the combined SB8-Tank 40 plus ARP after pre-concentration being 6000 gallons equivalent), the recommended range of stoichiometric factors for the DWPF acid equation for sludge-only processing and coupled flowsheet processing are the same.

\subsubsection{SRAT/SME Product Sample Results}

Calcined elemental results for the SRAT product slurries from SB8-D1 through D4 looked essentially identical and like the starting simulant, Table 3-4 in Section 3.1. This indicates generally correct and consistent batching of the SRAT feed slurries to the test vessels. The coupled flowsheet run, D5, contained a blend of SB8-Tank 40 simulant and ARP simulant. Elemental compositions for the ARP, SRAT receipt sample, and SRAT product sample are given in Table 3-9. Values are the average of two measurements from a single preparation. Expected values for the SRAT product are the same as the SRAT receipt sample (both have the ARP species in them).

Table 3-9. Calcined Elements of SB8-D5 Samples

\begin{tabular}{|l|c:c|c|}
\hline $\begin{array}{l}\text { Wt.\% } \\
\text { of: }\end{array}$ & $\begin{array}{c}\text { SB8-D5 } \\
\text { SRAT } \\
\text { Receipt }\end{array}$ & $\begin{array}{c}\text { SB8-D5 } \\
\text { SRAT } \\
\text { Product }\end{array}$ & $\begin{array}{c}\text { ARP } \\
\text { simulant }\end{array}$ \\
\hline $\mathrm{Al}$ & 7.62 & 7.95 & 1.27 \\
\hline $\mathrm{Ba}$ & 0.099 & 0.098 & 0 \\
\hline $\mathrm{Ca}$ & 1.42 & 1.64 & 0 \\
\hline $\mathrm{Ce}$ & 0.258 & 0.255 & 0 \\
\hline $\mathrm{Cr}$ & 0.116 & 0.116 & 0 \\
\hline $\mathrm{Cu}$ & 0.231 & 0.109 & 0 \\
\hline $\mathrm{Fe}$ & 20.95 & 21.25 & 0 \\
\hline $\mathrm{K}$ & 0.157 & 0.175 & 0.93 \\
\hline $\mathrm{La}$ & 0.071 & 0.070 & 0 \\
\hline $\mathrm{Mg}$ & 0.270 & 0.338 & 0 \\
\hline $\mathrm{Mn}$ & 6.85 & 6.73 & 0 \\
\hline $\mathrm{Na}$ & 20.45 & 20.10 & 41.0 \\
\hline $\mathrm{Ni}$ & 2.18 & 1.78 & 0 \\
\hline $\mathrm{P}$ & 0.095 & $<0.10$ & 0 \\
\hline $\mathrm{Pb}$ & $<0.01$ & $<0.10$ & 0 \\
\hline $\mathrm{S}$ & 0.35 & 0.37 & 0.58 \\
\hline $\mathrm{Si}$ & 1.27 & 1.51 & 0.03 \\
\hline $\mathrm{Sn}$ & 0.056 & 0.053 & 0 \\
\hline $\mathrm{Ti}$ & 0.82 & 0.83 & 17.72 \\
\hline $\mathrm{Zn}$ & 0.050 & 0.049 & 0 \\
\hline $\mathrm{Zr}$ & 0.127 & 0.165 & 0 \\
\hline & & & \\
\hline
\end{tabular}

Many elements agreed nearly exactly between the D5 SRAT receipt and product results, as expected, but there were several exceptions larger than $10 \%$ such as $\mathrm{Mg}, \mathrm{Si}$, and $\mathrm{Cu}$. The presence of the MST sorbent was clearly indicated in all of the Ti results. 
SRAT product anion data are given in Table 3-10. Selected results from caustic-quenched samples pulled 30 minutes prior to the end of the SRAT cycle are given for comparison to the SRAT product samples. The dilution of the caustic-quenched sample species by the added caustic has been removed computationally to present the results on a SRAT slurry basis prior to caustic quenching. Little happens on a time scale of 30 minutes at the end of SRAT reflux in general which is why these results should be very comparable. SRAT product samples sit at room temperature until analyzed, and reactions may potentially continue at a slower rate in the bottle prior to analysis, since the SRAT product sample is not caustic quenched.

Table 3-10. SRAT Product Anions, mg/kg slurry

\begin{tabular}{|c|c|c|c|c|c|}
\hline & D1 & D2 & D3 & $\mathrm{D} 4$ & D5 \\
\hline KMA factor & $105 \%$ & $140 \%$ & $120 \%$ & $140 \%$ & $120 \%$ \\
\hline Formate & 67,250 & 68,800 & 64,800 & 71,200 & 76,650 \\
\hline Formate $^{1}$ & 63,100 & 69,900 & 68,100 & 73,300 & 75,300 \\
\hline Nitrate & 36,650 & 36,950 & 36,000 & 37,050 & 40,700 \\
\hline Nitrate $^{1}$ & 33,500 & 37,000 & 36,400 & 38,200 & 38,800 \\
\hline Nitrite & $<500$ & $<500$ & $<500$ & $<500$ & $<500$ \\
\hline Chloride & 306 & 263 & 283 & 272 & 285 \\
\hline Chloride $^{1}$ & 280 & 245 & 280 & 270 & 275 \\
\hline Sulfate & 1,660 & 1,030 & 1,095 & 1,110 & 1,355 \\
\hline Sulfate $^{1}$ & 1,370 & 1,280 & 1,190 & 1,230 & 1,260 \\
\hline Fluoride & $<500$ & $<500$ & $<500$ & $<500$ & $<500$ \\
\hline Oxalate $^{2}$ & 650 & 468 & 356 & 598 & 743 \\
\hline Phosphate & $<500$ & $<500$ & $<500$ & $<500$ & $<500$ \\
\hline TIC & 856 & 251 & 848 & 278 & 221 \\
\hline TOC & 17,300 & 21,400 & 18,600 & 19,500 & 21,800 \\
\hline
\end{tabular}

1 - these are caustic quenched samples from 30 minutes before the end of the SRAT 2 - oxalate by weighted dilution is not equivalent to total oxalate; oxalate is expected to be about $4,000 \mathrm{mg} / \mathrm{kg}$ based on simulant oxalate content and process knowledge

Product and quenched sample nitrate were nearly the same in D2-D5 as expected. Product vs. quenched sample values for D1 formate, nitrate, sulfate, and chloride all suggest there may have been some instrument or sample preparation bias in the D1 results. Comparison of the $105 \%$ acid stoichiometry D1 to D2-D4 would suggest that formate and nitrate should have been less than seen in D3 at 15\% higher acid stoichiometry, but the SRAT product sample results do not show this trend while the quenched sample results do. From this one could infer that the D1 product sample anion results are biased high.

Anion results for D5 (coupled flowsheet) are 10-20\% higher than for D3 (sludge-only) due to shifts in oxalate from the ARP contribution and delays in putting nitrate in the MCU strip effluent simulant into the vessel combined with a higher SRAT product wt.\% total solids ( $8 \%$ higher). The increased wt. $\%$ total solids explains most of the variation between the two $120 \%$ acid runs. The data do not suggest a significant shift in chemistry between the two flowsheets. 
Table 3-11. Other SRAT Product Properties

\begin{tabular}{|c|c|c|c|c|c|}
\hline & D1 & D2 & D3 & D4 & $\overline{\mathrm{D} 5}$ \\
\hline Wt. \% total solids & 27.30 & 27.20 & 27.43 & 27.36 & 29.69 \\
\hline Wt. \% dissolved solids & 15.85 & 17.50 & 16.78 & 17.77 & 18.92 \\
\hline Wt. \% insoluble solids ${ }^{2}$ & 13.60 & 11.80 & 12.81 & 11.67 & 13.29 \\
\hline Wt. \% soluble solids ${ }^{2}$ & 13.70 & 13.45 & 14.63 & 15.69 & 16.40 \\
\hline Wt. \% calcined solids & 17.25 & 16.55 & 17.28 & 16.71 & 18.30 \\
\hline Slurry density, $\mathrm{g} / \mathrm{mL}$ & 1.203 & 1.208 & 1.203 & 1.213 & 1.232 \\
\hline Supernate density, $\mathrm{g} / \mathrm{mL}$ & 1.108 & 1.123 & 1.112 & 1.124 & 1.134 \\
\hline Slurry $\mathrm{pH}$ & 7.92 & 6.10 & 7.56 & 5.68 & 6.67 \\
\hline
\end{tabular}

1 - dissolved solids are the non-water, non-volatile species on an aqueous phase mass basis

2 - insoluble and soluble solids are calculated from the measured total and dissolved solids

Calcined element wt.\%'s for the five SME products are reported in Table 3-12. The first four SME products were targeted to the same waste loading (36\%), so similar elemental compositions were expected. From batching considerations, the coupled run, D5, should have had more Na and $\mathrm{Ti}$ than the other four runs. The $\mathrm{Ti}$ increase was clearly seen, but the Na increase was in the noise of the replicate results.

Table 3-12. Calcined Elements of Flowsheet SME Products

\begin{tabular}{|l|c:c:c:c|c|}
\hline $\begin{array}{l}\text { Wt.\% } \\
\text { of: }\end{array}$ & $\begin{array}{c}\text { SB8-D1 } \\
\text { SME } \\
\text { Product }\end{array}$ & $\begin{array}{c}\text { SB8-D2 } \\
\text { SME } \\
\text { Product }\end{array}$ & $\begin{array}{c}\text { SB8-D3 } \\
\text { PME }\end{array}$ & $\begin{array}{c}\text { SB8-D4 } \\
\text { SME } \\
\text { Product }\end{array}$ & $\begin{array}{c}\text { SB8-D5 } \\
\text { SME } \\
\text { Product }\end{array}$ \\
\hline $\mathrm{B}$ & 3.07 & 3.18 & 3.11 & 2.94 & 2.93 \\
\hline $\mathrm{Ba}$ & 1.37 & 1.37 & 1.37 & 1.41 & 1.44 \\
\hline $\mathrm{Ca}$ & 0.044 & 0.044 & 0.046 & 0.043 & 0.041 \\
\hline $\mathrm{Ce}$ & 0.106 & 0.507 & 0.504 & 0.474 & 0.439 \\
\hline $\mathrm{Cr}$ & 0.054 & 0.107 & 0.108 & 0.103 & 0.097 \\
\hline $\mathrm{Cu}$ & 0.068 & 0.057 & 0.053 & 0.054 & 0.046 \\
\hline $\mathrm{Fe}$ & 7.55 & 7.75 & 0.070 & 0.071 & 0.056 \\
\hline $\mathrm{K}$ & 0.091 & 0.089 & 0.087 & 0.085 & 0.096 \\
\hline $\mathrm{La}$ & 0.028 & 0.029 & 0.029 & 0.027 & 0.028 \\
\hline $\mathrm{Li}$ & 2.11 & 2.12 & 2.12 & 2.16 & 2.19 \\
\hline $\mathrm{Mg}$ & 0.122 & 0.122 & 0.123 & 0.120 & 0.110 \\
\hline $\mathrm{Mn}$ & 2.43 & 2.45 & 2.57 & 2.48 & 2.38 \\
\hline $\mathrm{Na}$ & 11.9 & 11.7 & 10.7 & 10.7 & 10.8 \\
\hline $\mathrm{Ni}$ & 0.764 & 0.781 & 0.680 & 0.655 & 0.618 \\
\hline $\mathrm{P}$ & $<0.10$ & $<0.10$ & $<0.10$ & $<0.10$ & $<0.10$ \\
\hline $\mathrm{Pb}$ & $<0.10$ & $<0.10$ & $<0.10$ & $<0.10$ & $<0.10$ \\
\hline $\mathrm{S}$ & 0.153 & 0.137 & 0.132 & 0.123 & 0.130 \\
\hline $\mathrm{Si}$ & 23.7 & 23.6 & 23.6 & 24.4 & 24.6 \\
\hline $\mathrm{Ti}$ & 0.058 & 0.057 & 0.061 & 0.064 & 0.331 \\
\hline $\mathrm{Zn}$ & 0.024 & 0.024 & 0.022 & 0.022 & 0.021 \\
\hline $\mathrm{Zr}$ & 0.175 & 0.174 & 0.137 & 0.133 & 0.165 \\
\hline
\end{tabular}

The average ratio of $\mathrm{Al} / \mathrm{Fe}$ in runs $\mathrm{D} 1-\mathrm{D} 4$ was $10 \%$ higher than in the simulant-SRAT product group, so this table may confirm that there was more aluminum in the simulants than indicated by 
Table 3-4, where the aluminum results came in lower than targeted by recipe. Certain elements, such as $\mathrm{Zr}, \mathrm{Na}$, and $\mathrm{Ni}$, seem to reflect the fact that D1 and D2 samples were analyzed by ICP in a different week (under a different calibration) from D3 and D4 samples. Nothing unusual was detected in the Mn results (in the SB8-Tank 51 with Tank 12 testing, there was some indication of Mn-formate-hydrate crystal formation which showed up as atypical Mn values in the ICP data).

Waste loadings were calculated from the measured composition (using simulant sludge and ARP data to partition $\mathrm{Na}$ and $\mathrm{Si}$ between waste and frit).

$$
\text { waste loading }=100 \%-\mathrm{B}_{2} \mathrm{O}_{3}-\mathrm{Li}_{2} \mathrm{O}-\left(\mathrm{SiO}_{2}\right)_{\text {frit }}-\left(\mathrm{Na}_{2} \mathrm{O}\right)_{\text {frit }}
$$

The $\mathrm{SiO}_{2 \text {,frit }}$ was calculated from $\mathrm{SiO}_{2 \text {,total }}$ minus $\mathrm{SiO}_{2, \text { sludge }}$, where $\mathrm{SiO}_{2 \text {,sludge }}$ was calculated using the simulant composition of $\mathrm{Fe}$ and $\mathrm{Si}$ combined with the iron in the SME product to calculate the sludge contribution. Sodium was handled similarly, but in SB8-D5, a correction was also made for MST sodium using a ratio to the titanium content of the SME product (after correcting the Ti slightly for the quantity in the sludge simulant by ratio to $\mathrm{Fe}$ ).

Waste loadings were also calculated from the overall solids material balance calculations made following the run (known mass of frit and known mass of SME product plus measured wt.\% calcined solids). These results are summarized in Table 3-13.

Table 3-13. Waste Loading of SME Products

\begin{tabular}{|c|c|c|c|c|c|}
\hline & $\begin{array}{c}\text { SB8-D1 } \\
\text { SME } \\
\text { Product }\end{array}$ & $\begin{array}{c}\text { SB8-D2 } \\
\text { SME } \\
\text { Product }\end{array}$ & $\begin{array}{c}\text { SB8-D3 } \\
\text { SME } \\
\text { Product }\end{array}$ & $\begin{array}{c}\text { SB8-D4 } \\
\text { SME } \\
\text { Product }\end{array}$ & $\begin{array}{c}\text { SB8-D5 } \\
\text { SME } \\
\text { Product }\end{array}$ \\
\hline Composition waste loading, $\%$ & 34.0 & 34.8 & 35.1 & 33.2 & 33.3 \\
\hline Mass balance waste loading, $\%$ & 35.9 & 36.2 & 36.2 & 36.0 & 35.5 \\
\hline SME product $\mathrm{pH}$ & 7.60 & 6.57 & 7.44 & 6.64 & 6.78 \\
\hline Wt.\% total solids & 51.7 & 50.2 & 50.7 & 51.5 & 55.6 \\
\hline
\end{tabular}

Results for waste loading were close to target and fairly consistent. Wt.\% total solids were at or above target $(50 \%)$ for the individual runs. D5 in particular was somewhat over de-watered due to performance issues of the SRAT/SME condenser (a single piece of equipment in lab-scale). There was a $\sim 180 \mathrm{~g}$ mass gain in the ammonia scrubber reservoir due to water that failed to condense in the SRAT/SME condenser and was subsequently collected in the ammonia scrubber reservoir during D5. This behavior is not normal in lab-scale testing, but it was noted while the test was still in progress (related equipment did not appear to be malfunctioning). The off-gas line from the SRAT condenser to the ammonia scrubber was warm to the touch, rather than about room temperature (normally $\sim 25^{\circ} \mathrm{C}$ ). After D5 was over, the mass gain was determined by weighing the contents in the scrubber reservoir and comparing the value to the initial charge. The water loss represented a $17 \%$ increase in SRAT condensate removal versus the target or a $7-8 \%$ over-dewatering over the entire SRAT/SME cycle.

Data were also obtained on the SME product anions, Table 3-14. The anions were primarily formate, nitrate, and sulfate. Oxalate by water dilution was obtained as a lower bound on total oxalate. Actual oxalate was probably in the $2,700-3,300 \mathrm{mg} / \mathrm{kg}$ range, but the impact at even these concentrations on REDOX is small. Substitution of the predicted oxalate by material balance and process knowledge is generally adequate, while acid strike preparations for oxalate have the potential for destroying a non-trivial fraction of the total oxalate when only $3,000 \mathrm{ppm}$ 
are available. TIC/TOC was also obtained. TIC was presumably carbonate formed from the absorption of $\mathrm{CO}_{2}$. TOC was primarily due to formate, plus any oxalate and antifoam.

Table 3-14. SME Product Anions, mg/kg slurry

\begin{tabular}{|l|r|r|r|r|r|}
\hline & \multicolumn{1}{|c|}{$\mathrm{D} 1$} & \multicolumn{1}{c|}{$\mathrm{D} 2$} & \multicolumn{1}{c|}{ D3 } & \multicolumn{1}{c|}{ D4 } & \multicolumn{1}{c|}{ D5 } \\
\hline KMA factor & $105 \%$ & $140 \%$ & $120 \%$ & $140 \%$ & $120 \%$ \\
\hline Formate & 54,950 & 60,000 & 56,500 & 60,250 & 68,700 \\
\hline Nitrate & 28,050 & 31,550 & 30,200 & 30,500 & 34,750 \\
\hline Nitrite & $<500$ & $<500$ & $<500$ & $<500$ & $<500$ \\
\hline Chloride & 256 & 240 & 242 & 232 & 248 \\
\hline Sulfate & 878 & 1010 & 969 & 1010 & 1310 \\
\hline Fluoride & $<500$ & $<500$ & $<500$ & $<500$ & $<500$ \\
\hline Oxalate & 340 & 352 & 475 & 489 & 898 \\
\hline Phosphate & $<500$ & $<500$ & $<500$ & $<500$ & $<500$ \\
\hline TIC & 614 & 257 & 879 & 227 & 181 \\
\hline TOC & 11,600 & 17,200 & 18,900 & 18,800 & 20,500 \\
\hline
\end{tabular}

1 - slurry oxalate by weighted dilution is not equivalent to total oxalate; oxalate is expected to be about $3,000 \mathrm{mg} / \mathrm{kg}$ based on simulant oxalate content and process knowledge

Formate and nitrate generally track with acid stoichiometry as expected (including D1, which did not track in the SRAT product results). Results for D5, however, are higher for formate and nitrate. The main reason for this is that D5 was concentrated about $10 \%$ more in all species than D1-D4. Oxalate and sulfate in D5 are further increased due to the impact of the ARP simulant. Chloride is generally a confirmation that a certain quantity of $\mathrm{RuCl}_{3}$ was added as one of the noble metals. TIC represents carbonate formed after destruction of the carbonate in the SRAT slurry feed during acid addition. TIC tracks with the $\mathrm{pH}$, since higher $\mathrm{pH}$ values promote increased absorption of $\mathrm{CO}_{2}$ formed from decomposition of formate ion. The TOC is primarily due to formate, with about $1000 \mathrm{ppm}$ from oxalate and $600 \mathrm{ppm}$ from antifoam.

Table 3-15. Other SME Product Properties

\begin{tabular}{|c|c|c|c|c|c|}
\hline & D1 & $\mathrm{D} 2$ & D3 & D4 & D5 \\
\hline Wt. \% total solids & 51.67 & 50.17 & 50.68 & 51.55 & 55.46 \\
\hline Wt. \% dissolved solids ${ }^{1}$ & 19.81 & 19.35 & 20.38 & 20.27 & 24.05 \\
\hline Wt. \% insoluble solids ${ }^{2}$ & 39.72 & 38.22 & 38.06 & 39.23 & 41.35 \\
\hline Wt. $\%$ soluble solids ${ }^{2}$ & 11.94 & 11.95 & 12.63 & 12.32 & 14.11 \\
\hline Wt. \% calcined solids & 42.91 & 40.80 & 41.84 & 42.42 & 45.55 \\
\hline Slurry density, $\mathrm{g} / \mathrm{mL}$ & 1.420 & 1.387 & 1.399 & $1.354^{3}$ & 1.484 \\
\hline Supernate density, $\mathrm{g} / \mathrm{mL}$ & 1.136 & 1.136 & 1.140 & 1.141 & 1.172 \\
\hline Slurry pH & 7.60 & 6.57 & 7.44 & 6.64 & 6.78 \\
\hline
\end{tabular}

1 - dissolved solids are the non-water, non-volatile species on an aqueous phase basis

2 - insoluble and soluble solids are calculated from the measured total and dissolved solids 3 - this slurry density result is somewhat suspicious (low)

One consequence of the relatively high wt.\% total solids, which was driven by rheological concerns, was an increase in the concentrations of the anions. For example, if D5 had been concentrated to $48 \mathrm{wt} . \%$ total solids instead of $55.46 \%$, then the nitrate concentration would have been $30,080 \mathrm{mg} / \mathrm{kg}$ instead of $34,750 \mathrm{mg} / \mathrm{kg}$. Two effects are combining to drive the reported 
anion concentrations up compared to previous batches. One is the impact of a less washed sludge with increased acid demand (more nitric and formic acids added), while the second is the need to increase wt.\% insoluble solids (and wt.\% total solids as a consequence) for reasonable rheological properties. There are potential operational issues related to REDOX control by anion concentration associated with the absolute magnitude of the inputs to the equation. These are discussed in Section 3.2.8.

Changes in formate, nitrite, and nitrate were calculated by species material balances for the SRAT and SME cycles from the anion data reported above, Table 3-16.

Table 3-16. Changes in Major Anions

\begin{tabular}{|l|r|r|r|r|r|}
\hline & \multicolumn{1}{|c|}{ D1 } & \multicolumn{1}{c|}{ D2 } & \multicolumn{1}{c|}{ D3 } & \multicolumn{1}{c|}{ D4 } & \multicolumn{1}{c|}{ D5 } \\
\hline KMA factor & $105 \%$ & $140 \%$ & \multicolumn{1}{c|}{$120 \%$} & $140 \%$ & $120 \%$ \\
\hline & SRAT & SRAT & SRAT & SRAT & SRAT \\
\hline Formate Loss & $22 \%$ & $37 \%$ & $34 \%$ & $33 \%$ & $28 \%$ \\
\hline Nitrite Loss & $100 \%$ & $100 \%$ & $100 \%$ & $100 \%$ & $100 \%$ \\
\hline Nitrite-to-nitrate & $26 \%$ & $2 \%$ & $9 \%$ & $5 \%$ & $8 \%$ \\
\hline & SME & SME & SME & SME & SME \\
\hline Formate Loss & $11 \%$ & $7 \%$ & $6 \%$ & $9 \%$ & $2 \%$ \\
\hline Nitrate Loss & $11 \%$ & $4 \%$ & $3 \%$ & $6 \%$ & $1 \%$ \\
\hline
\end{tabular}

Results in Table 3-16 are susceptible to the analytical uncertainties in the IC measurements of anions in the SRAT and SME product samples as well as to uncertainty in the SRAT product mass (a key parameter in partitioning the total anion change between the SRAT and SME cycles). The SRAT product mass is calculated by several methods including a running mass balance from the beginning of the SRAT adjusted for off-gas losses, a reverse running mass balance based on the SME product mass that puts dewater masses back in and takes frit slurry addition masses out, and a calculation based on conservation of the mass of calcined oxides (adjusted for samples) from the starting sludge to the SRAT product. It is not uncommon to have a 5-10\% spread in the SRAT product mass determined from the various independent calculations. For D1, for example, process knowledge ${ }^{1}$ suggests that there was probably more formate loss in the SRAT than calculated, less in the SME, plus a lower SRAT nitrite-to-nitrate conversion than indicated along with a lower SME nitrate loss. The values in the table must be interpreted in the context of fairly large uncertainty bars, e.g. $\pm 10 \%$ to the values as given ( $22 \%$ is probably somewhere in the $12 \%$ $32 \%$ range).

Data were obtained on the elements in the SRAT and SME product supernates. Many species were below detection limits or were minor species with minimal impact on processing chemistry. Other species have varying degrees of significance. $\mathrm{Ca}, \mathrm{Mg}$, and $\mathrm{Mn}$ are three of the more active elements chemically during the CPC, starting insoluble in the SRAT feed, typically dissolving close to $100 \%$ at some point during processing, and then partially reprecipitating by the end of the SME cycle. Table 3-17 gives a short list of SRAT product supernate results.

\footnotetext{
${ }^{1}$ Process knowledge suggests that, since D1 was boiled 24 hours during the SRAT versus 5 hours in the SME, that at least $80 \%$ of the overall formate loss was likely in the SRAT without even factoring in that the first $10 \%$ of formate loss typically occurs during formic acid addition in the SRAT. So, $22 \%$ and $11 \%$ for SRAT and SME were more likely something like $28 \%$ and $5 \%$, if the overall $33 \%$ loss is error free. $\mathrm{CO}_{2}$ from formate loss tends to confirm this but has to be adjusted to remove $\mathrm{CO}_{2}$ from carbonate destruction.
} 
Table 3-17. Major SRAT Product Supernate Elements, mg/L

\begin{tabular}{|l|c|c|c|c|c|}
\hline & $\mathrm{D} 1$ & $\mathrm{D} 2$ & $\mathrm{D} 3$ & $\mathrm{D} 4$ & $\mathrm{D} 5$ \\
\hline $\mathrm{KMA}$ factor & $105 \%$ & $140 \%$ & $120 \%$ & $140 \%$ & $120 \%$ \\
\hline $\mathrm{Ca}$ & 1,115 & 1,400 & 1,215 & 1,680 & 1,075 \\
\hline $\mathrm{Cr}$ & 0.24 & 0.77 & $<0.1$ & 0.12 & $<0.1$ \\
\hline $\mathrm{K}$ & 654 & 570 & 664 & 619 & 994 \\
\hline $\mathrm{Mg}$ & 217 & 339 & 333 & 367 & 207 \\
\hline $\mathrm{Mn}$ & 3,755 & 7,645 & 7,870 & 9,510 & 11,550 \\
\hline $\mathrm{Na}$ & 50,850 & 47,050 & 50,100 & 47,500 & 54,250 \\
\hline $\mathrm{Ni}$ & 0 & 180 & 5 & 284 & 73 \\
\hline $\mathrm{S}$ & 849 & 940 & 762 & 799 & 909 \\
\hline $\mathrm{Si}$ & 14 & 45 & 18 & 37 & 27 \\
\hline
\end{tabular}

Selected concentrations in Table 3-17 were converted to a slurry basis and compared to the total concentration of the element to assess the partitioning of the element between soluble and insoluble species, Table 3-18.

Table 3-18. Selected SRAT Product Supernate Elements, \% of total

\begin{tabular}{|l|c|c|r|r|c|}
\hline & D1 & D2 & D3 & D4 & D5 \\
\hline KMA factor & $105 \%$ & $140 \%$ & $120 \%$ & $140 \%$ & $120 \%$ \\
\hline $\mathrm{Ca}$ & 38 & 50 & 44 & 63 & 27 \\
\hline $\mathrm{K}$ & $\sim 100$ & $\sim 100$ & $\sim 100$ & $\sim 100$ & $\sim 100$ \\
\hline $\mathrm{Mg}$ & 35 & 59 & 52 & 57 & 26 \\
\hline $\mathrm{Mn}$ & 24 & 53 & 51 & 65 & 72 \\
\hline $\mathrm{Na}$ & $\sim 100$ & $\sim 100$ & $\sim 100$ & $\sim 100$ & $\sim 100$ \\
\hline $\mathrm{S}$ & $\sim 100$ & $\sim 100$ & 90 & 90 & $\sim 100$ \\
\hline
\end{tabular}

The high solubility of Mn has not been seen in recent sludge batches, particularly for D2-D5 where it was over 50\%. Sulfur was almost entirely in a dissolved form based on the paired ICP results for slurry and supernate.

Similar elements were found in the SME product supernate analyses as in the SRAT product supernate analyses. Small concentrations of B and Li also were detected in the SME product supernates, Table 3-19. 
Table 3-19. Major SME Product Supernate Elements, mg/L

\begin{tabular}{|l|c|c|c|c|c|}
\hline & $\mathrm{D} 1$ & $\mathrm{D} 2$ & $\mathrm{D} 3$ & $\mathrm{D} 4$ & $\mathrm{D} 5$ \\
\hline KMA factor & $105 \%$ & $140 \%$ & $120 \%$ & $140 \%$ & $120 \%$ \\
\hline $\mathrm{B}$ & 7 & 23 & 9 & 27 & 41 \\
\hline $\mathrm{Ca}$ & 1,320 & 1,740 & 1,480 & 1,850 & 1,450 \\
\hline $\mathrm{Cr}$ & 0.63 & 0.75 & 0.11 & 0.13 & $<0.1$ \\
\hline $\mathrm{K}$ & 800 & 740 & 850 & 830 & 1,260 \\
\hline $\mathrm{Li}$ & 210 & 210 & 220 & 250 & 295 \\
\hline $\mathrm{Mg}$ & 320 & 400 & 310 & 330 & 220 \\
\hline $\mathrm{Mn}$ & 6,440 & 7,500 & 9,800 & 9,750 & 6,600 \\
\hline $\mathrm{Na}$ & 62,200 & 58,700 & 61,400 & 61,000 & 73,400 \\
\hline $\mathrm{S}$ & 1,010 & 1,070 & 1,040 & 1,090 & 1,240 \\
\hline $\mathrm{Si}$ & 19 & 46 & 24 & 43 & 38 \\
\hline
\end{tabular}

The partitioning of the elements in the supernate between phases was calculated on the basis of percent of total element mass present (as determined by the slurry elemental analysis). These percentages are given in Table 3-20.

Table 3-20. Selected SME Product Supernate Elements, \% of total

\begin{tabular}{|l|c|c|c|c|c|}
\hline & $\mathrm{D} 1$ & $\mathrm{D} 2$ & $\mathrm{D} 3$ & $\mathrm{D} 4$ & $\mathrm{D} 5$ \\
\hline KMA factor & $105 \%$ & $140 \%$ & $120 \%$ & $140 \%$ & $120 \%$ \\
\hline $\mathrm{Ca}$ & 33 & 46 & 38 & 49 & 36 \\
\hline $\mathrm{K}$ & $\sim 100$ & $\sim 100$ & $\sim 100$ & $\sim 100$ & $\sim 100$ \\
\hline $\mathrm{Li}$ & 1.2 & 1.3 & 1.3 & 1.5 & 1.5 \\
\hline $\mathrm{Mg}$ & 32 & 33 & 33 & 35 & 22 \\
\hline $\mathrm{Mn}$ & 44 & 41 & 49 & 49 & 31 \\
\hline $\mathrm{Na}$ & 65 & 67 & 74 & 72 & 75 \\
\hline $\mathrm{S}$ & 82 & $\sim 100$ & $\sim 100$ & $\sim 100$ & $\sim 100$ \\
\hline
\end{tabular}

Mn solubility seen in the SRAT product was generally sustained through the SME cycle except in D5. The change in D5 lacks an obvious explanation. D5 SME product was also the most reduced of the five as discussed in Section 3.2.8. The two observations may be related. Room temperature $\mathrm{pH}$ of the SRAT and SME product D5 slurries was nearly identical, so the drop in $\mathrm{Mn}$ solubility apparently was not related to $\mathrm{pH}$. $\mathrm{Ca}, \mathrm{Mg}$, and $\mathrm{Mn}$ appeared to have lower fractional solubilities in the coupled flowsheet run than in the sludge-only flowsheet runs. This could simply indicate that these elements are close to (or at?) their solubility limits in the SME products, and thus less was found in the D5 supernate, because the D5 product was more concentrated (less water) than the other four.

Ideally the sodium partitioning would be constant in percent for D1-D4 under the two assumptions of no frit leaching and exactly at targeted waste loading, but the variations seen in the table are more typical of the analytical measurement results for sodium seen in prior sludge batch studies. A range of $65-74 \%$ neither predicts nor precludes a small amount of frit sodium leaching. Frit lithium leaching was small $(<2 \%)$ but detected. Boron and silicon were an order of magnitude less soluble than lithium. The SB8-Tank 40 simulant runs used frit 418 , however, which is not the nominal frit for SB8 in DWPF (sufficient quantities of frit 803 did not exist at the time of these tests to use it). 


\subsubsection{SRAT/SME Off-gas Results}

The usual sets of graphs are given below for hydrogen, carbon dioxide, and nitrous oxide generation rates at DWPF scale. The generation rate graphs are derived from the GC data. The calculation methodology is explained in detail in an earlier simulant report (Section 2.4.2 of WSRC-STI-2008-00002 ${ }^{10}$ ). Volume per cents are converted to flow rates using the known flow rate of the helium tracer gas. SRAT cycle hydrogen generation rates are shown in Figure 2.

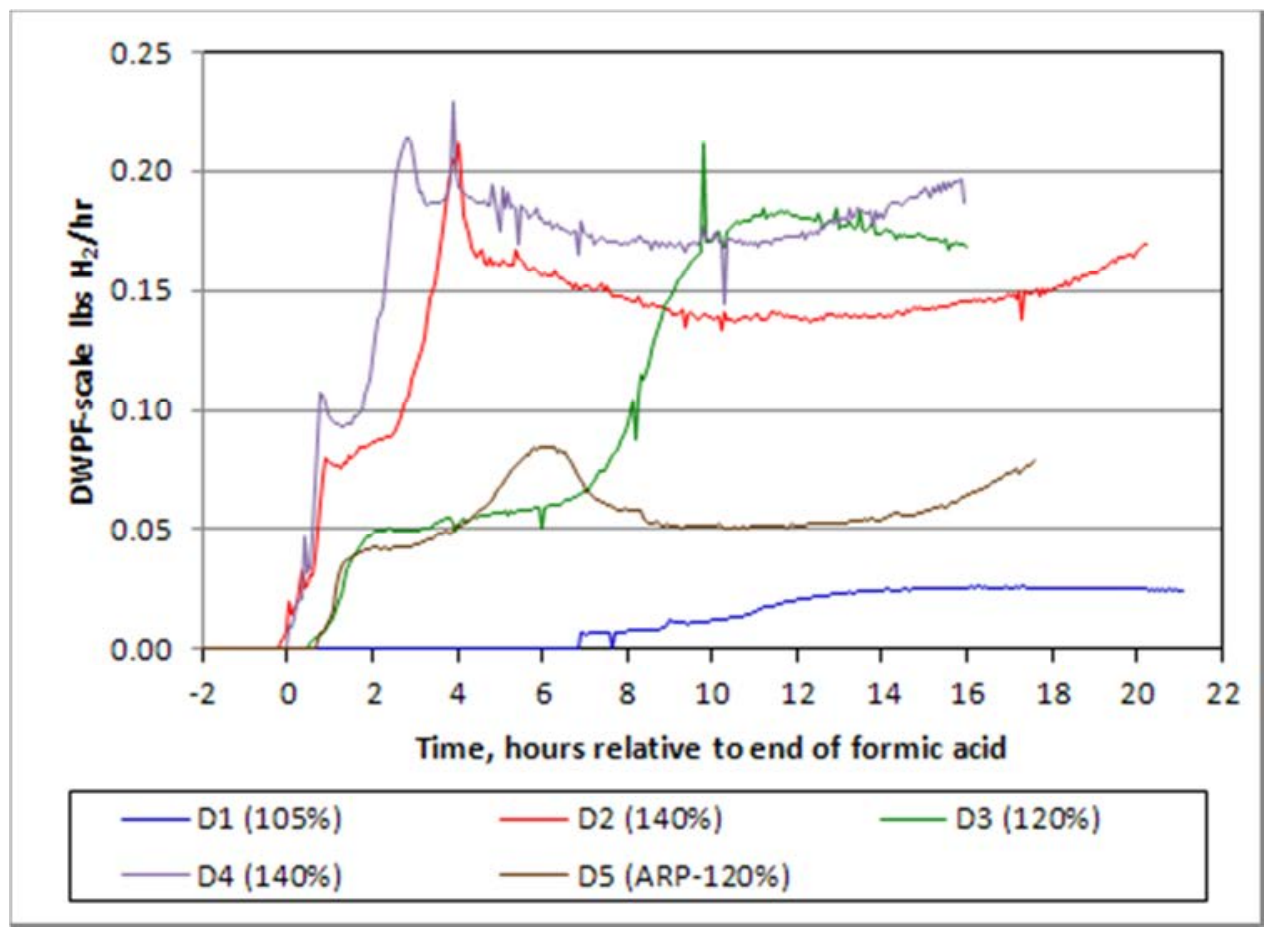

Figure 2. SRAT Cycle Hydrogen Generation Rates

Although it took about six hours longer, the $120 \%$ stoichiometry run managed to peak at nearly the same hydrogen generation rate as the pair of $140 \%$ stoichiometry runs. The $120 \%$ coupled flowsheet run did not approach these three runs during the SRAT. SME cycle hydrogen generation rates are compared in Figure 3. 


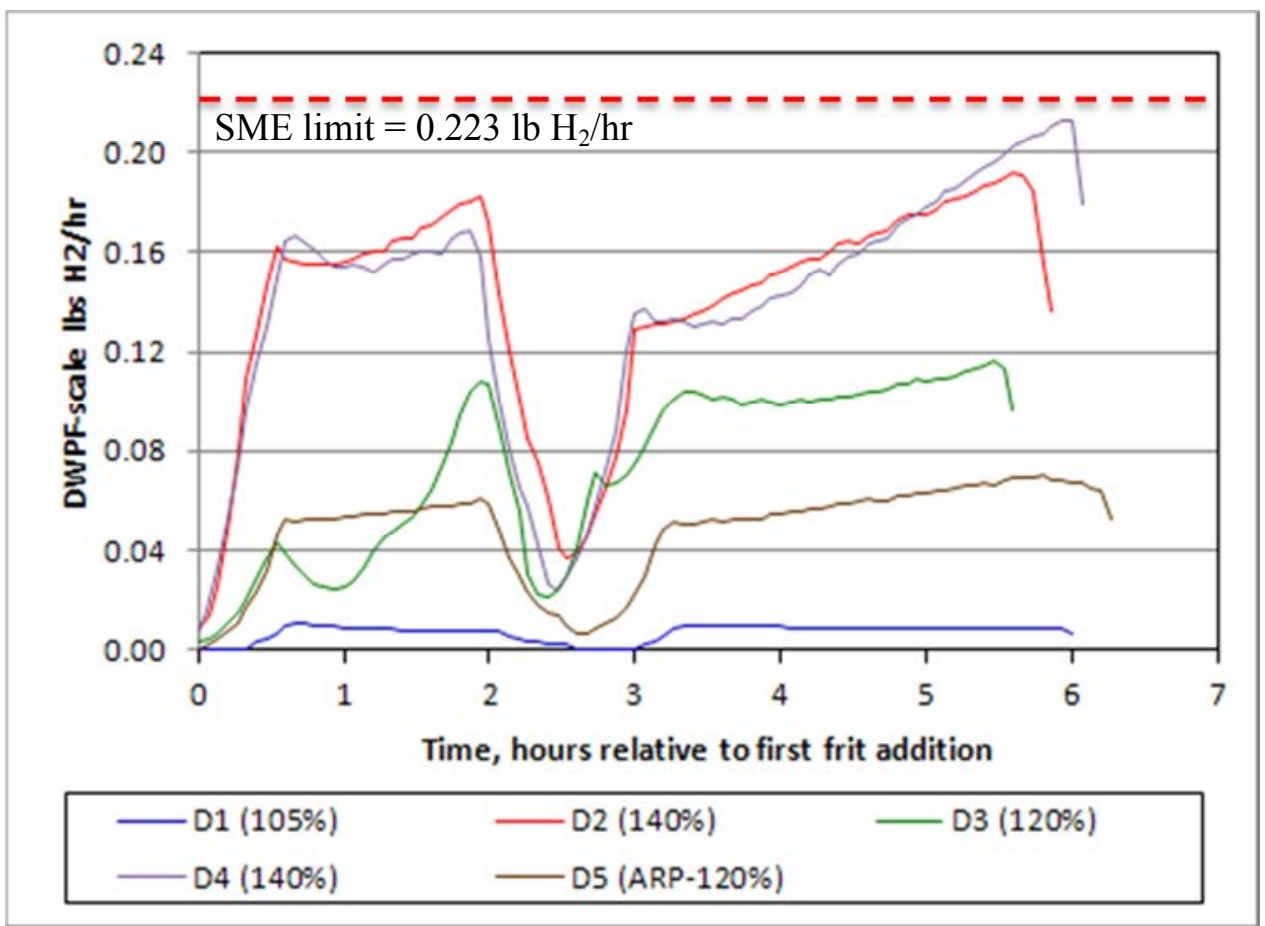

Figure 3. SME Cycle Hydrogen Generation Rates

The sludge-only $120 \%$ acid run bound the $120 \%$ coupled flowsheet run during the SME cycle. The two $140 \%$ stoichiometry runs showed a potential to come close to the DWPF SME limit. If they had been concentrated further, then they might have exceeded the limit given the trends seen in the last hour or so of the dewatering following the second frit slurry addition. Peak values for hydrogen generation rates in the SRAT and SME are given numerically in Table 3-21.

Table 3-21. SRAT and SME Maximum Hydrogen Generation Rate

\begin{tabular}{|l|c|c|c|c|c|}
\hline & D1 & D2 & D3 & D4 & D5 \\
\hline SRAT, DWPF-scale $\mathrm{lbs} \mathrm{H}_{2} / \mathrm{hr}$ & 0.027 & 0.21 & 0.21 & 0.23 & 0.085 \\
\hline SME, DWPF-scale $\mathrm{lbs} \mathrm{H} \mathrm{H}_{2} / \mathrm{hr}$ & 0.011 & 0.19 & 0.12 & 0.21 & 0.070 \\
\hline
\end{tabular}

One test that can be performed to compare the equivalency of the mathematical analysis of the off-gas data from a set of five runs with similar feeds is to align the $\mathrm{CO}_{2}$ generation rates from carbonate destruction. This alignment was done in Figure 4 by shifting the timelines of D2-D5 to align with the timeline of D1. The large peak at about -1.4 hours is the carbonate destruction $\mathrm{CO}_{2}$. 


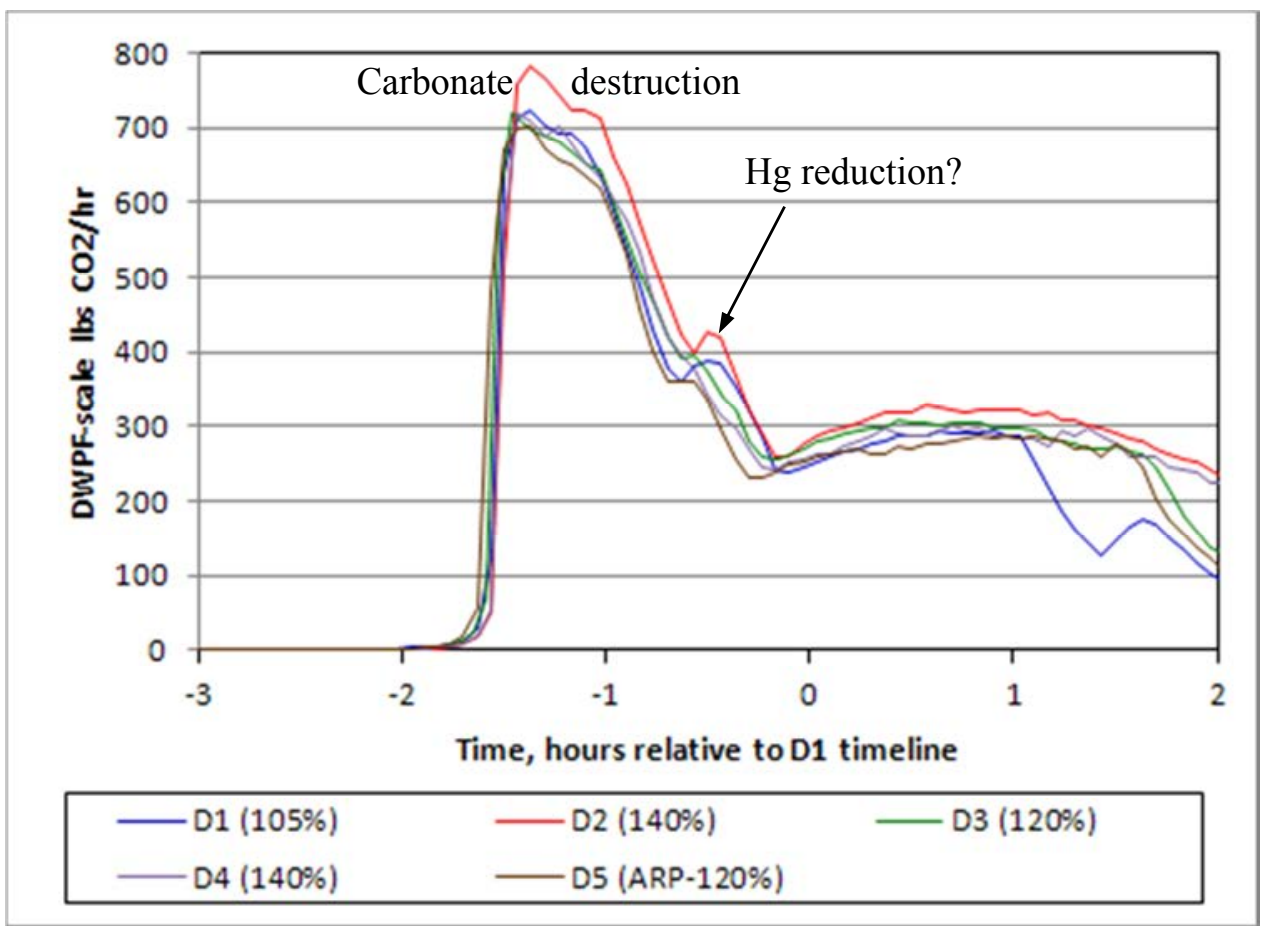

Figure 4. Comparison of Carbonate Destruction $\mathrm{CO}_{2}$

Four of the five runs aligned extremely well in both timing and magnitude, while D2 was running $7-8 \%$ higher. This is very good quantitative agreement for GC data. All five runs went from less than 2 vol. $\% \mathrm{CO}_{2}$ to about 30-31 vol.\% $\mathrm{CO}_{2}$ in under fifteen minutes. Total off-gas flow increased $45 \%$ as the $\mathrm{CO}_{2}$ peaked relative to the air purge alone based on nitrogen dilution ratios. The size of the carbonate peak is very sensitive to the TIC content of the starting slurry (caustic pre-concentration brought the simulant slurry TIC up to $1930 \mathrm{mg} / \mathrm{kg}$ ). There are indications that the simulants for SB8 were too bounding in terms of TIC. Reduced TIC in SB8-Tank 40 feed to DWPF would reduce the impact of the $\mathrm{CO}_{2}$ peak on off-gas flow rate that was seen at lab-scale. (For a DWPF SRAT receipt with heel and flush water, TIC $<\sim 1400 \mathrm{mg} / \mathrm{kg}$ would likely constitute "reduced" relative to the simulant testing.)

As carbonate derived $\mathrm{CO}_{2}$ is falling off, the $\mathrm{CO}_{2}$ produced during nitrite destruction and $\mathrm{Mn}$ reduction show up. There is a peak at about -0.5 hours. This peak is most noticeable in D1 and D2, and less obvious in D3 and D5 (more of a shelf), and essentially non-existent in D4. It is worth noting that D1 and D2 had the most $\mathrm{Hg}$, D3 and D5 had intermediate $\mathrm{Hg}$, and D4 had the least $\mathrm{Hg}$. Therefore, this peak may be indicating the time that some significant fraction of the $\mathrm{Hg}$ was reduced. The $\mathrm{pH}$ at this time was in the mid-fives (hard to be more precise, since there was significant calibration drift in three of the five $\mathrm{pH}$ probes during the runs). This compares well to some, but not all, of the previous data on the timing of mercury reduction. The new MS data discussed below confirm the peak and add some additional insight.

Figure 5 gives the $\mathrm{CO}_{2}$ generation rate after acid addition scaled to focus on reactions occurring after nitrite destruction $\mathrm{CO}_{2}$ has been purged from the head space (typically less than $50 \mathrm{lbs} / \mathrm{hr}$ in these runs). 


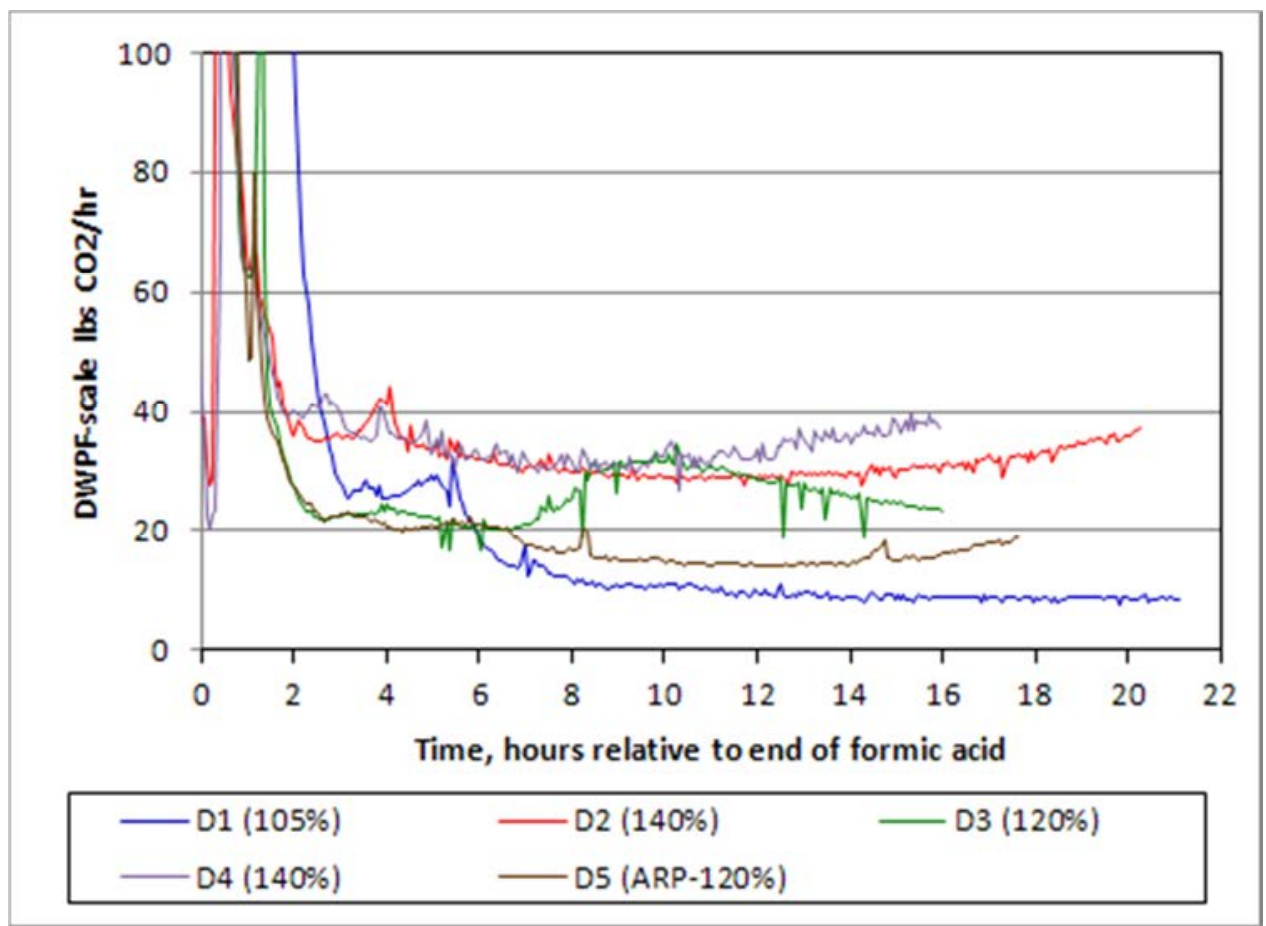

Figure 5. Carbon Dioxide after Acid Addition

Generally the $\mathrm{CO}_{2}$ generation rate results rank in the same order as acid stoichiometry with low stoichiometry (low excess acid) giving relatively little $\mathrm{CO}_{2}$ and high stoichiometry giving relatively more $\mathrm{CO}_{2}$ from about +4 hours onward. There is a fairly strong feature in the nominal sludge-only run, D3 (green trace), starting at about +6 hours, peaking at +10 hours, and then falling off. The period from 6-10 hours coincides with the major increase in catalytic hydrogen generation for D3. The $\mathrm{CO}_{2}$ data suggest that the nominal run, D3, was somewhat more catalytically active than the coupled flowsheet run, D5. This is consistent with what was seen for hydrogen. These two observations relate to the final conclusion in Section 3.2.1 that the stoichiometric factor window for sludge-only seems to be suitable for coupled flowsheet as well.

A variety of $\mathrm{CO}_{2}$ generation rate behaviors were seen in the SME cycle. Two of the lower acid runs, D1 and D3, had fairly sharp spikes in $\mathrm{CO}_{2}$ generation rate following resumption of boiling after each of the two frit additions, Figure 6 . The spikes were relatively milder in the other three runs. This may be related to something done slightly differently in the lab rather than to something fundamentally different in processing chemistry, for example the time allowed for cooling after the SRAT cycle and minimum temperature reached adding the frit slurry might have some impact on the behavior going back to boiling. 


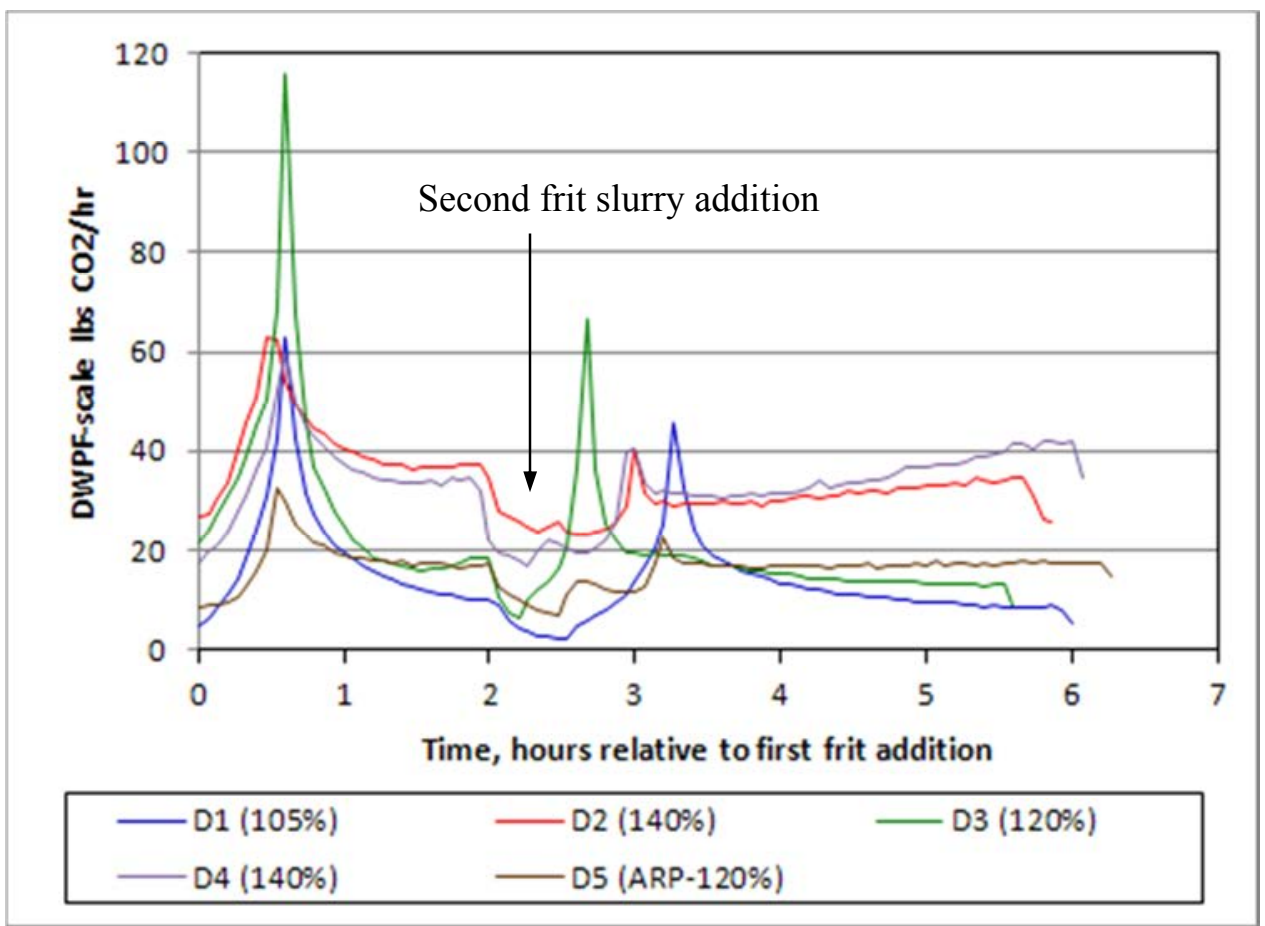

Figure 6. SME Cycle $\mathrm{CO}_{2}$ Generation Rates

Sudden drops in $\mathrm{CO}_{2}$ generation rates around two hours into the SME cycle graph and around 5.5-6 hours correspond to when the power to the rod heaters was turned off. The one at two hours is between the first frit slurry addition dewatering and the start of second frit slurry addition dewatering. The second drop is at the end of the SME cycle.

Nitrous oxide generation rates are compared for the SRAT cycle in Figure 7. Nitrous oxide (and $\mathrm{CO}_{2}$ ) eluted on the back tail of the bimolecular gas peak in several of the runs rather than on the baseline. Reprocessing was able to recover $\mathrm{CO}_{2}$ fairly well, but the smaller and broader $\mathrm{N}_{2} \mathrm{O}$ peaks were more problematic. $\mathrm{N}_{2} \mathrm{O}$ generation rates less than $2 \mathrm{lb} / \mathrm{hr}$ at DWPF scale were very susceptible to this problem, and the results were of a hit-or-miss variety that looks like a lot of up and down noise in Figure 7. The actual $\mathrm{N}_{2} \mathrm{O}$ peak on the raw chromatographs was not doing this from scan to scan. It was fairly consistent in size from scan to scan, but the software would integrate the peak differently on consecutive chromatographs. A better recovery of these data is potentially possible should someone identify a need for it (this could be fairly time consuming). Until then, the best way to interpret D4 and most of D1 is to trace a curve though the high points mentally and ignore the dips. 


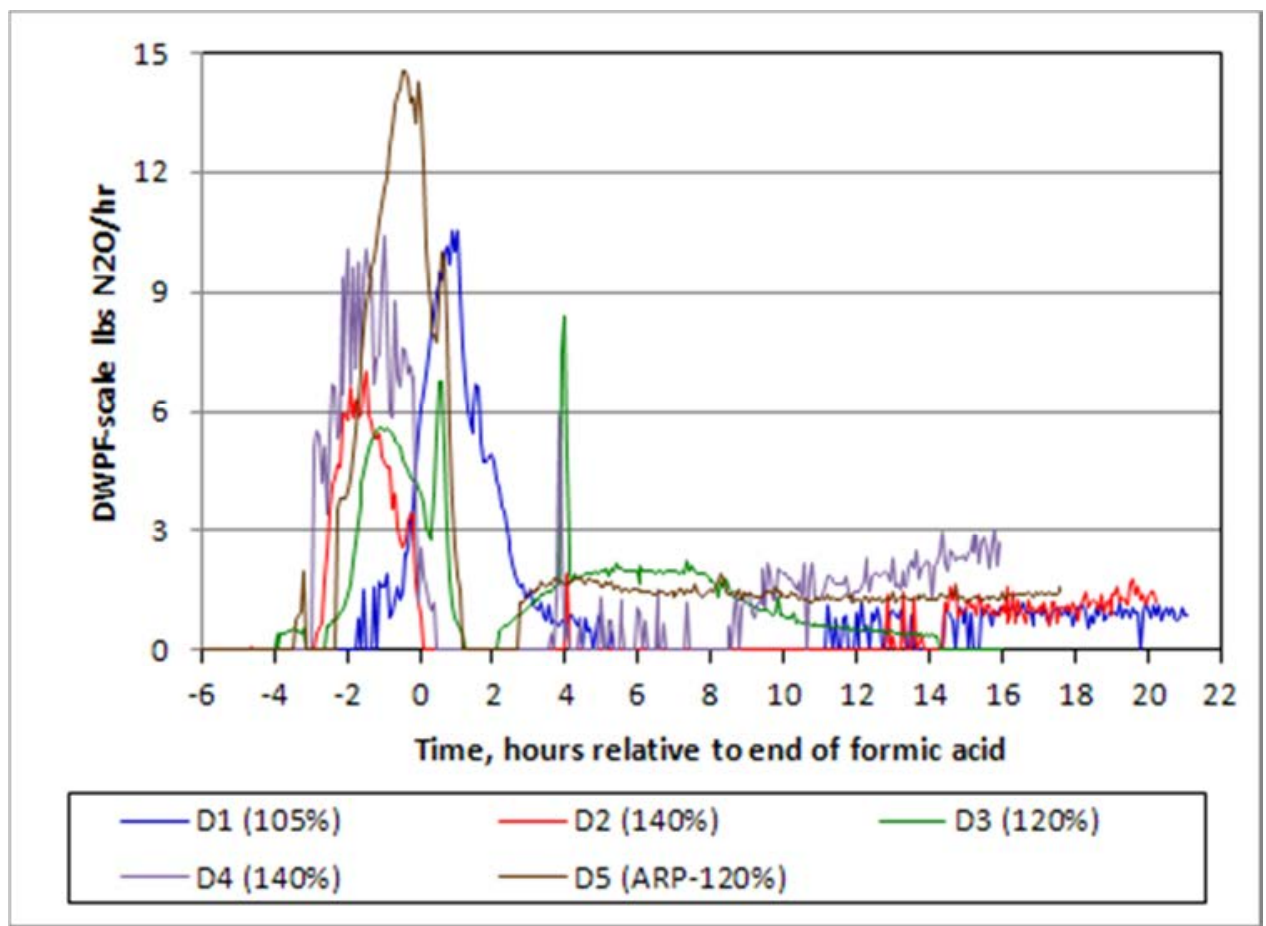

Figure 7. Nitrous Oxide Generation during SRAT Cycle

The coupled flowsheet run, D5, had the greatest $\mathrm{N}_{2} \mathrm{O}$ generation. The D5 peak generation rate of $14.5 \mathrm{lb} / \mathrm{hr}$ at DWPF-scale was significantly above D1 and D4 that both reached about $10.5 \mathrm{lb} / \mathrm{hr}$. D5 peaked at about 0.9 vol. $\% \mathrm{~N}_{2} \mathrm{O}$. These rates are considerably less than were seen in the SB7b flowsheet testing for the sludge-only case. SB7b sludge-only reached $\mathrm{N}_{2} \mathrm{O}$ generation rates in the $30-33 \mathrm{lb} / \mathrm{hr}$ range, or about three times that seen in D1-D4. The SB7b coupled run was fairly similar to the SB8 coupled run (peak rate of $21.8 \mathrm{lb} / \mathrm{hr}$ at DWPF-scale, max of $0.93 \mathrm{vol} . \%, 2.6 \mathrm{~g}$ total produced versus $3.2 \mathrm{~g}$ in SB8-D5 at lab-scale) in terms of nitrous oxide behavior.

There was an unusual result with respect to nitrous oxide during the SB8 -Tank 40 testing, Figure 8. Nitrous oxide was seen at some point in all five SME cycles. Often $\mathrm{N}_{2} \mathrm{O}$ is not detected in any SME cycles for an acid stoichiometry series, or only in runs at one extreme of the range of factors tested. It was not detected in the SB8-Tank 51 SME cycles. 


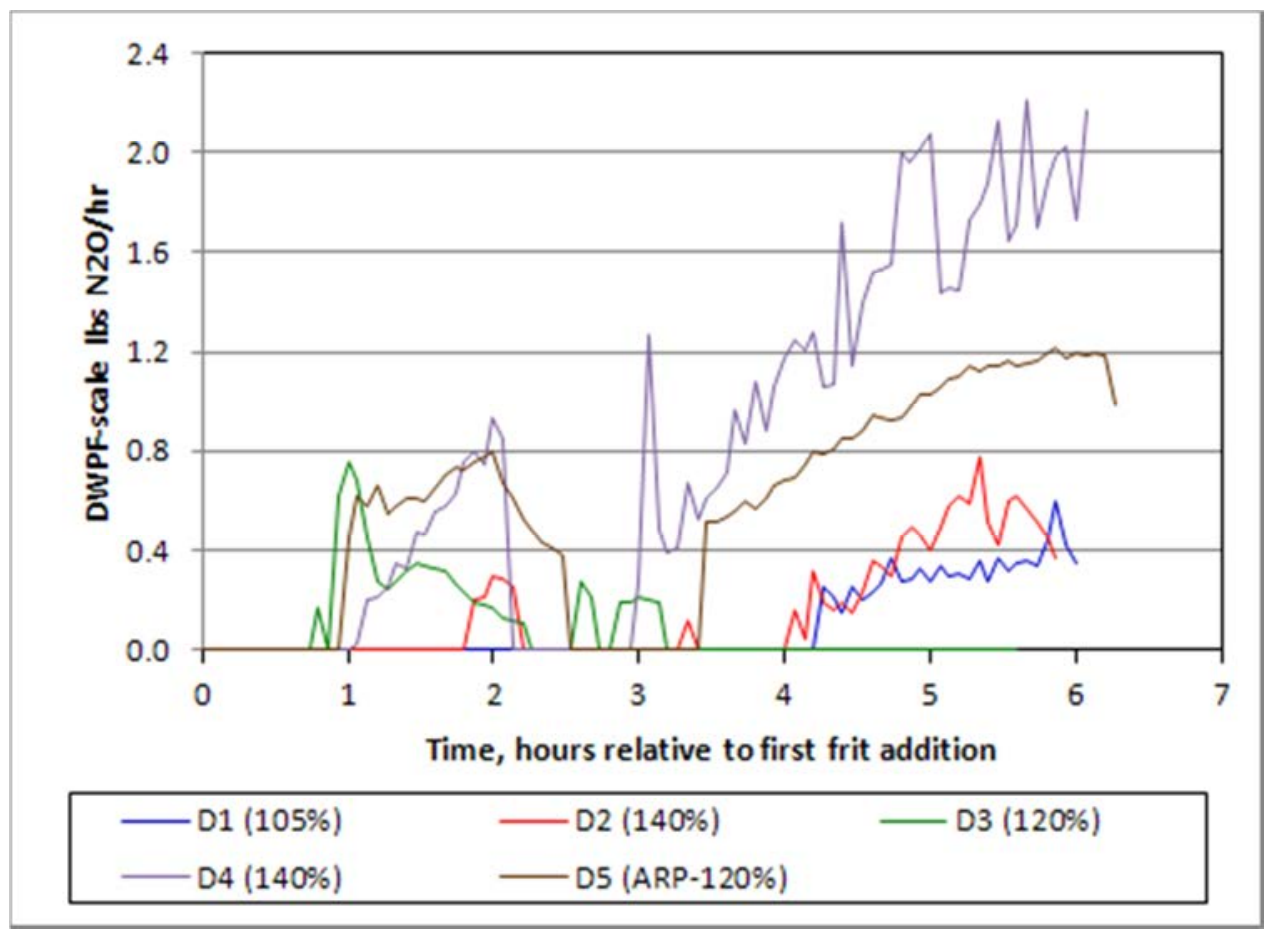

Figure 8. SME Cycle $\mathrm{N}_{2} \mathrm{O}$ Generation Rates

SME cycle rates were about a tenth of the peak rates seen in the SRAT cycle, but the rates seemed to be slowly increasing with processing time. Presumably the $\mathrm{N}_{2} \mathrm{O}$ was being produced by the nitrate-to-ammonium reaction sequence from nitrite ion that was released from the catalytic substrate into the surrounding aqueous phase where residual formic acid converted it into $\mathrm{N}_{2} \mathrm{O}$. Nitrite ion is the product of the first step of the four step reduction of nitrate to ammonium where nitrogen is changed from +5 to -3 in oxidation state in increments of two (each formate can perform a two electron reduction, e.g. $\mathrm{Hg}^{2+}$ to $\mathrm{Hg}^{0}$ or $\mathrm{Mn}^{4+}$ to $\mathrm{Mn}^{2+}$ ).

Mass spectrometer data were obtained in addition to GC data for selected runs. Carbon dioxide data from the D3-D4 pair of runs for the period around formic acid addition are shown in Figure 9 along with the coupled run, D5. There is somewhat better resolution for the feature that might be due to $\mathrm{Hg}$ reduction that shows up as the $\mathrm{CO}_{2}$ is falling from 400 to $300 \mathrm{lb} / \mathrm{hr}$, especially in D3. The MS cycled to D4 right in the middle of the feature in run D3 for two minutes, 40 seconds, and then it cycled back to D3 (the normal sampling cycle) again. There was a $28 \mathrm{lb} / \mathrm{hr}$ drop during the interval. The data do seem to confirm that there was a plateau at about $370-375 \mathrm{lb} / \mathrm{hr}$ of at least a six minute duration $\left(\mathrm{CO}_{2}\right.$ was holding for an entire sampling cycle, the MS cycled to D4, came back and it was still holding in this range for a second sampling cycle, the MS cycled to D4, and the next time it came back $\mathrm{CO}_{2}$ was falling again). This all occurred in a ten minute period during which the GC would only generate three to four data points while the MS generated about 40 data points. 


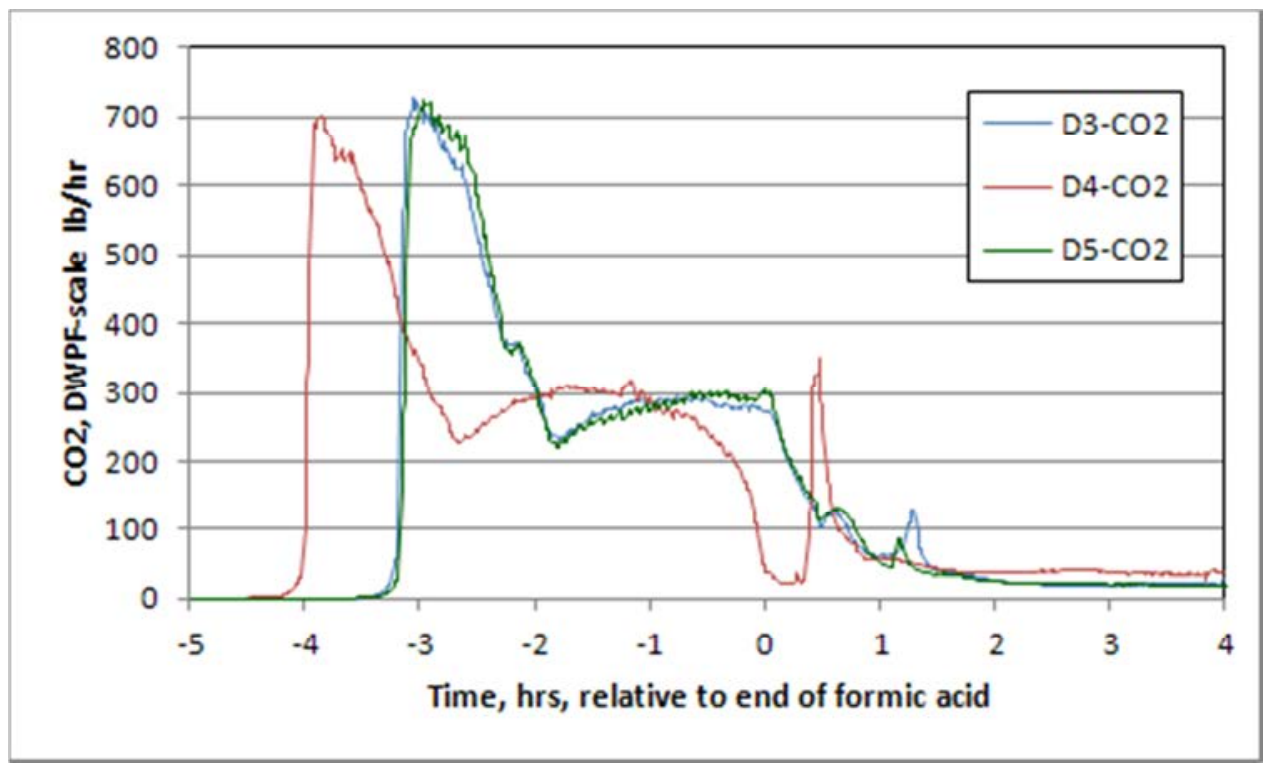

Figure 9. Carbon Dioxide by Mass Spectrometer

The nominal and coupled $120 \%$ acid runs were remarkably similar. The $\mathrm{CO}_{2}$ data indicates the potential value of a higher sampling rate with the MS compared to the GC. The MS also obtained quantitative data for $\mathrm{NO}_{2}$ and $\mathrm{NO}$, Figure 10 and Figure 11.

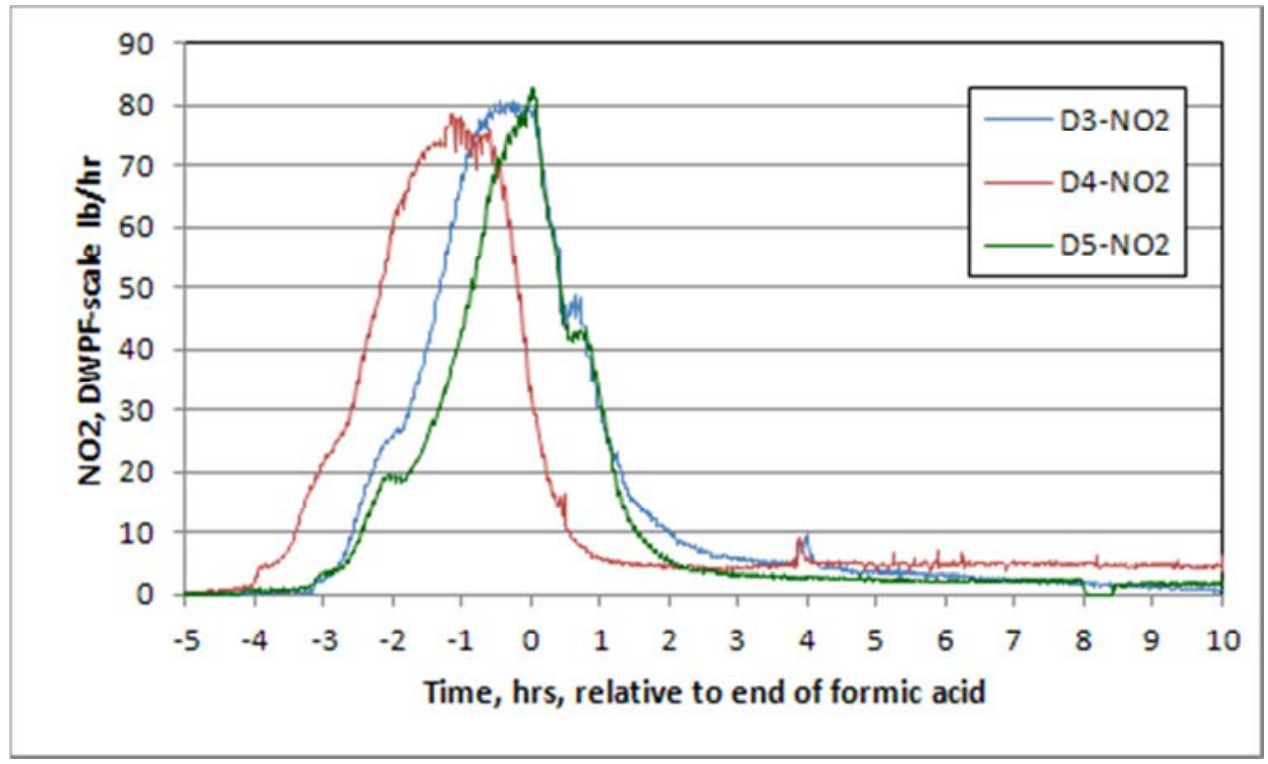

Figure 10. Nitrogen Dioxide by Mass Spectrometer

The profiles for $\mathrm{NO}_{2}$ are very similar during nitrite destruction. Afterwards, the higher acid stoichiometry run, D4, produced at a higher rate than D3 and D5. The onset of reflux just before +4 hours was seen in both sets of data. Nitrite accumulated in the MWWT during dewatering is reintroduced into the SRAT at the start of reflux and gets converted rapidly to $\mathrm{NO}, \mathrm{NO}_{2}$ and $\mathrm{N}_{2} \mathrm{O}$.

The quantity of $\mathrm{NO}_{2}$ being detected after the FAVC by the MS was only about $25 \%$ of the predicted amount based on the assumption that oxygen loss was solely due the reaction $2 \mathrm{NO}+\mathrm{O}_{2}$ $\rightarrow 2 \mathrm{NO}_{2}$. These data don't disprove the assumption, but they imply that, for that case, the 
majority of the $\mathrm{NO}_{2}$ is being partially removed upstream at the very least, e.g. in the FAVC and the ammonia scrubber. The FAVC condensate is too low in mass to account for all of the potentially missing $\mathrm{NO}_{2}$. Alternatively, the oxygen loss (both the $\mathrm{GC}$ and MS see the oxygen loss) may be due to one or more reactions that have not been previously identified. Future testing should attempt to perform a nitrate balance on the ammonia scrubber liquid (the liquid starts with about $0.5 \mathrm{~g}$ of nitrate, and the missing $\mathrm{NO}_{2}$ is on the order of $45 \mathrm{~g}$, so if the $\mathrm{NO}_{2}$ is being scrubbed out of the off-gas, then it should show up as a large gain in nitrate ion in this stream).

The MS data confirm the prior assumptions about the relative significance of $\mathrm{NO}$ versus $\mathrm{NO}_{2}$. The NO data are shown in Figure 11 along with uncalibrated GC estimates for NO. The MS peak generation rates for $\mathrm{NO}$ are about an order of magnitude less than the MS peak rates for $\mathrm{NO}_{2}$.

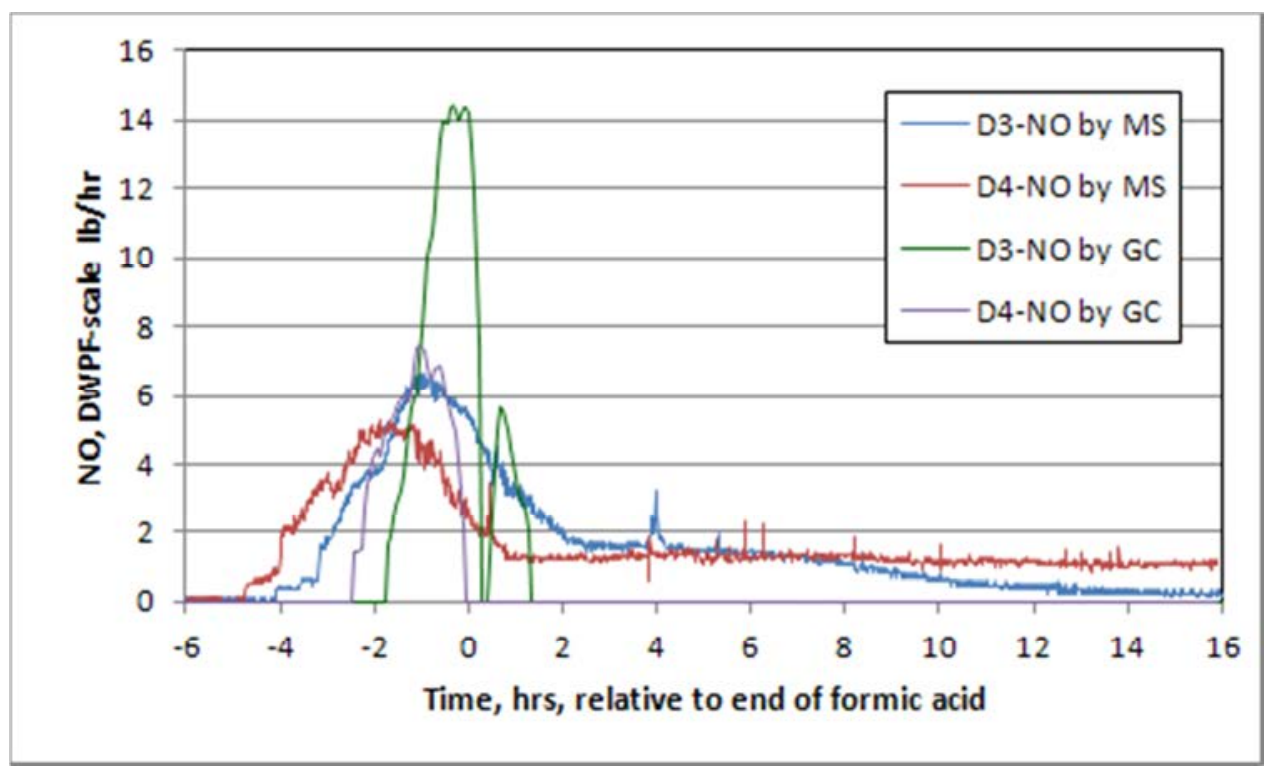

Figure 11. NO by Mass Spectrometer and GC

The MS NO data indicate more total NO formation than was being estimated from the uncalibrated GC data (sum over the entire SRAT cycle). The NO peak rate estimate was also off significantly in one of the two GC data sets (D3). These issues would have had only a minor impact on overall estimates for the fate of nitrite and nitrate in the $\mathrm{CPC}$, however, because the $\mathrm{NO}$ is the least significant of the three nominal nitrogen oxides, $\mathrm{NO}, \mathrm{NO}_{2}$, and $\mathrm{N}_{2} \mathrm{O}\left(\mathrm{N}_{2} \mathrm{O}_{4}\right.$ is lumped with $\mathrm{NO}_{2}$, since it is the $\mathrm{NO}_{2}$ dimer). The onset of reflux in $\mathrm{D} 4$ was visible in the MS data just prior to +4 hours, and there was a hint of a feature for D3 as well.

The much lower sensitivity of the GC for NO in general is also evident in Figure 11. MS data during nitrite destruction was much broader in time than indicated by the GC (detection of NO started sooner and ended later). There were almost no GC results between 0 and $2 \mathrm{lb} / \mathrm{hr}$ presumably because the NO peak is too subtle to integrate easily (it is a wide, broad peak on the GC, that doesn't get very high and is consequently difficult to distinguish from the background). NO was not detected by the GC in the last 14 hours of either SRAT cycle. The new MS data show that NO production was sustained through reflux. As with $\mathrm{NO}_{2}$, there was more $\mathrm{NO}$ in the higher acid stoichiometry run, D4, than in the nominal run, D3, during the last nine hours of reflux. This period has been assigned to catalytic attack on nitrate ion by formic acid, which may or may not lead to ammonium ion formation. The $\mathrm{NO}$ and $\mathrm{NO}_{2}$ data during reflux should help in future attempts to explain nitrate destruction and ammonium ion formation in the SRAT and SME. 
MS data for the D4 SME cycle were impacted by an unexpected loss of sensitivity or spurious dilution (MS read at about $60 \%$ of the $\mathrm{GC}$ reading for $\mathrm{H}_{2}, \mathrm{He}$, and $\mathrm{CO}_{2}$ ). D3 did not suffer the same problem even though it was sharing the MS with D4 at the time. D3 found the peak $\mathrm{H}_{2}$ rate in the SME to be $0.118 \mathrm{lb} / \mathrm{hr}$ by MS versus $0.117 \mathrm{lb} / \mathrm{hr}$ from the $\mathrm{GC}$ data. SME cycle $\mathrm{CO}_{2}$ generation peaked at about $116.5 \mathrm{lb} / \mathrm{hr}$ by both instruments.

The FTIR took data on $\mathrm{NO}$ and $\mathrm{NO}_{2}$ during D4. The FTIR is able to detect very low levels of $\mathrm{NO}_{2}$, but the instrument can saturate at moderate concentrations (greater than about $0.5 \mathrm{vol} \%$ ). FTIR and MS data are compared in Figure 12 for $\mathrm{NO}$ and $\mathrm{NO}_{2}$.

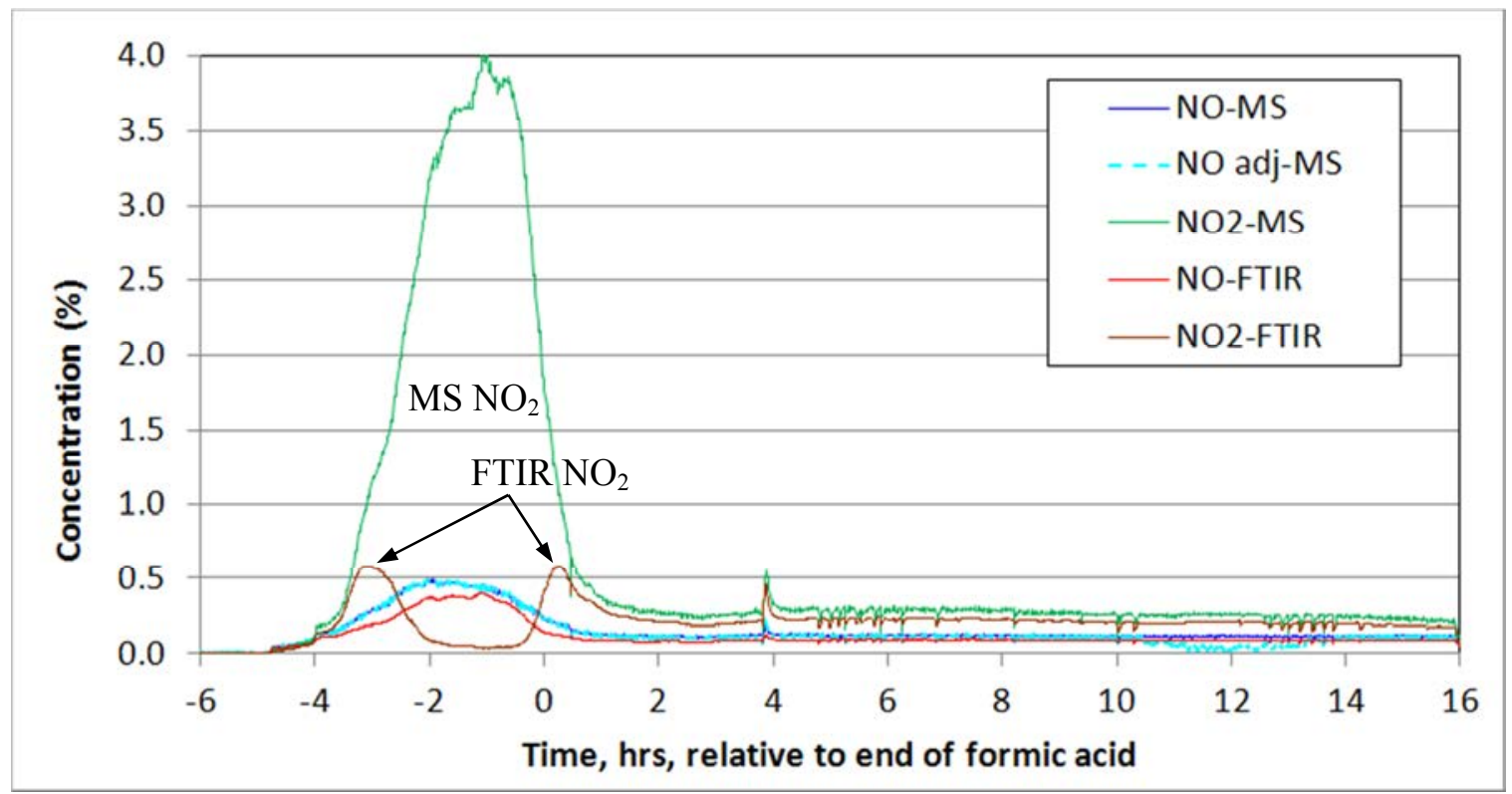

Figure 12. FTIR and MS Data Comparison for D4

Raw NO data on the MS is post-run adjusted for $\mathrm{N}_{2} \mathrm{O}$ using the GC data, since $\mathrm{NO}$ is a fragment from $\mathrm{N}_{2} \mathrm{O}$, but the MS can't calibrate for $\mathrm{N}_{2} \mathrm{O}$ (NO is also a fragment from $\mathrm{NO}_{2}$, but the MS software has an internal correction for $\mathrm{NO}$ fragments due to $\mathrm{NO}_{2}$ that it can perform, since the MS is also analyzing for $\mathrm{NO}_{2}$ ). At D4 levels of $\mathrm{N}_{2} \mathrm{O}$, the correction to the MS NO data had little impact. FTIR NO closely tracked with MS NO, although the FTIR values were a little lower during the peak around -2 hours (middle of nitrite destruction during formic acid addition). FTIR $\mathrm{NO}_{2}$ also closely tracked with $\mathrm{MS} \mathrm{NO}_{2}$, although the FTIR couldn't capture the big peak during nitrite destruction (it caught the beginning and end, but the middle was outside the quantifiable range, see arrows on graph). The FTIR confirms the finding from the MS regarding $\mathrm{NO}_{2}$ that indicates that $\mathrm{NO}_{2}$ leaving the FAVC is much less than could be present based on consumption of oxygen. Some additional FTIR data is discussed in Section 3.2.4 in the context of antifoam behavior during processing.

SB8 is the first set of sludge batch flowsheet studies with the nitric acid-formic acid flowsheet that had access to the mass spectrometer and FTIR spectrometer data. The new data is helping to advance the understanding of CPC chemistry as the preceding discussion hopefully made clear. Additional MS and FTIR data exist for several SB8 SRAT/SME runs that have not been through intermediate processing (to convert the data into a readily manipulated form). This includes periodic full spectrum scans out to atomic weights of 250 on the MS. These scans have the 
potential to detect volatile mercury and mercury compounds as well as antifoam fragments. Once species of interest have been detected in full scans, the regular SRAT/SME MS method can be updated to track them routinely so that more can be learned about their timing and relative magnitudes through the $\mathrm{CPC}$ cycles.

\subsubsection{SRAT/SME Processing Data}

Antifoam behavior continues to be a concern for DWPF and a study area for SRNL. ${ }^{18}$ Data to support a better understanding of antifoam behavior are being obtained when possible. FTIR data were obtained during the D4 run at 140\% acid for hexamethyl disiloxane (HMDSO), an antifoam decomposition product. The data from the SRAT cycle is shown in Figure 13. Note that many of the spikes in HMDSO concentration follow antifoam additions (see arrows and legend).

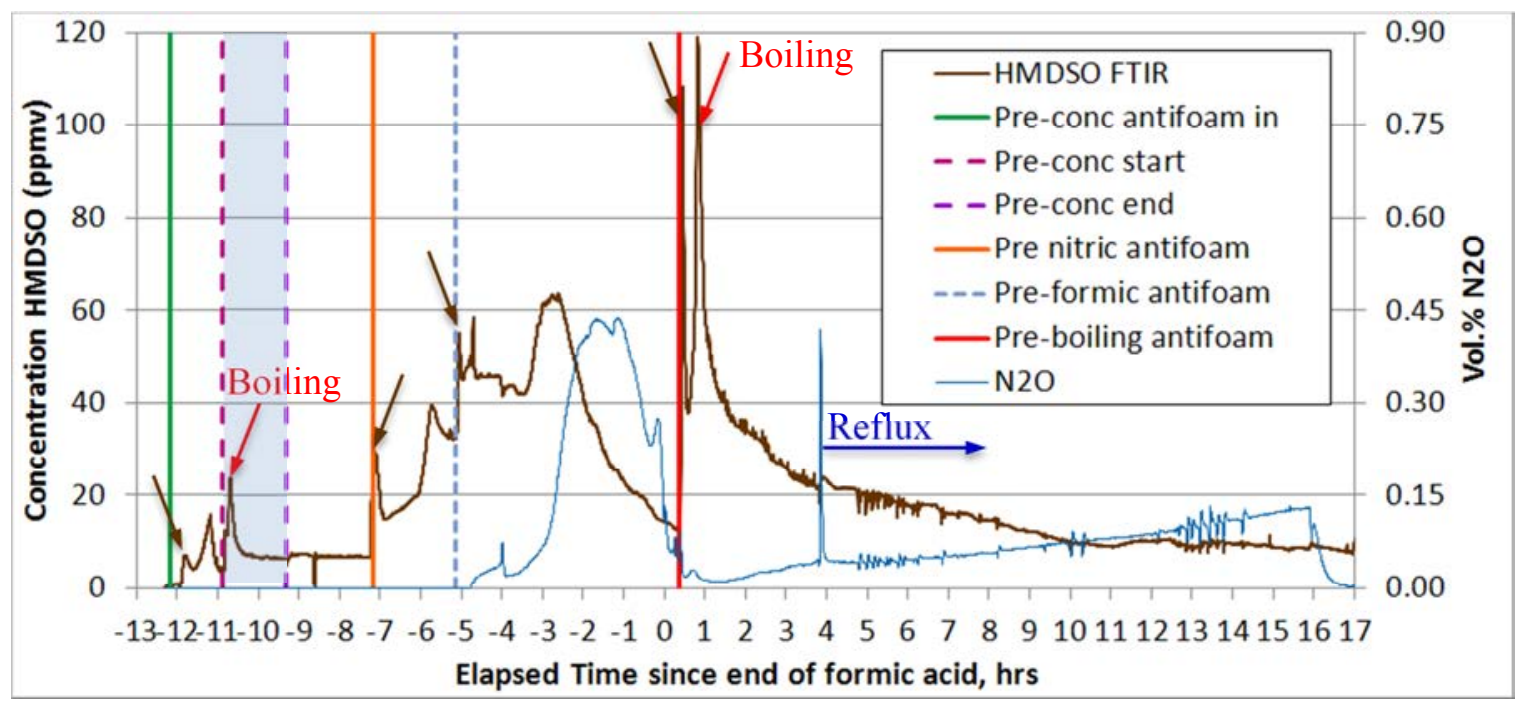

Figure 13. Antifoam Decomposition During D4 SRAT Cycle

HMDSO began showing up in the off-gas while the SRAT was heating up for the preconcentration boiling period ( -12.3 to $-11 \mathrm{hrs})$ following the initial $100 \mathrm{ppm}$ antifoam addition. There was a brief surge in HMDSO as the SRAT went to boiling ( $-10.9 \mathrm{hrs}$, red arrow). This was followed by a fairly steady detection during pre-concentration and a hold at $93{ }^{\circ} \mathrm{C}$ to trim in $\mathrm{HgO}$ and take a sample. Pre-nitric acid addition antifoam $(200 \mathrm{ppm})$ was added at $-7.2 \mathrm{hrs}$ followed by another jump in HDMSO concentration. HDMSO concentration climbed during nitric acid addition before slowing somewhat as the line was flushed with water to ensure $100 \%$ of the desired nitric acid had been added. A $100 \mathrm{ppm}$ antifoam addition was made at $-5.1 \mathrm{hrs}$, or just prior to starting formic acid addition. This addition was also followed by another spike in observed HMDSO. The presence of some formate/formic acid raised the HMDSO concentration to the highest level since the test began.

Nitrous oxide was observed after formic acid addition began, and it was included on the graph to put the HDMSO behavior in the context of other SRAT chemistry. Observed HDMSO began to fall as $\mathrm{N}_{2} \mathrm{O}$ moved toward its maximum concentration at about -1.5 hours. SRAT $\mathrm{pH}$ was in the 5 to 3.6 range during the $\mathrm{N}_{2} \mathrm{O}$ peak period, with the minimum $\mathrm{pH}$ occurring at zero hours. It appears that antifoam was competing with nitrite ion and/or $\mathrm{MnO}_{2}$ for the incoming formic acid resulting in a decreasing HDMSO off-gas concentration with time during the latter part of formic 
acid addition (the SRAT was acidic in $\mathrm{pH}$ at this time). It is also possible that the HMDSO in the off-gas was declining because there was significant on-going depletion of the HMDSO/antifoam concentrations in the slurry. In other words, that the generation rate of HMDSO vapor was falling because the rate of HMDSO generation in the slurry depended on the concentration of remaining antifoam, which was falling, and the rate of decline was very significant during formic acid addition (relative to the amount of antifoam present at the time).

At $0.37 \mathrm{hrs}$ after formic acid addition, a $500 \mathrm{ppm}$ antifoam addition was made at $93{ }^{\circ} \mathrm{C}$, after which the SRAT temperature was increased to boiling (boiling start was at +0.7 hours). HMDSO spiked twice, once after the actual antifoam addition (brown arrow) and a second time when the SRAT went to boiling (dewatering; red arrow). ${ }^{2}$ HMDSO concentration then slowly declined during the remainder of the SRAT. The onset of reflux at +3.8 hours (very obvious in the $\mathrm{N}_{2} \mathrm{O}$ data) was marked by a small dip and spike in the HDMSO of fairly minor significance. If the MWWT had significant HMDSO accumulated in it during dewatering, then its presence was not overly obvious when reflux was started and any accumulated HDMSO was returned to the SRAT.

The general decline in HMDSO concentration during boiling could be due to cumulative destruction of the antifoam (loss of reactant), but it could also be due to the slow destruction of excess formic acid during reflux (formic acid is presumably one of the compounds that is attacking the antifoam chemically, and potentially catalytically, in addition to any thermal degradation). HMDSO continued to be detected after the SRAT was cooling down for sampling following the completion of the refluxed boiling period.

A crude material balance was attempted for HMDSO. A sustained loss of $20 \mathrm{ppm}(0.002 \mathrm{vol} \%)$ HMDSO in the SRAT air purge is roughly $0.24 \mathrm{~g}$ over a 30 hour period. For antifoam at molecular weight $550-600$, one HMDSO molecule represents about $30 \%$ of one antifoam molecule, so $0.24 \mathrm{~g}$ of HMDSO equates roughly to $0.8 \mathrm{~g}$ of decomposed antifoam. During the D4 SRAT cycle, about $3.0 \mathrm{~g}$ of neat antifoam was added to the vessel, so such a loss to HMDSO corresponds to $25-30 \%$ of the antifoam being broken down based on by-products detected in the off-gas. This is a very rough number simply intended to give an order of magnitude sense to the data being presented here and, in this case, to show that the antifoam loss to HMDSO represents a significant fraction of the total SRAT antifoam. A more refined calculation of HMDSO mass using the actual time-dependent concentrations, interpolated helium concentrations, and helium purge flow is possible, but this has not been done.

Foaming was not observed during the test, so presumably the effectiveness of the antifoam was sufficient to prevent foaming in spite of the decomposition of a portion of the antifoam to produce the HMDSO. The correlation between spikes in HMDSO with antifoam additions suggests that a portion (all?) of the antifoam undergoes a chemical transformation shortly after it is introduced to the simulant slurry. As with any new type of data, the interpretation presented here should be considered preliminary until more is learned about the chemical behavior of antifoam during CPC processing and how the HDMSO off-gas data relates to antifoam degradation.

\footnotetext{
${ }^{2}$ Note that the transition to boiling typically purges the SRAT head-space of accumulated off-gas species and replaces them (and much of the purge air) with steam which causes surges that are seen in the graphs for many off-gas species, not just HMDSO. This surge is not a surge in "generation rate" by which is meant the formation rate of the species from whatever reactants are involved. Instead, it is a manifestation of a process dynamics effect (an abruptly reduced residence time). Conversely, while the effective SRAT head space purge rate (air purge plus steaming boil-up rate) is fairly constant ( $99 \%$ of the time), the off-gas analysis does reflect the species generation rate by formation from the reactant(s).
} 
The concentration of $\mathrm{Si}$ in the SRAT condenser condensate held fairly constant during boiling following formic acid addition during D4. The dewater condensate collected in the first 3.5 hours of boiling was at $230 \mathrm{mg} \mathrm{Si} / \mathrm{L}$, while the aqueous phase in the MWWT at the end of the SRAT cycle was at $234 \mathrm{mg} \mathrm{Si} / \mathrm{L}$. This $\mathrm{Si}$ is likely due to antifoam decomposition compounds such as HMDSO that were partially condensable. The magnitude and rate of change varied noticeably from run to run, Table 3-22. SRAT dewater condensate is nearly a liter in these runs, so 200 $\mathrm{mg} / \mathrm{L}$ of $\mathrm{Si}$ is about $200 \mathrm{mg}$ of $\mathrm{Si}, \mathrm{Si}$ is $34.6 \%$ of HMDSO, so $200 \mathrm{mg}$ of $\mathrm{Si}$ is potentially equivalent to $1.9 \mathrm{~g}$ of antifoam (a significant fraction of $\sim 3 \mathrm{~g}$ ) assuming that it is in a species such as HMDSO (vaporized silicic acid from sludge Si that is condensed in the SRAT condenser is an alternate source for condensate Si that cannot be ruled out a priori). The conclusion, however, is that further investigation of the nature of the Si species in the SRAT dewater condensate appears to be warranted in the context of understanding antifoam decomposition.

Table 3-22. Condensate $\mathrm{Si}, \mathrm{mg} / \mathrm{L}$

\begin{tabular}{|l|c|c|c|c|c|}
\hline & D1 & D2 & D3 & D4 & D5 \\
\hline KMA factor & $105 \%$ & $140 \%$ & $120 \%$ & $140 \%$ & $120 \%$ \\
\hline Post-acid supernate & 20 & 23 & 23 & 26 & 30 \\
\hline SRAT dewater cond. & 76 & 350 & 150 & 230 & 110 \\
\hline MWWT aqueous & 75 & 200 & 90 & 230 & 370 \\
\hline FAVC condensate & 160 & 310 & 370 & 450 & 220 \\
\hline
\end{tabular}

To the extent that $\mathrm{Si}$ is a marker for antifoam fragments, the above data do suggest that there was increasing loss of antifoam with increasing acid stoichiometry (D1 $<$ D3 $<$ D2, D4) for the sludge-only flowsheet. The coupled flowsheet run, D5, appeared to be similar to the matching sludge-only flowsheet run, D3.

Acid stoichiometry impacted other species found in the SRAT dewater condensate as seen in previous testing, Table 3-23

Table 3-23. SRAT Dewater Condensate Anions

\begin{tabular}{|l|c|c|c|c|c|}
\hline & $\mathrm{D} 1$ & $\mathrm{D} 2$ & $\mathrm{D} 3$ & $\mathrm{D} 4$ & $\mathrm{D} 5$ \\
\hline KMA factor & $105 \%$ & $140 \%$ & $120 \%$ & $140 \%$ & $120 \%$ \\
\hline Nitrate, $\mathrm{mg} / \mathrm{L}$ & 8,830 & 370 & 2,380 & 1,320 & 7,500 \\
\hline Nitrite, $\mathrm{mg} / \mathrm{L}$ & 450 & $<100$ & $<100$ & $<100$ & $<100$ \\
\hline Formate, $\mathrm{mg} / \mathrm{L}$ & $<100$ & $<100$ & $<100$ & $<100$ & 4,520 \\
\hline
\end{tabular}

The presence of significant formate ion in the coupled flowsheet condensate stood out as a distinctly different result from the four sludge-only condensates. Formate is normally seen in the 100 's-1000's $\mathrm{mg} / \mathrm{L}$ in the SRAT dewater condensate from all runs. The sludge-only runs are the tests that appear to be different from historical behavior. Reduced loss of formate ion to the SRAT dewater condensate, however, likely has minimal negative consequences for DWPF.

Generally, nitrate and nitrite concentrations increased in the condensate as acid stoichiometry decreased for sludge-only tests. This correlates with the concentration of SRAT supernate nitrite surviving to the end of formic acid addition, Table 3-24. The majority of the SRAT nitrite remaining after formic acid addition is converted to gaseous oxides of nitrogen during dewatering, i.e. during the next 3-4 hours after formic acid addition. Fresh nitrite and nitrate are formed from $\mathrm{NO}_{\mathrm{x}}$ absorption in the SRAT condenser and accumulated in the SRAT dewater condensate. 
Because of the low condensate $\mathrm{pH}$, much of the absorbed nitrite is subsequently converted to nitrate and $\mathrm{NO}_{\mathrm{x}}$. Suspicious analytical results (those not consistent with the body of analytical results) were tabulated using a reduced font size to indicate that they should not form the basis for any conclusions related to processing.

Table 3-24. SRAT Supernate Anions (after formic), mg/L

\begin{tabular}{|l|r|r|r|r|r|}
\hline & \multicolumn{1}{|c|}{ D1 } & \multicolumn{1}{c|}{ D2 } & \multicolumn{1}{c|}{ D3 } & \multicolumn{1}{c|}{ D4 } & \multicolumn{1}{c|}{ D5 $^{1}$} \\
\hline KMA factor & $105 \%$ & $140 \%$ & $120 \%$ & $140 \%$ & $120 \%$ \\
\hline Nitrate & 30,650 & 42,700 & 33,050 & 38,000 & 67,000 \\
\hline Nitrite & 6,050 & $<100$ & 530 & $<100$ & 2,920 \\
\hline Formate ${ }^{2}$ & 60,800 & 84,400 & 69,400 & 89,500 & 137,500 \\
\hline Sulfate & 2,010 & 2,500 & 2,280 & 2,600 & 3,440 \\
\hline Oxalate & 1,130 & 2,330 & 1,120 & 1,900 & 1,380 \\
\hline Chloride & 230 & 220 & 180 & $<100$ & 530 \\
\hline
\end{tabular}

1 - the anion results for D5 supernate are not credible based on known feed and acid masses and compositions (about double expected values; also see Table 3-25 for slurry anions)

2 - formate results seem to be high

Caustic quenched slurry samples were also taken following formic acid addition, at two points in the middle of boiling, and once just before the end of the SRAT reflux period. Results for the slurry after acid addition, Table 3-25, were expected to closely track those of the supernate sample above after the necessary corrections for insoluble solids mass and density were made. Oxalate is an exception, since the sodium in the caustic quench could impact oxalate solubility. For example, taking D1 nitrate: [(30,650 mg nitrate/L supernate $) /(\sim 1.1 \mathrm{~kg} / \mathrm{L}$ supernate $)]^{*}(\sim 0.87$ $\mathrm{kg}$ supernate $/ \mathrm{kg}$ slurry $)=24,240 \mathrm{mg} / \mathrm{kg}$ which is acceptably close to $22,450 \mathrm{mg} / \mathrm{kg}$ in Table $3-25$ for D1 nitrate. The results in Table 3-25 have been corrected for the dilution from causticquenching (about $7-8 \%$ of the sample is added caustic solution at approximately $1 \mathrm{M}$ ).

Table 3-25. SRAT Slurry Anions (after formic), mg/kg

\begin{tabular}{|l|r|r|r|r|r|}
\hline & \multicolumn{1}{|c|}{$\mathrm{D} 1$} & \multicolumn{1}{c|}{$\mathrm{D} 2$} & \multicolumn{1}{c|}{$\mathrm{D} 3$} & \multicolumn{1}{c|}{ D4 } & \multicolumn{1}{c|}{ D5 } \\
\hline KMA factor & $105 \%$ & $140 \%$ & $120 \%$ & $140 \%$ & $120 \%$ \\
\hline Nitrate & 22,450 & 31,080 & 27,630 & 31,890 & 27,060 \\
\hline Nitrite & $2,640^{3}$ & $<500$ & 1,000 & $<500$ & 1,480 \\
\hline Formate & 49,030 & 59,500 & 55,850 & $72,250^{1}$ & 58,940 \\
\hline Added formate lost, \% & 17 & 20 & 15 & 3 & 12 \\
\hline Sulfate & 1,000 & 880 & 800 & 860 & 970 \\
\hline Oxalate & 650 & 800 & 300 & 1080 & 350 \\
\hline Chloride $^{2}$ & 190 & 190 & $<100^{2}$ & 200 & $<100^{2}$ \\
\hline
\end{tabular}

1 - The D4 formate result appears unrealistically high (and loss \% unrealistically low)

2 - Chloride is expected to be near $200 \mathrm{mg} / \mathrm{kg}$

3 - D1 nitrite appears to be low based on off-gas data

In D3, caustic-quenching seemed to preserve nitrite, while in D1, the caustic-quenched slurry nitrite value is clearly lower than the supernate equivalent value. Off-gas data for D1 indicate that potentially less than half the starting nitrite $(16,000 \mathrm{ppm}$ after pre-concentration) had been destroyed by the end of formic acid (when these samples were taken). Therefore, the D1 nitrite in Table 3-24 is probably a more credible result than the value in Table 3-25. 
Sulfate solubility appeared to suffer in the caustic-quenched samples as a group compared to the supernate samples. Starting slurry sulfate was at $1,850 \mathrm{mg} / \mathrm{kg}$ slurry by IC. If $100 \%$ was in solution that would equate to about $2,200 \mathrm{mg} / \mathrm{L}$ following pre-concentration. Acid addition caused about a $12-18 \%$ dilution of the starting feed depending on stoichiometry, so post acid addition sulfate of about $1,900 \mathrm{mg} / \mathrm{L}$ supernate would be roughly the expected value at full solubility, which is similar to Table 3-24 though somewhat lower, but not similar to Table 3-25. Even though the caustic-quenched samples underwent a large weighted dilution with water $(100 x)$ prior to IC analysis, the sulfate results were about half that of the supernate anion samples. The primary difference would appear to be that the supernate samples were acidic in $\mathrm{pH}$, while the weighted dilution caustic-quenched slurry samples were mildly basic. It is not clear why the weighted dilution IC method produced $1,850 \mathrm{mg} / \mathrm{kg}$ in the caustic starting simulant and only 800 $1000 \mathrm{mg} / \mathrm{kg}$ in the caustic-quenched post-acid addition slurry samples. Potentially, cations dissolved during acid addition may have been able to form water insoluble sulfates following caustic-quenching that were not present/possible in the starting simulant.

Comparing Table 3-24 with Table 3-25 shows that there are issues with formate results in the two $140 \%$ stoichiometry runs in Table 3-25 which should be fairly similar. The formate concentration could be as high as $75,000 \mathrm{mg} / \mathrm{kg}$ if none of the added formate had been destroyed by the end of acid addition (not true, but it gives an upper bound for formate concentration). The loss indicated for D2 of $20 \%$ is far more consistent with the bulk of the data and the observed $37 \%$ overall SRAT formate loss than the $<4 \%$ loss indicated for D4. While the two results in Table 3-24 for D2 and D4 formate are similar, they are not credible either. They correspond to roughly $69,000 \mathrm{mg} / \mathrm{kg}$ slurry or an $8 \%$ formate loss by the end of acid addition. Off-gas $\mathrm{CO}_{2}$ data indicate that the majority of formate loss occurs during acid addition at high acid stoichiometric factors.

None of the $<100 \mathrm{mg} /(\mathrm{kg}$ or $\mathrm{L})$ values for chloride are considered credible (values should be $\sim 200$ $\mathrm{mg} /(\mathrm{kg}$ or $\mathrm{L})$ ). $\mathrm{RuCl}_{3}$ is the main source of chloride in the simulant, and other sample data confirm the approximate equivalence of the five runs with respect to chloride ion concentration. Far more credible values are reported for the caustic-quenched D5 slurry sample in Table 3-25 than for the supernate sample.

Caustic-quenched slurry samples were taken about one-third and two-thirds of the way between the end of regular dewatering and the end of the SRAT cycle (for example, if the SRAT was refluxed for twelve hours, the samples were pulled at four hours and eight hours into reflux). The values were expected to be fairly close to those of the SRAT product given in Table 3-10, since the total slurry mass was nearly constant during the last two-thirds of reflux. Formate and nitrate were expected to fall slightly with time as they react to form hydrogen, $\mathrm{CO}_{2}, \mathrm{NO}_{\mathrm{x}}$, and ammonia. The results are generally as expected to within about $\pm 10 \%$. As with the earlier results, oxalate values represent a lower limit on the total oxalate in the system, since much of the oxalate is present in insoluble solid form during reflux. 
Table 3-26. SRAT Slurry Anions (1/3), mg/kg

\begin{tabular}{|l|r|r|r|r|r|}
\hline & \multicolumn{1}{|c|}{ D1 } & \multicolumn{1}{c|}{ D2 } & \multicolumn{1}{c|}{ D3 } & \multicolumn{1}{c|}{ D4 } & \multicolumn{1}{c|}{ D5 } \\
\hline KMA factor & $105 \%$ & $140 \%$ & $120 \%$ & $140 \%$ & $120 \%$ \\
\hline Nitrate & 33,100 & 40,600 & 37,500 & 40,300 & 34,200 \\
\hline Nitrite & $<500$ & $<500$ & $<500$ & $<500$ & $<500$ \\
\hline Formate & 63,400 & 70,200 & 71,600 & 79,000 & 69,800 \\
\hline Sulfate & 1,390 & 1,290 & 1,140 & 1,300 & 1,200 \\
\hline Oxalate & 500 & 800 & 400 & 1,000 & 500 \\
\hline Chloride & 275 & 250 & 275 & 275 & 250 \\
\hline
\end{tabular}

The effect of dewatering was to increase the concentrations of most anions (except nitrite) relative to their concentrations at the end of acid addition. Note that in the coupled flowsheet run, D5, a dilute nitric acid simulant for the MCU strip effluent was being added and simultaneously dewatered, whereas the other four runs were in reflux. So a gradual increase in nitrate might have been seen in D5 (it did, but not until the SRAT product samples), while volatile species might have been slowly lost in the dewater condensate.

Table 3-27. SRAT Slurry Anions (2/3), mg/kg

\begin{tabular}{|l|r|r|r|r|r|}
\hline & \multicolumn{1}{|c|}{ D1 } & \multicolumn{1}{c|}{ D2 } & \multicolumn{1}{c|}{ D3 } & \multicolumn{1}{c|}{ D4 } & \multicolumn{1}{c|}{ D5 } \\
\hline KMA factor & $105 \%$ & $140 \%$ & $120 \%$ & $140 \%$ & $120 \%$ \\
\hline Nitrate & 33,800 & 39,300 & 36,300 & 39,100 & 32,400 \\
\hline Nitrite & $<500$ & $<500$ & $<500$ & $<500$ & $<500$ \\
\hline Formate & 63,300 & 68,800 & 69,100 & 79,500 & 65,100 \\
\hline Sulfate & 1,350 & 1,300 & 1,170 & 1,280 & 1,100 \\
\hline Oxalate & 400 & 700 & 500 & 800 & 500 \\
\hline Chloride & 275 & 250 & 275 & 275 & 250 \\
\hline
\end{tabular}

Nitrate ion concentration was trending downwards during reflux, especially in the two $140 \%$ acid stoichiometry runs (most reactive runs). Formate in D5 jumped back up in the SRAT product, so the D5 data do not indicate an evaporative loss of any significance during the MCU dewatering.

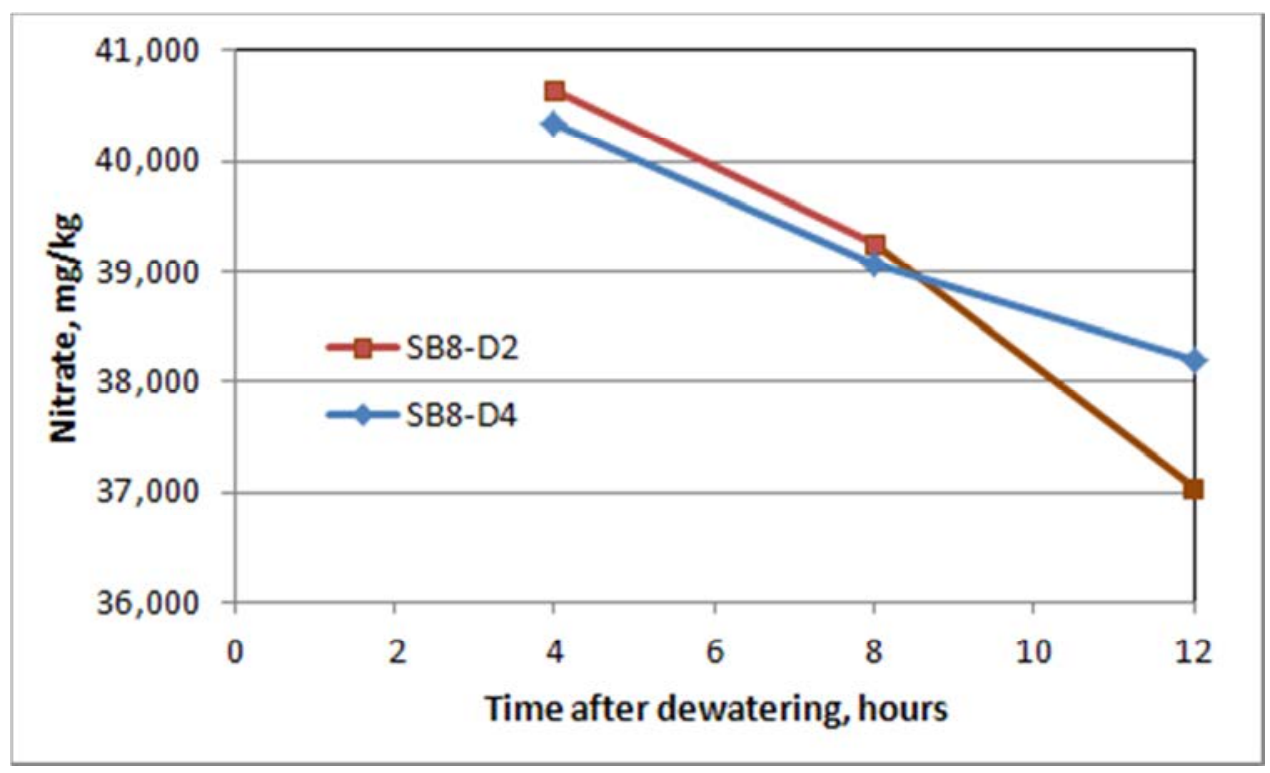




\section{Figure 14. Rate of Nitrate Loss at High Acid Stoichiometry}

The nitrate loss was on the order of 3,000 ppm in eight hours of boiling in the two high acid runs. The implication is that extended time at high temperature in the SME cycle (40-50 hours) could significantly deplete the nitrate ion concentration of the melter feed in the presence of excess acid and noble metal catalysts.

The $\mathrm{pH}$ profiles from the five flowsheet runs are shown in Figure 15.

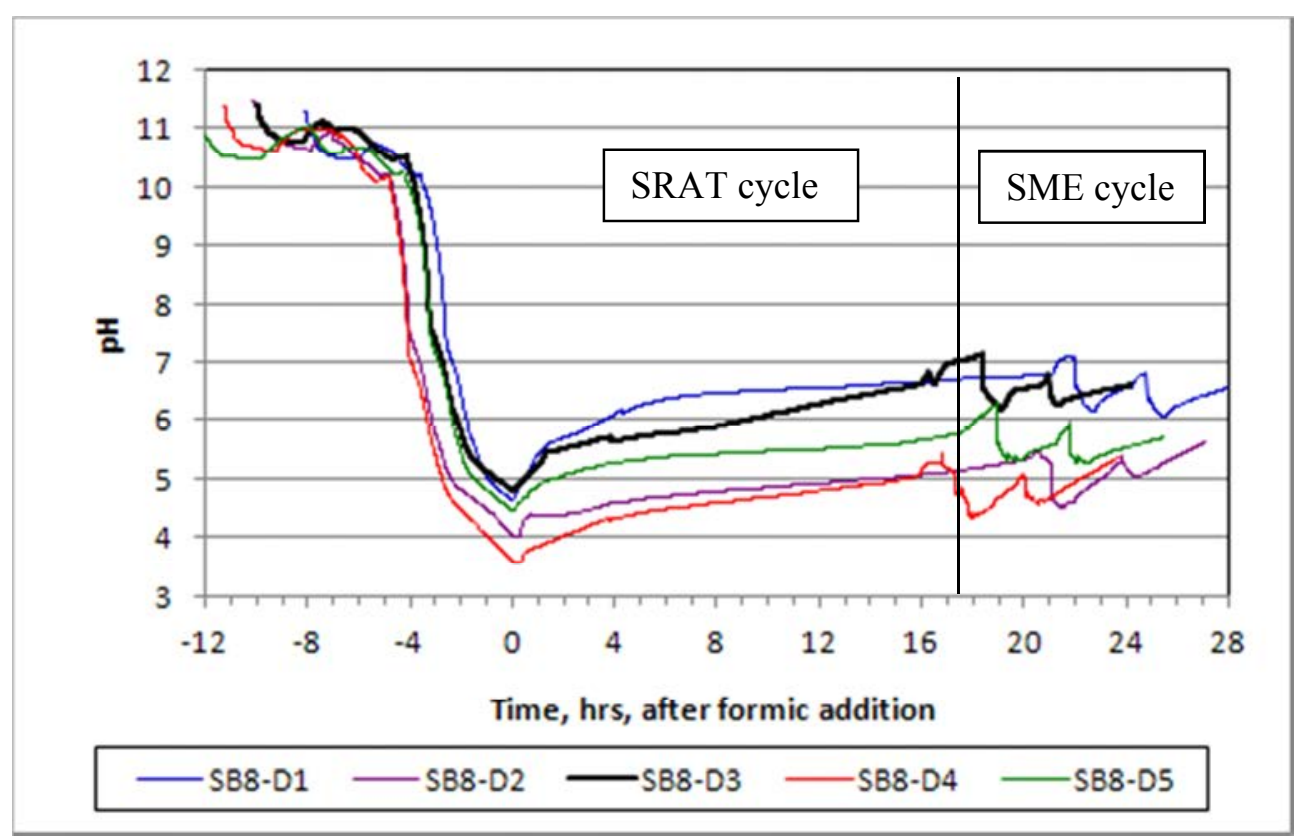

Figure 15. SRAT/SME pH Profiles

The two $140 \%$ stoichiometry runs reached minimum $\mathrm{pH}$ readings in the $3.6-4.0$ range at the end of formic acid addition. The sludge-only and coupled runs at $120 \%$ reached minimum $\mathrm{pH}$ values in the mid 4's, which is more typical and less likely to be followed by excessive hydrogen generation. The $\mathrm{pH}$ rose by at least one unit from the end of acid addition to the end of the SRAT cycle in all five runs. This is typical of runs with moderate catalytic activity. It represents the catalytic destruction of excess formic acid in most runs, although at low acid stoichiometry formic acid is still being consumed in nitrite destruction and manganese reduction during boiling. The SME products at boiling temperature were all at $\mathrm{pH}$ values less than 7 , although values slightly above 7 occurred during processing (and the SME products at room temperature had higher $\mathrm{pH}$ values). There appeared to also be some correlations between $\mathrm{pH}$ and power demand (SRAT heat input). These are discussed a little later in this section.

Data are presented in Figure 16 for the SRAT/SME vessel mixer torque as a function of time. 


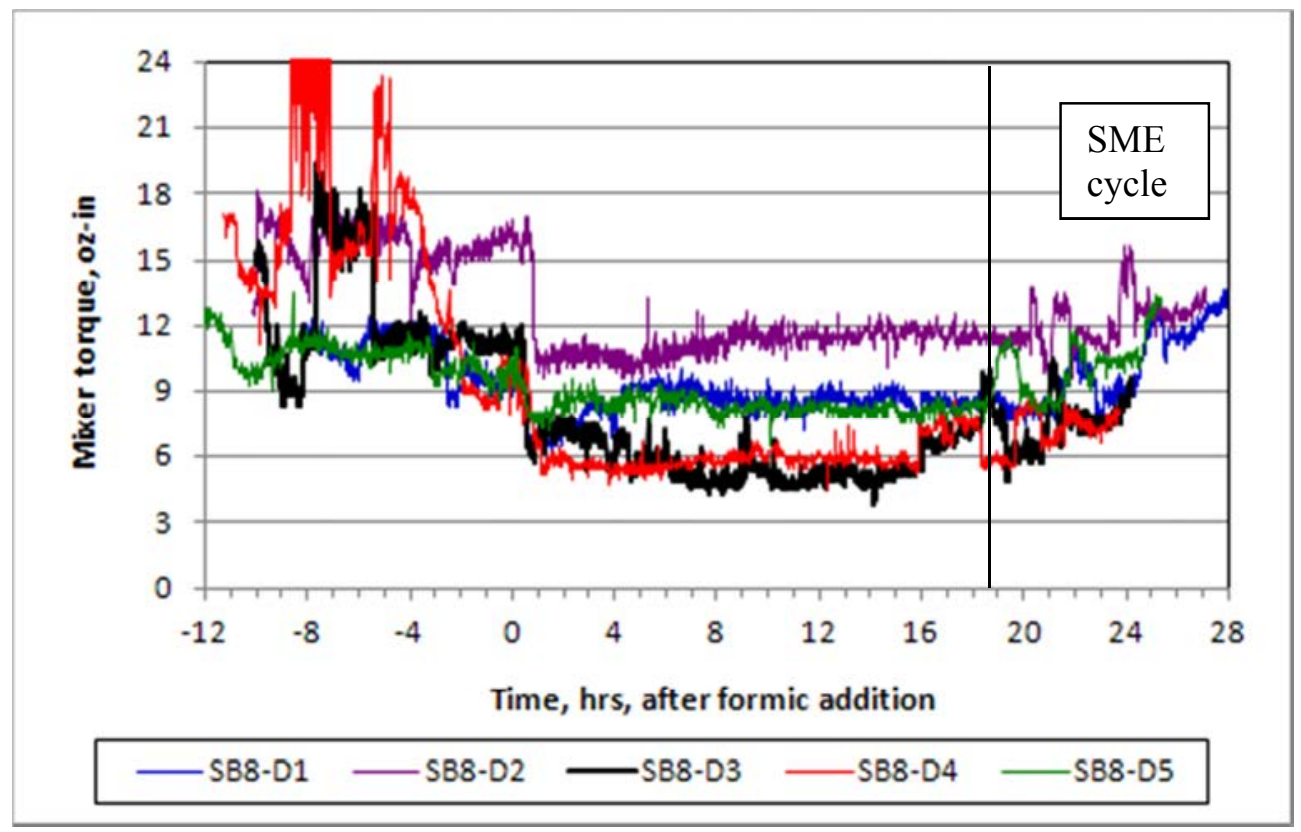

Figure 16. Mixer Torque as a Function of Time

There appeared to be some impact of pre-concentration on mixer torque (around -8 to -10 hours). Mixer torque was fairly constant through acid addition, although in a few runs it appeared that there was a small drop around the time that acid addition switched over from nitric to formic. There was a significant drop in mixer torque as the SRAT went to boiling following acid addition (this may be a density induced shift due to the water vapor phase). Torque remained fairly constant during SRAT boiling, and began increasing in the SME cycle as frit was added and as the slurry was concentrated to its final wt.\% solids target.

Data was obtained for the heat input to the heating rods. During boiling, the heat input is controlled, and the data are essentially horizontal lines, but during acid addition the heat demand responds to the chemical reactions occurring with the acids. The data were challenging to interpret at as a function of time, so the data are plotted as a function of decreasing $\mathrm{pH}$ (which is sort of in the same sense as time, since $\mathrm{pH}$ falls continuously during acid addition), Figure 17. The SB8-D2 power draw feature around $\mathrm{pH}$ of 9-9.5 is unique at this point, and the reason for it is unknown. 
SRNL-STI-2013-00106

Revision 0

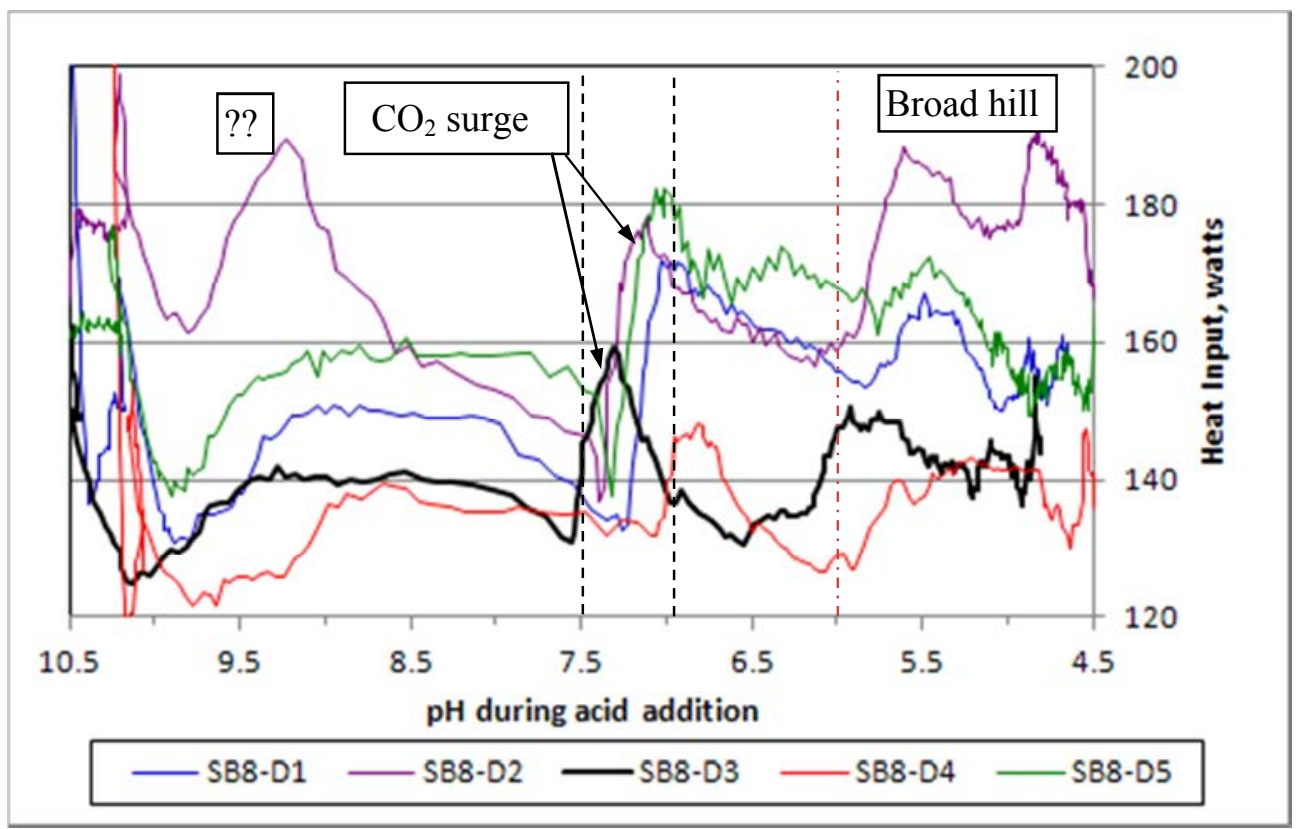

Figure 17. SRAT Heat Input during Acid Addition

There is some variability in $\mathrm{pH}$ probe calibration and behavior during processing. Plotting $\mathrm{CO}_{2}$ versus $\mathrm{pH}$, Figure 18, showed that carbonate destruction occurred at about 7-7.5 pH as measured by individual probes, but presumably it initiated at the same actual $\mathrm{pH}$ in all five runs.

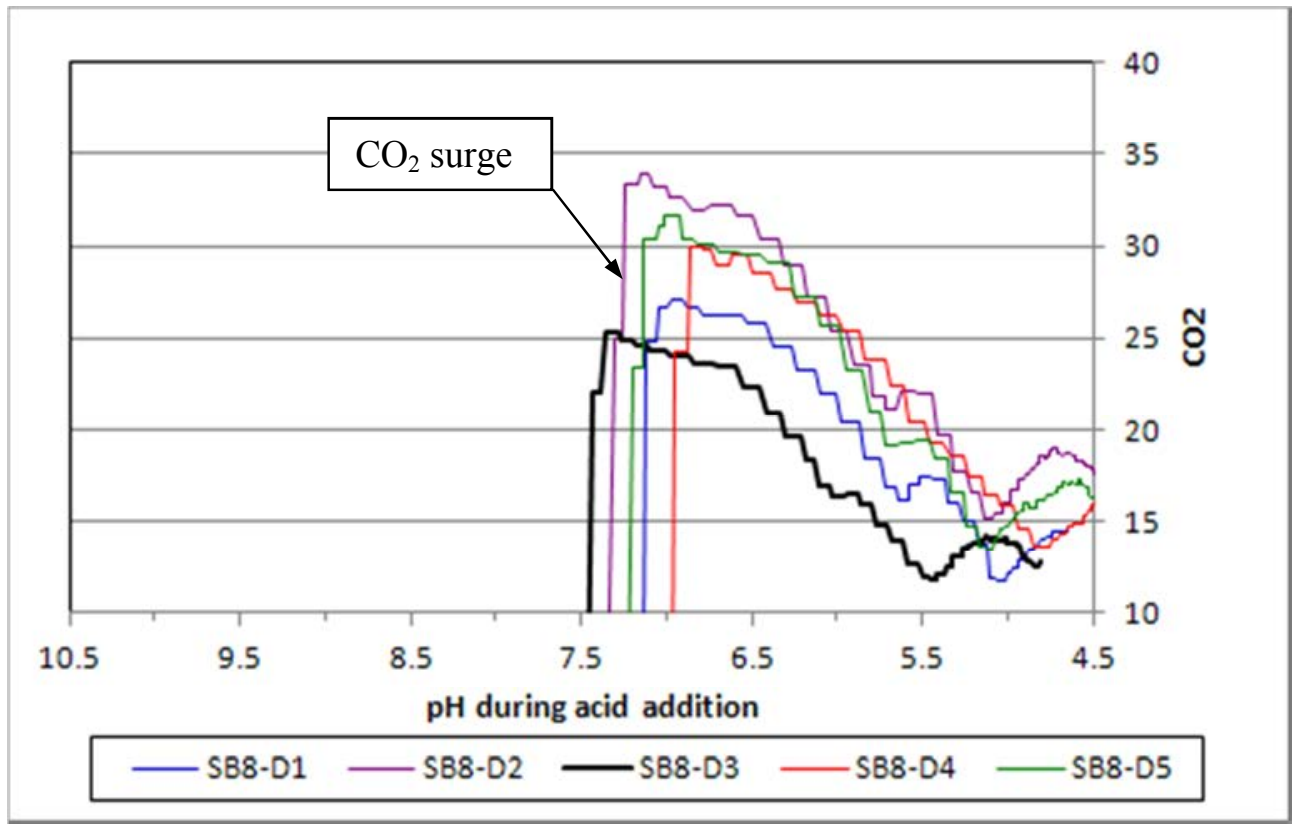

Figure 18. $\mathrm{CO}_{2}(\mathrm{vol} \%)$ Release as a Function of pH Probe Reading

There is a clear indication of increased power draw (roughly 15-30 watts) in Figure 17 for each of the five runs at about the same $\mathrm{pH}$ reading (7-7.5) as the surge in $\mathrm{CO}_{2}$ associated with carbonate destruction. The power draw peaked and started declining in much the same way as the $\mathrm{CO}_{2}$ varied with $\mathrm{pH}(\mathrm{pH}>6.3)$. Presumably some of the lack of alignment in the power curves is 
associated with the lack of alignment in the $\mathrm{CO}_{2}-\mathrm{pH}$ data. The change in power draw varied from run to run. All runs except D5 had identical masses of starting carbonate to the extent it was possible to put equal, representative masses of the SB8-Tank 40 simulant in the SRAT vessel (certainly there were no $10-50 \%$ sized variations in concentrations of selected feed species). A hypothesis for why the power draw varied from run to run during this period is still needed.

A second period of increased power draw appeared to come at about $\mathrm{pH} 6.0$ and to continue until $\mathrm{pH}$ had fallen into the 4's. No matching event in the off-gas data coincided as cleaning with this time like occurred with the $\mathrm{CO}_{2}$ surge from carbonate destruction. A possible interpretation is that one of the overall reactions toward the latter half of formic acid addition (Mn reduction or nitrite destruction for example) is made up of several reaction steps in series. An early (potentially the first) reaction step is endothermic and has no associated gas release, while a subsequent step is not particularly energetic, but needs a lower $\mathrm{pH}$ to proceed, and is associated with observed gas release (e.g. $\mathrm{NO}_{\mathrm{x}}, \mathrm{N}_{2} \mathrm{O}$, and/or $\mathrm{CO}_{2}$ ).

The SRAT configuration used in these tests has a pair of heating rods to supply the power instead of the external heating mantle configuration used in the 1990-2011 time frame. The rods have internal temperature sensors and known heated areas. It is therefore possible to calculate a heat transfer coefficient, $\mathrm{h}$, from the rod-slurry temperature difference, $\Delta \mathrm{T}$; power draw, $\mathrm{Q}$; and known heated rod area, $\mathrm{A} ; \mathrm{h}=\mathrm{Q} /(\mathrm{A} \Delta \mathrm{T})$. The calculated heat transfer resistance is essentially the slurry film heat transfer coefficient on the outside rod area. The relative resistance of the rod wall is negligible in the context of the accuracy of the overall heat transfer process. The resulting heat transfer coefficient calculation was performed at each measurement time, and the results are graphed in Figure 19 for the five flowsheet runs.

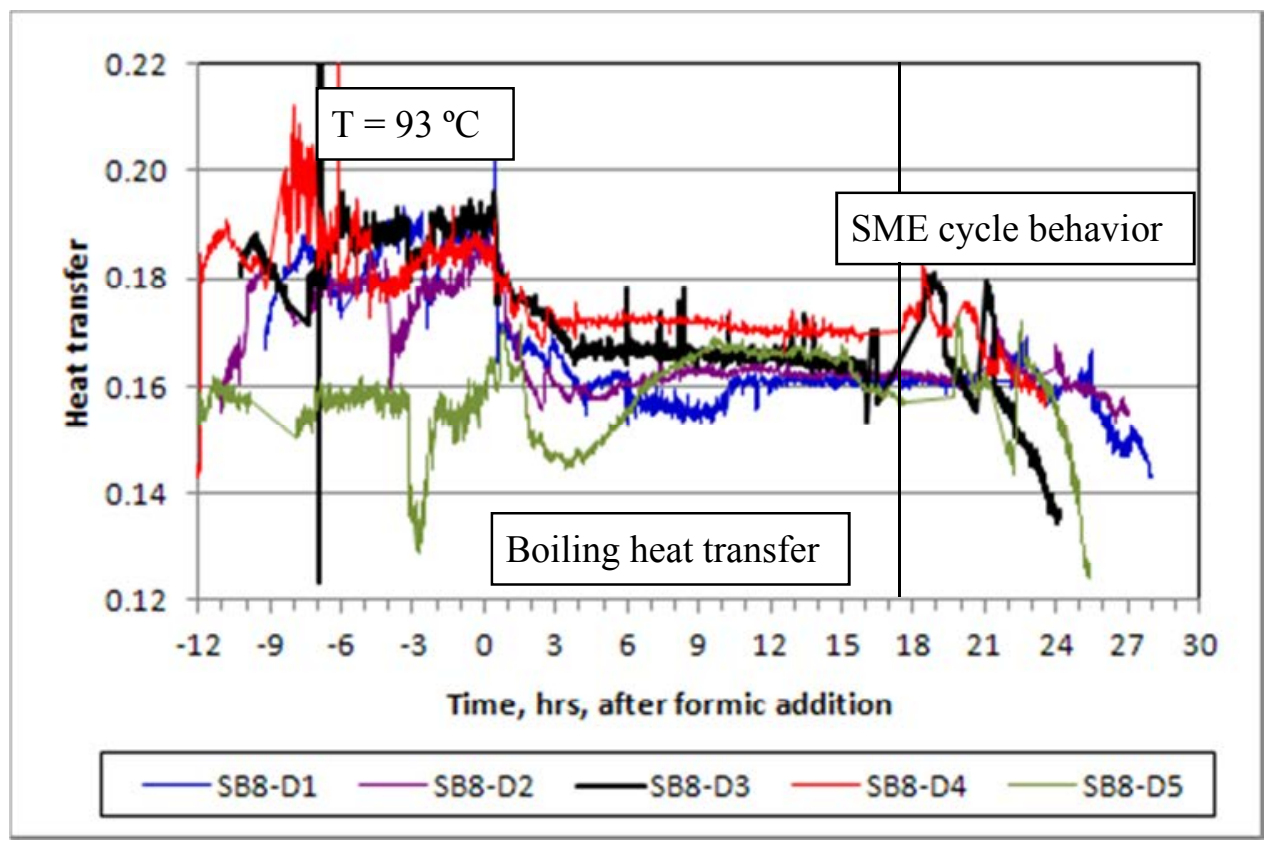

Figure 19. Slurry Film Heat Transfer Coefficient as a Function of Processing Time

The heat transfer coefficient values are somewhat noisy (some runs more than others), and there are some lab artifacts. Nevertheless, there is a clear difference between maintaining the SRAT at $93{ }^{\circ} \mathrm{C}$ (0 to -6 hours) where the fluid medium is primarily liquid-solid versus maintaining the SRAT at constant boil-up rate (0.5-15 hours) where the boiling bubbles must be created at or near 
the rod walls. Boiling had a less effective heat transfer coefficient than sensible heat control. A third phenomenon occurred near the end of the SME cycle (20-28 hours depending on run). A further drop in heat transfer coefficient was observed. The effect was largest in SB8-D5 which was concentrated to the highest wt.\% total solids (as well as one of the highest yield stresses). The heat transfer coefficient drop was also fairly large in SB8-D3 which was another run that finished with a relatively high yield stress. In all cases the effective viscosity of the SME slurry was increasing relative to that of the SRAT product slurry that was present at the beginning of the SME cycle. In other words the heat transfer coefficient appeared to fall due to the increasing viscosity of the SME slurry as a function of SME cycle time. No evidence of rod fouling was observed in the heated areas of the rods which were kept wetted by slurry at all times that power was being supplied.

While there was nothing alarming in the SRAT/SME processing data presented in Section 3.2.4, the observed rapid breakdown of at least some of the antifoam immediately following a new antifoam addition appears to warrant further study. If a certain mass of antifoam is fragmented nearly instantaneously as it reaches the slurry, then it is possible that metering in antifoam at a slow rate could cause all the added antifoam to be fragmented as fast as it is added. The question then becomes whether or not the fragmented antifoam is itself a reasonably effective antifoamer. There are suggestions of possible significant unidentified reactions, or of intermediate reactions, in the SRAT power data. More data should be collected and correlated to determine if the trends seen here persist under other conditions (different sludges, different flowsheets).

\subsubsection{SRAT/SME Mercury Results}

Recovery of mercury by steam stripping followed a similar pattern to previous sludge batches and the recent mercury study. ${ }^{19}$ Mercury was collected in the MWWT. Suspended elemental mercury in the SRAT and SME product slurries was analyzed by ICP and is reported relative to the total solids in these slurries in Table 3-28. Suspended mercury was well below the DWPF target of $0.80 \mathrm{wt} \% \mathrm{Hg}$ in the SRAT product slurry total solids in all five flowsheet tests. Additional mercury was usually found on the bottom of the SME vessel after the majority of the slurry had been pumped out for weighing.

Table 3-28. SRAT and SME Product Slurry Mercury

\begin{tabular}{|l|c|c|c|c|c|}
\hline & D1 & D2 & D3 & D4 & D5 \\
\hline SRAT total solids, wt.\% Hg & 0.039 & 0.043 & 0.034 & 0.095 & 0.021 \\
\hline SME total solids, wt.\% Hg & 0.023 & 0.106 & 0.023 & 0.152 & 0.008 \\
\hline
\end{tabular}

The D4 SME product analysis represents $26 \%$ of the starting mercury at the beginning of the SRAT cycle.

Table 3-29. SRAT Mercury Stripping to MWWT

\begin{tabular}{|l|c|c|c|c|c|}
\hline & D1 & D2 & D3 & D4 & D5 \\
\hline Elemental Hg, g & 3.64 & 2.79 & 2.18 & 2.19 & 2.47 \\
\hline \% of starting Hg & 27 & 21 & 21 & 28 & 24 \\
\hline
\end{tabular}

The nominal flowsheet run (D3) MWWT recovery was atypical for lab-scale process simulations. Instead of free settling beads of elemental $\mathrm{Hg}$, either small or large, the $\mathrm{Hg}$ formed a relatively stable suspension of very fine material within the aqueous phase. It was necessary to centrifuge and then dry the collected material in a desicator in order to obtain a mass for mercury recovered. 
Even then, it was a sticky lump, probably not homogeneous, and the mass in Table 3-29 may be a bit overstated. Only after doing this, however, was it possible to confirm that D3 had stripped elemental mercury and recovered a comparable amount to the other runs. Such behavior in DWPF would presumably make recovery of elemental Hg in the MWWT very difficult. The finely dispersed material would probably end up in the Slurry Mix Evaporator Condensate Tank or be refluxed back into the SRAT.

Recovery of elemental mercury in the MWWT was only fair at $20-30 \%$. Generally, nearly $70 \%$ of the mercury added to the sludge prior to the SRAT cycle was not suspended in the product slurry or recovered from the MWWT as elemental mercury. Hg beads were observed in the SME dewater condensate and on the bottom of the vessel after pumping out most of the SME product slurry. The amount varied considerably from run to run but was not a large fraction of the total mercury mass in any run. D3 (nominal run) had the least visible mercury in the SME dewater condensate but finely dispersed $\mathrm{Hg}$ like that seen in the MWWT may have been present and too dispersed to notice.

SRAT dewater condensate showed no visible beads of $\mathrm{Hg}$ in any of the five runs, however there were varying amounts of dissolved mercury detected, Table 3-30. The mercury concentration combined with SRAT dewater condensate mass gave the mass of elemental mercury in the condensate. This does not mean that the mercury itself was in oxidation state zero, only that the calculated result is for the element $\mathrm{Hg}$, and not for a compound of mercury.

Table 3-30. SRAT Mercury Stripping to Dewater Condensate

\begin{tabular}{|l|c|c|c|c|c|}
\hline & D1 & D2 & D3 & D4 & D5 \\
\hline Hg conc. in condensate, $\mathrm{mg} / \mathrm{L}$ & 455 & 2.7 & 59 & 25 & 54 \\
\hline Elemental Hg mass, g & 0.46 & 0.002 & 0.057 & 0.023 & 0.055 \\
\hline \% of starting Hg & 3.4 & 0.02 & 0.56 & 0.29 & 0.53 \\
\hline
\end{tabular}

Mercury in excess of $0.5 \%$ of total available mercury was found in the SRAT dewater condensate from the low and medium acid stoichiometry runs. There was less mercury dissolved in the two high acid stoichiometry (140\%) run condensates, especially D2 (the higher mercury case). Results for the sludge-only and coupled runs at $120 \%$ stoichiometry were nearly identical (D3, D5).

Concentrations of mercury in the aqueous phase of the MWWT at the end of the SRAT cycle were in the $5-500 \mathrm{~g} / \mathrm{mL}$ range (in about $40 \mathrm{~mL}$ ), and the aqueous phase mass was roughly $1 / 20^{\text {th }}$ the SRAT dewater condensate. The peak was $0.2 \%$ of total $\mathrm{Hg}$ in D5. Therefore the dissolved mercury in the MWWT was trivial by the end of the SRAT cycle (from a mercury material balance perspective). Concentrations of mercury in the FAVC condensate were in the 200-350 $\mathrm{mg} / \mathrm{L}$ range. FAVC condensate mass was about half that of the aqueous phase in the MWWT. The dissolved mercury was less than $0.1 \%$ of the total amount added in all five runs. Note that FAVC condensate mercury had to successfully pass through the lab-scale SRAT ammonia scrubber to reach the FAVC.

\subsubsection{SRAT/SME Ammonia Results}

Ammonia release from the SRAT to the off-gas was a good measure of ammonium ion production during SB6, SB7, and SB7b testing, along with nitrate loss in some cases. The 
accumulation of ammonium ion in the ammonia scrubber reservoir (nominally $750 \mathrm{~g}$ of liquid) was tracked by taking samples at the end of the SRAT cycle and end of the SME cycle.

Table 3-31. Ammonia Detection in Scrubber Liquid

\begin{tabular}{|l|c|c|c|c|c|}
\hline & D1 & D2 & D3 & D4 & D5 \\
\hline Acid Stoichiometry (KMA) & $105 \%$ & $140 \%$ & $120 \%$ & $140 \%$ & $120 \%$ \\
\hline After SRAT, mg/L & 9 & $<5$ & 31 & $<5$ & $<1$ \\
\hline After SME, mg/L & 11 & $<5$ & 40 & $<5$ & $<1$ \\
\hline Collected in SME cycle & 2 & 0 & 9 & 0 & 0 \\
\hline SME nitrate loss, \% & 11 & 4 & 3 & 6 & 1 \\
\hline SRAT product pH & 7.92 & 6.10 & 7.56 & 5.68 & 6.67 \\
\hline SME product $\mathrm{pH}$ & 7.60 & 6.57 & 7.44 & 6.64 & 6.78 \\
\hline
\end{tabular}

Nitrate is the assumed source of ammonium ion after nitrite is destroyed. SME nitrate losses were small in the SB8 simulant tests which do not include canister decon water removals and boil at design rates. The processing time to dewater the two frit additions was on the order of five hours at boiling. It may be that some additional testing of SME cycle time at temperature and the impact of that time on nitrate, formate, and ammonia is warranted to gain a better understanding of this phase of DWPF processing. Only limited previous work has been done with canister dewaterings, and perhaps none at all has been done at reduced boiling rates (several SRAT cycles have been performed at reduced boiling rates). First principles kinetic concepts, however, suggest that these reactions will proceed to greater and greater extents as the time near boiling is extended.

Unlike SB6 and SB7, the maximum in ammonium ion production was not seen in the runs at highest acid stoichiometry. Even though the two high acid runs had a calculated nitrate loss of 4$6 \%$ compared to $3 \%$ in the $120 \%$ nominal run, there was no detectable ammonia release captured in the scrubber liquid. This could well be due to the $\mathrm{pH}$ of the high acid runs which were in the low to mid 6's in the SME cycle compared to the mid 7's in the nominal run. The two runs where ammonium was detected in the scrubber corresponded to runs where the SME pH went above 7. DWPF often gets to pH's above 7 in the SME cycle, especially when doing multiple canister decon water additions or low steaming rate operation (long times at temperature). DWPF should anticipate that they will potentially see more ammonium ion production and ammonia in the SRAT and SME off-gas than was seen in the SB8 simulant flowsheet tests. SRNL has started a small program to review the data obtained in SB6, SB7, SB7b, and SB8 and to look for correlations between ammonium ion production and other processing parameters such as noble metals, $\mathrm{Hg}, \mathrm{pH}$, etc.

\subsubsection{SRAT/SME Rheology Results}

Rheological properties of slurries are known to depend on particle size, insoluble solids content, $\mathrm{pH}$, and ionic strength (molarity of ionic charges from cations and anions). For a given insoluble solids matrix, the major factor for SRAT and SME slurries has historically been the wt. \% insoluble solids content. The effect of $\mathrm{pH}$ is not trivial. There is generally a yield stress maximum somewhere in or near the middle $\mathrm{pH}$ region $(\mathrm{pH}$ 6-8). Flow curves were obtained for the five SRAT product slurries and the five SME product slurries from the flowsheet runs. Measurements were made at $25{ }^{\circ} \mathrm{C}$. Previously established flow curve protocols were used. ${ }^{23}$ The SRAT results, fit to the Bingham plastic model, are given in Table 3-32. Wt. \% insoluble 
solids and $\mathrm{pH}$ are given, as well as the measured supernate sodium molarity (representing the major soluble cation, and thus giving an order of magnitude sense of ionic strength).

Table 3-32. SRAT Product Slurry Rheology

\begin{tabular}{|l|c|c|c|c|c|}
\hline Run & $\begin{array}{c}\text { Yield } \\
\text { Stress } \\
\mathrm{Pa}\end{array}$ & $\begin{array}{c}\text { Plastic } \\
\text { Viscosity } \\
\mathrm{cP}\end{array}$ & $\begin{array}{c}\text { Wt. \% } \\
\text { Insoluble } \\
\text { Solids }\end{array}$ & $\mathrm{pH}$ & $\begin{array}{c}{[\mathrm{Na}]} \\
\mathrm{M}\end{array}$ \\
\hline D1 & 0.79 & 5.2 & 13.6 & 7.9 & 2.2 \\
\hline D2 & 0.40 & 4.4 & 11.8 & 6.1 & 2.0 \\
\hline D3 & 0.79 & 5.0 & 12.8 & 7.6 & 2.2 \\
\hline D4 & 0.38 & 4.4 & 11.7 & 5.9 & 2.1 \\
\hline D5 & 0.75 & 7.4 & 16.4 & 6.7 & 2.4 \\
\hline
\end{tabular}

Effects due to wt. \% insoluble solids, $\mathrm{pH}$, and sodium molarity appear to be present in the data (JMP statistical software found them to be of roughly equal significance in explaining variation between runs, and putting three variables (four constants) into a model to explain five data points is of little practical value). The yield stress values are actually lower than DWPF would want to run particularly if there were any larger dense particles in the slurry. Once in motion, these slurries are not too different from Newtonian liquids with 5-10 cP viscosities (whole milk or cream type viscosity), Figure 20. There could be issues with large particles dropping out in horizontal flow at these yield stress values.

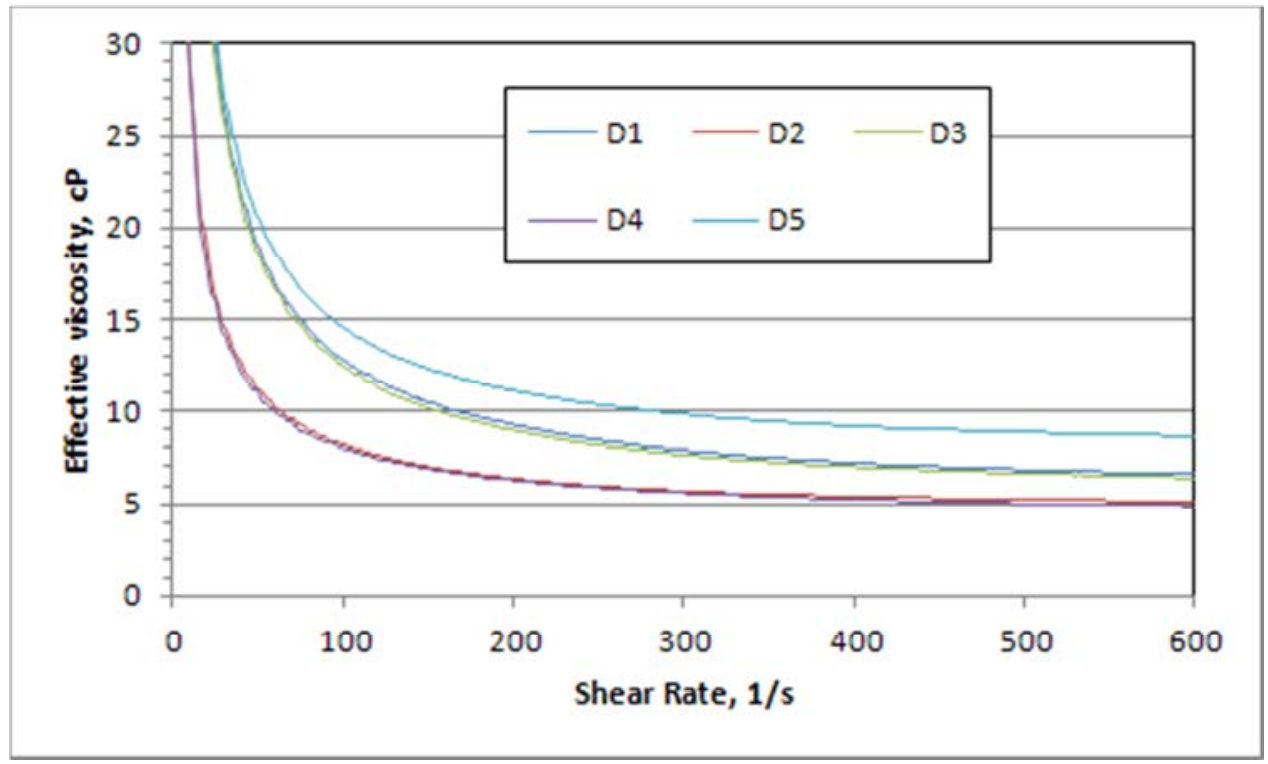

Figure 20. Effective Viscosity of SRAT Product Slurries

Figure 20 is not the normal presentation of flow curve data (see Appendix). The effective viscosity of a non-Newtonian fluid is equivalent to the Newtonian viscosity at a fixed shear rate. The effective viscosity is defined as the shear stress divided by the shear rate. (the effective viscosity of water is a horizontal line at slightly less than $1 \mathrm{cP}$ in these coordinates). NonNewtonian materials have shear rate dependent effective viscosities, but the behavior at higher shear rates $(>100 / \mathrm{s})$ are easier to conceptualize in the context of more familiar Newtonian fluids. 
SME product rheology is summarized in Table 3-33. The $\mathrm{pH}$ range was generally narrower than for the SRAT products and the sodium molarity was higher. Statistically, however, it was $\mathrm{pH}$ and sodium molarity that explained the variation in yield stress between runs, not wt. \% insoluble solids (yield stress $=-27.95+3.56 * \mathrm{pH}+3.57 *[\mathrm{Na}]$ with $\mathrm{R}^{2}=0.997$ ). One should be careful not to draw too many conclusions from the fit, since there were three adjustable constants and only five data points. In a step-wise regression, the $\mathrm{pH}$ was the first variable put in the model based on relative ability to reduce unexplained variation, and it explained about $70 \%$ of the observed variation.

Table 3-33. SME Product Slurry Rheology

\begin{tabular}{|l|c|c|c|c|c|}
\hline Run & $\begin{array}{c}\text { Yield } \\
\text { Stress } \\
\mathrm{Pa}\end{array}$ & $\begin{array}{c}\text { Plastic } \\
\text { Viscosity } \\
\mathrm{cP}\end{array}$ & $\begin{array}{c}\text { Wt. \% } \\
\text { Insoluble } \\
\text { Solids }\end{array}$ & $\mathrm{pH}$ & $\begin{array}{c}{[\mathrm{Na}]} \\
\mathrm{M}\end{array}$ \\
\hline D1 & 8.7 & 32 & 39.7 & 7.6 & 2.7 \\
\hline D2 & 4.9 & 25 & 38.2 & 6.6 & 2.6 \\
\hline D3 & 8.1 & 33 & 38.1 & 7.4 & 2.7 \\
\hline D4 & 5.1 & 29 & 39.2 & 6.6 & 2.7 \\
\hline D5 & 7.7 & 39 & 41.4 & 6.8 & 3.2 \\
\hline
\end{tabular}

All five SRAT and five SME product slurries were analyzed in duplicate. The twenty sets of raw flow curve rheogram data are presented graphically in Appendix A.

\subsubsection{SME Product REDOX Discussion}

SME product Mn, total solids, and anions were used to calculate a predicted REDOX value using the current DWPF REDOX equation ( $\mathrm{Mn}$ at +5 electron equivalents, and including the new antifoam term). ${ }^{20}$

$$
\frac{F e^{2+}}{\sum F e}=0.2358+0.1999 *\left(2 *[F]+4 *[O]+2.8815 *\left[C_{A}\right]-5 *\left[N O_{3}^{-}\right]-5 *[M n]\right) * \frac{45}{T}
$$

[F] formate, moles/kg melter feed slurry

[O] oxalate, moles/kg melter feed slurry

$\left[\mathrm{C}_{\mathrm{A}}\right]$ antifoam carbon, moles $\mathrm{C} / \mathrm{kg}$ melter feed $(0.041 \mathrm{~mol} \mathrm{C} / \mathrm{kg}$ melter feed $)$

$\left[\mathrm{NO}_{3}{ }^{-}\right]$nitrate, moles/kg melter feed slurry

[Mn] manganese, moles $/ \mathrm{kg}$ melter feed slurry

$\mathrm{T} \quad$ wt. $\%$ total solids of melter feed slurry

Note that the equation above has been abbreviated, and that the full equation includes additional terms for coal and nitrite ion; these two species were negligible in SB8 simulant melter feed. Also, the $3.39 *$ efficiency term for antifoam (with efficiency $=0.85$ ) in the referenced report was combined to give 2.8815. The collection of terms inside the parentheses is referred to as the electron equivalents term. The antifoam impact was calculated assuming $100 \%$ retention of antifoam carbon in the process slurry.

The target REDOX was 0.10 for all five SB8 flowsheet runs, but the pre-run targeting did not include the new antifoam impact term making the likely outcome closer to 0.12 once antifoam was included in the calculation (based on $\left.0.1999 *\left(2.8815^{*} 0.041\right) *(45 / 51)=0.0208\right)$. SME 
product samples were also dried and then vitrified in closed crucibles, and the resulting iron REDOX was determined experimentally for comparison.

Table 3-34. Waste Loading and REDOX

\begin{tabular}{|c|c|c|c|c|c|}
\hline & $\begin{array}{c}\text { SB8-D1 } \\
\text { SME } \\
\text { Product }\end{array}$ & $\begin{array}{c}\text { SB8-D2 } \\
\text { SME } \\
\text { Product }\end{array}$ & $\begin{array}{c}\text { SB8-D3 } \\
\text { SME } \\
\text { Product }\end{array}$ & $\begin{array}{c}\text { SB8-D4 } \\
\text { SME } \\
\text { Product }\end{array}$ & $\begin{array}{c}\text { SB8-D5 } \\
\text { SME } \\
\text { Product }\end{array}$ \\
\hline Composition waste loading, $\%$ & 34.0 & 34.8 & 35.1 & 33.2 & 33.3 \\
\hline Mass balance waste loading, $\%$ & 35.9 & 36.2 & 36.2 & 36.0 & 35.5 \\
\hline REDOX by SME analysis & 0.11 & 0.11 & 0.12 & 0.15 & 0.16 \\
\hline REDOX by closed crucible & 0.14 & 0.22 & 0.21 & 0.25 & 0.29 \\
\hline Percent Mn dissolved $(+2)$ & 33 & 41 & 49 & 49 & 31 \\
\hline Wt.\% total solids, or "T" & 51.7 & 50.2 & 50.7 & 51.5 & $\overline{55.6}$ \\
\hline
\end{tabular}

Waste loadings were close to target. REDOX by SME analysis was close to the 0.12 value expected accounting for antifoam. REDOX values tended to be higher than expected in the measured closed crucible results based on the DWPF REDOX equation and SME product analyses. Several reasons have been proposed. One observation was that a third to a half of the Mn was still in solution in the SME product, and this Mn is presumably in the +2 oxidation state going into the crucibles. This is more dissolved Mn than normal following a flowsheet simulation, for example Mn dissolution was 5-27\% in SB7b SME products. The oxidizing power of the dissolved Mn may be overstated in the current equation resulting in a lower predicted REDOX than measured. An adjustment to the REDOX equation above was recommended for SB8. ${ }^{21}$ This change increases the predicted REDOX by SME analysis by about $+0.08-0.11$, e.g. from 0.11 to $0.19-0.22$ for a typical SB8 SME product.

A second REDOX observation was that the wt.\% total solids of these SME products was comparatively high (for rheological reasons, see Section 3.2.7). Consequently, the magnitude of the $(45 / T)$ term multiplying the electron equivalents in the REDOX equation was smaller than in many previous sludge batch SME product series that had SME products in the 47-48 wt.\% total solids range. It may be that the significance of higher solids concentrations on REDOX is not linear out into the $51-55 \%$ range.

Third, there has been a trend for the coupled flowsheet SME product to show the largest departure from the REDOX model over the past four sludge batches, although the shift has not always been in the same direction. In the SB8 case, the sign of electron equivalents term is negative, but needs to be positive, in order to move the equation result from below 0.2358 to above 0.2358 , i.e. to move the prediction from 0.16 to 0.29 . Further investigation of this phenomenon may be in order to determine whether REDOX is simply more scattered when MST is present, or if there is some variable alteration in MST during CPC processing of different sludge batches that has a direct impact on REDOX.

The fourth consideration was that the magnitude of the individual terms in the electron equivalent term of the REDOX equation might be getting large enough that propagation of analytical uncertainties is adversely impacting the usefulness of the equation to control/predict REDOX. The individual terms in the equation (ignoring antifoam) were split out for the four sludge-only flowsheet runs and are given in Table 3-35. The oxalate term is based on the feed oxalate rather than an analytical measurement, since the concentration is low enough that the acid strike method is not necessarily reliable at recovering (without destroying) the insoluble oxalate. 
Table 3-35. REDOX Equation Term by Term

\begin{tabular}{|l|c:c:c:c|}
\hline & $\begin{array}{c}\text { SB8-D1 } \\
\text { SME }\end{array}$ & $\begin{array}{c}\text { SB8-D2 } \\
\text { PME }\end{array}$ & $\begin{array}{c}\text { SB8-D3 } \\
\text { PME }\end{array}$ & $\begin{array}{c}\text { SB8-D4 } \\
\text { PME }\end{array}$ \\
Product & Product & Product \\
\hline Formate, $\mathrm{mol} / \mathrm{kg}$ & 1.221 & 1.333 & 1.255 & 1.338 \\
\hline Oxalate, $\mathrm{mol} / \mathrm{kg}$ & 0.034 & 0.033 & 0.034 & 0.033 \\
\hline Nitrate, $\mathrm{mol} / \mathrm{kg}$ & 0.452 & 0.509 & 0.487 & 0.492 \\
\hline Manganese, $\mathrm{mol} / \mathrm{kg}$ & 0.227 & 0.215 & 0.196 & 0.192 \\
\hline Electron Equivalents, mol/kg & -0.818 & -0.823 & -0.771 & -0.610 \\
\hline $10 \%$ error combining worst way & \pm 0.60 & \pm 0.64 & \pm 0.61 & \pm 0.62 \\
\hline Electron Equivalents*0.1999 & -0.163 & -0.165 & -0.154 & -0.122 \\
\hline $10 \%$ error*0.1999 & \pm 0.12 & \pm 0.12 & \pm 0.12 & \pm 0.12 \\
\hline
\end{tabular}

D2 and D4 were very nearly identical runs (both at $140 \%$ acid stoichiometry, similar $\mathrm{H}_{2}$ generation, etc.). The formate term reflects this, but the Mn term clearly does not. The Mn shift appears to be normal analytical uncertainty. A shift of 0.043 in REDOX is predicted by the equation based on a $30 \%$ change in electron equivalents, while the closed crucible results showed a 0.03 REDOX change in the same direction. This is not bad superficially, but there is no reason for the Mn term to shift starting with the same feed simulant.

The last two rows in Table 3-35 are in units of REDOX $\left(\mathrm{Fe}(\mathrm{II}) / \sum \mathrm{Fe}\right)$. The last row indicates that errors in REDOX should typically be less than \pm 0.12 , if the uncertainties of the measured inputs are controlled to less than $\pm 10 \%$. That level of uncertainty appears to be just barely acceptable, if the goal is to target 0.21 and stay between 0.09 and 0.33 . About $80 \%$ of the uncertainty comes from the formate and nitrate terms (nearly equally), so measuring formate and nitrate accurately is critical to tight REDOX control. The SB8 flowsheet runs are at about $31,000 \mathrm{mg} / \mathrm{kg}$ nitrate and $60,000 \mathrm{mg} / \mathrm{kg}$ formate, which are both high by historical DWPF standards.

This analysis suggests that DWPF may be approaching the limit of where consistent REDOX control is practical (in terms of feeding less washed sludges). Further increasing nitrate and formate would lead to larger potential uncertainties in the electron equivalents relative to the same nominal value (roughly $-0.8 \mathrm{~mol} / \mathrm{kg}$ seen here for 0.1 REDOX target). The impact of less washed-higher acid demand sludges is shown graphically in Figure 21. 


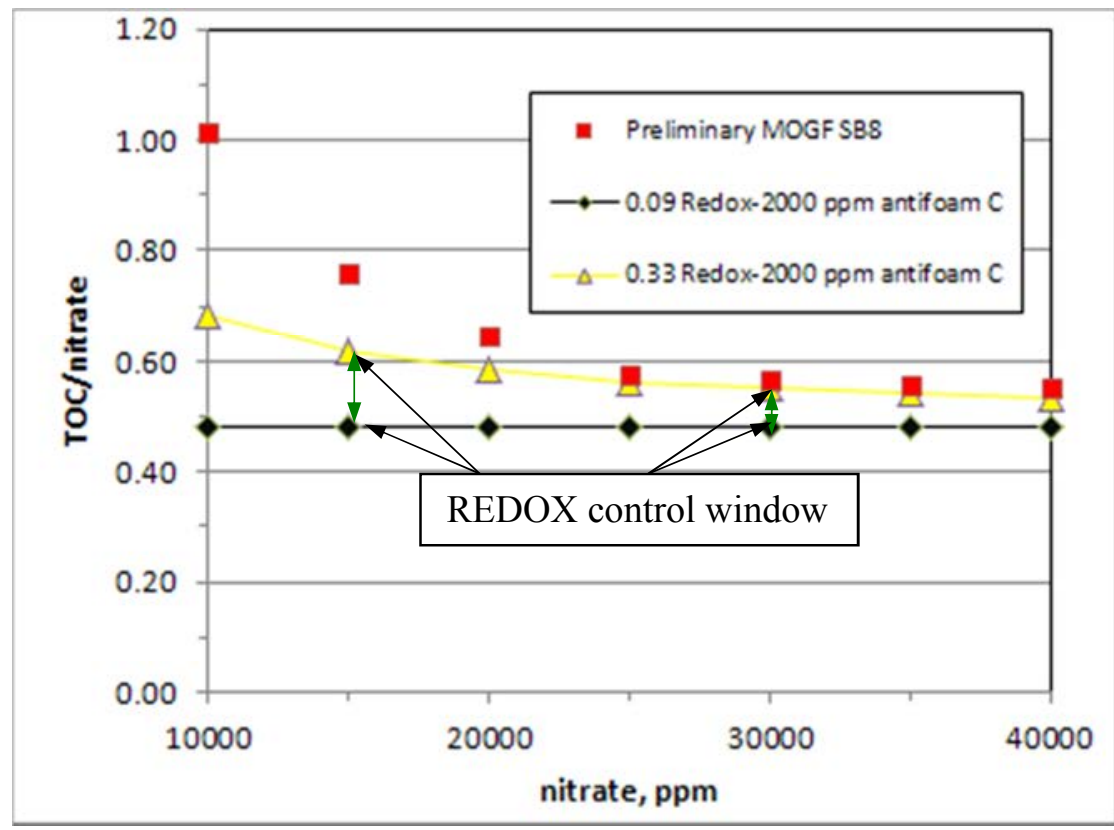

Figure 21. REDOX Operating Window vs. Melter Flammability Constraint

One mole of oxalate is equivalent to two moles of formate in terms of either REDOX or TOC, so moving carbon from one species to the other has no impact on the graphed REDOX curves (it does move the flammability curve). Figure 21 is terminated at $40,000 \mathrm{mg}$ nitrate $/ \mathrm{kg}$ melter feed, since this is the upper nitrate concentration limit of the REDOX model equation fit. For 2,000 $\mathrm{mg}$ antifoam $\mathrm{C} / \mathrm{kg}$, neither extreme of the REDOX control operating limits exceeded the MOGF constraint curve over the range of nitrate ion concentrations evaluated suggesting that REDOX control is feasible for SB8 without conflicting with off-gas flammability constraints. (The two extreme REDOX curves shift upwards if antifoam carbon is replaced by formate carbon).

It is worth noting that the region of REDOX control narrows sharply as nitrate ion concentration exceeds $20,000 \mathrm{mg} / \mathrm{kg}$. As nitrate increases from 15,000 to 30,000 ppm the range of TOC/nitrate that gives acceptable REDOX shrinks by $50 \%$. A formate concentration uncertainty of over $\pm 16 \%$ could be tolerated at $15,000 \mathrm{ppm}$ nitrate targeting the middle of the REDOX window, but this tolerable uncertainty drops to $\pm 7.5 \%$ at $30,000 \mathrm{ppm}$ nitrate (assuming no oxalate and 2,000 $\mathrm{mg}$ antifoam $\mathrm{C} / \mathrm{kg}$ ). Realistic uncertainty in the TOC value, converted to TOC/nitrate, could be larger than the space between the two curves for the REDOX control extremes at the upper nitrate ion concentrations of Figure 21. It may be difficult to control the TOC/nitrate ratio of the melter feed within such a narrow REDOX window (regardless of the specific REDOX target) at nitrate values much above $20,000 \mathrm{ppm}$.

It is recommended that a similar graph to Figure 21 should be developed for the alternative reductant flowsheet (glycolic acid-nitric acid flowsheet) to check operational feasibility and proximity to the MOGF curve. A prerequisite is a reliable modification to the REDOX equation for glycolate. Many of the glycolic acid flowsheet tests have produced SME products with fairly high nitrate ion concentrations ( $>40,000 \mathrm{mg}$ nitrate/ $\mathrm{kg}$ melter feed). 


\subsection{Results from Qualification Simulant (Tank 51) Testing}

Three SB8-Tank 51 SRAT/SME simulations were performed for the projected composition without Tank 12 waste (SB8-B3, -B4, and -B5). Two earlier SB8 simulations (-B1 and -B2) that included a Tank 12 component are documented in a separate report. ${ }^{3}$ Both sets of Tank 51 CPC simulations were sludge-only runs. There were no major issues with runs B3-B5. Results from process samples, off-gas analysis, and material balance calculations are organized into the seven sections below. An interesting facet of SB8 was that SB7b-Tank40 (the significant heel for SB8Tank 40) contained twice the noble metal concentrations of $\mathrm{Rh}$ and $\mathrm{Ru}$ in the dried solids of SB8Tank 51, while SB8-Tank 51 contained more mercury and acid demand (as a less-washed sludge). Typically, maximum acid demand, maximum noble metals, and minimum mercury lead to the worst case with respect to hydrogen generation in the presence of excess acid.

\subsubsection{SRAT/SME Product Sample Results}

Elemental results for the SRAT products from SB8-B3 through B5 looked essentially identical to the starting simulant, Section 3.1, Table 3-1 (Tank-51r simulant).

SRAT product anion data are given in Table 3-36. Selected results from caustic-quenched samples pulled 30 minutes prior to the end of the SRAT cycle are given for comparison to the SRAT product samples. The dilution of the caustic-quenched sample species by the added caustic has been removed computationally to present the results on a SRAT slurry basis prior to caustic quenching. SRAT product samples sit at room temperature until analyzed, and reactions may potentially continue at a slower rate in the bottle prior to analysis.

Table 3-36. SRAT Product Anions, mg/kg slurry

\begin{tabular}{|c|c|c|c|}
\hline & B3 & B4 & B5 \\
\hline KMA factor & $105 \%$ & $140 \%$ & $115 \%$ \\
\hline Formate & 74,550 & 81,900 & 79,400 \\
\hline Formate $^{1}$ & 74,980 & $74,260^{3}$ & 80,410 \\
\hline Nitrate & 38,100 & 39,400 & 40,000 \\
\hline Nitrate $^{1}$ & 37,620 & 40,790 & 39,940 \\
\hline Nitrite & $<500$ & $<500$ & $<500$ \\
\hline Chloride & 192 & 186 & 230 \\
\hline Chloride $^{\mathrm{I}}$ & 193 & 179 & 222 \\
\hline Sulfate & 710 & 970 & 1,350 \\
\hline Sulfate $^{1}$ & 1,625 & 1,695 & 1,595 \\
\hline Fluoride & $<500$ & $<500$ & $<500$ \\
\hline Oxalate $^{2}$ & $<500$ & 780 & 657 \\
\hline Phosphate & $<500$ & $<500$ & $<500$ \\
\hline TIC & 684 & 311 & 820 \\
\hline TOC & 22,800 & 23,000 & 26,300 \\
\hline
\end{tabular}

1 - these are caustic quenched samples from 30 minutes before the end of the SRAT

2 - oxalate by weighted dilution is not equivalent to total oxalate

3 - B4 formate expected to exceed B5 formate

Product and quenched sample nitrate were nearly the same in B3-B5 as expected. Product vs. quenched sample values for B4 formate and sulfate suggest there may have been some instrument 
or sample preparation bias in the B4 results. Differences are within accepted analytical uncertainties and are not a cause of concern to DWPF, but they do impact the quality of data interpretation that can be completed for the tests. Additional results for the SRAT product samples are given in Table 3-37.

Table 3-37. Other SRAT Product Properties

\begin{tabular}{|c|c|c|c|}
\hline & B3 & B4 & B5 \\
\hline Wt. $\%$ total solids & 29.15 & 28.24 & 30.24 \\
\hline Wt.\% dissolved solids ${ }^{1}$ & 19.24 & 18.94 & 20.43 \\
\hline Wt. \% insoluble solids ${ }^{2}$ & 12.27 & 11.47 & 12.33 \\
\hline Wt. \% soluble solids ${ }^{2}$ & 16.88 & 16.77 & 17.91 \\
\hline Wt. \% calcined solids & 18.84 & 17.51 & 19.32 \\
\hline Slurry density, $\mathrm{g} / \mathrm{mL}$ & 1.212 & 1.219 & 1.227 \\
\hline Supernate density, $\mathrm{g} / \mathrm{mL}$ & 1.118 & 1.117 & 1.130 \\
\hline Slurry $\mathrm{pH}$ & 7.82 & 7.08 & 8.02 \\
\hline
\end{tabular}

1 - dissolved solids are the non-water, non-volatile species on an aqueous phase mass basis 2 - insoluble and soluble solids are calculated from the measured total and dissolved solids

Calcined element wt.\%'s for the SME products are reported in Table 3-38 including results from the tests with Tank 12 oxalate. Calcining was performed at $1100{ }^{\circ} \mathrm{C}$. The SME products were targeted to the same waste loading (36\%), so similar elemental compositions were expected for all five $\mathrm{SME}$ products ( $\mathrm{Na}$ was a potential exception). 
Table 3-38. Calcined Elements in Qualification SME Products

\begin{tabular}{|c|c:c|c|c|c|}
\hline $\begin{array}{l}\text { Wt.\% } \\
\text { of: }\end{array}$ & $\begin{array}{c}\text { SB8-B1 } \\
\text { SME } \\
\text { Product }\end{array}$ & $\begin{array}{c}\text { SB8-B2 } \\
\text { SME } \\
\text { Product }\end{array}$ & $\begin{array}{c}\text { SB8-B3 } \\
\text { SME } \\
\text { Product }\end{array}$ & $\begin{array}{c}\text { SB8-B4 } \\
\text { SME } \\
\text { Product }\end{array}$ & $\begin{array}{c}\text { SB8-B5 } \\
\text { SME } \\
\text { Product }\end{array}$ \\
\hline $\mathrm{Al}$ & 2.49 & 2.59 & 2.20 & 2.18 & 2.21 \\
\hline $\mathrm{B}$ & 1.50 & 1.50 & 1.32 & 1.35 & 1.33 \\
\hline $\mathrm{Ba}$ & 0.038 & 0.037 & 0.039 & 0.039 & 0.040 \\
\hline $\mathrm{Ca}$ & 0.608 & 0.567 & 0.633 & 0.620 & 0.608 \\
\hline $\mathrm{Ce}$ & 0.129 & 0.123 & 0.138 & 0.136 & 0.133 \\
\hline $\mathrm{Cr}$ & 0.336 & 0.310 & 0.074 & 0.077 & 0.072 \\
\hline $\mathrm{Cu}$ & 0.020 & 0.017 & 0.031 & 0.025 & 0.038 \\
\hline $\mathrm{Fe}$ & 8.68 & 8.35 & 9.01 & 8.99 & 9.50 \\
\hline $\mathrm{K}$ & 0.195 & 0.194 & 0.071 & 0.071 & 0.084 \\
\hline $\mathrm{La}$ & 0.022 & 0.021 & 0.023 & 0.022 & 0.022 \\
\hline $\mathrm{Li}$ & 2.26 & 2.29 & 2.16 & 2.16 & 2.13 \\
\hline $\mathrm{Mg}$ & 0.095 & 0.089 & 0.099 & 0.098 & 0.105 \\
\hline $\mathrm{Mn}$ & 3.30 & 2.99 & 3.26 & 3.28 & 3.66 \\
\hline $\mathrm{Na}$ & 10.3 & 10.0 & 10.05 & 10.10 & 10.02 \\
\hline $\mathrm{Ni}$ & 0.364 & 0.357 & 0.347 & 0.350 & 0.354 \\
\hline $\mathrm{P}$ & $\mathrm{n} . \mathrm{m}$. & $n . m$. & $<0.10$ & $<0.10$ & 0.027 \\
\hline $\mathrm{Pb}$ & 0.017 & 0.016 & $<0.10$ & $<0.10$ & $<0.10$ \\
\hline $\mathrm{S}$ & 0.111 & 0.048 & 0.118 & 0.107 & 0.095 \\
\hline $\mathrm{Si}$ & 23.6 & 24.0 & 23.03 & 23.37 & 23.28 \\
\hline $\mathrm{Ti}$ & 0.045 & 0.048 & 0.018 & 0.018 & $<0.10$ \\
\hline $\mathrm{Zn}$ & 0.015 & 0.015 & 0.016 & 0.017 & 0.022 \\
\hline $\mathrm{Zr}$ & 0.139 & 0.141 & 0.068 & 0.066 & 0.154 \\
\hline $\mathrm{n}$ & & & & &
\end{tabular}

n.m. - not measured

Washing the original Tank 51 simulant and trimming in a new supernate was expected to impact aluminum and potassium (and perhaps sodium, though it was added back). $\mathrm{Cr}$ was soluble at 69 $\mathrm{mg} / \mathrm{L}$ in the original Tank 51 simulant and at $18 \mathrm{mg} / \mathrm{L}$ in the washed/retrimmed simulant for no Tank 12, so it appears that soluble $\mathrm{Cr}$ was lost during the wash and retrim operation as indicated by the drop in SME product Cr from B1-2 versus B3-5. The Cr loss was not expected to impact $\mathrm{CPC}$ processing. Conversely, $\mathrm{Zr}$ had no detectable solubility in either simulant, suggesting that the B3 and B4 values for Zr could be biased low. Otherwise, the elemental data across B1 to B5 look fairly consistent for essentially the same insoluble solids, nearly equal sodium molarity, and equal waste loading target.

Data were also obtained on the SME product anions, Table 3-39. The significant anions were formate, nitrate, and sulfate. Oxalate by water dilution was obtained as a lower bound on total oxalate. Actual total oxalate was probably in the $1,500-2,500 \mathrm{mg} / \mathrm{kg}$ range, but the impact at these concentrations on REDOX is small (about a 0.02 increase on the $\mathrm{Fe}^{2+} / \sum \mathrm{Fe}$ ratio versus assuming none). Substitution of a predicted oxalate by material balance and process knowledge is generally adequate in these cases to account for oxalate in REDOX. Acid strike preparations for oxalate by IC have not been validated for reasonable recovery efficiency when oxalate is less than 3,000 ppm. TIC/TOC was also obtained in addition to the IC results. TIC was presumably carbonate formed from the absorption of $\mathrm{CO}_{2}$. TOC was primarily due to formate, plus any oxalate and antifoam. 
Table 3-39. SME Product Anions, mg/kg slurry

\begin{tabular}{|l|r|r|r|}
\hline & \multicolumn{1}{|c|}{ B3 } & B4 & \multicolumn{1}{c|}{ B5 } \\
\hline KMA factor & $105 \%$ & $140 \%$ & $115 \%$ \\
\hline Formate & 60,000 & 67,000 & 63,450 \\
\hline Nitrate & 28,350 & 32,050 & 31,950 \\
\hline Nitrite & $<500$ & $<500$ & $<500$ \\
\hline Chloride & 150 & 150 & 179 \\
\hline Sulfate & 1,210 & 1,460 & 1,430 \\
\hline Fluoride & $<500$ & $<500$ & $<500$ \\
\hline Oxalate & 580 & 1,550 & 730 \\
\hline Phosphate & $<500$ & $<500$ & $<500$ \\
\hline TIC & 504 & 312 & 308 \\
\hline TOC & 19,900 & 27,000 & $(6,840)^{2}$ \\
\hline
\end{tabular}

1 - slurry oxalate by weighted dilution is not equivalent to total oxalate

2 - the B5 TOC value is not credible

Formate and nitrate generally track with acid stoichiometry as expected (factoring in that B5 is about 3\% more concentrated, i.e. less dilution water so higher anions, than B3 and B4). Chloride is generally a confirmation that a certain quantity of $\mathrm{RuCl}_{3}$ was added as one of the noble metal trim chemicals. TIC should track with the $\mathrm{pH}$ in a broad sense and with allowances for analytical uncertainties in both measurements. Here the $\mathrm{pH}$ values were all fairly close to seven, and the TIC results were within a $100 \mathrm{ppm}$ of 405 . The TOC was primarily due to formate, with lesser contributions of about $600 \mathrm{ppm}$ from oxalate and $600 \mathrm{ppm}$ from antifoam. The B5 TOC value clearly had analytical issues. Wt.\% data and calculations, slurry and supernate density, and $\mathrm{pH}$ are reported in Table 3-40.

Table 3-40. Other SME Product Properties

\begin{tabular}{|l|c|c|c|}
\hline & B3 & B4 & B5 \\
\hline Wt.\% total solids & 50.63 & 49.91 & 51.71 \\
\hline Wt.\% dissolved solids $^{1}$ & 21.68 & 19.78 & 22.61 \\
\hline Wt. \% insoluble solids $^{2}$ & 36.96 & 37.56 & 37.60 \\
\hline Wt. \% soluble solids & 13.67 & 12.36 & 14.11 \\
\hline Wt. \% calcined solids & 42.21 & 40.62 & 42.58 \\
\hline Slurry density, g/mL & 1.437 & 1.412 & 1.426 \\
\hline Supernate density, g/mL & 1.134 & 1.132 & 1.143 \\
\hline Slurry pH & 7.23 & 6.66 & 7.41 \\
\hline
\end{tabular}

1 - dissolved solids are the non-water, non-volatile species on an aqueous phase basis

2 - insoluble and soluble solids are calculated from the measured total and dissolved solids

Changes in formate, nitrite, and nitrate were calculated by species material balances for the SRAT and SME cycles from the anion data reported above, Table 3-41. 
Table 3-41. Changes in Major Anions

\begin{tabular}{|l|c|c|c|}
\hline & B3 & B4 & B5 \\
\hline KMA factor & $105 \%$ & $140 \%$ & $115 \%$ \\
\hline & SRAT & SRAT & SRAT \\
\hline Formate Loss & 25 & 32 & 30 \\
\hline Nitrite Loss & $99 \%$ & $100 \%$ & $100 \%$ \\
\hline Nitrite-to-nitrate & 32 & 15 & 29 \\
\hline & SME & SME & SME \\
\hline Formate Loss & 5 & 6 & 5 \\
\hline Nitrate Loss & 7 & 1 & 0 \\
\hline
\end{tabular}

Results in Table 3-41 are susceptible to the analytical uncertainties in the IC measurements of anions in the SRAT and SME product samples as well as to uncertainty in the SRAT product mass. The expected outcome is for values in the medium acid run, B5, to fall between those in the high and low acid runs. That was true for the SRAT cycle, and true within uncertainty for the SME cycle.

Data were obtained on the elements in the SRAT and SME product supernates. Many species were below detection limits or were minor species with minimal impact on processing chemistry. Other species have varying degrees of significance. $\mathrm{Ca}, \mathrm{Mg}$, and $\mathrm{Mn}$ are three of the more active elements chemically during the CPC, starting insoluble in the SRAT feed, typically dissolving close to $100 \%$ at some point during processing, and then partially reprecipitating by the end of the SME cycle. Table 3-42 gives a short list of SRAT product supernate results.

Table 3-42. Major SRAT Product Supernate Elements, mg/L

\begin{tabular}{|l|c|c|c|}
\hline & B3 & B4 & B5 \\
\hline KMA factor & $105 \%$ & $140 \%$ & $115 \%$ \\
\hline $\mathrm{Ca}$ & 2,260 & 2,530 & 2,540 \\
\hline $\mathrm{Cr}$ & 0.33 & 0.70 & 0.30 \\
\hline $\mathrm{K}$ & 730 & 660 & 830 \\
\hline $\mathrm{Mg}$ & 400 & 410 & 440 \\
\hline $\mathrm{Mn}$ & 5,640 & 9,830 & 10,700 \\
\hline $\mathrm{Na}$ & 54,200 & 49,700 & 51,300 \\
\hline $\mathrm{Ni}$ & 1.8 & 33 & 1.1 \\
\hline $\mathrm{S}$ & 680 & 690 & 690 \\
\hline $\mathrm{Si}$ & 9.1 & 20 & 11 \\
\hline
\end{tabular}

Selected concentrations in Table 3-42 were converted to a slurry basis and compared to the total concentration of the element to assess the partitioning of the element between soluble and insoluble species, Table 3-43. 
Table 3-43. Selected SRAT Product Supernate Elements, \% of total

\begin{tabular}{|l|r|r|r|}
\hline & B3 & B4 & B5 \\
\hline KMA factor & $105 \%$ & $140 \%$ & $115 \%$ \\
\hline $\mathrm{Ca}$ & 50 & 61 & 58 \\
\hline $\mathrm{K}$ & $\sim 100$ & $\sim 100$ & $\sim 100$ \\
\hline $\mathrm{Mg}$ & 70 & 80 & 77 \\
\hline $\mathrm{Mn}$ & 25 & 49 & 44 \\
\hline $\mathrm{Na}$ & $\sim 100$ & $\sim 100$ & $\sim 100$ \\
\hline $\mathrm{S}$ & 86 & 97 & 85 \\
\hline
\end{tabular}

The high solubility of Mn has not been seen in recent sludge batch SRAT products, particularly for B4-B5 where it was over 40\%. The B4-B5 Mn supernate concentration was comparable to that in D2-D5. Mn fractional solubility was somewhat less than in D2-D5, perhaps because there was more total Mn in the SB8-Tank 51 simulant. Sulfur was almost entirely in a dissolved form based on the paired ICP results for slurry and supernate, but the two lower acid runs (B3, B5) may have potentially had a small concentration of insoluble sulfur species. ${ }^{3}$

Table 3-44 gives a short list of major SME product elements and their concentrations in the SME product supernatant phase.

Table 3-44. Major SME Product Supernate Elements, mg/L

\begin{tabular}{|l|r|r|r|}
\hline & B3 & B4 & B5 \\
\hline KMA factor & $105 \%$ & $140 \%$ & $115 \%$ \\
\hline $\mathrm{B}$ & 21 & 31 & 13 \\
\hline $\mathrm{Ca}$ & 2,650 & 2,900 & 2,780 \\
\hline $\mathrm{K}$ & 750 & 770 & 960 \\
\hline $\mathrm{Li}$ & 270 & 270 & 240 \\
\hline $\mathrm{Mg}$ & 460 & 410 & 450 \\
\hline $\mathrm{Mn}$ & 8,460 & 7,460 & 8,330 \\
\hline $\mathrm{Na}$ & 58,400 & 56,800 & 58,100 \\
\hline $\mathrm{S}$ & 790 & 810 & 850 \\
\hline $\mathrm{Si}$ & 18 & 31 & 15 \\
\hline
\end{tabular}

It appears as though the concentrations of $\mathrm{Mg}$ and $\mathrm{Mn}$ in the supernate were decreasing as the acid stoichiometry increased. The $\mathrm{pH}$ data give little insight into this, since they did not trend with acid stoichiometry. The data in Table 3-44 were combined with solids, density, and slurry elemental concentrations to calculate the fractional solubility (partitioning between soluble and insoluble forms) of the elements with significant solubility, Table 3-45.

\footnotetext{
${ }^{3}$ A calculated value of $85 \%$ of total $\mathrm{S}$ in solution arguably has at least $\pm 15 \%$ potential uncertainty from error propagation considerations; sources of uncertainty include the $\mathrm{wt} \%$ calcined slurry $\mathrm{S}$ by ICP, wt $\%$ calcined solids of the slurry, supernate density, supernate $\mathrm{S}$ concentration by ICP, $\mathrm{wt}_{\mathrm{t}} \%$ insoluble solids, plus any imperfections in the subsampling and dilution process during preparation; that being said, a fractional solubility of $115 \%$ by calculation rarely occurs even though it should be equally as likely as $85 \%$; it is this final consideration that led to the conclusion that there could potentially be some insoluble sulfur species present. This tentative conclusion is pushing the sample data to the limits.
} 
Table 3-45. Selected SME Product Supernate Elements, \% of total

\begin{tabular}{|l|c|c|c|}
\hline & B3 & B4 & B5 \\
\hline KMA factor & $105 \%$ & $140 \%$ & $115 \%$ \\
\hline $\mathrm{Ca}$ & 55 & 64 & 58 \\
\hline $\mathrm{K}$ & $\sim 100$ & $\sim 100$ & $\sim 100$ \\
\hline $\mathrm{Li}$ & 1.7 & 1.7 & 1.4 \\
\hline $\mathrm{Mg}$ & 62 & 56 & 55 \\
\hline $\mathrm{Mn}$ & 34 & 31 & 29 \\
\hline $\mathrm{Na}$ & 77 & 76 & 74 \\
\hline $\mathrm{S}$ & 88 & $\sim 100$ & $\sim 100$ \\
\hline
\end{tabular}

Mn fractional solubility seen in the SRAT product was somewhat reduced after the SME cycle, but it was still relatively high compared to the last several sludge batches. Ideally the sodium partitioning would be constant in percent for B3-B5 under the two assumptions of no frit leaching and exactly at targeted waste loading (36\%). The small variations in sodium partitioning do not contradict these two assumptions. There were only minimal indications of lithium leaching $(<2 \%)$ from the frit which, nevertheless, exceeded boron or silicon leaching by an order of magnitude (based on the assumption that soluble equals leached). Behavior was similar to that seen in the D series. Both simulant test series used frit 418 , however, which is not the nominal frit for SB8 in DWPF.

\subsubsection{SRAT/SME Off-gas Data}

The three SRAT cycles with Tank 51 simulant produced very different peak hydrogen generation rates during the SRAT cycle, Figure 22. Lengthy SRAT cycle times were due to mercury $(2.38$ wt.\% in the starting dried total solids).

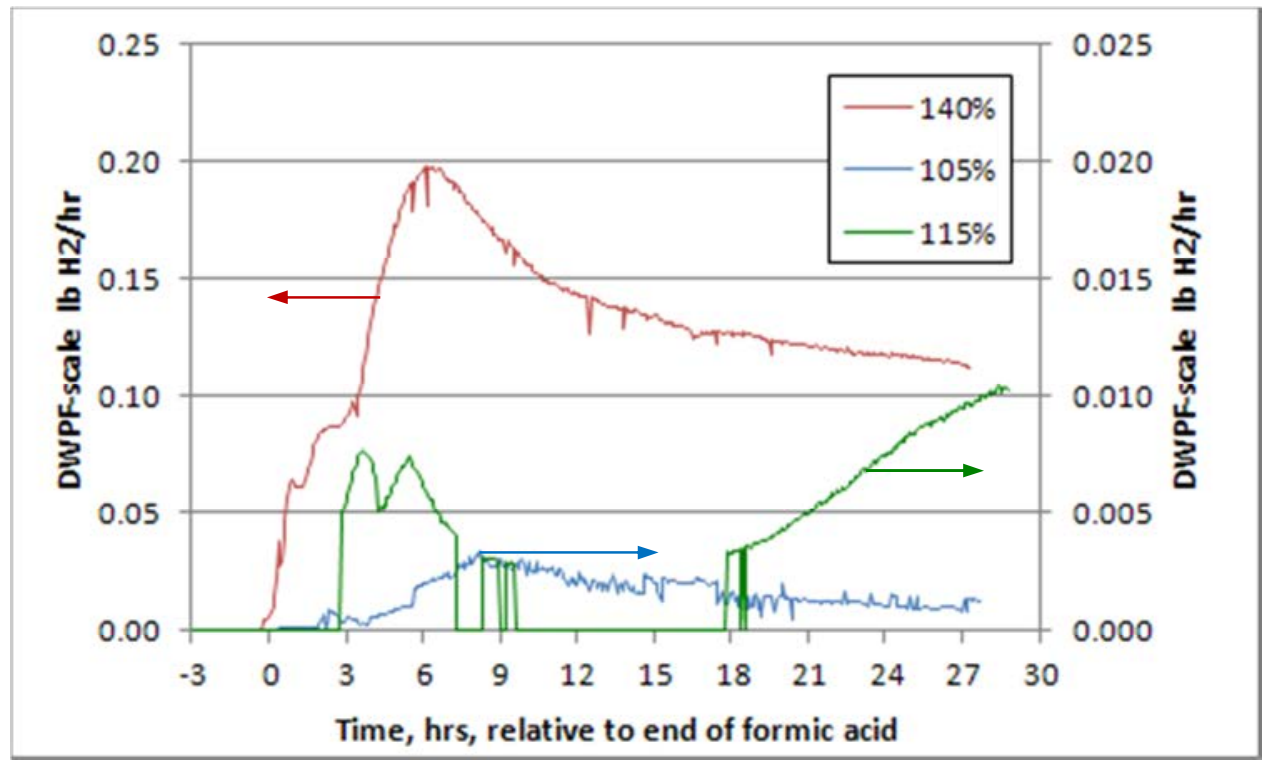

Figure 22. SB8-Tank 51 SRAT Hydrogen Generation Rates 
The nominal qualification simulant test at $115 \%$ acid (KMA) had some sensitivity issues during reflux, where the hydrogen peak could not be quantified (most of the period from 7-18 hours). Hydrogen generation rates were low during this period, i.e. the maximum hydrogen generation rate did not occur here (if it had, it would have been quantified). Both the $105 \%$ and $115 \%$ acid runs spent most of the SRAT cycle at less than $0.0065 \mathrm{lb} \mathrm{H}_{2} / \mathrm{hr}$ at DWPF-scale, or at less than 1\% of the DWPF SRAT limit for hydrogen of $0.65 \mathrm{lb} \mathrm{H}_{2} / \mathrm{hr}$.

Hydrogen generation rates during the SME cycle (two frit slurry additions plus dewaterings) is shown in Figure 23.

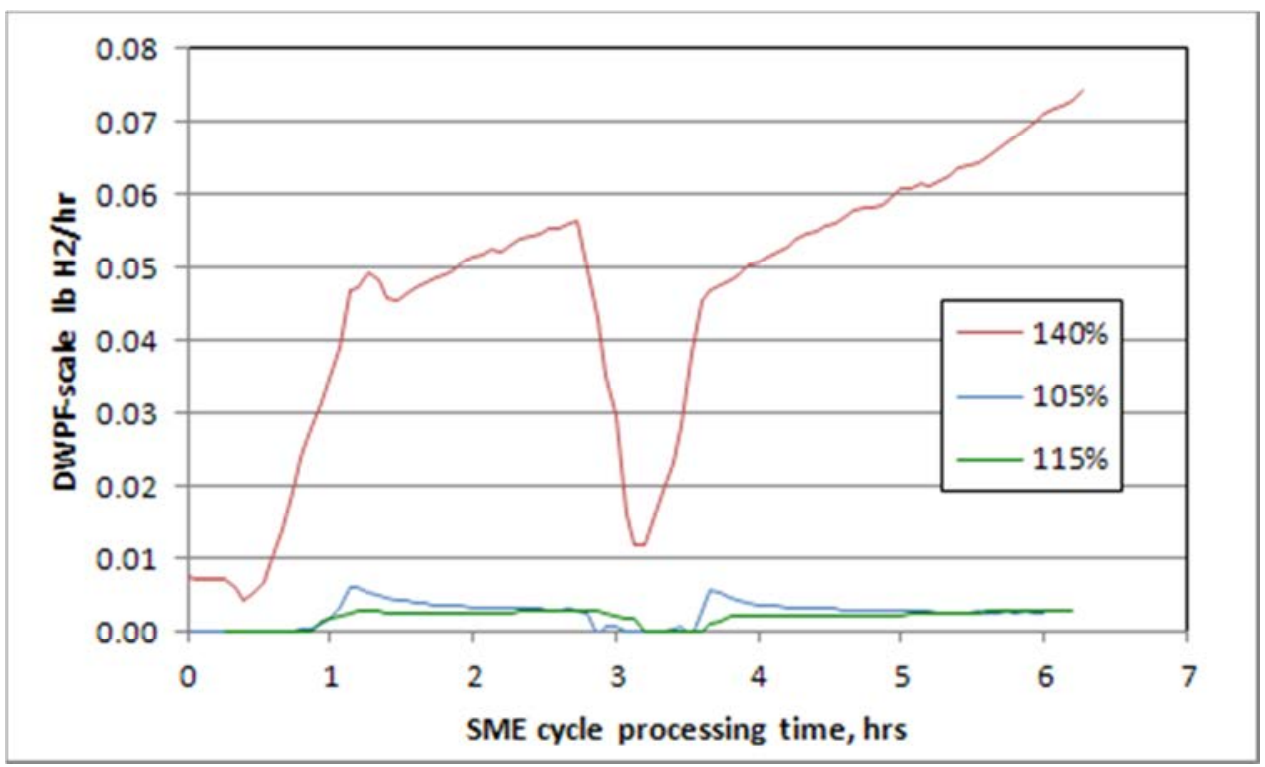

Figure 23. SB8-Tank 51 SME Hydrogen Generation Rates

Hydrogen generation stayed at less than $34 \%$ of the DWPF SME cycle limit of $0.223 \mathrm{lb} \mathrm{H}_{2} / \mathrm{hr}$. The highest acid stoichiometry run produced the most hydrogen as expected with a peak rate of $0.075 \mathrm{lb} / \mathrm{hr}$ or $33.5 \%$ of the maximum allowable rate. The hydrogen generation rate peaked as the SME slurry was brought to its maximum concentrations of soluble and insoluble species just before the cycle was terminated. This same behavior was seen in the SB8-Tank 40 SME cycles that had appreciable hydrogen generation. The $115 \%$ acid run, which was showing increasing hydrogen generation rates at the end of the SRAT cycle, had a fairly bland SME cycle with respect to hydrogen. The combination of nitrite destruction at $105 \% \mathrm{KMA}$ with maximum hydrogen generation in the SRAT and SME both less than $35 \%$ of the DWPF limits at $140 \%$ KMA indicated an acceptably wide processing window for SB8-Tank 51 from the standpoint of acid stoichiometry.

SRAT $\mathrm{CO}_{2}$ results by $\mathrm{GC}$ are given in Figure 24. 


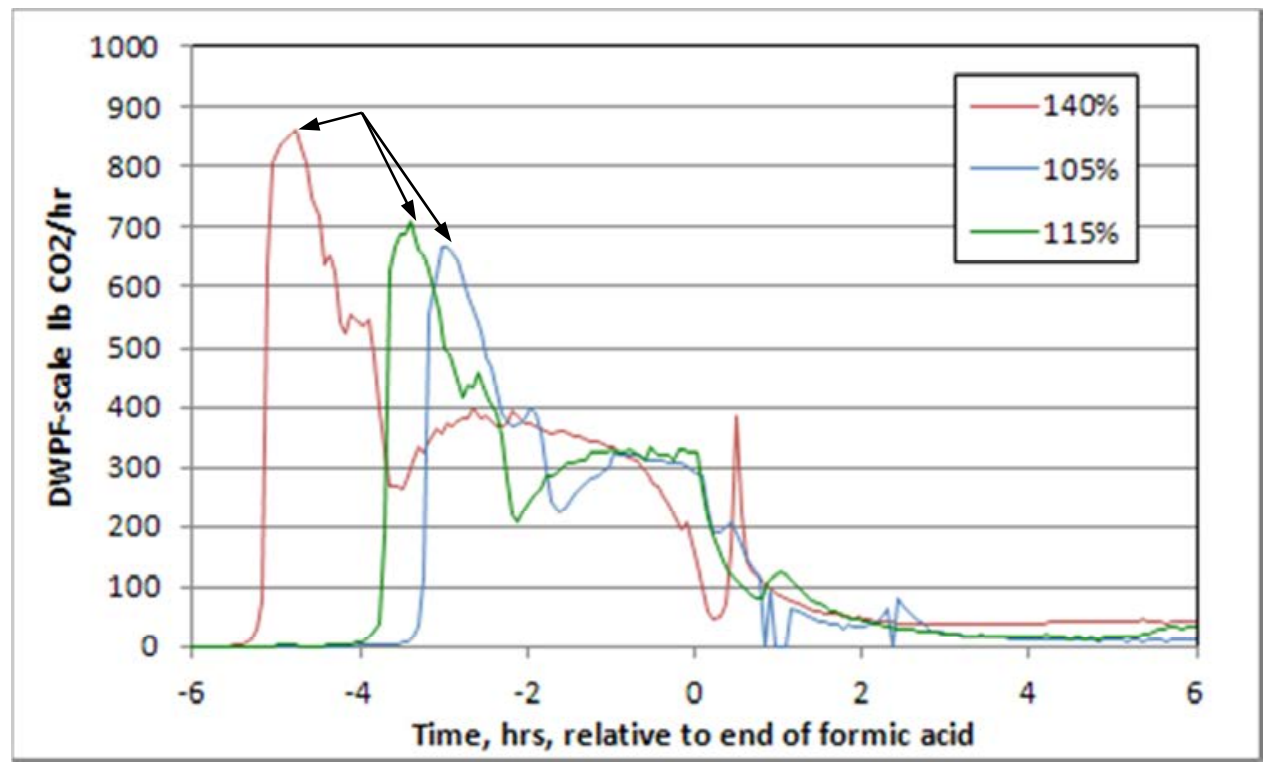

Figure 24. SB8-Tank 51 SRAT $\mathrm{CO}_{2}$ Generation Rate by GC

It is apparent that the $140 \% \mathrm{KMA}$ run produced $\sim 20 \%$ more $\mathrm{CO}_{2}$ at maximum rates than the other two runs even without aligning the carbonate destruction peaks on the time axis (see arrows). This was unlike pre-run expectations or the SB8-Tank 40 results. The results indicate the presence of more than desired uncertainty in the GC results for the high acid run $(<10 \%$ desired). Secondary peaks were visible as the generation rates fell from the maximum values into the valley that precedes the broad peak associated with nitrite destruction and manganese reduction (in the $400-550 \mathrm{lb} / \mathrm{hr}$ range). These could be the mercury reduction $\mathrm{CO}_{2}$ peaks as postulated from the higher $\mathrm{Hg}$ runs in the SB8-Tank 40 tests. In this case, there was good MS data for $\mathrm{CO}_{2}$ during acid addition, Figure 25, for the first two tests. 


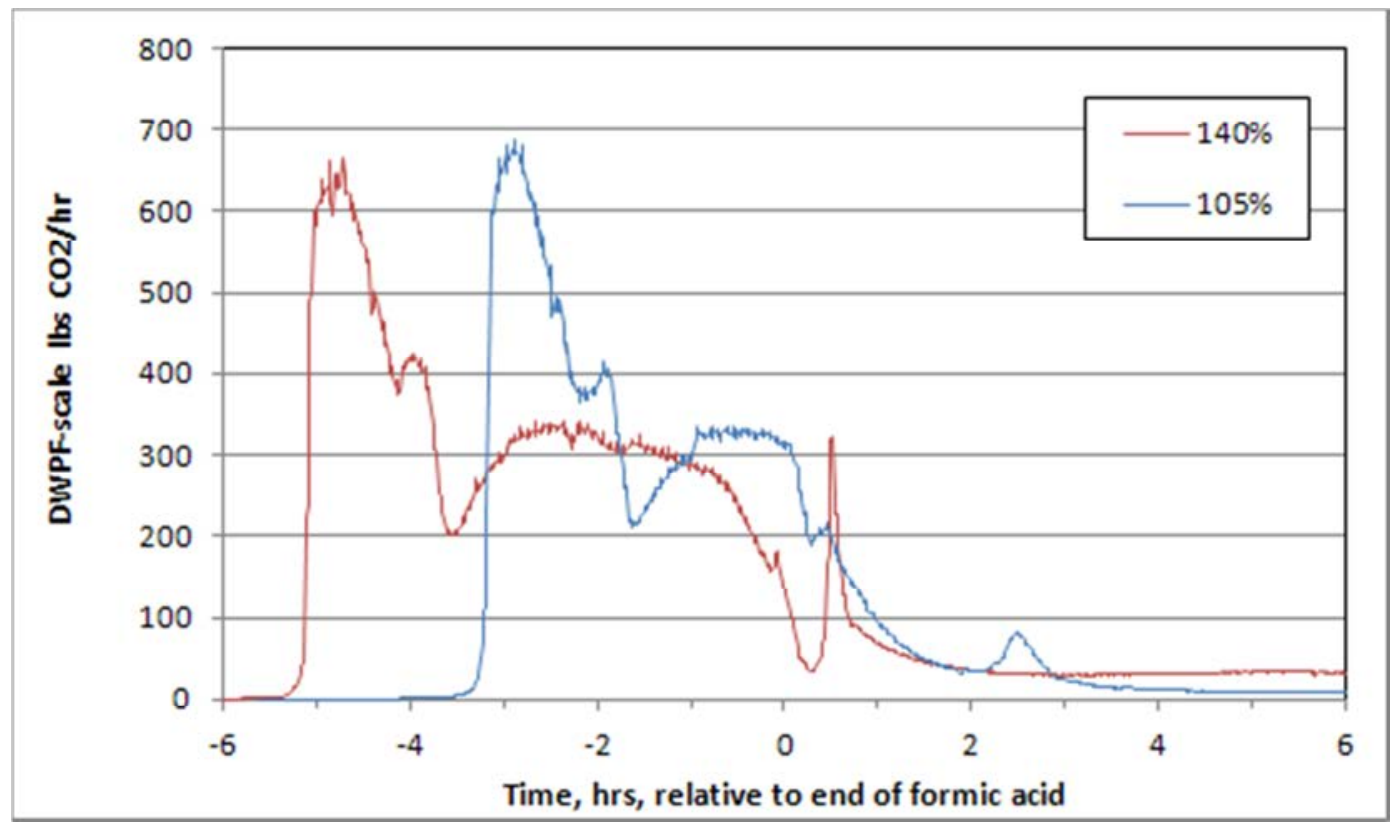

Figure 25. SB8-Tank 51 SRAT $\mathrm{CO}_{2}$ Generation Rate by MS

The results at 105\% KMA are nearly identical between GC and MS, while the MS results for the $140 \%$ run have fallen relative to the GC results. In this instance, the MS results are preferr ed for the $140 \%$ run over the GC results, since the carbonate destruction peaks at $105 \%$ and $140 \%$ are nearly identical as expected. The MS data also helps confirm that the $105 \%$ and $115 \%$ GC data for $\mathrm{CO}_{2}$ are essentially correct. The MS and FTIR are combining to improve off-gas composition data validation.

The excellent time resolution of the MS data has clearly defined peaks at $-4.1 \mathrm{hrs}$ for $140 \% \mathrm{KMA}$ and $-2.0 \mathrm{hrs}$ for $105 \% \mathrm{KMA}$. The $\mathrm{pH}$ at $-4.1 \mathrm{hr}$ and $140 \%$ acid was 5.54 . This was the $\mathrm{pH}$ region that showed peaks in $\mathrm{CO}_{2}$ in the SB8-Tank 40 higher $\mathrm{Hg}$ runs. SB8-Tank $51 \mathrm{Hg}$ is even higher than SB8-Tank 40. Unfortunately, there is no $\mathrm{pH}$ data for the $105 \%$ run, but it was likely at a similar $\mathrm{pH}$, since a similar quantity of acid had been added at that time. The quantity of circumstantial evidence that these peaks in $\mathrm{CO}_{2}$ are due to $\mathrm{Hg}$ is growing. (The MS data for the first day of the $115 \%$ KMA run disappeared from the MS control PC and could not be recovered.)

The impact of the end of acid addition on the $\mathrm{CO}_{2}$ generation rate at $105 \%$ acid is clearly seen. This run was barely in the middle of nitrite ion destruction at the end of formic acid addition (compare to the $140 \%$ run and its sustained, gently falling period of $\mathrm{CO}_{2}$ production in the last three hours of formic acid addition). There was a very rapid drop of nearly $30 \%$ in $\mathrm{CO}_{2}$ generation rate when formic acid stopped feeding in B3. Previous testing had shown that nitrite destruction and Mn reduction typically did not consume acid as quickly as it was being added (at 2 gpm equivalent in DWPF). ${ }^{22}$ The new data indicates that at this point in B3 about $60-70 \%$ of the $\mathrm{CO}_{2}$ generation rate was coming from accumulated acid and $30-40 \%$ from freshly added acid. It could be argued that feeding formic acid at $1 \mathrm{gpm}$ instead of $2 \mathrm{gpm}$ during this period near the end of formic acid addition would not greatly reduce the rate of nitrite destruction and $\mathrm{Mn}$ reduction (which are being sustained by accumulated acid), but would allow most of the off-gas generation from these reactions to vent prior to going to boiling. DWPF has processed this way (half design flow rate) at various times, but little data to defend it has been developed previously in the lab-scale tests. 
The $\mathrm{GC} \mathrm{CO}_{2}$ generation rate results from the SME cycle are given in Figure 26.

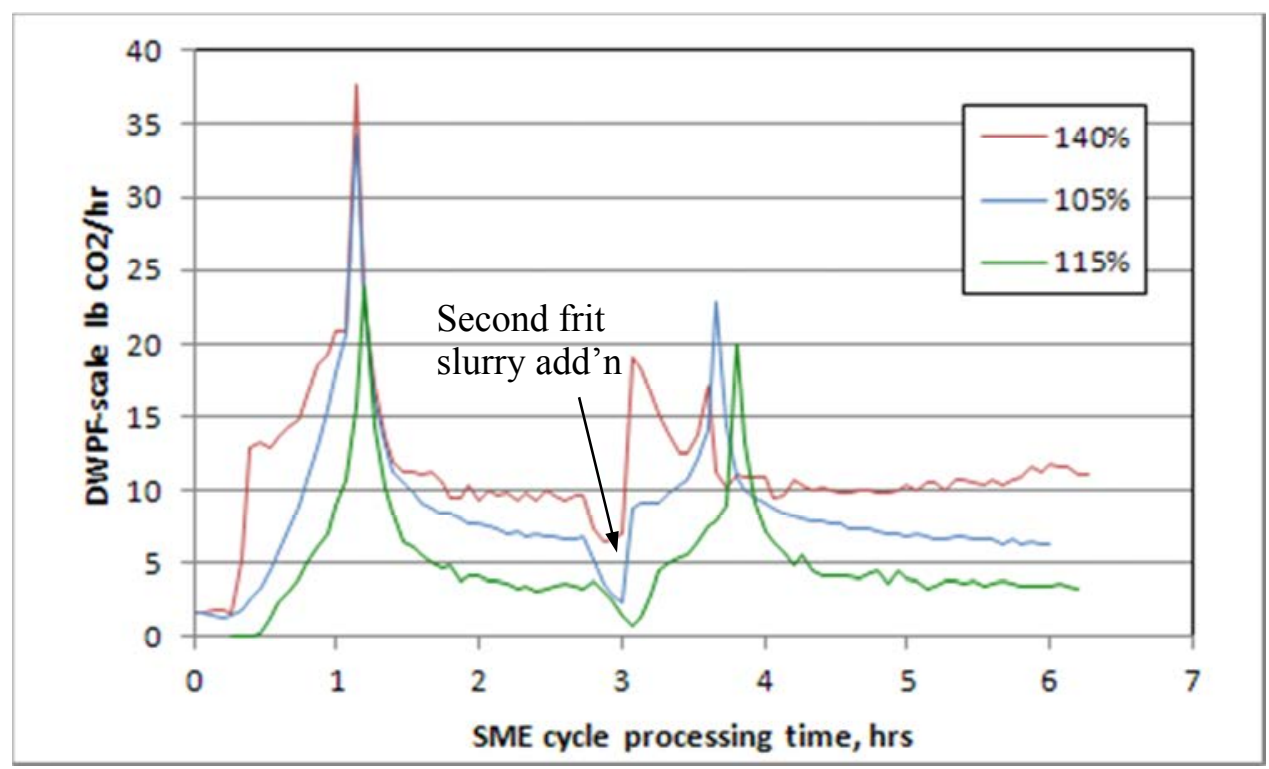

Figure 26. SB8-Tank $51 \mathrm{SME} \mathrm{CO}_{2}$ Generation Rates

SME cycle $\mathrm{CO}_{2}$ behavior was surprisingly similar unlike the SRAT cycle. SME averaged rates in the 5-10 lb/hr range, however, are fairly small compared to acid addition $\mathrm{CO}_{2}$ in the SRAT cycle. SRAT cycle data for $\mathrm{N}_{2} \mathrm{O}$ generation are given in Figure 27.

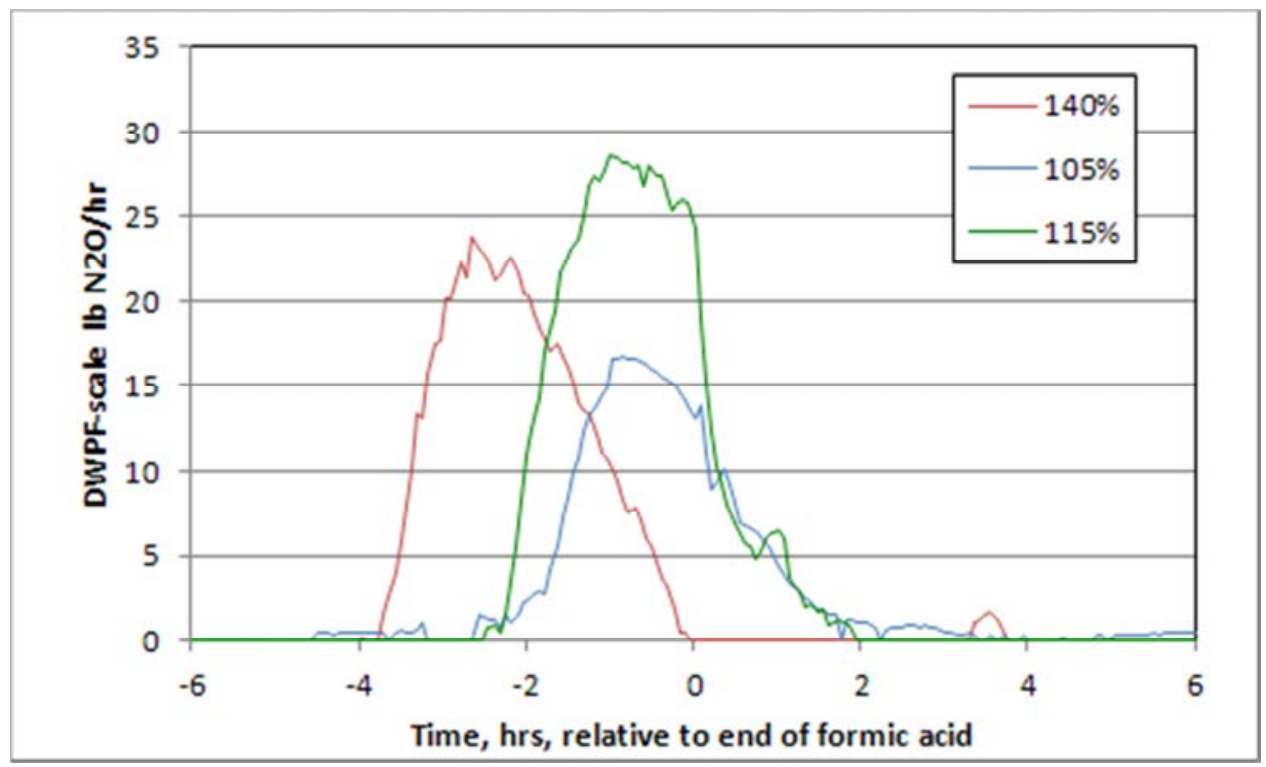

Figure 27. SB8-Tank 51 SRAT $\mathrm{N}_{2} \mathrm{O}$ Generation Rates

The $\mathrm{N}_{2} \mathrm{O}$ peaks occurred at the expected times for the variations in acid stoichiometry. A high acid run reaches suitable processing conditions for nitrite destruction sooner with respect to the end of formic acid than lower acid runs. The $140 \%$ run had $<100 \mathrm{ppm}$ nitrite ion in the sample immediately following formic acid addition which is consistent with the $\mathrm{N}_{2} \mathrm{O}$ generation rate 
going to essentially zero by time zero. $\mathrm{N}_{2} \mathrm{O}$ is also partly due to catalytic reactions, which are favored in runs with some excess acid (noting that not all of the excess acid is necessarily present when the nitrite is being destroyed). The smaller $\mathrm{N}_{2} \mathrm{O}$ peak rate in the $105 \% \mathrm{KMA}$ run is not unexpected for these reasons. $\mathrm{N}_{2} \mathrm{O}$ was not detected in any of the three SB8-Tank 51 SME cycles. $\mathrm{N}_{2} \mathrm{O}$ was detected in all five SB8-Tank 40 flowsheet SME cycles. The reason for this has not been identified.

MS data for $\mathrm{NO}_{2}$ were also developed for the high and low acid SRAT runs, Figure 28.

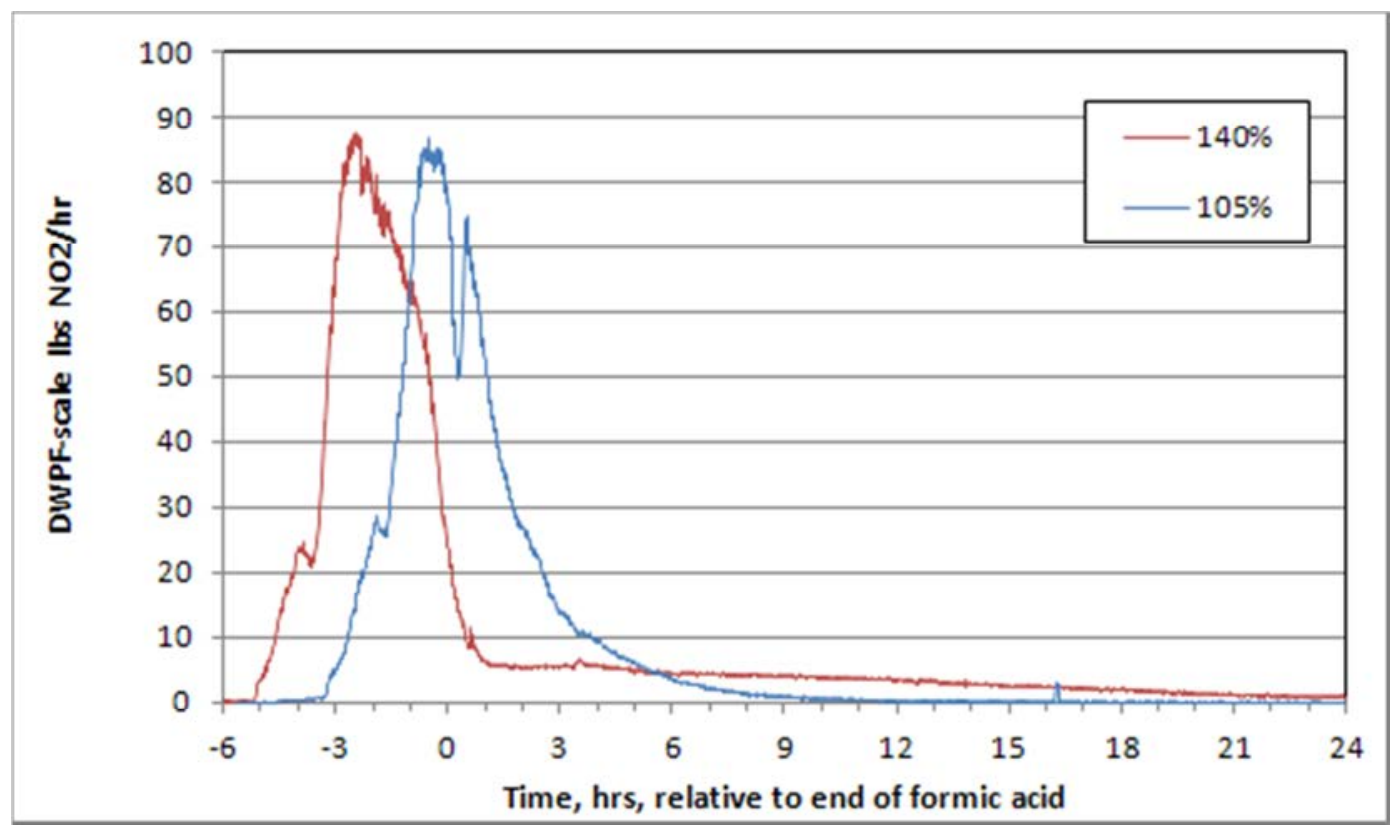

Figure 28. SB8-Tank 51 SRAT $\mathrm{NO}_{2}$ Generation Rate by MS

The $\mathrm{NO}_{2}$ profiles are fairly similar up to the end of formic acid in the $105 \% \mathrm{KMA}$ run. This includes a small feature at about $25 \mathrm{lbs} / \mathrm{hr}$ as the $\mathrm{NO}_{2}$ generation rate was making its initial climb up to its maximum value. These peaks occur at the same time as the peaks in $\mathrm{CO}_{2}$ that were tentatively assigned to $\mathrm{Hg}$ reduction. Nitrite ion is not considered necessary for mercury reduction, so an $\mathrm{NO}_{2}$ feature associated with $\mathrm{Hg}$ reduction might be contrary evidence to the hypothesis that the $\mathrm{CO}_{2}$ peaks were due to $\mathrm{Hg}$ reduction. The simultaneous occurrence of a $\mathrm{CO}_{2}$ signature for $\mathrm{Hg}$ reduction with an $\mathrm{NO}_{2}$ release could potentially indicate that a modified nitritebased species is participating in the reduction (though the $\mathrm{pH}$ seems too mild to form other acids with nitrogen at $3+$ oxidation state). On a quantitative note, the $\mathrm{CO}_{2}$ peaks are of order $20 \mathrm{lb} / \mathrm{hr}$ off the background, while the $\mathrm{NO}_{2}$ peaks are only about $3 \mathrm{lb} / \mathrm{hr}$ off background implying that whatever is causing the reaction is consuming considerably more formic acid than nitrite or nitrate ion.

$\mathrm{NO}_{2}$ generation was sustained through reflux at a significantly higher rate in the $140 \%$ acid run than in the $105 \%$ acid run. This $\mathrm{NO}_{2}$ is presumably associated with catalytic conversion of nitrate ion back into nitrite ion followed by desorption and subsequent destruction to off-gas species by excess acid. The $105 \%$ run may still have been in the process of destroying nitrite ion when the SRAT cycle ended. The total $\mathrm{NO}_{2}$ detected at the MS was much less than suggested by oxygen consumption (identical finding to the SB8-Tank 40 data). The $140 \%$ run $\mathrm{N}_{2}$ data was too noisy to extract a smooth curve for oxygen loss calculation, but the $105 \%$ run had an $\mathrm{O}_{2}$ loss sufficient to 
produce $68 \mathrm{~g}$ of $\mathrm{NO}_{2}$; the MS totals were in the 16-19 $\mathrm{g} \mathrm{NO}_{2}$ range for the low and high acid runs respectively.

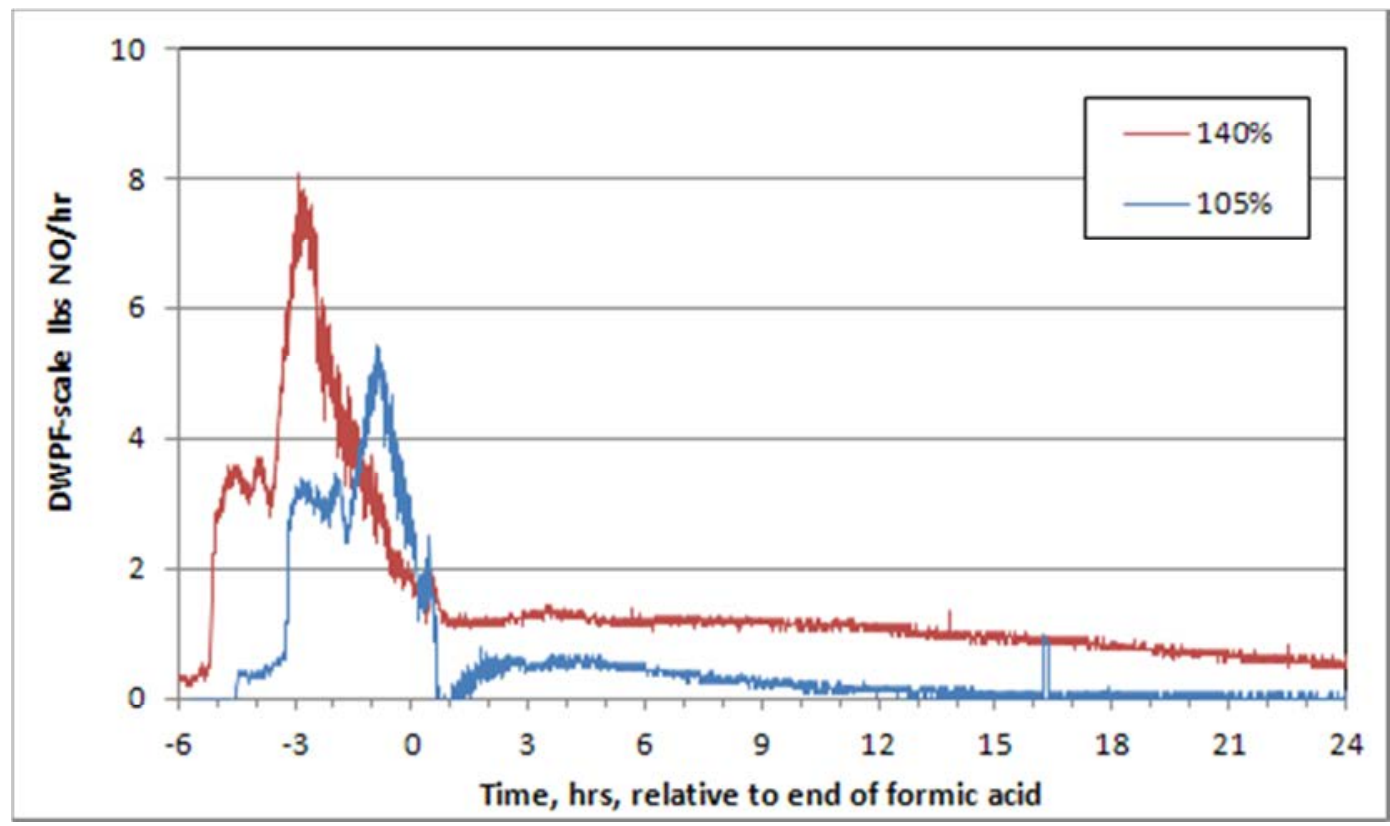

Figure 29. SB8-Tank 51 SRAT NO Generation Rate by MS

The NO detected after the FAVC in the high and low acid SRAT cycles was an order of magnitude lower than $\mathrm{NO}_{2}$ during the peak portion of nitrite destruction in formic acid addition. Conversely, the $\mathrm{NO}$ detected was about half of the $\mathrm{NO}_{2}$ detected (by mass) during the latter stages of reflux in the high acid run, so the relative significance of $\mathrm{NO}$ to $\mathrm{NO}_{2}$ increased as time passed. This could mean different things, for example it could mean that the ratio of $\mathrm{NO} / \mathrm{NO}_{2}$ produced was constant, but that the ammonia scrubber removed a larger fraction of the $\mathrm{NO}_{2}$ as the concentration of $\mathrm{NO}_{2}$ fell in the SRAT off-gas, while $\mathrm{NO}$ was essentially not being scrubbed any of the time. It could mean that the ratio of $\mathrm{NO} / \mathrm{NO}_{2}$ being produced changed with time (this change is in a counter-intuitive direction, since there is more oxygen available to convert NO to $\mathrm{NO}_{2}$ late in the SRAT than there is during nitrite destruction; $\mathrm{O}_{2}$ is nearly back to $20 \mathrm{vol} \%$ late in the SRAT whereas it dipped to less than 4 vol\% during nitrite destruction). An abrupt drop in NO production was seen in the low acid run when formic acid addition ended.

\subsubsection{SRAT/SME Processing Data}

Data to support a better understanding of antifoam behavior are being obtained when possible. The concentration of $\mathrm{Si}$ in the SRAT condenser condensate held fairly constant during boiling following formic acid addition during D4. The dewater condensate collected in the first 3.5 hours of boiling was at $230 \mathrm{mg} \mathrm{Si} / \mathrm{L}$, while the aqueous phase in the MWWT at the end of the SRAT cycle was at $234 \mathrm{mg} \mathrm{Si} / \mathrm{L}$. This $\mathrm{Si}$ is likely due to antifoam decomposition compounds such as HMDSO. The magnitude and rate of change varied noticeably from run to run, Table 3-46. 
Table 3-46. Condensate $\mathrm{Si}, \mathrm{mg} / \mathrm{L}$

\begin{tabular}{|l|c|c|c|}
\hline & B3 & B4 & B5 \\
\hline KMA factor & $105 \%$ & $140 \%$ & $115 \%$ \\
\hline Post-acid supernate & 70 & 20 & n.m. \\
\hline SRAT dewater cond. & 110 & 290 & 100 \\
\hline MWWT aqueous & 20 & 140 & 110 \\
\hline FAVC condensate & 240 & 40 & 90 \\
\hline
\end{tabular}

To the extent that $\mathrm{Si}$ is a marker for antifoam fragments, the above data do suggest that there was increasing loss of antifoam with increasing acid stoichiometry $(\mathrm{B} 3 \approx \mathrm{B} 5<\mathrm{B} 4)$ given that the dewater condensate is the largest volume of condensate material.

Acid stoichiometry impacted other species found in the SRAT dewater condensate as seen in previous testing, Table 3-47.

Table 3-47. SRAT Dewater Condensate Anions

\begin{tabular}{|l|c|c|c|}
\hline & B3 & B4 & B5 \\
\hline KMA factor & $105 \%$ & $140 \%$ & $115 \%$ \\
\hline Nitrate, $\mathrm{mg} / \mathrm{L}$ & 14,350 & 4,730 & 6,520 \\
\hline Nitrite, $\mathrm{mg} / \mathrm{L}$ & $<100$ & $<100$ & 180 \\
\hline Formate, mg/L & 625 & 3,420 & 720 \\
\hline
\end{tabular}

Formate is normally seen in the 100's-1000's mg/L in the SRAT dewater condensate from all runs. The B series runs followed expected patterns unlike the D series runs in Table 3-23.

Generally, nitrate and nitrite concentrations increased in the condensate as acid stoichiometry decreased for sludge-only tests. This correlates with the concentration of nitrite surviving to the end of formic acid addition, Table 3-48 and Table 3-49. Nitrite survived in B3, but was destroyed by the end of acid addition in B4 and B5. Anion data were not obtained for B5 post-formic supernate (sample lost).

Table 3-48. SRAT Supernate Anions (after formic), mg/L

\begin{tabular}{|l|r|r|}
\hline & \multicolumn{1}{|c|}{ B3 } & \multicolumn{1}{c|}{ B4 } \\
\hline KMA factor & $105 \%$ & $140 \%$ \\
\hline Nitrate & 35,100 & 47,050 \\
\hline Nitrite & 4,720 & $<100$ \\
\hline Formate & 72,600 & 88,700 \\
\hline Sulfate & 1,940 & 2,450 \\
\hline Oxalate & 500 & 1,070 \\
\hline Chloride & 158 & 156 \\
\hline
\end{tabular}

Caustic-quenched slurry samples were also taken following formic acid addition, at two points in the middle of boiling, and once just before the end of the SRAT reflux period. Results for the slurry after acid addition, Table 3-49, were expected to closely track those of the supernate samples in Table 3-48, but be about 20\% smaller numerically. The results in Table 3-49 have been corrected for the dilution from caustic-quenching (about $7-8 \%$ of the sample is added caustic solution at approximately $1 \mathrm{M}$ ). 
SRNL-STI-2013-00106

Revision 0

Table 3-49. SRAT Slurry Anions (after formic), mg/kg

\begin{tabular}{|l|r|r|r|}
\hline & \multicolumn{1}{|c|}{ B3 } & B4 & \multicolumn{1}{|c|}{ B5 } \\
\hline KMA factor & $105 \%$ & $140 \%$ & $115 \%$ \\
\hline Nitrate & 26,900 & 37,200 & 28,650 \\
\hline Nitrite & 4,360 & $<100$ & $<100$ \\
\hline Formate & 60,500 & 78,550 & 63,000 \\
\hline Sulfate & 1,490 & $3,300^{1}$ & 1,920 \\
\hline Oxalate & 710 & 1,300 & 640 \\
\hline Chloride & 144 & $<100$ & $<100$ \\
\hline
\end{tabular}

In B3, both caustic-quenching the slurry and separating the supernate from the slurry solids seemed to do equally well in preserving undestroyed nitrite ion. In the $105 \%$ acid run, D1, the caustic-quenched slurry nitrite value was clearly lower than the supernate equivalent value. Chloride was near detection limits for the pre-dewatering (unconcentrated) B series samples.

Caustic-quenched slurry samples were taken about one-third and two-thirds of the way between the end of regular dewatering and the end of the SRAT cycle (for example, if the SRAT was refluxed for 24 hours, the samples were pulled at eight hours, Table 3-50, and 16 hours, Table $3-51$, into reflux). The values were expected to be fairly close to those of the SRAT product given in Table 3-36, since the total slurry mass was nearly constant during the last two-thirds of reflux. Formate and nitrate were expected to fall slightly with time as they react to form hydrogen, $\mathrm{CO}_{2}, \mathrm{NO}_{\mathrm{x}}$, and ammonia but only $\mathrm{B} 4$ (high acid stoichiometry) showed any real evidence of this. The results are generally as expected to within about $\pm 10 \%$. The results tended to vary with acid stoichiometry in the manner expected. As with the earlier results, oxalate values represent a lower limit on the total oxalate in the system, since much of the oxalate is present in insoluble solid form during reflux.

Table 3-50. SRAT Slurry Anions (1/3), mg/kg

\begin{tabular}{|l|r|r|r|}
\hline & \multicolumn{1}{|c|}{ B3 } & \multicolumn{1}{c|}{ B4 } & \multicolumn{1}{c|}{ B5 } \\
\hline KMA factor & $105 \%$ & $140 \%$ & $115 \%$ \\
\hline Nitrate & 36,400 & 43,600 & 38,400 \\
\hline Nitrite & $<100$ & $<100$ & $<100$ \\
\hline Formate & 76,000 & 79,600 & 77,800 \\
\hline Sulfate & 1,740 & $2,850^{1}$ & 1,800 \\
\hline Oxalate & 930 & 1,500 & 1,600 \\
\hline Chloride & 190 & 180 & 210 \\
\hline
\end{tabular}

The effect of dewatering (which occurred after results in Table 3-49 and before results in Table 3-50) was to increase the concentrations of most anions (except nitrite) relative to their concentrations at the end of acid addition. The 2,850 sulfate value for B4 was much higher than expected. A review of data indicated that the mass after dewatering was essentially the same as that of the feed to the SRAT. The SRAT feed had $1,800 \mathrm{mg} / \mathrm{kg}$ sulfate, so that was essentially the predicted value for B4 sulfate after dewatering. Subsequent B4 samples fell much closer to this expectation than to the result in Table 3-50, e.g. Table 3-51 and Table 3-36. 
Table 3-51. SRAT Slurry Anions (2/3), mg/kg

\begin{tabular}{|l|r|r|r|}
\hline & \multicolumn{1}{|c|}{ B3 } & \multicolumn{1}{c|}{ B4 } & \multicolumn{1}{c|}{ B5 } \\
\hline KMA factor & $105 \%$ & $140 \%$ & $115 \%$ \\
\hline Nitrate & 36,900 & 41,700 & 38,100 \\
\hline Nitrite & $<100$ & $<100$ & $<100$ \\
\hline Formate & 75,200 & 72,800 & 76,800 \\
\hline Sulfate & 1,730 & 1,840 & 1,550 \\
\hline Oxalate & 850 & 1,500 & 1,300 \\
\hline Chloride & 190 & 180 & 220 \\
\hline
\end{tabular}

1 - subsequent formate values were higher (more like Table 3-50)

Formate concentration in the B4 sample was lower than after $1 / 3^{\text {rd }}$ of reflux or in the SRAT product (and end of SRAT caustic-quenched sample), so the B4 result does not indicate an evaporative or catalytic loss of any noteworthy significance (falls within accepted analytical uncertainties). There seemed to be more minor deviations (off-trend behavior) in anion IC data during SB8 simulant testing than past sludge batches. This could simply be random chance, or it could indicate that something about SB8 was challenging the analytical methods more than in the past. SB8 is less washed than previous sludge batches, meaning anion concentrations are going up. Fortunately, the simulant tests were generally at higher anion concentrations than are expected in DWPF during SB8 processing, so this potential and fairly minor issue might never be seen at full-scale.

The $\mathrm{pH}$ profiles from two of the three qualification simulant runs are shown in Figure $30 . \mathrm{B} 3 \mathrm{pH}$ data was recorded manually every 20 minutes, but these data were reviewed and are implausible based on experience with previous SRAT runs (electronic recording of B3 $\mathrm{pH}$ was not possible due to a failed com port on the cable bus hub). Consequently, the data were not transcribed and incorporated into Figure 30.

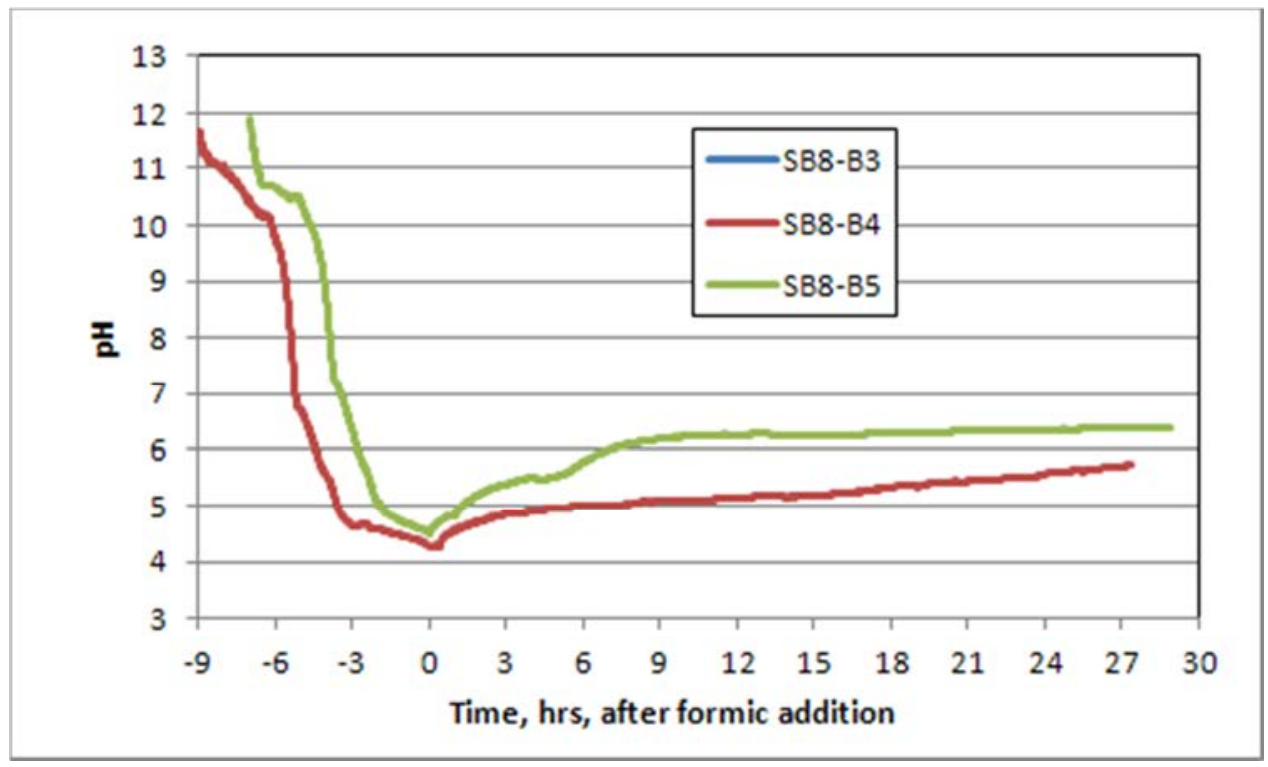

Figure 30. SRAT pH Profiles 
The $140 \%$ stoichiometry run reached a minimum $\mathrm{pH}$ reading in the 4.2-4.3 range at the end of formic acid addition. This minimum value for $\mathrm{pH}$ is fairly typical of tests where subsequent processing produces significant hydrogen.

Data are presented in Figure 31 for the SRAT vessel mixer torque as a function of time. Note that absolute values of torque are of less significance than changes in torque for the lab-scale SRAT. Much of the absolute torque is related to overcoming friction due to the tightness of the shaft seal on the vessel lid. This baseline torque loading varies from run to run which causes shifts up and down in the relative position of data for multiple runs. The baseline torque is also not necessarily constant during a run (as the seal wears, the frictional torque can drop).

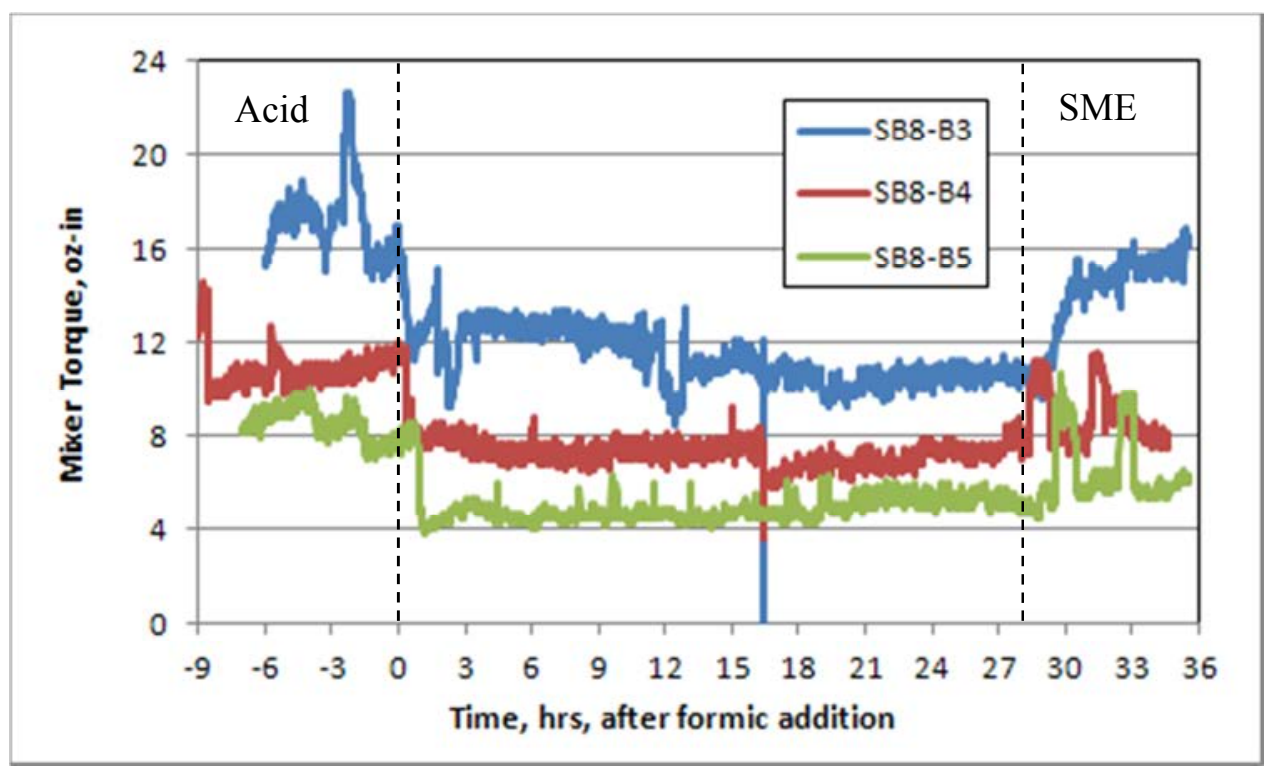

Figure 31. Mixer Torque as a Function of Time

Patterns were broadly similar to those seen in the five D series flowsheet runs. Mixer torque was fairly constant through acid addition, although there were some ups and downs of varying magnitude. There was a significant drop in mixer torque as the SRAT went to boiling following acid addition in all three runs (reduced fluid density). Torque remained fairly constant during SRAT boiling, and began increasing in the SME cycle as frit was added and as the slurry was concentrated to its final wt.\% solids target.

Data was obtained for the heat input to the heating rods. The data were challenging to interpret as a function of time, Figure 32, but could not be cross-plotted to $\mathrm{pH}$ like the D series since one set of $\mathrm{pH}$ data was missing. 


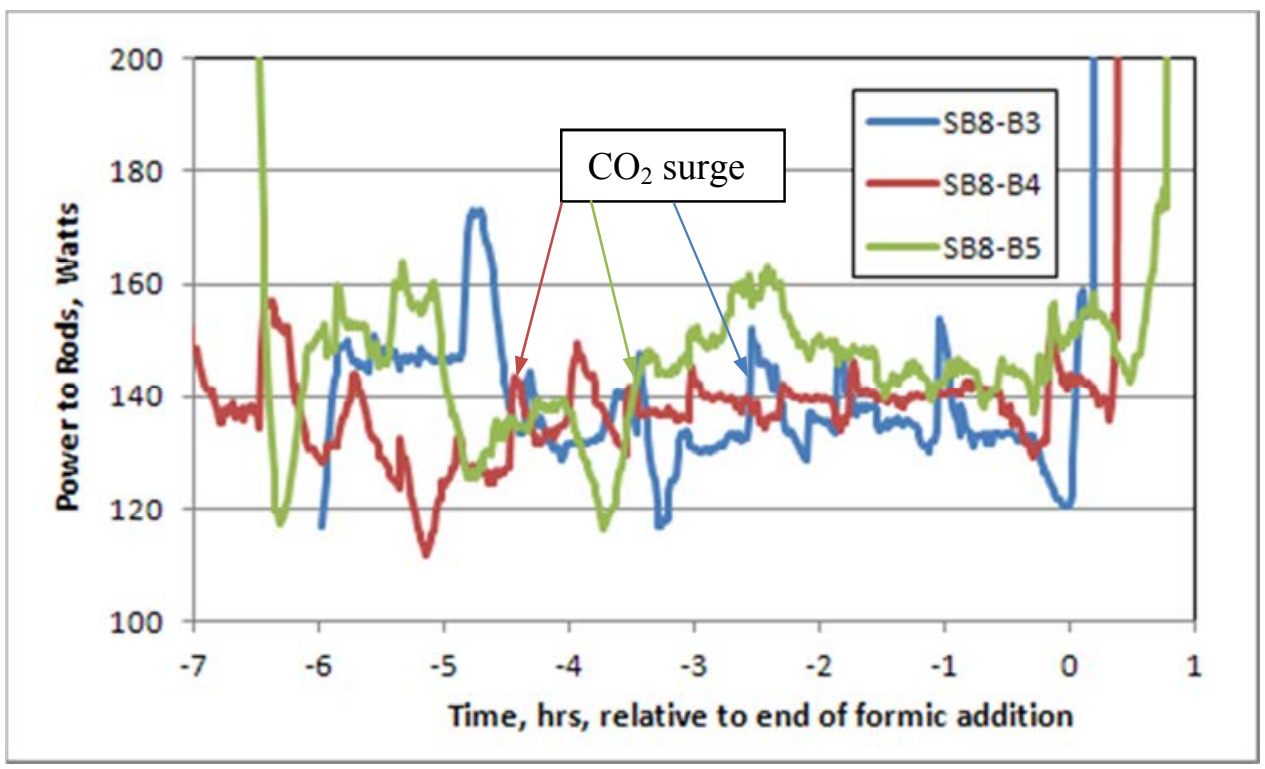

Figure 32. SRAT Heat Input during Acid Addition

Power surges corresponding to the $\mathrm{CO}_{2}$ released from carbonate destruction were visible in the data (marked by matched color arrows) as was the case for the five $\mathrm{D}$ series runs. These were of order 15-30 watts (carbonate loading of SB8-Tank 51 simulant was very similar to that for SB8Tank 40, so similar magnitude power increases are consistent with the power demand coming from carbonate). The change in power draw varied from run to run. All three runs were intended to have identical masses of starting carbonate. The reasons for other sharp changes in power draw during acid addition have not yet been identified.

The SRAT configuration used in these tests has a pair of heating rods as discussed in Section 3.2.4. A heat transfer coefficient calculation was performed at each measurement time, and the results are graphed in Figure 33 for the three qualification simulant SRAT runs.

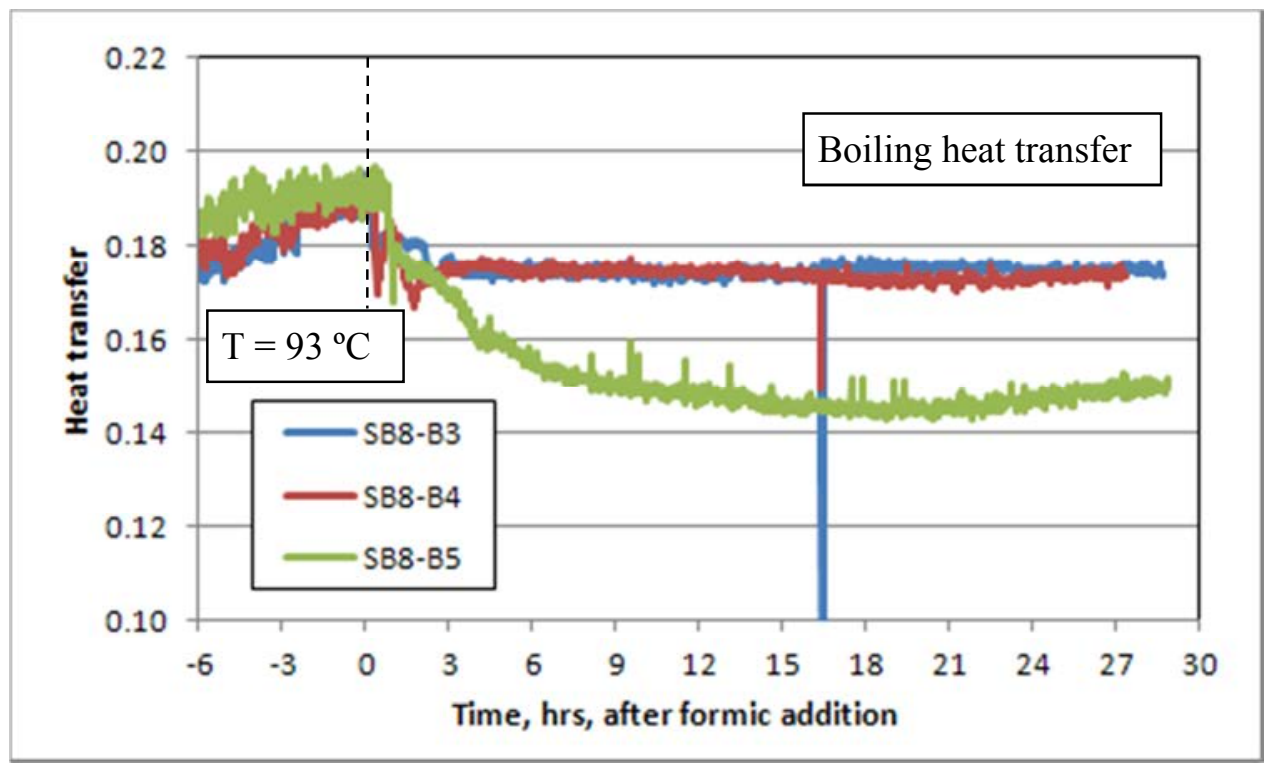

Figure 33. Slurry Film Heat Transfer Coefficient as a Function of Processing Time 
The heat transfer coefficient values are somewhat noisy (some runs more than others), and there are some lab artifacts. Nevertheless, there is a clear difference between maintaining the SRAT at $93{ }^{\circ} \mathrm{C}$ (0 to -6 hours) where the fluid medium is primarily liquid-solid versus maintaining the SRAT at constant boil-up rate (0.5-26 hours) where the boiling bubbles must be created at or near the rod walls. Boiling had a less effective heat transfer coefficient than sensible heat control. In B5 the upper set of impeller blades came loose and slid down the shaft to rest on top of the lower set of impeller blades. This potentially explains the reduction in heat transfer coefficient seen during that run.

SME heat transfer coefficient data are presented in Figure 34.

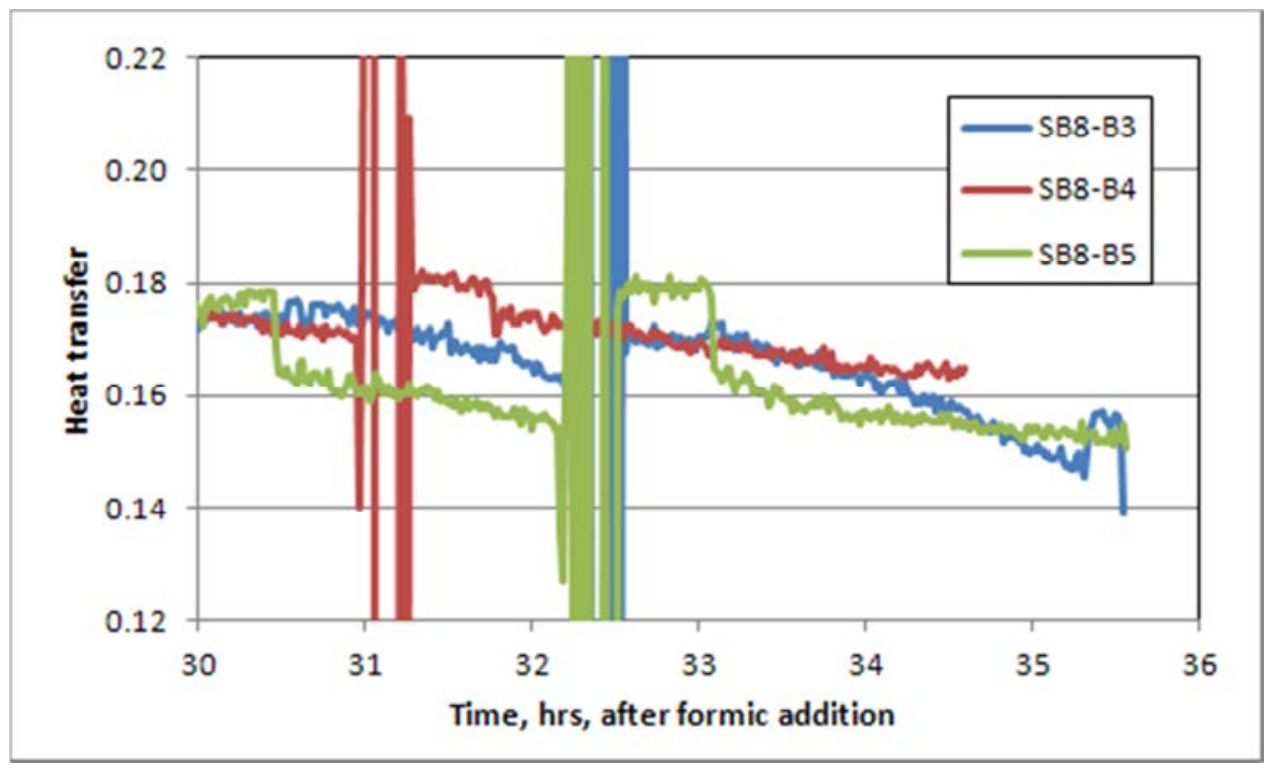

Figure 34. SME Cycle Heat Transfer Coefficients

Generally, heat transfer coefficients in the SME cycle declined slowly with time at boiling (periods between the vertical noise bars). Values were initially in the 0.17-0.18 range and declined by the end of SME dewatering into the 0.15-0.165 range, presumably due to the thickening rheological properties as the SME solids were increased by frit addition and water removal.

\subsubsection{SRAT/SME Mercury Results}

Recovery of mercury by steam stripping followed a similar pattern to previous sludge batches and the recent fate of mercury study. ${ }^{19}$ Mercury was collected in the MWWT. Suspended elemental mercury in the SRAT and SME product slurries was analyzed by ICP and is reported relative to the total solids in these slurries in Table 3-52. Suspended mercury was well below the DWPF target of $0.80 \mathrm{wt} \% \mathrm{Hg}$ in the SRAT product slurry total solids in all three qualification simu lant tests. Additional mercury was usually found on the bottom of the SME vessel after the majority of the slurry had been pumped out for weighing. 
SRNL-STI-2013-00106

Revision 0

Table 3-52. SRAT and SME Product Slurry Mercury

\begin{tabular}{|l|c|c|c|}
\hline & B3 & B4 & B5 \\
\hline SRAT total solids, wt\% Hg & 0.041 & 0.057 & 0.069 \\
\hline SME total solids, $\mathrm{wt} \% \mathrm{Hg}$ & 0.019 & 0.078 & 0.026 \\
\hline
\end{tabular}

The B4 SME product analysis represents just $2.5 \%$ of the mercury present at the beginning of the SRAT cycle even though it contained more than the other two runs. Soluble mercury was $<0.05$ $\mathrm{mg} / \mathrm{L}$ in the liquid phase of all three SME products.

Table 3-53. SRAT Mercury Stripping to MWWT

\begin{tabular}{|l|c|c|c|}
\hline & B3 & B4 & B5 \\
\hline Elemental Hg, g & 2.15 & 5.71 & 8.62 \\
\hline \% of starting Hg & 12 & 33 & 49 \\
\hline
\end{tabular}

Recovery of elemental mercury was only fair except in B5. Generally, nearly $60 \%$ of the mercury added to the sludge prior to the SRAT cycle was not suspended in the product slurry or recovered from the MWWT as elemental mercury. In B5 $\mathrm{Hg}$ beads were observed in the SME dewater condensate and on the bottom of the vessel after pumping out most of the SME product slurry.

SRAT dewater condensate typically showed no visible beads of $\mathrm{Hg}$ in any of the three runs, however there were varying amounts of dissolved mercury detected, Table 3-54. The mercury concentration combined with SRAT dewater condensate mass gave the mass of elemental mercury in the condensate. This does not mean that the mercury itself was in oxidation state zero, only that the calculated result is for the element $\mathrm{Hg}$, not for a compound of mercury.

Table 3-54. SRAT Mercury Stripping to Dewater Condensate

\begin{tabular}{|l|c|c|c|}
\hline & B3 & B4 & B5 \\
\hline Hg conc. in condensate, $\mathrm{mg} / \mathrm{L}$ & 389 & 10 & 249 \\
\hline Elemental Hg mass, $\mathrm{g}$ & 0.33 & 0.008 & 0.21 \\
\hline \% of starting Hg & 1.9 & 0.04 & 1.2 \\
\hline
\end{tabular}

Non-trivial amounts $(>1 \%$ total available $\mathrm{Hg}$ ) of dissolved mercury were found in the SRAT dewater condensate from the low and medium acid stoichiometry runs, however there was very little in the high acid stoichiometry run.

Concentrations of mercury in the aqueous phase of the MWWT at the end of the SRAT cycle were in the $9-22 \mathrm{~g} / \mathrm{mL}$ range, and the MWWT aqueous phase mass was roughly $1 / 20^{\text {th }}$ the SRAT dewater condensate mass. Therefore the dissolved mercury in the MWWT was trivial from a material balance standpoint. Concentrations of mercury in the FAVC condensate were in the 70$250 \mathrm{mg} / \mathrm{L}$ range. FAVC condensate mass was about half that of the aqueous phase in the MWWT. Even though FAVC condensate sample $\mathrm{Hg}$ concentrations were up to 10x those in the MWWT aqueous phase samples, the dissolved mercury represented only approximately $0.02 \%$ of the total mercury added to the starting simulant. 


\subsubsection{SRAT/SME Ammonia Results}

Ammonia release was a good measure of ammonium ion production, along with nitrate loss in some cases, of the ammonium producing tendency of sludge during SB6, SB7, and SB7b testing. The potential accumulation of ammonium ion in the ammonia scrubber reservoir (nominally 750 $\mathrm{g}$ of liquid) was tracked by taking samples at the end of the SRAT cycle and end of the SME cycle. Some selected data from runs B1 and B2 with the earlier version of the Tank 51 simulant (containing Tank 12) are given for comparison, Table 3-55.

Table 3-55. Ammonia Detection in Scrubber Liquid

\begin{tabular}{|l|c|c|c|c|c|}
\hline & B1 & B2 & B3 & B4 & B5 \\
\hline Acid Stoichiometry (KMA) & $109 \%$ & $145 \%$ & $105 \%$ & $140 \%$ & $115 \%$ \\
\hline After SRAT, mg/L & $<50$ & $<50$ & $<5$ & $<5$ & $<5$ \\
\hline After SME, mg/L & - & - & $<5$ & $<5$ & $<5$ \\
\hline SME nitrate loss, \% & 5 & 4 & 7 & 1 & $(-1)$ \\
\hline SRAT product pH & 7.78 & 7.62 & 7.82 & 7.08 & 8.02 \\
\hline SME product $\mathrm{pH}$ & - & - & 7.23 & 6.66 & 7.41 \\
\hline
\end{tabular}

Nitrate is the assumed source of ammonium ion after nitrite is destroyed. SME nitrate losses, however, were small in the SB8-Tank 51 simulant tests. These tests do not include canister decon water removals and boil at design rates, so time at boiling is of order five hours. Unlike SB6, SB7, SB7b, and the SB8-Tank 40 flowsheet simulations, no ammonium ion was detected in the scrubber solution in any of the SB8-Tank 51 runs although the SRAT/SME $\mathrm{pH}$ range appeared to be favorable. Understanding why ammonium ion was not detected in either the SRAT or SME scrubber solution samples and why nitrate apparently was not destroyed in the SME cycle for this series of runs could significantly enhance the current understanding of formic attack of nitrate ion in the latter stages of the SRAT cycle and in the SME cycle.

\subsubsection{SRAT/SME Rheology Results}

This section presents the rheological and related properties for the SRAT and SME product slurries produced during the qualification simulant CPC testing. Table 3-56 gives the SRAT product results fit to a Bingham plastic model along with wt.\% insoluble solids, $\mathrm{pH}$, and sodium molarity. SRAT slurry measurements were made in duplicate at $25^{\circ} \mathrm{C}$ using established rheology protocols. ${ }^{23}$ This set of data was too small to apply statistical modeling (too few degrees of freedom), unlike the D series discussed in Section 3.2.7.

Table 3-56. SRAT Product Slurry Rheology

\begin{tabular}{|l|c|c|c|c|c|}
\hline Run & $\begin{array}{c}\text { Yield } \\
\text { Stress } \\
\mathrm{Pa}\end{array}$ & $\begin{array}{c}\text { Plastic } \\
\text { Viscosity } \\
\mathrm{cP}\end{array}$ & $\begin{array}{c}\text { Wt. \% } \\
\text { Insoluble } \\
\text { Solids }\end{array}$ & $\mathrm{pH}$ & $\begin{array}{c}{[\mathrm{Na}]} \\
\mathrm{M}\end{array}$ \\
\hline B3 & 0.98 & 5.3 & 12.3 & 7.8 & 2.36 \\
\hline B4 & 0.42 & 4.1 & 11.5 & 7.1 & 2.16 \\
\hline B5 & 1.0 & 6.6 & 12.3 & 8.0 & 2.23 \\
\hline
\end{tabular}


SRAT results generally fell below or at the bottom end of the design basis range for yield stress (1-5 Pa). Table 3-57 gives the results from duplicate flow curve measurements of the three SME product slurries at $25^{\circ} \mathrm{C}$ using established protocols.

Table 3-57. SME Product Slurry Rheology

\begin{tabular}{|l|c|c|c|c|c|}
\hline Run & $\begin{array}{c}\text { Yield } \\
\text { Stress } \\
\mathrm{Pa}\end{array}$ & $\begin{array}{c}\text { Plastic } \\
\text { Viscosity } \\
\text { cP }\end{array}$ & $\begin{array}{c}\text { Wt. \% } \\
\text { Insoluble } \\
\text { Solids }\end{array}$ & $\mathrm{pH}$ & $\begin{array}{c}{[\mathrm{Na}]} \\
\mathrm{M}\end{array}$ \\
\hline B3 & 7.0 & 26 & 37.0 & 7.2 & 2.54 \\
\hline B4 & 3.4 & 18 & 37.6 & 6.7 & 2.47 \\
\hline B5 & 5.5 & 27 & 37.6 & 7.4 & 2.53 \\
\hline
\end{tabular}

The three SME slurries were inside the SME design basis range of 2.5-15 $\mathrm{Pa}$ and 10-40 cP. SME wt. $\%$ total solids were in the $50-52 \%$ range, however, to achieve the necessary insoluble solids loadings to get the yield stress into the right range. The twelve sets of raw flow curve rheogram data are given in Appendix A (six SRAT and six SME - each sample run in duplicate).

\subsubsection{Processing Recommendations for the Shielded Cells}

Based on the work described in Section 3.3, a set of processing recommendations and assumptions was prepared for the SRAT cycle, Table 3-58, and the SME cycle, Table 3-59, of the SB8-Tank 51 washed qualification sample run in the SRNL Shielded Cells in late 2012.

Table 3-58. Processing Targets for Qualification SRAT Cycle

\begin{tabular}{|c|c|c|}
\hline Conversion of nitrite to nitrate in SRAT cycle & 29 & $\mathrm{gmol} \mathrm{NO}_{3}{ }^{-} / 100 \mathrm{gmol} \mathrm{NO}_{2}^{-}$ \\
\hline Destruction of nitrite in SRAT and SME cycle & 100 & $\%$ of starting nitrite destroyed \\
\hline Destruction of formic acid charged in SRAT & 30 & $\% \mathrm{HCO}_{2}^{-}$destroyed in SRAT \\
\hline Destruction of oxalate charged & 2 & $\%$ of total oxalate destroyed \\
\hline Percent excess acid stoichiometry & 115 & \% KMA equation \\
\hline SRAT product target solids & 30 & wt. $\%$ \\
\hline Nitric acid molarity & 10.237 & Molar \\
\hline Formic acid molarity & 23.548 & Molar \\
\hline DWPF nitric acid addition rate & 2 & gallons per minute \\
\hline DWPF formic acid addition rate & 2 & gallons per minute \\
\hline REDOX target & 0.1 & $\mathrm{Fe}^{+2} / \sum \mathrm{Fe}$ \\
\hline SRAT receipt sample mass, if any & TBD & $\mathrm{g}$ \\
\hline Wt.\% active agent in antifoam solution & 10 & $\%$ \\
\hline Antifoam addition basis for SRAT & 100 & $\mathrm{mg} / \mathrm{kg}$ slurry \\
\hline Basis antifoam additions during SRAT cycle & 8 & $\begin{array}{l}2 \text { pre nitric, } 1 \text { pre formic, } 5 \text { pre } \\
\text { boiling }\end{array}$ \\
\hline SRAT air purge (full scale) & 230 & scfm \\
\hline SRAT boil-up rate (full scale) & 5000 & $\mathrm{lbs} / \mathrm{hr}$ \\
\hline Target mercury concentration in SRAT product & 0.8 & wt.\% (dried solids basis) \\
\hline SRAT steam stripping factor & 750 & g steam/g mercury \\
\hline
\end{tabular}


Table 3-59. Processing Targets for Qualification SME Cycle

\begin{tabular}{|l|c|l|}
\hline Frit type & 803 & - \\
\hline Destruction of formic acid in SME & 5 & $\%$ formate destroyed in SME \\
\hline Destruction of nitrate in SME & 2 & $\%$ nitrate destroyed in SME \\
\hline Destruction of oxalate in SME & 0 & $\%$ oxalate destroyed in SME \\
\hline Assumed SME product density & 1.4 & $\mathrm{~kg} / \mathrm{L}$ \\
\hline Basis antifoam addition for SME cycle & 100 & $\mathrm{mg} / \mathrm{kg}$ slurry \\
\hline Number of basis antifoam additions during SME & 1 & - \\
\hline Sludge oxide waste loading in glass & 36 & $\%$ \\
\hline Frit slurry formic acid ratio & 1.5 & $\mathrm{~g} 90 \mathrm{wt} \%$ FA/100 g Frit \\
\hline Target SME solids total wt.\% & 50 & wt.\% \\
\hline Number of frit additions in SME cycle & 2 & - \\
\hline \# DWPF canister decon's simulated & 5 & - \\
\hline Volume of water per decon'ed can & 1,000 & gal at DWPF scale \\
\hline Water flush volume after frit slurry addition & 0 & gal \\
\hline SME air purge (full scale) & 74 & scfm \\
\hline SME boil-up rate (full scale) & 5,000 & lbs $/ \mathrm{hr}$ \\
\hline
\end{tabular}

The SRNL qualification SRAT/SME is documented in SRNL-STI-2013-00116. ${ }^{4}$

\subsection{Conclusions}

The SB8 CPC studies without Tank 12 consisted of two parts. The first study involved CPC testing of an SB8 simulant for Tank 51 to support the CPC demonstration of the washed Tank 51 qualification sample in the SRNL Shielded Cells facility. SB8-Tank 51 was a high iron-low aluminum waste with fairly high mercury and moderate noble metal concentrations. Tank 51 was ultimately washed to about $1.5 \mathrm{M}$ sodium which may be the highest wash endpoint since SB3Tank 51. This study included three simulations of the DWPF SRAT cycle and SME cycle with the sludge-only flowsheet at nominal DWPF processing conditions and three different acid stoichiometries. These runs produced a set of recommendations that were used to guide the successful SRNL qualification SRAT/SME demonstration with actual Tank 51 washed waste.

The second study involved five SRAT/SME runs with SB8-Tank 40 simulant. Four of the runs were designed to define the acid requirements for sludge-only processing in DWPF with respect to nitrite destruction and hydrogen generation. The fifth run was a nominal acid stoichiometry demonstration of the coupled flowsheet for SB8. These runs produced a set of processing recommendations for DWPF (Section 5.0) along with some data related to Safety Class documentation at DWPF. The eight SRAT/SME cycles in the second phase of SB8 studies all met the DWPF processing criteria (nitrite destruction, acceptable hydrogen generation rates).

Subsequent changes in the projected composition of SB8 between November 2012 and the May 2013 transfer date have been evaluated as they arose. In each instance the results presented in this report continued to be bounding with respect to acid stoichiometry and hydrogen generation. The primary change was to a more washed Tank 51 endpoint than expected initially. The actual DWPF acid required to process a SRAT batch is expected to be less than in the simulant tests by approximately $20 \%$ for an equivalent volume of similarly concentrated fresh sludge. 
SRNL-STI-2013-00106

Revision 0

\subsection{Recommendations for SB8 Processing and Future Work}

DWPF should not expect to process SB8 feed slurry in the $12-17 \mathrm{wt} . \%$ total solids range due to the reduced level of washing in Tank 51. Soluble solids are projected to account for $5-6 \mathrm{wt} . \%$ of the feed slurry compared to $\sim 3 \%$ in SB1. The Tank Farm is projecting $17.2 \mathrm{wt} . \%$ total solids in their SB8-Tank 40 estimate of 4/22/2013 which are divided into $11.6 \%$ insoluble solids and 5.6\% soluble solids (vs. $9.5 \%$ and $4.3 \%$ at the end of SB7b). These wt.\% solids levels (or higher) will be necessary to produce reasonable yield stress slurries and achieve DWPF canister production goals with minimal caustic pre-concentration times.

DWPF should begin SB8 processing by targeting $115-120 \%$ stoichiometry by the current DWPF acid equation (Hsu equation) for the initial SRAT batches.

DWPF should initially assume $30-35 \%$ formate loss in the SRAT cycle and a $5-10 \%$ gain in nitrate ion from conversion of nitrite to nitrate. Extended SRAT processing time (from lower steaming rates) could increase formate loss and reduce nitrate gain (increase nitrate loss). SME formate losses could be in the neighborhood of 1\% per hour at boiling, while SME nitrate losses could be $0.5 \%$ per hour. (The effects of long SME boiling time durations would need to studied further before better recommendations could be made.)

After the initial SB8 SRAT batches, DWPF should still constrain processing of SB8 to $110-126 \%$ of the DWPF acid equation due to uncertainties in the inputs to the stoichiometric acid equation and potential unknowns in the ARP slurry and MCU (strip effluent) stream as well as the hydrogen generation rate tendencies in the upper half of the processing window simulated (126$147 \%$ of DWPF acid equation). DWPF processing experience with early SB8 SRAT/SME batches can be used as a guide to moving toward higher acid stoichiometries if this seems necessary due to processing issues. Higher acid stoichiometries, however, could lead to more issues with ammonia formation and mercury stripping.

DWPF may experience surges from carbonate destruction in their SRAT off-gas generation rates, and should consider lowering the formic acid addition rates downward during in the first few batches while gaining processing experience and quantifying TIC in the feed.

DWPF should raise the expected (or target) wt.\% solids levels for the SRAT and SME cycle for SB8 to off-set the diluting effect of the higher soluble sodium compound concentrations and to maintain suitable slurry rheology, especially in the SME cycle where frit must stay suspended. Increases of at least $2-3 \%$ in total solids relative to SB7b appear to be in order depending on the exact range that DWPF has been using for SB7b.

DWPF should analytically characterize dissolved Mn in the initial SB8 SRAT products and evaluate the potential impact on the SRAT acid demand and REDOX. Product slurry should be filtered and analyzed by ICP. It may be advisable to take credit for soluble heel $\mathrm{Mn}$ in the acid calculation during SB8, although the current DWPF equation handles Mn somewhat conservatively already. DWPF should not equate SRAT receipt soluble Mn with reduced Mn from the heel, since $\mathrm{Mn}^{2+}$ is not very soluble under caustic $\mathrm{pH}$ conditions.

Over-concentrating the SME slurry at the higher end of the acid stoichiometry window should be avoided, since this could lead to hydrogen generation rate issues. 
The current DWPF WAC limit for $\mathrm{NO}_{\mathrm{x}}$ production will suffice for SB8.

SRNL continues to recommend minimizing formic acid addition in the frit slurry.

A study of SME cycle chemistry for catalytically active slurries may be warranted to better understand the changes in formate and nitrate ion concentrations during DWPF length SME cycles. Catalytic attack by formic acid on nitrate is seen in tests such as SB8 flowsheet studies, but the lab-scale SME cycles are designed to bound hydrogen generation rather than to understand formate-nitrate chemistry. Both formate and nitrate are important to REDOX control, so a better understanding of their behavior would help to improve predictions of SME cycle behavior related to REDOX.

Species related to antifoam (potentially) were found in the off-gas by FTIR and in the off-gas condensate. If the HMDSO is from antifoam, and if the condensate $\mathrm{Si}$ is from antifoam, then it appears that high fraction of antifoam has decomposed during processing. If so, there should be some follow-up work. Data suggest that only a minor fraction of the antifoam that is added needs to stay effective to control foaming. It may also be that the Si in the SRAT dewater condensate is primarily silicic acid rather than an antifoam fragment.

The species involved in REDOX control and melter off-gas flammability control overlap. Constraints are present on both in DWPF. There are indications that less washed sludges are moving DWPF into a region where it may become challenging to measure the key species accurately enough to control the process reasonably well. A mathematical or statistical analysis using historical DWPF analytical data and associated uncertainties, shifted to higher concentrations, could be performed to estimate the percentage of the time that DWPF is likely to experience off target compositions in the melter feed. 
SRNL-STI-2013-00106

Revision 0

\subsection{References}

${ }^{1}$ Bricker, J. M., Sludge Batch 8 Flowsheet Studies, HLW-DWPF-TTR-2012-0004, December 6, 2011.

${ }^{2}$ Newell, J. D., Task Technical and Quality Assurance Plan for Sludge Batch 8 Simulant Flowsheet Studies, SRNL-RP-2011-01679, SRNL, Aiken, SC, 29808 (December 2011).

${ }^{3}$ Newell, J. D., Sludge Batch 8 with Tank 12 report, SRNL-STI-2012-00620, Rev. 0, SRNL, Aiken, SC, 29808 (May 2013).

${ }^{4}$ Pareizs, J. M., and C. L. Crawford, Sludge Washing and Demonstration of the DWPF Flowsheet in the SRNL Shielded Cells for Sludge Batch 8 Qualification, SRNL-STI-2013-00116, SRNL, Aiken, SC, 29808 (April 2013).

${ }^{5}$ Stone, M. E., Lab-scale CPC Equipment Setup, SRNL-L3100-2011-00127, SRNL, Aiken, SC, 29808 (July 2011).

${ }^{6}$ Koopman, D. C., A. I. Fernandez, and B. R. Pickenheim, Preliminary Evaluations of Two Proposed Stoichiometric Acid Equations, SRNL-L3100-2009-00146, Savannah River Site, Aiken, SC, 29808 (2009).

${ }^{7}$ Marek, J. C. and R. E. Eibling, Calculational Algorithms for Nitric Acid Sludge Adjustment, SRTC-PTD92-0050, Savannah River Site, Aiken, SC, 29808 (September 1992).

${ }^{8}$ Jantzen, C. M. and M. E. Stone, Role of Manganese Reduction/Oxidation (REDOX) on Foaming and Melt Rate in High Level Waste Melters, WSRC-STI-2006-00066, Savannah River Site, Aiken, SC, 29808 (March 2007).

${ }^{9}$ SRNL L29 Manual, Procedure ITS-0094, Rev. 7, Laboratory Scale Chemical Process Cell Simulations, SRNL, Aiken, SC, 29808.

${ }^{10}$ Koopman, D. C., Noble Metal Chemistry and Hydrogen Generation during Simulated DWPF Melter Feed Preparation, WSRC-STI-2008-00002, SRNL, Aiken, SC, 29808 (June 2008).

${ }^{11}$ Bannochie, C. J., Tank 40 Final SB7b Chemical Characterization Results, SRNL-STI-2012-00097, SRNL, Aiken, SC, 29808 (March 2012).

${ }^{12}$ Pareizs, J. M., C. L. Crawford, and D. R. Click, Sludge Batch 8 Qualification - Summary of Results from Radioactive CPC Simulation and Glass Analysis, SRNL-L3100-2013-00018, SRNL, Aiken, SC, 29808 (February 2013).

${ }^{13}$ Koopman, D. C., DWPF Simulant CPC Studies for SB7b, SRNL-STI-2011-00547, SRNL, Aiken, SC, 29808 (November 2011).

${ }^{14}$ Pareizs, J. M., A. L. Billings, S. H. Reboul, D. P. Lambert, D. R. Click, Sludge Batch $7 b$ Qualification Activities with SRS Tank Farm Sludge, SRNL-STI-2011-00548, SRNL, Aiken, SC, 29808 (November 2011).

${ }^{15}$ Baich, M. A., C. C. Herman, D. C. Koopman, D. R. Best, T. K. Snyder, M. F. William, Processing Options and Impact of Incorporation of ARP in the DWPF Process Flow Sheet, WSRC-TR-2003-00326, SRNL, Aiken, SC, 29808 (August 2003).

${ }^{16}$ Koopman, D. C., C. C. Herman, M. A. Baich, D. R. Best, T. K. Snyder, M. F. Williams, Impact of a Bounding Quantity of ARP Waste on the DWPF Process Flow Sheet, WSRC-TR-2003-00403, SRNL, Aiken, SC, 29808 (September 2003). 
${ }^{17}$ Newell, J. D., Actinide Removal Process Simulant Composition, SRNL-L3100-2012-00090, SRNL, Aiken, SC, 29808 (July 2013).

${ }^{18}$ Lambert, D. P., D. C. Koopman, J. D. Newell, D. T. Wasan, A. P. Nikolov, and E. K. Weinheimer, Improved Antifoam Agent Study End of Year Report, EM Project 3.2.3, SRNL-STI-2011-00515, SRNL, Aiken, SC, 29808 (September 2011).

${ }^{19}$ Zamecnik, J. R., and D. C. Koopman, Behavior of Mercury During DWPF Chemical Process Cell Processing, SRNL-STI-2012-00051, SRNL, Aiken, SC, 29808 (January 2012).

${ }^{20}$ Jantzen, C. M., and F. C. Johnson, Impacts of Antifoam Additions and Argon Bubbling on Defense Waste Processing Facility (DWPF) REDuction/OXidation (REDOX), SRNL-STI-2011-00652, SRNL, Aiken, SC, 29808 (June 2012).

${ }^{21}$ Jantzen, C. M., Basis for Changing the DWPF Manganese REDOX Model Term for SB8 and Maintaining the Historical Minimum REDOX Limit, SRNL-L3100-2013-00056, SRNL, Aiken, SC, 29808 (April 2013).

${ }^{22}$ Koopman, D. C., D. R. Best, and B. R. Pickenheim, SRAT Chemistry and Acid Consumption during Simulated DWPF Melter Feed Preparation, WSRC-STI-2008-00131, SRNL, Aiken, SC, 29808 (December 2008).

${ }^{23}$ Koopman, D. C., Rheology Protocols for DWPF Samples, WSRC-TR-2004-00470, SRNL, Aiken, SC, 29808 (October 2004). 
SRNL-STI-2013-00106

Revision 0

Appendix A - Rheograms 
Graphs of the raw rheological data are included in this Appendix.

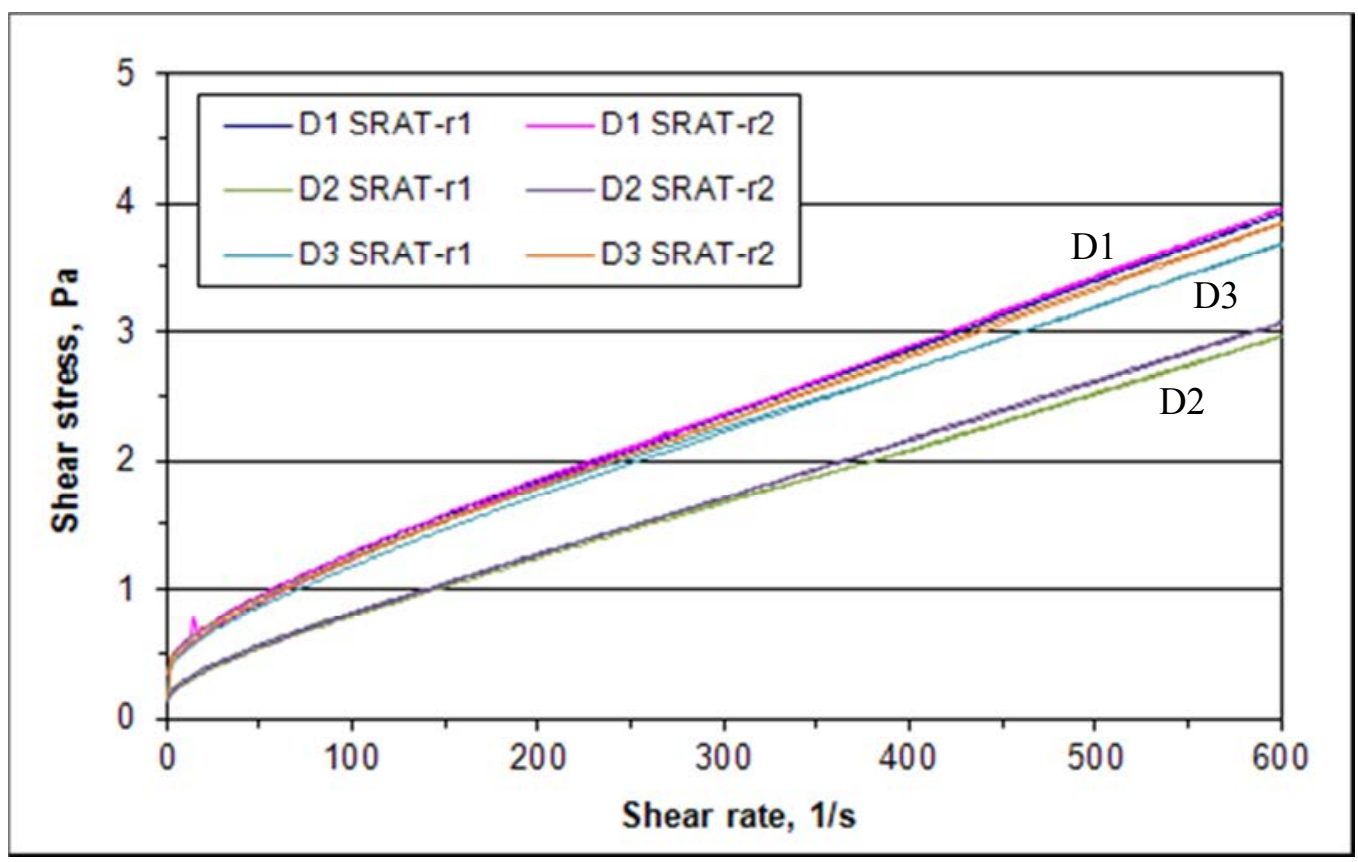

Figure 35. SB8-Tank 40 SRAT Product Rheograms-1

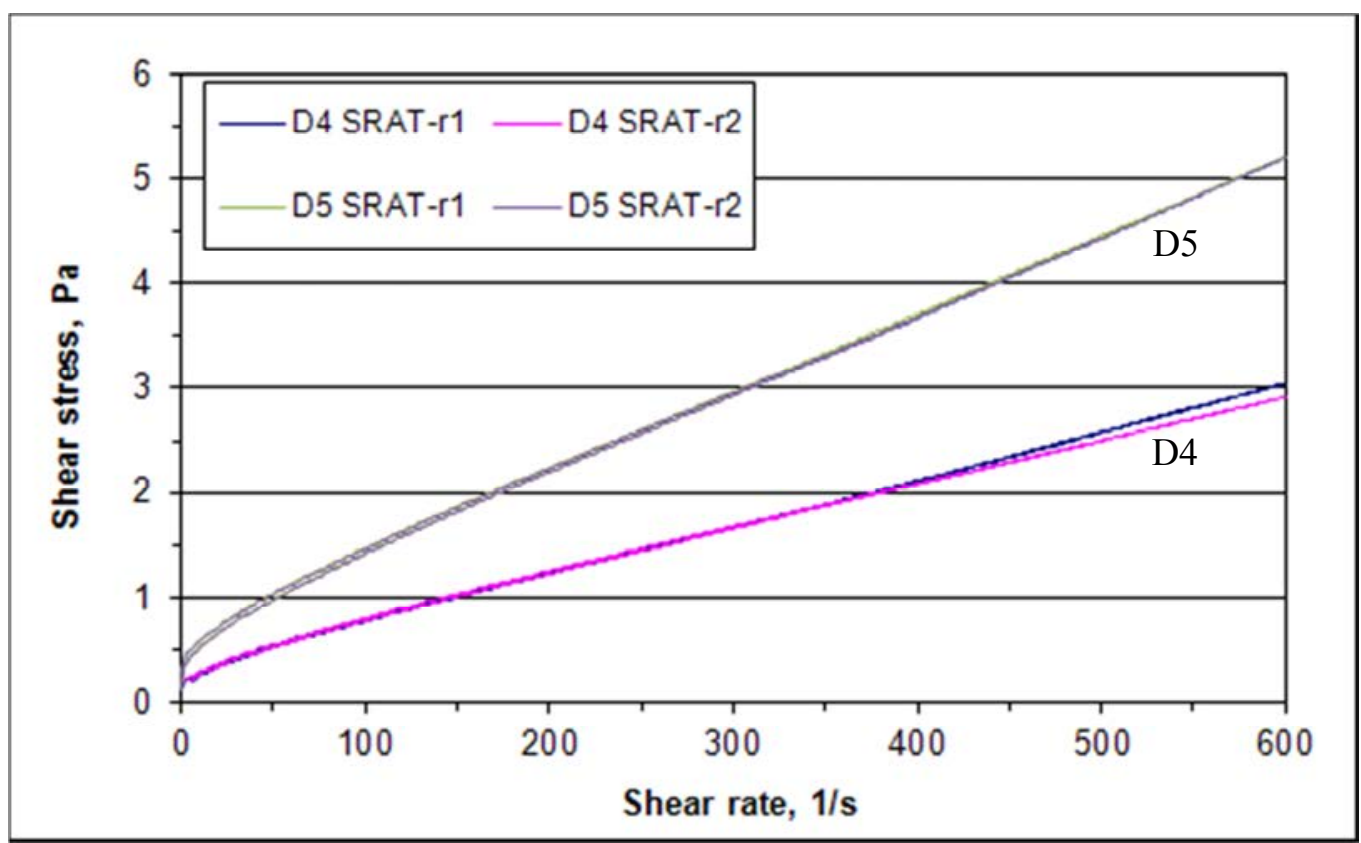

Figure 36. SB8-Tank 40 SRAT Product Rheograms-2

SB8-Tank 40 SRAT product rheograms were generally well reproduced in the replicate pairs and showed negligible hysterisis between up and down flow curves (not unusual for low viscosity slurries.) 


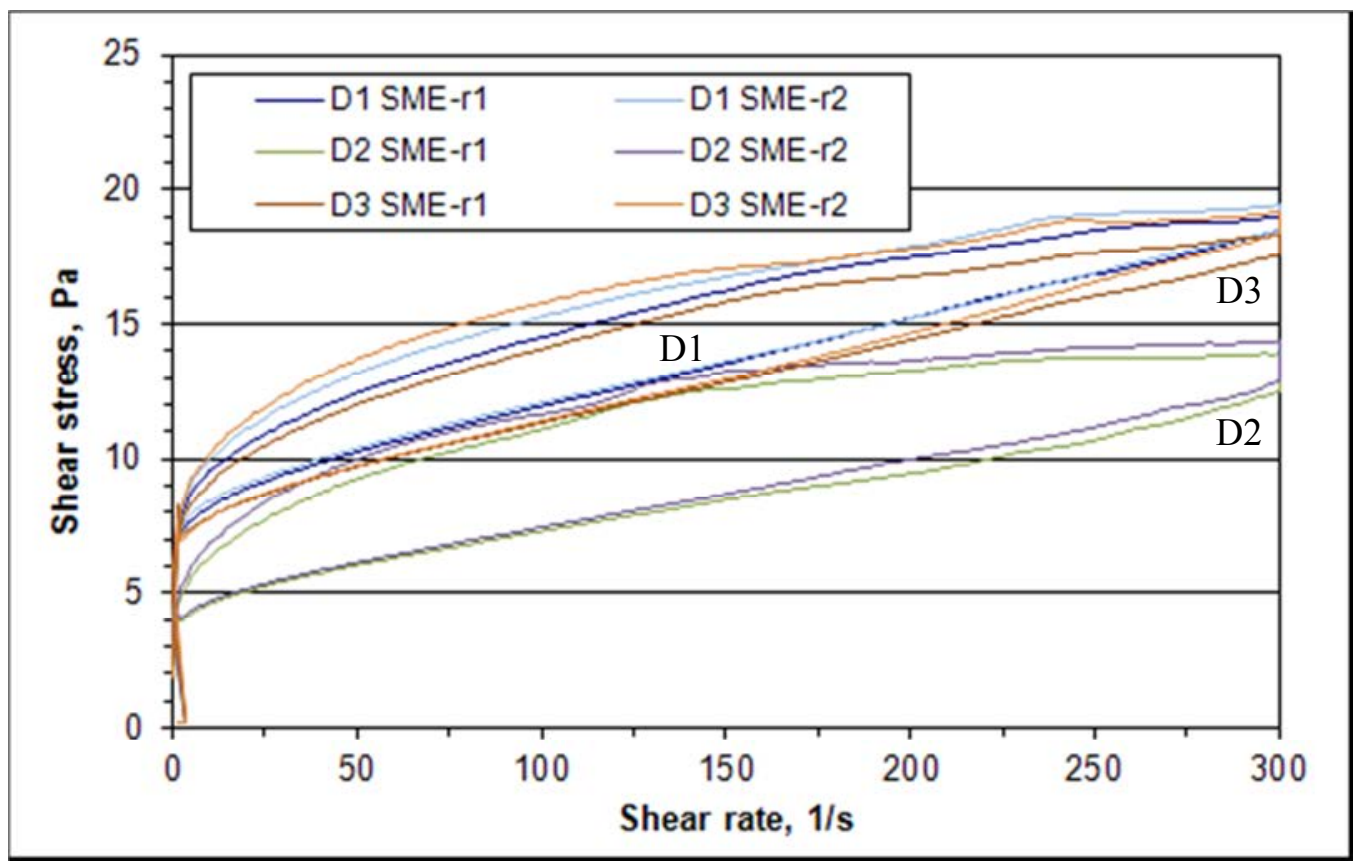

Figure 37. SB8-Tank 40 SME Product Rheograms-1

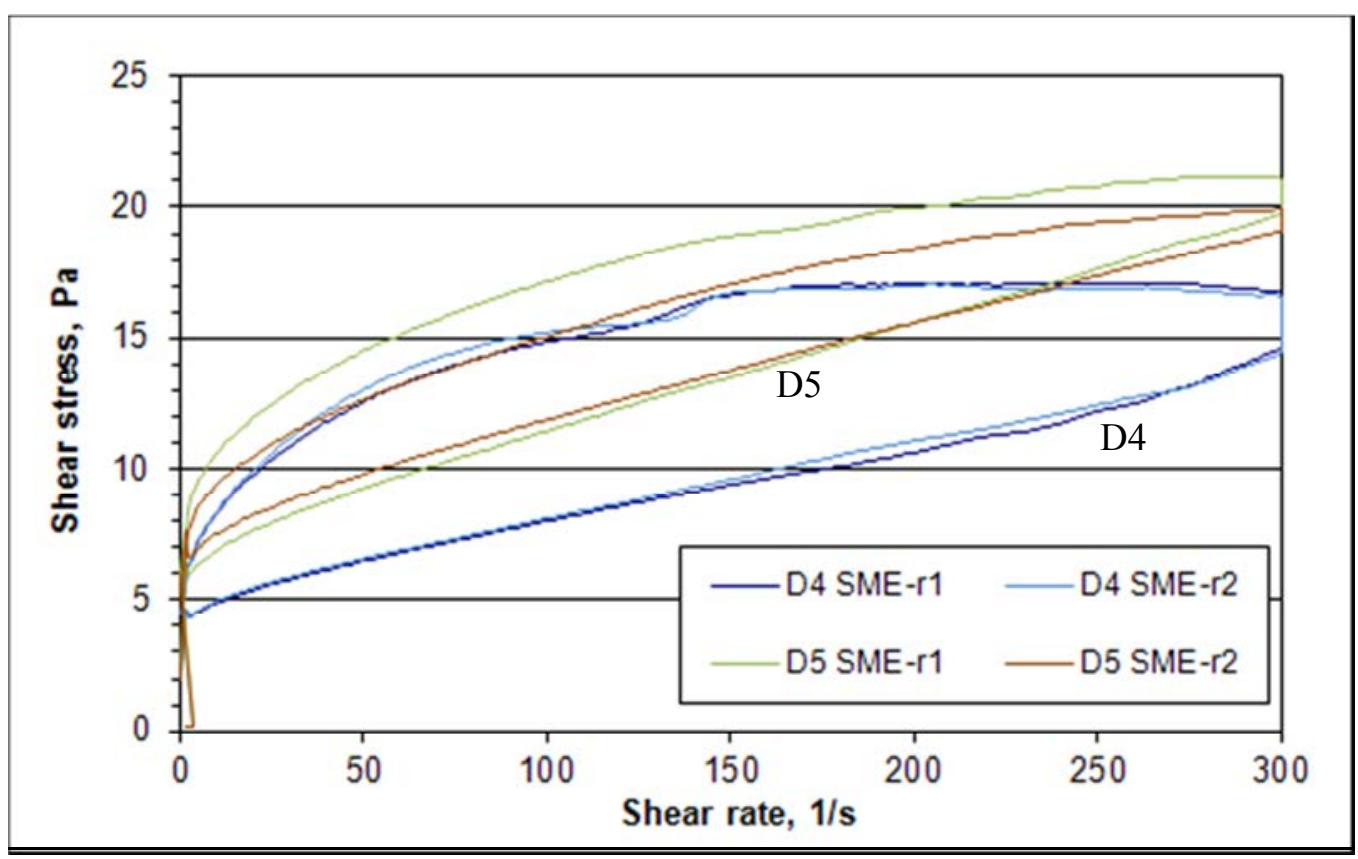

Figure 38. SB8-Tank 40 SME Product Rheograms-2

The SME product slurries were on the low viscosity side end of the range. The rheograms showed evidence of radial segregation (probably of the frit) leading to apparent hysterisis (down flow curves above up flow curves). Consequently, the Bingham plastic model fit was performed on the up flow curves. Up flow curves were fairly well reproduced and were fairly linear. 


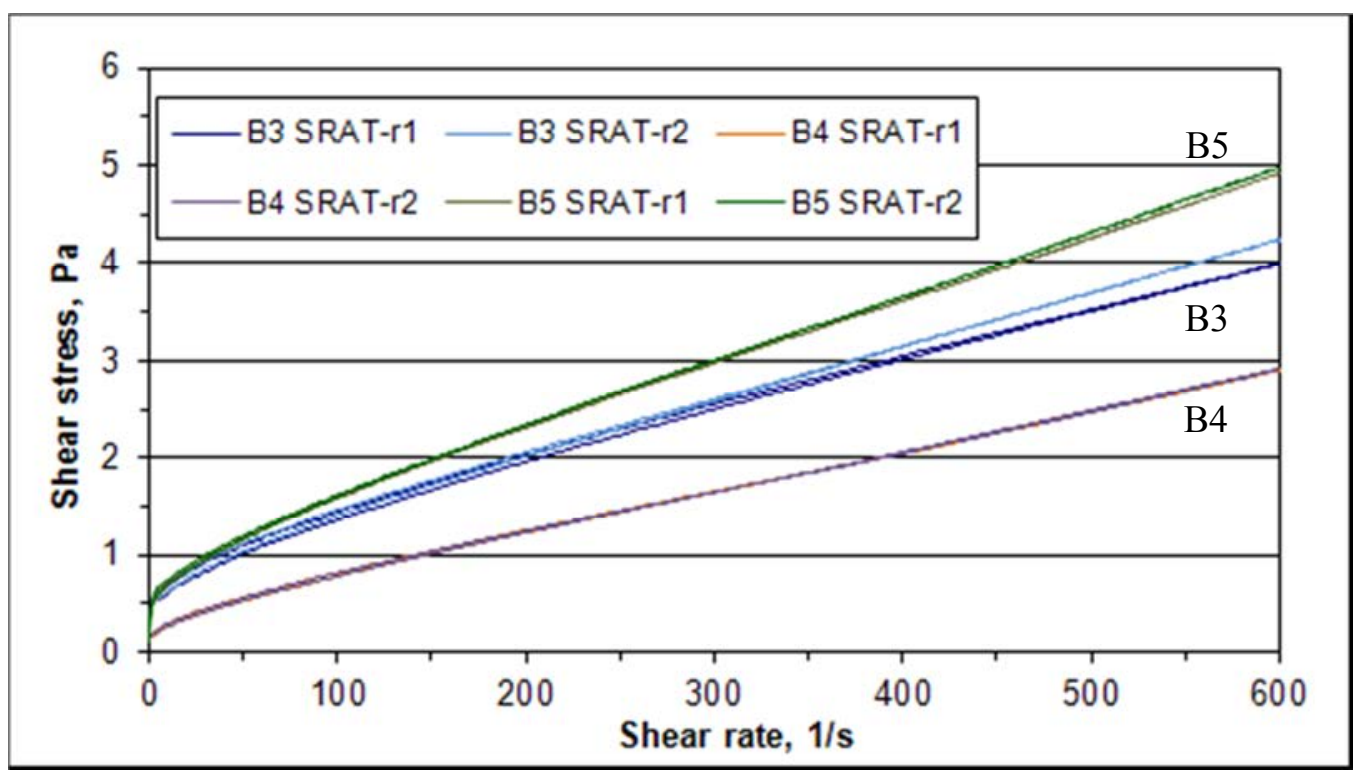

Figure 39. SB8-Tank 51 SRAT Product Rheograms

SB8-Tank 51 SRAT products behaved similarly to the SB8-Tank 40 SRAT products.

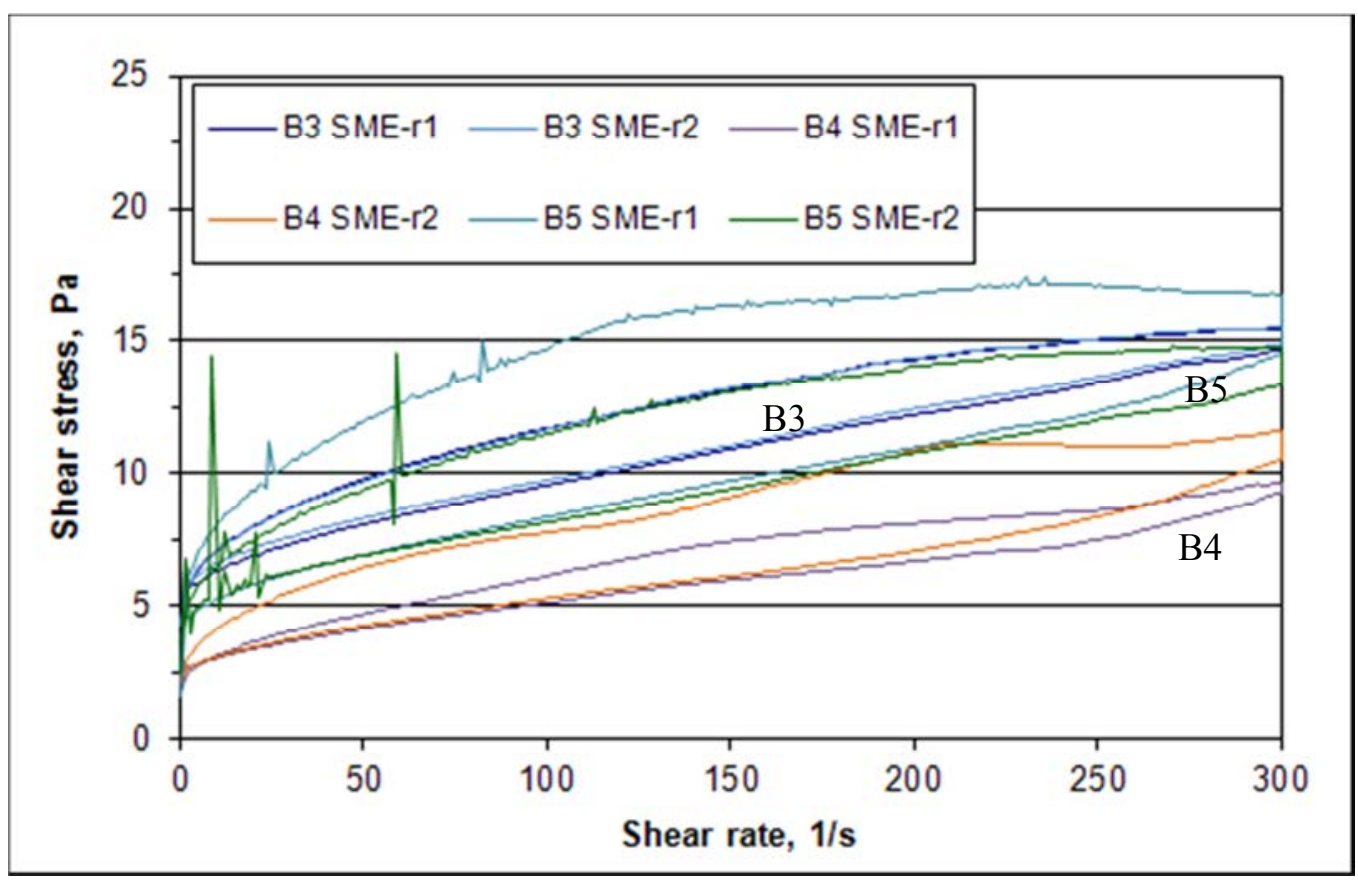

Figure 40. SB8-Tank 51 SME Product Rheograms

SB8-Tank 51 SME product rheograms were generally similar in behavior to the SB8 -Tank 40 rheograms. The nominal run, B5, however, did have some evidence of erratic behavior in its two flow curves. This could be due to mild clumping of frit or some foreign (to the usual SME) particles being present. 


\section{Distribution:}
E. J. Freed, 704-S
D. C. Sherburne, 704-S
J. F. Iaukea, 704-30S
K. H. Subramanian
H. B. Shah, 766-H
D. R. Click, 999-W
S. D. Fink, 773-A
C. C. Herman, 773-A
E. N. Hoffman, 999-W
S. L. Marra, 773-A
F. M. Pennebaker, 773-42A
M. E. Stone, 999-W
J. D. Newell, 999-W
D. K. Peeler, 999-W
C. J. Bannochie, 773-42A
J. M. Gillam, 766-H
B. A. Hamm, 766-H
D. K. Peeler, 999-W
J. W. Ray, 704-S
M. E. Stone, 999-W
J. M. Bricker, 704-27S
T. L. Fellinger, 704-26S
E. W. Holtzscheiter, 704-15S
A. Samadi-Dezfouli, 704-27S
P. J. Ryan, 704-30S
P. R. Jackson, 703-46A
Records Administration (EDWS) 